ESCOLA POLITÉCNICA DA UNIVERSIDADE DE SÃO PAULO DEPARTAMENTO DE ENGENHARIA DE TRANSPORTES

PALOMA CRUZ GENTIL FIALHO

Validação de Resultados do Inventário Funcional de Pavimentos Flexíveis com o Emprego do Equipamento Pavement Scanner 


\section{Validação de Resultados do Inventário Funcional de Pavimentos Flexíveis com o Emprego do Equipamento Pavement Scanner}

Dissertação de Mestrado apresentada à Escola Politécnica da Universidade de São Paulo para obtenção do Título de Mestre em Engenharia.

Área de Concentração:

Engenharia de Transportes

Orientador:

Prof $^{\mathbf{0}}$ Doutor

Carlos Yukio Suzuki

São Paulo 
Este exemplar foi revisado e corrigido em relação à versão original, sob responsabilidade única do autor e com a anuência de seu orientador.

São Paulo, de de

Assinatura do autor:

Assinatura do orientador:

\section{Catalogação-na-publicação}

fialho, paloma cruz gentil

Validação de Resultados do Inventário Funcional de Pavimentos Flexíveis com o Emprego do Equipamento Pavement Scanner / P. C. G. fialho -- versão corr. -- São Paulo, 2015.

$185 \mathrm{p}$.

Dissertação (Mestrado) - Escola Politécnica da Universidade de São Paulo. Departamento de Engenharia de Transportes.

1.pavimentos flexíveis 2.defeito 3.levantamentos amostrais I.Universidade de São Paulo. Escola Politécnica. Departamento de Engenharia de Transportes II.t. 


\section{DEDICATÓRIA}

Ao André, meu marido, por seu companheirismo, compreensão e incentivo. Aos meus pais, pelo apoio em minhas escolhas e decisões. À minha avó Tomaza, com muita gratidão, pela educação, amor e confiança. Ao meu avô Angelino (in memorian) pela dedicação em me fazer feliz. 


\section{AGRADECIMENTOS}

À minha família, por ceder muitas horas da minha atenção para que eu pudesse dedicar à minha dissertação.

Ao Professor Dr. Carlos Suzuki pela confiança e orientação, essenciais para o desenvolvimento deste mestrado.

Aos professores do curso de Engenharia Civil e de Pós-Graduação da Escola Politécnica pelos ensinamentos transmitidos.

Às professoras Dr ${ }^{\mathrm{a}}$ Liedi Bernucci e Dr ${ }^{\mathrm{a}}$ Rosângela Motta pela contribuição durante o meu exame de qualificação.

Aos colegas da Dynatest que me deram apoio e incentivo, em especial, Luciana Barbosa, André Vale e Douglas Negrão.

À Dynatest que possibilitou o desenvolvimento deste estudo, disponibilizando sua equipe e equipamento.

A todos que, de alguma forma direta ou indireta, contribuíram para a concretização deste trabalho. 


\section{RESUMO}

A elaboração de um programa de gerenciamento de uma rede rodoviária implica na utilização de montantes consideráveis de recursos em sua recuperação e manutenção. Neste cenário, ressalta-se a importância da validação de uma nova tecnologia de avaliação funcional de pavimentos para aplicação em rodovias brasileiras que permita a coleta de informações de forma automática, sem a interferência do profissional, minimizando o tempo de coleta e processamento de dados, reduzindo-se as interferências com o tráfego e garantindo informações de qualidade e de rápida restituição.

O presente trabalho tem como objetivo a contribuição para o processo de avaliação funcional de pavimentos através validação de resultados do inventário funcional de pavimentos flexíveis com o emprego do equipamento Pavement Scanner, o que pode ser um novo processo que garanta a integridade, a confiabilidade e a plena restituição das informações para o projeto e programa de gestão de pavimentos.

Para tanto, seções-teste foram inventariadas e estudadas, onde avaliou-se as condições funcionais do pavimento de acordo com a metodologia tradicional de avaliação da superfície do pavimento e sob a utilização do equipamento Pavement Scanner. Os resultados obtidos pelos diferentes métodos foram analisados e comparados, buscando-se determinar a variação obtida pelas diferentes técnicas de avaliação do pavimento, além da análise da repetitividade e reprodutividade de cada uma destas técnicas. Adicionalmente, foi estudada a aplicabilidade dos resultados obtidos pelo Pavement Scanner no cálculo do PCI (Índice da Condição do Pavimento, do inglês Pavement Condition Index), que é muito utilizado no exterior e considerado uma ferramenta eficaz na gerência de pavimentos.

Palavras Chave: avaliação funcional, defeitos, equipamentos para inventário funcional, pavement scanner. 


\begin{abstract}
The development of a road network management program implies the use of significant amounts of resources in their recovery and maintenance. In this scenario, it emphasizes the importance of validating a new technology of functional Pavement assessment for use in Brazilian highways that allows the automatic collection of information, without the interference of a professional, minimizing the time in collecting and processing of data, reducing interference with traffic and ensuring information quality and fast refund.
\end{abstract}

This study aims to contribute to the process of functional pavement evaluation through the validation of results of the functional inventory of flexible pavements with the use of Pavement Scanner equipment, which can be a new process to ensure the integrity, reliability and full refund of information for the pavement management program.

With this purpose, sections-tests were surveyed and studied, in which the functional pavement conditions were evaluated according to the traditional method of pavement surface evaluation and with the use of Pavement Scanner equipment. The results obtained by different methods were analyzed and compared, in order to determine the variation obtained by the different pavement evaluation techniques, in addition to the analysis of repeatability and reproducibility of each of these techniques. Furthermore, it was studied the applicability of the results obtained by Pavement Scanner in the calculation of PCI (Pavement Condition Index), which is widely used abroad and considered an effective tool in pavement management.

Keywords: functional evaluation, surface distresses, equipment for functional inventory, pavement scanner. 


\section{LISTA DE FIGURAS}

Figura 1.1 - Exemplo de Seção do Pavimento com Mapeamento dos Defeitos (adaptado do LCMS - Manual, 2009)

Figura 2.1 - Evolução da Abrangência das Funções de um Sistema de Gerência de

Pavimentos (adaptada de KULKARNI \& MILLER, 2003). 10

Figura 2.2 - Componentes que Interagem em um Sistema de Gerência de Pavimentos (adaptada de Manual de Gerência de Pavimentos, DNIT, 2011)... 11

Figura 2.3 - Pirâmide dos Níveis de Qualidade de Informação (adaptada de Bennett e Paterson, 2000). 13

Figura 2.4 - Comparação entre o Nível de Rede e Nível de Projeto e os tipos de Levantamentos de Pavimento (adaptada de Timm e McQueen, 2004) ...................... 14

Figura 2.5 - Trincamento Isolado - Longitudinal Longo ........................................ 18

Figura 2.6 - Aspecto do Trincamento em Bloco (BERNUCCI et al., 2006) .............. 18

Figura 2.7 - Rodovia com Trincamento tipo Couro de Jacaré ................................... 19

Figura 2.8 - Afundamento Plástico (a) e Afundamento por Consolidação (b) .......... 21

Figura 2.9 - Escorregamento do Revestimento Asfáltico ......................................... 24

Figura 2.10 - Segmento com Exsudação................................................................ 24

Figura 2.11 - Exemplo de Desgaste ………......................................................... 25

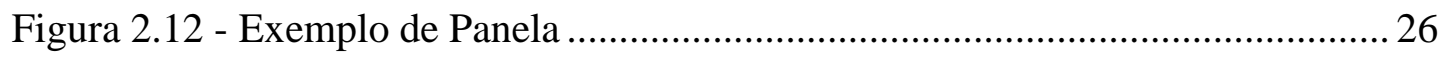

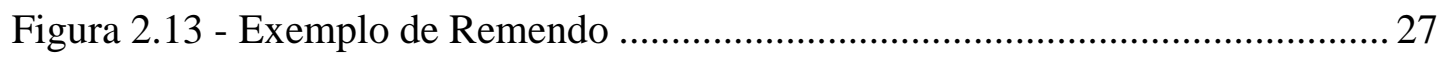

Figura 2.14 - Treliça Metálica para Medição da Trilha de Roda (DNIT, 2006)........ 31

Figura 2.15 - Fluxograma do Processo de Inventário e Cálculo para Obtenção do IGG

Figura 2.16 - Ondulação Longitudinal e Transversal (adaptada de YODER e

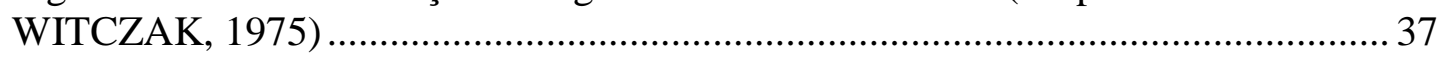

Figura 2.17 - Formulário para Inspeção de Pavimento (Adaptado do HEADQUARTERS DEPARTAMENT OF THE ARMY, 1982) ............................. 44

Figura 2.18 - Gráfico da Curva de Dedução do IRI (adaptado de NYSDOT, 2010). 51

Figura 2.19 - Gráfico da Curva de Dedução do Afundamento (adaptado de NYSDOT,

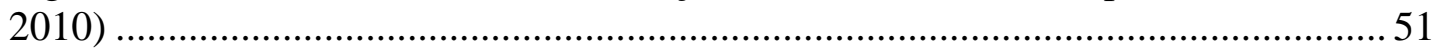

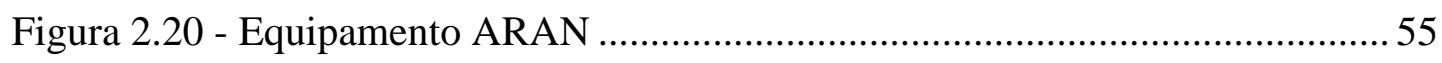

Figura 2.21 - Equipamento ROMDAS - TPL …................................................. 56

Figura 2.22 - Perfilômetro Laser Dynatest............................................................... 58

Figura 2.23 - Equipamento AMAC - VECTRA (NGUYEN et al., 2010) ................. 59

Figura 2.24 - Caracterização do Perfil Transversal, Longitudinal e Seção de Rodovia (adaptado do LCMS Manual, 2013) 
Figura 2.25 - Disposição dos Sensores a Laser (a). Detalhe do Laser Levantando o Trincamento (b) (adaptado do LCMS Manual, 2013)

Figura 2.26 - Vista Esquemática Frontal e Lateral da Geometria da Linha de Laser (adaptado do LCMS Manual, 2013) .....

Figura 2.27 - Veículo de Inspeção com Unidades de Sensores a Laser (foto superior). Imagem de uma Unidade de Sensor a Laser, com o Projetor a Laser e Câmera (foto inferior) (adaptado do LCMS Manual, 2013)

Figura 2.28 - Diagrama dos Resultados do 3D e da Intensidade no Pavement Scanner (adaptado do LCMS Manual, 2013)

Figura 2.29 - Dados da Modelagem (a), Dados de Intensidade (b), Mistura dos Dois

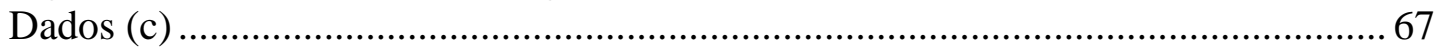

Figura 2.30 - IMU (dourado) Inserido nos Sensores do Pavement Scanner .............. 67

Figura 2.31 - Exemplo de Afundamentos Processados no Pavement Scanner (a) Afundamento de Raio Grande, (b) Afundamento de Raio Pequeno, (c) Múltiplos Afundamentos. (adaptado do LCMS Manual, 2013) 74

Figura 2.32 - Imagem do Sistema Clássico de Levantamento Dependendo da Trajetória do Veículo (a). Imagem do sistema do Pavement Scanner que utiliza as marcações de faixa para compensar desvios do motorista (b) (LCMS Manual, 2013) .................... 75

Figura 2.33 - Exemplo da Detecção de Panelas pelo Pavement Scanner .................. 76

Figura 2.34 - Exemplo da Detecção Automática de Perdas de Agregado pelo Pavement

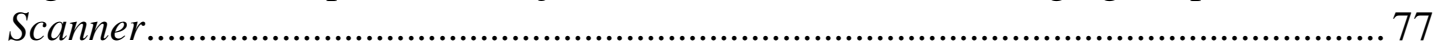

Figura 3.1 - Mapa de Situação das Seções-teste ..................................................... 84

Figura 3.2 - Locais das Seções-teste para Ensaios .................................................. 88

Figura 3.3 - Marcação com Tinta Branca em Pista Dupla ........................................ 91

Figura 3.4 - Marcação com Tinta Branca em Pista Simples ...................................... 91

Figura 3.5 - Levantamento com Pavement Scanner. Imagem do Equipamento (a). Imagem da Tela de Levantamento no Interior do Veículo do Equipamento (b). ...... 92

Figura 3.6 - Mapeamento dos Trincamentos em uma Mesma Seção. Imagem de Fundo em 3D (b). Imagem de Fundo da Intensidade (a).................................................... 94

Figura 3.7 - Mapeamento do Remendo em uma mesma seção. Imagem de Fundo em 3D (b). Imagem de Fundo da Intensidade (a) ....................................................... 95

Figura 3.8 - Levantamentos Tradicionais na Seção-Teste 01 ................................... 95

Figura 3.9 - Levantamentos Tradicionais na Seção-Teste 02 ……............................ 96

Figura 3.10 - Levantamentos Tradicionais na Seção-Teste 03 ................................. 96

Figura 3.11 - Levantamentos Tradicionais na Seção-Teste 04................................. 96

Figura 3.12 - Levantamentos Tradicionais na Seção-Teste 05 ................................. 97

Figura 3.13 - Levantamentos Tradicionais na Seção-Teste 06................................. 97

Figura 3.14 - Levantamentos Tradicionais na Seção-Teste 07................................. 97 
Figura 3.15 - Levantamentos Tradicionais na Seção-Teste 08

Figura 3.16 - Levantamento com Perfilômetro Laser. Equipe preparando-se para início do levantamento (a). Preparação para início do levantamento com o equipamento (b).

Figura 4.1 - Coeficiente de Variação dos Resultados de IGG................................ 103

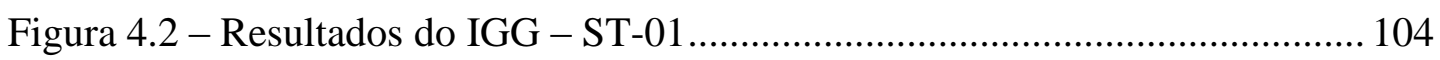

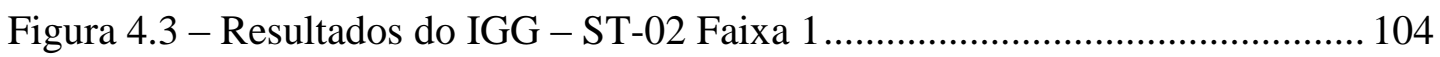

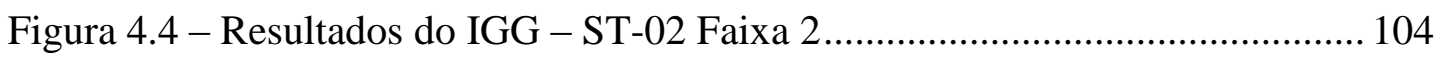

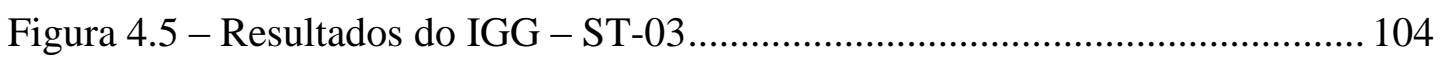

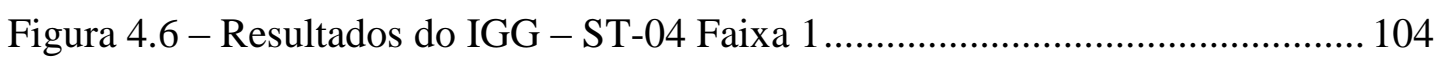

Figura 4.7 - Resultados do IGG - ST-04 Faixa 2 .................................................... 104

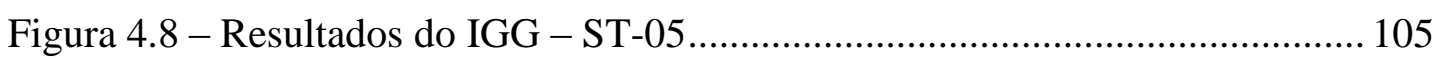

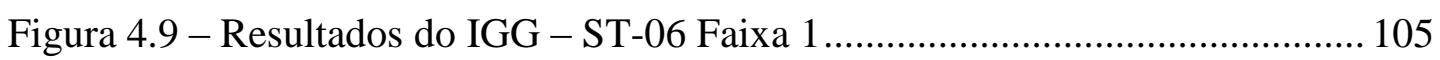

Figura 4.10 - Resultados do IGG - ST-06 Faixa 2 .............................................. 105

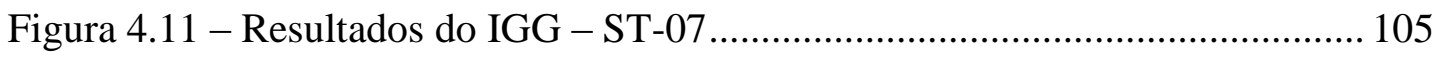

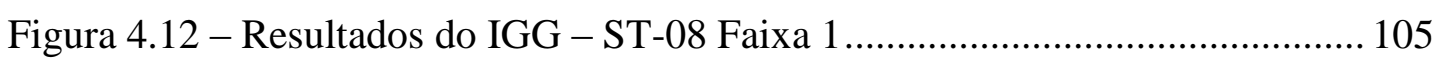

Figura 4.13 - Resultados do IGG - ST-08 Faixa 2 ............................................... 105

Figura 4.14 - Correlação das médias de IGG obtido com o Pavement Scanner e o

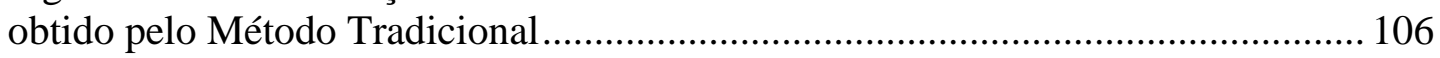

Figura 4.15 - Correlação do IGG do Pavement Scanner e o obtido pelo Método

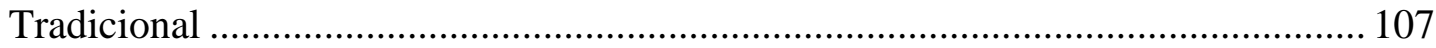

Figura 4.16 - Resultados do Trincamento - ST-01 ............................................ 111

Figura 4.17 - Resultados do Trincamento - ST-02 Faixa 1 .................................. 111

Figura 4.18 - Resultados do Trincamento - ST-02 Faixa 2 .................................. 112

Figura 4.19 - Resultados do Trincamento - ST-03 ….......................................... 112

Figura 4.20 - Resultados do Trincamento - ST-04 Faixa 1 ................................... 112

Figura 4.21 - Resultados do Trincamento - ST-04 Faixa 2 .................................. 112

Figura 4.22 - Resultados do Trincamento - ST-05 .............................................. 112

Figura 4.23 - Resultados do Trincamento - ST-06 Faixa 1 ................................... 112

Figura 4.24 - Resultados do Trincamento - ST-06 Faixa 2 .................................. 113

Figura 4.25 - Resultados do Trincamento - ST-07 ............................................... 113

Figura 4.26 - Resultados do Trincamento - ST-08 Faixa 1 .................................. 113

Figura 4.27 - Resultados do Trincamento - ST-08 Faixa 2 ................................. 113

Figura 4.28 - Comparação entre a resolução do levantamento visual (tradicional) e do levantamento mecanizado na ST-03 entre a posição 0,040 e 0,043 m. 
Figura 4.29 - Comparação entre a resolução do levantamento visual (tradicional) e do levantamento mecanizado na ST-04, faixa 2 entre a posição 0,261 e 0,263 m. ...... 116

Figura 4.30 - Comparação entre a resolução do levantamento visual (tradicional) e do levantamento mecanizado na ST-04, faixa 2 entre a posição 0,300 e 0,303 m. ...... 117

Figura 4.31 - Resultados do Afundamento médio na Trilha de Roda - ST-01 ....... 121

Figura 4.32 - Resultados do Afundamento médio na Trilha de Roda - ST-02 Faixa 1 121

Figura 4.33 - Resultados do Afundamento médio na Trilha de Roda - ST-02 Faixa 2 122

Figura 4.34 - Resultados do Afundamento médio na Trilha de Roda - ST-03 ....... 122

Figura 4.35 - Resultados do Afundamento médio na Trilha de Roda - ST-04 Faixa 1 122

Figura 4.36 - Resultados do Afundamento médio na Trilha de Roda - ST-04 Faixa 2 122

Figura 4.37 - Resultados do Afundamento médio na Trilha de Roda - ST-05 ....... 122

Figura 4.38 - Resultados do Afundamento médio na Trilha de Roda - ST-06 Faixa 1 122

Figura 4.39 - Resultados do Afundamento médio na Trilha de Roda - ST-06 Faixa 2 123

Figura 4.40 - Resultados do Afundamento médio na Trilha de Roda - ST-07 ....... 123

Figura 4.41 - Resultados do Afundamento médio na Trilha de Roda - ST-08 Faixa 1 123

Figura 4.42 - Resultados do Afundamento médio na Trilha de Roda - ST-08 Faixa 2 123

Figura 4.43 - Correlação da média dos valores de Trilha de Roda obtidos com o Pavement Scanner e com o Levantamento Tradicional. 124

Figura 4.44 - Correlação entre afundamento na Trilha de Roda do Pavement Scanner e o Levantamento Tradicional 125

Figura 4.45 - Resultados do IRI- ST-01 - Lado Direito ........................................ 129

Figura 4.46 - Resultados do IRI- ST-02 Faixa 1 ............................................... 129

Figura 4.47 - Resultados do IRI- ST-05 Lado Direito ............................................ 130

Figura 4.48 - Resultados do IRI- ST-06 Faixa 1 ................................................ 130

Figura 4.49 - Resultados do IRI- ST-07 - Lado Direito ........................................ 130

Figura 4.50 - Resultados do IRI- ST-08 Faixa 1 .............................................. 130

Figura 4.51 - Resultados do IRI- ST-01 Lado Esquerdo ...................................... 130

Figura 4.52 - Resultados do IRI- ST-02 - Faixa 2 ….......................................... 130

Figura 4.53 - Resultados do IRI- ST-03 Lado Esquerdo ..................................... 131 
Figura 4.54 - Resultados do IRI-ST-04 Faixa 2

Figura 4.55 - Resultados do IRI- ST-05 Lado Esquerdo ....................................... 131

Figura 4.56 - Resultados do IRI- ST-06 - Faixa 2 ........................................... 131

Figura 4.57 - Resultados do IRI- ST-07 Lado Esquerdo ...................................... 131

Figura 4.58 - Resultados do IRI- ST-07 - Faixa 2 .............................................. 131

Figura 4.59 - Correlação dos valores médios de IRI do Pavement Scanner x Perfilômetro Laser........................................................................................ 132

Figura 4.60 - Correlação dos valores de IRI do Pavement Scanner x Perfilômetro Laser 133

Figura 4.61 - Influência da Velocidade no Cálculo do IGG................................... 135

Figura 4.62 -Influência da Luminosidade no Cálculo do IGG ............................... 138

Figura 4.63 - Análise da Repetitividade dos Defeitos - ST-02 ............................... 140

Figura 4.64 - Análise da Repetitividade dos Defeitos - ST-03 .............................. 141

Figura 4.65 - Análise da Repetitividade dos Defeitos - ST-04 .............................. 141

Figura 4.66 - Análise da Repetitividade dos Defeitos - ST-05 .............................. 142

Figura 4.67 - Análise da Repetitividade dos Defeitos - ST-06.............................. 143

Figura 4.68 - Análise da Repetitividade dos Defeitos - ST-07 .............................. 143

Figura 4.69 - Análise da Repetitividade dos Defeitos - ST-08 ............................... 144

Figura 4.70 - Análise da Repetitividade dos Defeitos ............................................. 145

Figura 4.71 - Correlação entre o PCI e o IGG, ambos do Pavement Scanner ........ 158

Figura 4.72 - Escala de conceitos do PCI.............................................................. 159

Figura 4.73 - Escala de Conceitos do IGG ............................................................. 160

Figura 4.74 - Correlação do IGG contínuo e IGG amostral, ambos do Pavement Scanner. 


\section{LISTA DE TABELAS}

Tabela 2.1 - Resumo das Causas e tipo de Deformações Permanentes (DNER, 1998)

Tabela 2.2 - Resumo das Causas e tipo de Deformações Permanentes (DNER, 1998) .22

Tabela 2.3 - Descrição da Escala de Conceito do IGG (DNIT, 2003) 29

Tabela 2.4 - Ficha Padrão para Inventário da Superfície do Pavimento (DNIT, 2006) 30

Tabela 2.5 -Tabela de Ponderação para Cálculo do IGG (adaptada de DNIT, 2006) 32

Tabela 2.6 - Relação entre o Tipo de Onda, Comprimento e Amplitude (OLIVEIRA, 2002) 36

Tabela 2.7 - Relação entre a Condição do Pavimento e os Níveis de Irregularidade (PINTO e PREUSSLER, 2010) .... 41

Tabela 2.8 - Classificação do Pavimento pelo Método do PCI 42

Tabela 2.9 - Resumo da Classificação da Superfície e suas Condições (adaptado de NYSDOT, 2010) 46

Tabela 2.10 - Classificação Detalhada da Superfície e suas Características (adaptado de NYSDOT, 2010)

Tabela 2.11 - Classificação Detalhada da Superfície e suas Características (adaptado de NYSDOT, 2010)

Tabela 2.12 - Dedução Máxima Relativa a cada Tipo de Defeito para o Cálculo do PCI (adaptado de NYSDOT, 2010).

Tabela 2.13 - Classificação da Superfície Correlacionada aos Valores de Dedução no $1^{\circ}$ Ano de Análise e a Dedução Completa (adaptado de NYSDOT, 2010) .

Tabela 2.14 - Defeitos Dominantes do tipo Trincamento Couro de Jacaré Correlacionados aos Valores de Dedução no $1^{\circ}$ ano de Análise e a Dedução Completa (adaptado de NYSDOT, 2010)

Tabela 2.15 - Resultados Finais dos 10.000 km Inventariados pelo Pavement Scanner e Posteriormente Classificado Manualmente (adaptado de LAURENT e HÉBERT; 2008) 71

Tabela 2.16 - Resultados Finais dos 770 km Inventariados pelo Pavement Scanner e Comparados aos Dados de Vídeo-Registro (adaptado de LAURENT e HÉBERT; 2008) 72

Tabela 3.1 - Planejamento das Seções-Teste para Ensaios .83

Tabela 3.2 - Localização das Seções-Teste para Ensaios .85

Tabela 3.3 - VDM das Seções-teste (Adaptado de DER - SP - Estatística do Volume Médio Diário da Rodovias, 2014). 
Tabela 3.4 - Descrição das Campanhas Realizadas com o Pavement Scanner 92

Tabela 3.5 - Descrição das Campanhas Realizadas pelas Metodologias Tradicionais

Tabela 4.1 - Resultados de IGG para Pista Simples................................................ 101

Tabela 4.2 - Resultados de IGG para Pista Dupla .................................................. 102

Tabela 4.3 - Resultados de Trincamento para Pista Simples ................................. 109

Tabela 4.4 - Resultados de Trincamento para Pista Dupla..................................... 110

Tabela 4.5 - Resultados de Afundamento na Trilha de Roda para Pista Simples ... 119

Tabela 4.6 - Resultados de Afundamento na Trilha de Roda para Pista Dupla ...... 120

Tabela 4.7 - Resultados de IRI para Faixa 1 (pista dupla) e Faixa Crescente (pista simples)

Tabela 4.8 - Resultados de IRI para Faixa 2 (pista dupla) e Faixa Decrescente (pista simples)

Tabela 4.9 - Análise da Influência da Velocidade nos Resultados do IGG ............ 134

Tabela 4.10 - Análise da Influência da Luminosidade nos Resultados do IGG...... 137

Tabela 4.11 - Análise do Coeficiente de Variação para os Diferentes Tipos de

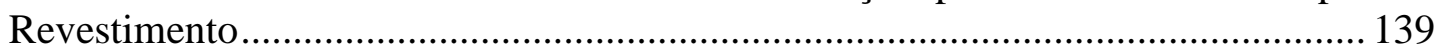

Tabela 4.12 - Análise do Desvio Padrão de Repetitividade e Reprodutividade do

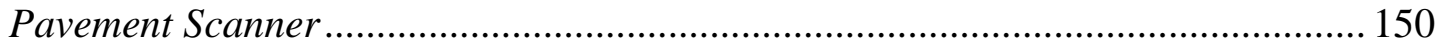

Tabela 4.13 - Valor da Repetitividade do Pavement Scanner ................................ 152

Tabela 4.14 - Análise do Desvio Padrão de Repetitividade e Reprodutividade do IGG pelo Método Tradicional ...................................................................................... 153

Tabela 4.15 - Valor da Repetitividade do Levantamento Tradicional .................... 154

Tabela 4.16 - Resultados do PCI para cada Seção-Teste ......................................... 157

Tabela 4.17 - Resultados do IGG amostral e do IGG contínuo............................... 162

Tabela 4.18 - Análise da Variabilidade de Resultados do Método Tradicional- ST-02

Tabela 4.19 - Análise da Variabilidade de Resultados do Método Tradicional - ST-03

Tabela 4.20 - Análise da Variabilidade de Resultados do Método Tradicional - ST-04

Tabela 4.21 - Análise da Variabilidade de Resultados do Método Tradicional - ST-07

Tabela 4.22 - Análise da Variabilidade de Resultados do Método Tradicional - ST-08

Tabela 4.23 - Análise da Variabilidade de Resultados do Pavement Scanner- ST-02 168 
Tabela 4.24 - Análise da Variabilidade de Resultados do Pavement Scanner- ST-03 169

Tabela 4.25 - Análise da Variabilidade de Resultados do Pavement Scanner- ST-04 170

Tabela 4.26 - Análise da Variabilidade de Resultados do Pavement Scanner- ST-05 171

Tabela 4.27 - Análise da Variabilidade de Resultados do Pavement Scanner- ST-06 172

Tabela 4.28 - Análise da Variabilidade de Resultados do Pavement Scanner- ST-07 173

Tabela 4.29 - Análise da Variabilidade de Resultados do Pavement Scanner- ST-08 174 


\section{LISTA DE ABREVIATURAS E SIGLAS}

A

AASHO

AASHTO

Ag

$\mathrm{Ai}$

ALC

ATC

ALP

ATP

AP

APL

ARAN

ASTM

CBR

CBUQ

CERL

CNT

D

DER

DNER

DNIT

E

Ex

ES

F

FC-1

FC-2
Afundamentos

American Association of State Highway Officials

American Association of State Highway and Transportation

Officials

Trincamento Geral

Trincamento Isolado

Afundamento de Consolidação Local

Afundamento de Consolidação na Trilha de Roda

Afundamento Plástico Local

Afundamento Plástico na Trilha de Roda

Afundamento Plástico

Analisador do Perfil Longitudinal

Automatic Road Analyser

American Society of Testing and Materials

California Bearing Ratio

Concreto Betuminoso Usinado a Quente

Construction Engineering Research Laboratory

Confederação Nacional do Transporte

Desgaste

Departamento de Estradas de Rodagem

Departamento Nacional de Estradas de Rodagem

Departamento Nacional de Infraestrutura de Transportes

Escorregamento de Massa

Exsudação

Especificação de Serviço

Fendas

Trincas Classe 1

Trincas Classe 2 


\begin{tabular}{|c|c|}
\hline FC-3 & Trincas Classe 3 \\
\hline FHWA & Federal Highway Administration \\
\hline FI & Fissuras \\
\hline $\mathrm{ICPF}$ & Índice de Condição de Pavimentos Flexíveis \\
\hline IES & Índice de Estado da Superfície \\
\hline IGG & Índice de Gravidade Global \\
\hline IGGE & Índice de Gravidade Global Expedito \\
\hline IMU & Unidades de medidas inerciais \\
\hline IPR & Instituto de Perquisas Rodoviárias \\
\hline IRI & International Roughness Index \\
\hline $\mathrm{J}$ & Jacaré \\
\hline $\mathrm{JE}$ & Jacaré com Erosão \\
\hline LCMS & Laser Cracking Measurement System \\
\hline LCPC & Laboratóire Central des Ponts et Chaussèes \\
\hline LTPP & Long-Term Pavement Performance \\
\hline LVC & Levantamento Visual Contínuo \\
\hline LVC & Levantamento Visual Detalhado \\
\hline MTD & Mean Texture Depth \\
\hline ND & Não Disponível \\
\hline NQI & Níveis de Qualidade de Informação \\
\hline NYSDOT & New York State Department of Transportation \\
\hline $\mathrm{O}$ & Ondulações \\
\hline $\mathrm{P}$ & Panela ou Buraco \\
\hline PCI & Pavement Condition Index \\
\hline PICR & Pesquisa de Inter-relacionamento de Custos Rodoviários \\
\hline PRO & Procedimento \\
\hline PSR & Present Serviciability Rating \\
\hline QI & Quociente de Irregularidade \\
\hline $\mathrm{R}$ & Remendos \\
\hline
\end{tabular}




$\begin{array}{ll}\text { RI } & \begin{array}{l}\text { Ravelling Index } \\ \text { ROMDAS - TPL }\end{array} \\ \text { Road Measurement Data Acquisition System - Transverse } \\ \text { Profile Logger } \\ \text { Índice de Porosidade } \\ \text { SG } & \text { Índice de Severidade Global } \\ \text { SHRP } & \text { Sistema de Gerência de Pavimentos } \\ \text { ST } & \text { Strategic Highway Research Program } \\ \text { TB } & \text { Seção-Teste } \\ \text { TBE } & \text { Trincas em Blocos } \\ \text { TLC } & \text { Trincas em Blocos com Erosão } \\ \text { TLL } & \text { Trincas Longitudinais Curtas } \\ \text { TRR } & \text { Trincas Longitudinais Longas } \\ \text { TRRL } & \text { Trincas de Retração do Revestimento } \\ \text { TTC } & \text { Transport Road Research Laboratory } \\ \text { TTL } & \text { Trincas Transversais Curtas } \\ \text { UA } & \text { Trincas Transversais Longas } \\ \text { USP } & \text { Unidade Amostral } \\ \text { VDC } & \text { Universidade de São Paulo } \\ \text { Vdi } & \text { Valor-dedução corrigido } \\ \text { VDM } & \text { Valores-dedução individuais } \\ \text { VDT } & \text { Valor-dedução total } \\ \text { VAe Serventia Atual }\end{array}$




\section{LISTA DE SÍMBOLOS E UNIDADES}

$\begin{array}{ll}\mathrm{cm} & \text { centímetro } \\ \mathrm{R}^{2} & \text { coeficiente de correlação } \\ \mathrm{p} & \text { conjunto de população de dados } \\ \mathrm{S} & \text { desvio padrão } \\ \mathrm{Sr} & \text { desvio padrão de repetitividade } \\ \mathrm{S}_{\mathrm{L}} & \text { desvio padrão do laboratório } \\ \mathrm{GB} & \text { Gigabyte } \\ \circ & \text { grau } \\ \mathrm{Hz} & \text { hertz } \\ \mathrm{h} & \text { hora } \\ m & \text { média aritmética } \\ \bar{x}_{i j} & \text { média aritmética } \\ \overline{\bar{x}}_{j} & \text { média geral dos resultados } \\ \mathrm{MG} & \text { megabyte } \\ \mathrm{m} & \text { metro } \\ \mathrm{m}^{2} & \text { metro quadrado } \\ \mu \mathrm{m} & \text { micrometro } \\ \mathrm{mm} & \text { milímetro } \\ \mathrm{n} & \text { número de amostras } \\ \mathrm{E} & \text { número de diferenças de leituras maiores que r } \\ \mathrm{C} & \text { número de diferenças totais de leitura } \\ \% & \text { por cento } \\ \mathrm{kg} & \text { quilograma } \\ \mathrm{km} & \text { quilômetro } \\ \mathrm{r} & \text { repetitividade } \\ \mathrm{R} & \text { reprodutivade } \\ \mathrm{s} & \text { segundo } \\ \mathrm{r} \text { e } & \text { valor de repetitividade do ensaio } \\ \mathrm{S}^{2} & \text { variância } \\ \mathrm{VAC} & \mathrm{W} \\ \mathrm{W} & \end{array}$




\section{SUMÁRIO}

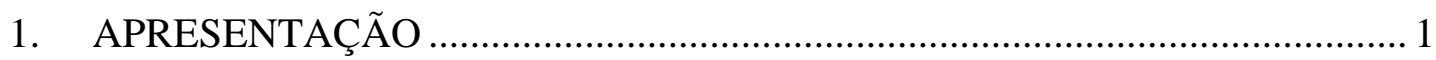

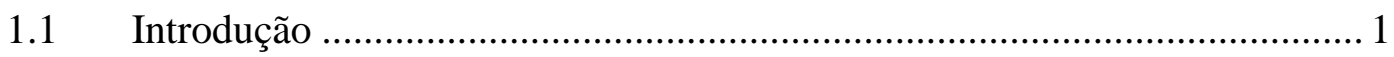

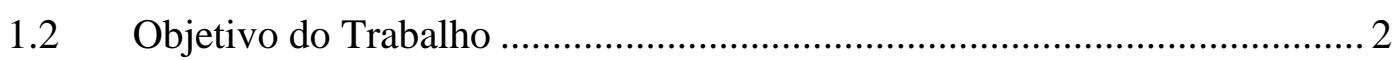

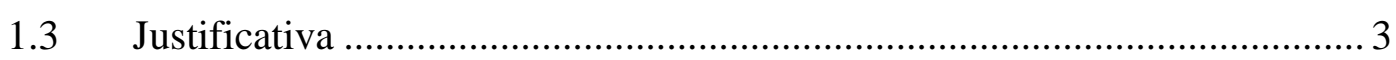

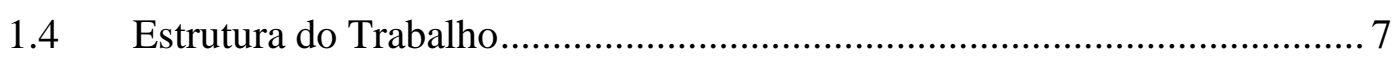

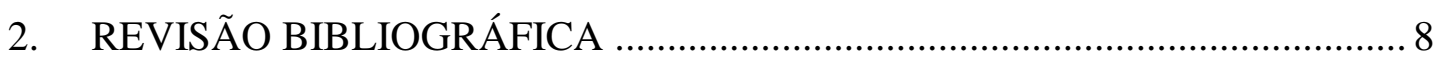

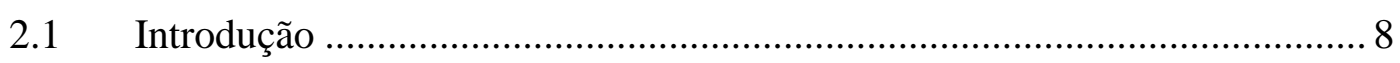

2.2 Sistema de Gerência de Pavimentos ......................................................... 8

2.2.1 Visão Geral do Sistema de Gerência de Pavimentos .................................... 8

2.2.2 Coleta de Dados do Gerenciamento de Pavimentos ................................... 12

2.3 Defeitos em Pavimentos Flexíveis ............................................................ 15

2.3.1 Mecanismo e Terminologia dos Defeitos .................................................. 16

2.4 Métodos de Avaliação da Superfície do Pavimento …………………….... 27

2.4.1 Procedimento - DNIT-PRO 006/2003 ……………………………….... 28

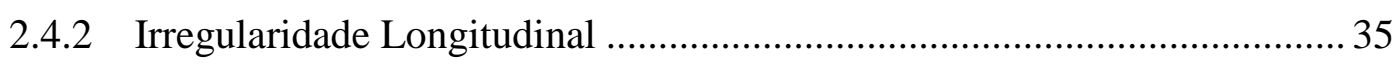

2.4.3 Método do PCI do NYSDOT .................................................................... 41

2.5 Equipamentos de Avaliação Funcional ........................................................53

2.5.1 ARAN (Automatic Road Analyser)....................................................... 54

2.5.2 ROMDAS - TPL (Road Measurement Data Acquisition System -

Transverse Profile Logger) .......................................................................... 55

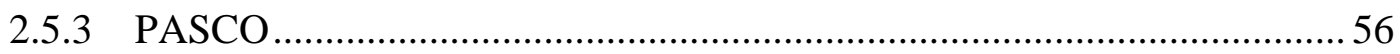

2.5.4 Perfilômetro Laser................................................................................. 57

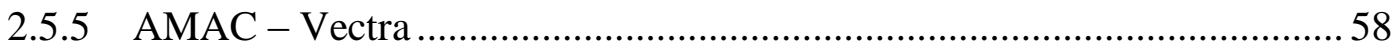

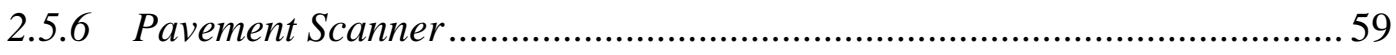

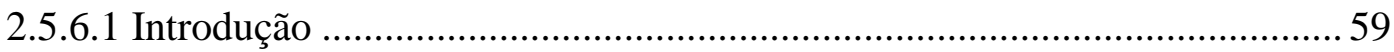

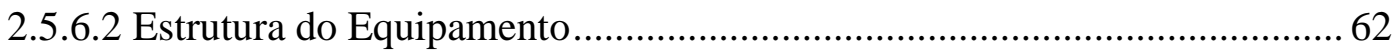

2.5.6.3 Descrição dos Módulos de Processamento do Pavement Scanner ............. 69

3 METODOLOGIA DA PESQUISA ………………………………….......... 79

3.1 Definição da Metodologia da Pesquisa ........................................................ 79

3.2 Definição das Seções-teste....................................................................... 82

3.3 Levantamentos de Campo ..................................................................... 90 
3.3.1 Levantamentos com Pavement Scanner

3.3.2 Levantamentos com Metodologia Tradicional........................................... 95

4 RESULTADOS E ESTUDOS COMPARATIVOS ....................................... 100

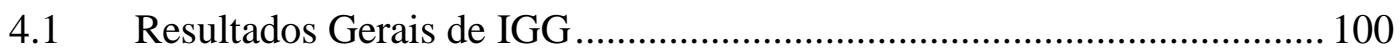

4.2 Resultados de Trincamento ................................................................ 108

4.3 Resultados do Afundamento na Trilha de Roda .................................... 118

4.4 Resultados da Irregularidade Longitudinal ............................................ 126

4.5 Análise da Influência da Velocidade do Veículo ..................................... 133

4.6 Análise da Influência da Luminosidade durante o Levantamento ........... 136

4.7 Análise da Influência do Tipo de Revestimento ...................................... 138

4.8 Resultados da Repetitividade dos Defeitos ............................................. 139

4.9 Análise da Reprodutividade e Repetitividade ........................................... 146

4.9.1 Procedimento para Obtenção da Reprodutividade e Repetitividade......... 146

4.9.2 Resultados da Reprodutividade e Repetitividade do IGG....................... 149

4.10 Correlação entre IGG e PCI ................................................................ 155

4.11 Análise do IGG com relação ao percentual amostral .............................. 160

4.12 Análise da Variabilidade do IGG com Relação à Posição Inicial............ 164

5 CONCLUSÕES E SUGESTÕES PARA NOVAS PESQUISAS ..................... 176

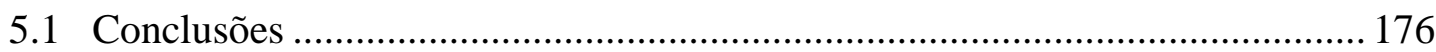

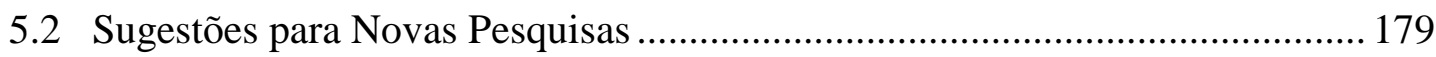

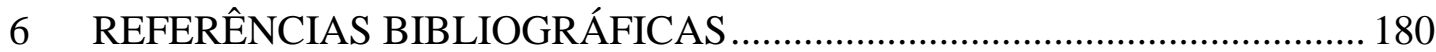




\section{APRESENTAÇÃO}

\subsection{Introdução}

A comunidade rodoviária nacional encontra-se em um momento de aprimoramento tecnológico, impulsionando a pesquisa, em busca da excelência de qualidade, com um gerenciamento mais efetivo, utilizando técnicas diferenciadas de avaliação dos pavimentos da malha.

Atualmente, no Brasil, as rodovias pavimentadas correspondem a aproximadamente 12,5\% de todo sistema de rodovias. Dados do Sistema de Gerência de Pavimentos do DNIT (2011), indicam que o Brasil, possui uma rede de rodovias com uma extensão de $1.712 .517 \mathrm{~km}$, sendo aproximadamente $214.000 \mathrm{~km}$ pavimentados.

Segundo os estudos realizados pela Confederação Nacional do Transporte - CNT (2013), a maioria das rodovias federais apresenta baixo conforto ao rolamento, apontando que o nível de estradas classificadas como regular/ruim/péssimo era de $74,7 \%$ em 2004 e de 69,0\% em 2009. Além disso, 60\% do transporte de carga é realizado pelo modal rodoviário. Nesse cenário nacional, cujas rodovias apresentam baixa qualidade ao usuário, justifica-se a necessidade de um gerenciamento mais efetivo das mesmas, que se dá a partir de levantamentos cadastrais, pesquisas e inventários do pavimento existente.

A malha viária quando bem conservada permite o escoamento das safras, acelerando o desenvolvimento da região, contribuindo assim para promover a indústria e o comércio, para melhorar a viabilidade das zonas urbanas, com o aumento dos empregos, com a educação e com a geração de novas oportunidades (QUEIROZ et al., 1992).

Tendo em vista os parâmetros de conforto, segurança e serviço, faz-se necessário estabelecer mecanismos para garantir a manutenção da estrutura rodoviária nacional, 
de modo a orientar a priorização dos investimentos em restauração. Com este procedimento evita-se a degradação do sistema viário com prejuízos imensos à sociedade, tanto pela necessidade de reconstrução precoce em rodovias mal conservadas, como pelo aumento do custo operacional dos veículos ou custo dos usuários.

Assim, a análise das características funcionais dos pavimentos tem apresentado um alto grau de importância, decorrente da procura em se caracterizar adequadamente a condição da via, de forma a se obter um gerenciamento mais efetivo das intervenções, em busca de melhores níveis de conforto, segurança e serviço.

\subsection{Objetivo do Trabalho}

O presente trabalho tem como objetivo a contribuição para o processo de avaliação funcional, através da validação de resultados do inventário funcional de pavimentos flexíveis com o emprego do equipamento Pavement Scanner. A utilização deste equipamento poderá garantir a integridade, a confiabilidade e a plena restituição das informações para o projeto e programa de gestão de pavimentos.

Para tanto, foram definidas seções-teste, onde avaliou-se as condições funcionais do pavimento, de acordo com a metodologia tradicional de avaliação da superfície do pavimento e sob a utilização do equipamento Pavement Scanner.

Os levantamentos pelos métodos tradicionais foram obtidos através da aplicação do Procedimento DNIT-PRO-006, que estabelece o Índice de Gravidade Global (IGG) do pavimento e pela utilização do perfilômetro laser para determinação do Índice de Irregularidade Internacional (IRI). Os resultados obtidos pelo método tradicional e pela nova tecnologia foram analisados e comparados, buscando-se determinar a variação obtida pelas diferentes técnicas de avaliação do pavimento, além da análise da repetitividade e reprodutividade de cada uma destas técnicas. 
Adicionalmente foi estudada a aplicabilidade dos resultados obtidos pelo Pavement Scanner no cálculo do PCI (Índice da Condição do Pavimento, do inglês Pavement Condition Index).

\subsection{Justificativa}

A elaboração de um programa de gerenciamento de uma rede rodoviária implica na definição da aplicação de montantes consideráveis de recursos em sua recuperação e manutenção, o que se dá com base em levantamentos cadastrais, pesquisa e inventários de elementos rodoviários, em especial associados à condição dos pavimentos existentes.

Neste cenário, a tendência tem sido a de se procurar quantificar, por meio de medidas e ensaios adequados, uma escala arbitrária qualitativa baseada em ponderações de vários tipos de usuários. Dentro dessa linha, surgiu durante a realização dos ensaios na American Association of the State Highway Officials, AASHO Road Test, o conceito de serventia, uma avaliação qualitativa construída através de opinião de vários usuários na escala numérica variando de 0 a 5 , em que 0 indica um pavimento totalmente destruído ou inaceitável e 5 seria o valor correspondente a um pavimento perfeito. Definida a escala, foram desenvolvidos ensaios para a medida de certas características julgadas associadas ao comportamento do pavimento e que, combinadas adequadamente por meio de uma equação experimental, fornecessem o índice numérico correspondente à escala de opinião. Atualmente, os ensaios utilizados ou as medidas efetuadas dizem respeito, principalmente, à irregularidade longitudinal, à intensidade de trincamento e à profundidade média das trilhas provocada pelas rodas.

De acordo com o DER/SP (2006), a "avaliação funcional" é a determinação da capacidade de desempenho funcional momentânea, serventia, que o pavimento proporciona ao usuário, ou seja, o conforto em termos de qualidade de rolamento. $\mathrm{O}$ desempenho funcional refere-se à capacidade do pavimento de satisfazer sua função 
principal, que é a de fornecer superfície com serventia adequada em termos de qualidade de rolamento.

A avaliação das condições de superfície trata de identificar defeitos existentes, proceder ao seu cadastro e interpretar os resultados obtidos. Tal avaliação dependia, até pouco tempo, da realização de um inventário no qual um avaliador, caminhando sobre o pavimento anotava em planilhas, ou em computador de mão ou mesmo em um notebook acoplado a um hodômetro de precisão, os defeitos existentes em áreas selecionadas como amostras.

Nos últimos anos, o emprego de equipamentos de avaliação contínua e integrada de pavimentos tem ganhado destaque no meio técnico rodoviário, em especial os que possibilitam levantamento de informações em velocidade de tráfego com grande acurácia e reprodutividade.

No que tange o desenvolvimento e a introdução de novas tecnologias de avaliação de pavimentos, no Brasil é utilizado amplamente os perfilômetros laser para determinação de irregularidade longitudinal e alternativas aos procedimentos convencionais de cadastro de defeitos de superfície são buscadas, com vistas a maior agilidade na coleta de dados, menor interferência do avaliador no resultado, melhora nas condições de segurança dos técnicos envolvidos na coleta de informações e menor interferência com os usuários da rodovia.

De acordo com DNIT (2006), os procedimentos sistemáticos de avaliação devem ser iniciados pela definição das informações a serem coletadas por processo sistêmico e sequencial, de maneira que o custo de avaliação e o tempo despendido sejam mínimos. Os dados devem ser cuidadosamente avaliados e os resultados sumarizados de maneira sistematizada, devendo os mesmos abranger os seguintes aspectos:

- Fornecer informações qualitativas para determinação das causas da deterioração e para o desenvolvimento de alternativas apropriadas no reparo do defeito e na prevenção de sua recorrência; 
- Fornecer informações quantitativas para a estimativa de demanda de serviços de restauração, dimensionamento de alternativa de restauração, avaliação do estágio de deterioração e das consequências de se postergar a restauração e ainda executar estudo econômico de alternativas de restauração.

O próprio Manual de Restauração de Pavimentos Asfálticos do DNIT (2006) indica que devem ser desenvolvidos procedimentos padronizados e manuais para avaliação de pavimentos, compatíveis com as especificidades locais e os equipamentos disponíveis. De acordo com o DER/SP (2006), “é importante que as avaliações sejam executadas de forma planejada e criteriosa, considerando a segurança dos usuários da rodovia e também da equipe de avaliação das condições dos pavimentos".

Neste sentido, ressalta-se a importância da validação de uma nova tecnologia de avaliação funcional de pavimentos para aplicação em rodovias brasileiras que permita a coleta de informações de forma automática, sem a interferência do profissional encarregado pela atividade de inventário de superfície, minimizando o tempo de coleta e processamento de dados, reduzindo-se as interferências com o tráfego, considerandose, inclusive, que muitas vezes as estradas possuem tráfego extremamente elevado e garantindo informações de qualidade e de rápida restituição.

O Pavement Scanner é um equipamento montado sobre um veículo adaptado para avaliação rodoviária integrada, que verifica o perfil transversal da superfície do pavimento através da iluminação com radiação a laser emitida por seus dispositivos. Dispõe de duas bases na posição traseira, nos lados direito e esquerdo do veículo. Cada base contém dois sensores laser que geram dois perfis distintos, ambos com câmera de alta potência. Um dos perfis tem a função de apresentar informações referentes à intensidade ou imagem (cor) do pavimento e o outro, de coleta de dados com o mapeamento da superfície em termos de coordenadas x,y,z. O levantamento é realizado em até $100 \mathrm{~km} / \mathrm{h}$, obtendo-se imagens em 3D ou 2D, em uma largura de até $4 \mathrm{~m}$ do pavimento, de forma a permitir a determinação do seu grau de deterioração superficial. 
São geradas seções de cada faixa de tráfego individualmente, com extensões de até 10 $\mathrm{m}$, onde é possível analisar as imagens do pavimento, mapeando os seus defeitos, bem como quantificar, com base em parâmetros de entrada de largura e espessura, a classificação das trincas. O equipamento também possibilita a visualização da demarcação da sinalização horizontal na pista, panelas, exsudação, desagregação, afundamento na trilha de roda e macrotextura. Os mapeamentos e o grau dos trincamentos são apresentados como, por exemplo, na Figura 1.1:

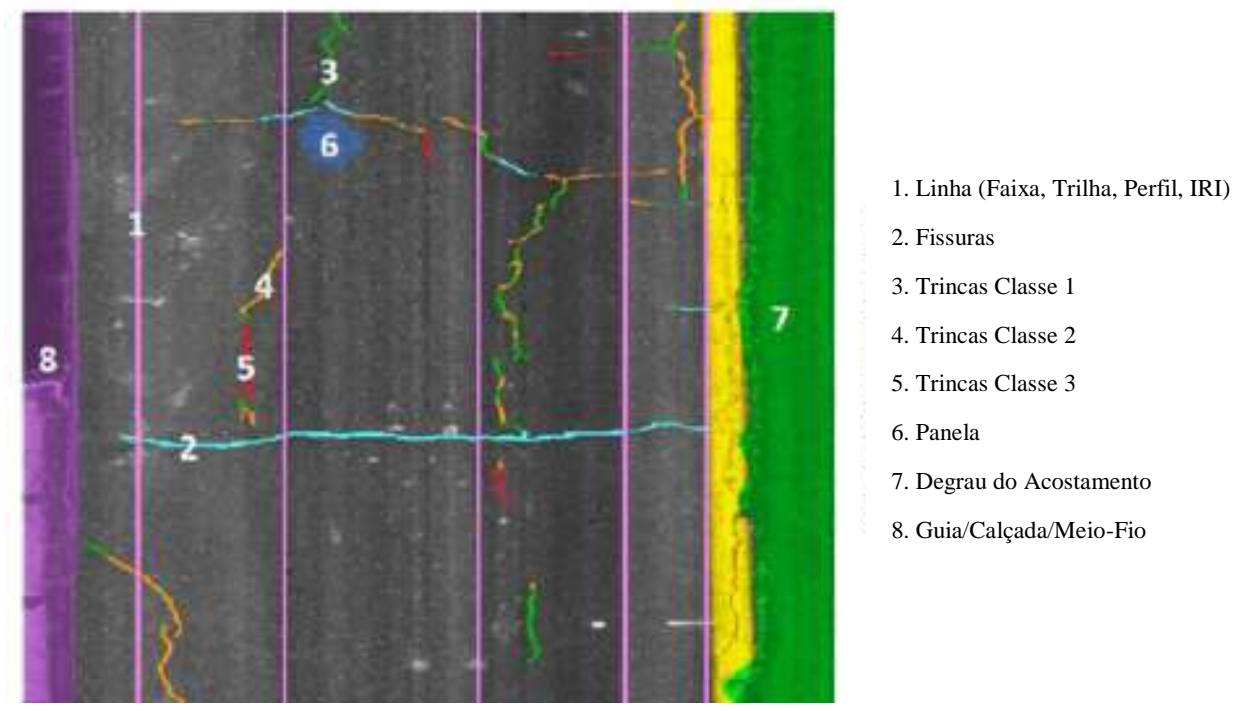

Figura 1.1 - Exemplo de Seção do Pavimento com Mapeamento dos Defeitos (adaptado do LCMS - Manual, 2009)

A forma da linha imaginária transversal à superfície do pavimento, obtida através dos dois sensores a laser e dois acelerômetros, permitem a determinação do perfil longitudinal dos pavimentos e dos parâmetros de irregularidade em termos de IRI. É possível obter o perfil transversal e longitudinal da rodovia com elevada resolução por levantamento do tipo varredura ou contínuo, ou seja, não pontual.

Em teoria, o emprego do Pavement Scanner na avaliação funcional de pavimentos sob elevado volume de tráfego parece muito vantajoso sob o aspecto técnico, com a possibilidade de análise integrada de todos os parâmetros funcionais, com mínima interferência no tráfego da rodovia (pois o levantamento ocorre em velocidade elevada e possibilidade de restituição das informações e imagens dos locais inventariados, 
eliminando a interferência de técnicos de campo no resultado final da avaliação do pavimento.

\subsection{Estrutura do Trabalho}

O presente estudo foi organizado em 6 capítulos, que são resumidos a seguir:

O Capítulo 1 introduz o tema da dissertação e sua relevância no contexto rodoviário brasileiro. Apresenta também o objetivo, a justificativa e a estrutura do trabalho.

O Capítulo 2 apresenta a revisão bibliográfica referente aos defeitos em pavimentos flexíveis, com suas terminologias e classificações, os métodos de avaliação da superfície do pavimento, bem como os equipamentos utilizados para a avaliação funcional no cenário mundial.

O Capítulo 3 consiste na apresentação da metodologia da pesquisa, com a definição das seções-teste. Consta, ainda a avaliação funcional realizada em campo nas seções teste pelos modelos tradicionais e com a utilização do equipamento Pavement Scanner.

No Capítulo 4 são apresentados os resultados e estudos comparativos entre o levantamento com o Pavement Scanner e o realizado com as metodologias tradicionais.

No Capítulo 5 são apresentadas as conclusões e recomendações obtidas e finalmente, no Capítulo 6, as referências bibliográficas utilizadas nesta dissertação. 


\section{REVISÃO BIBLIOGRÁFICA}

\subsection{Introdução}

Para a validação de resultados do inventário funcional de pavimentos flexíveis com o emprego do equipamento Pavement Scanner é importante discorrer sobre a visão geral de um sistema de gerência de pavimento, dos defeitos apresentados nos pavimentos flexíveis, com suas terminologias e classificações, os métodos de avaliação da superfície do pavimento, bem como, os equipamentos existentes para o inventário dos revestimentos.

\subsection{Sistema de Gerência de Pavimentos}

\subsubsection{Visão Geral do Sistema de Gerência de Pavimentos}

A manutenção de uma rodovia ou sistema rodoviário é uma função básica de sua operação e dela dependem a condição funcional, conforto e segurança, bem como, os níveis de gastos futuros em obras de recuperação.

Para gerir toda a sistemática de manutenção, vêm sendo desenvolvidos desde a década de 1960 os Sistemas de Gerência de Pavimentos (SGP), com maior crescimento na década de 1980, segundo o Manual de Gerência de Pavimentos do DNIT (2011).

As agências, concessionárias e órgãos públicos estão desenvolvendo procedimentos e manuais para gerenciar a qualidade dos dados do pavimento inventariado, já que este atributo tem um grande efeito nas tomadas de decisões e a coleta de dados representa a parcela mais onerosa do SGP.

De acordo com a AASHTO (1990), o Sistema de Gerência de Pavimentos pode ser definido como um conjunto de ferramentas que serve para auxiliar os tomadores de decisão na busca de estratégias viáveis, para avaliar, prover e manter os pavimentos em boas condições durante um determinado período de tempo. 
Originalmente descrita como uma abordagem de sistemas para a concepção do pavimento, o termo sistema de gerência de pavimentos (SGP) entrou em uso popular no final dos anos 1960 e início de 1970 para descrever as ferramentas de apoio à decisão para toda a gama de atividades envolvidas no fornecimento e manutenção de pavimento (PETERSON, 1987). Hudson e Haas (1978) descrevem como um conjunto coordenado de atividades, que objetiva alcançar o menor custo para os órgãos públicos, assegurando níveis de conforto e segurança.

Kulkarni e Miller (2003) destacam o progresso obtido nas três últimas décadas nos Sistemas de Gerência de Pavimentos. Os autores avaliam o passado (até a década de 1980), o presente (considerada a década de 1990) e o futuro (o início do século vinte e um) dos SGP e apresentam oito elementos-chave do sistema. Também é destacado que o SGP, desde a sua introdução no final dos anos 1960 e início dos anos 1970, tem evoluído em termos de escopo, aplicação e metodologia. O SGP foi idealizado acompanhando a mudança da tendência dominante de modelos de projeto e construção para os modelos de reparos e manutenção. Os oito elementos-chave abordados são:

- Funções;

- Gerenciamento e coleta de dados;

- Previsão de desempenho de pavimentos;

- Análise econômica;

- Avaliação de prioridades;

- Otimização;

- Medidas institucionais;

- Informações tecnológicas.

É observada uma mudança no escopo das funções dos Sistemas de Gerência de Pavimentos ao longo dos anos, conforme Figura 2.1, adaptada de Kulkarni e Miller (2003). 


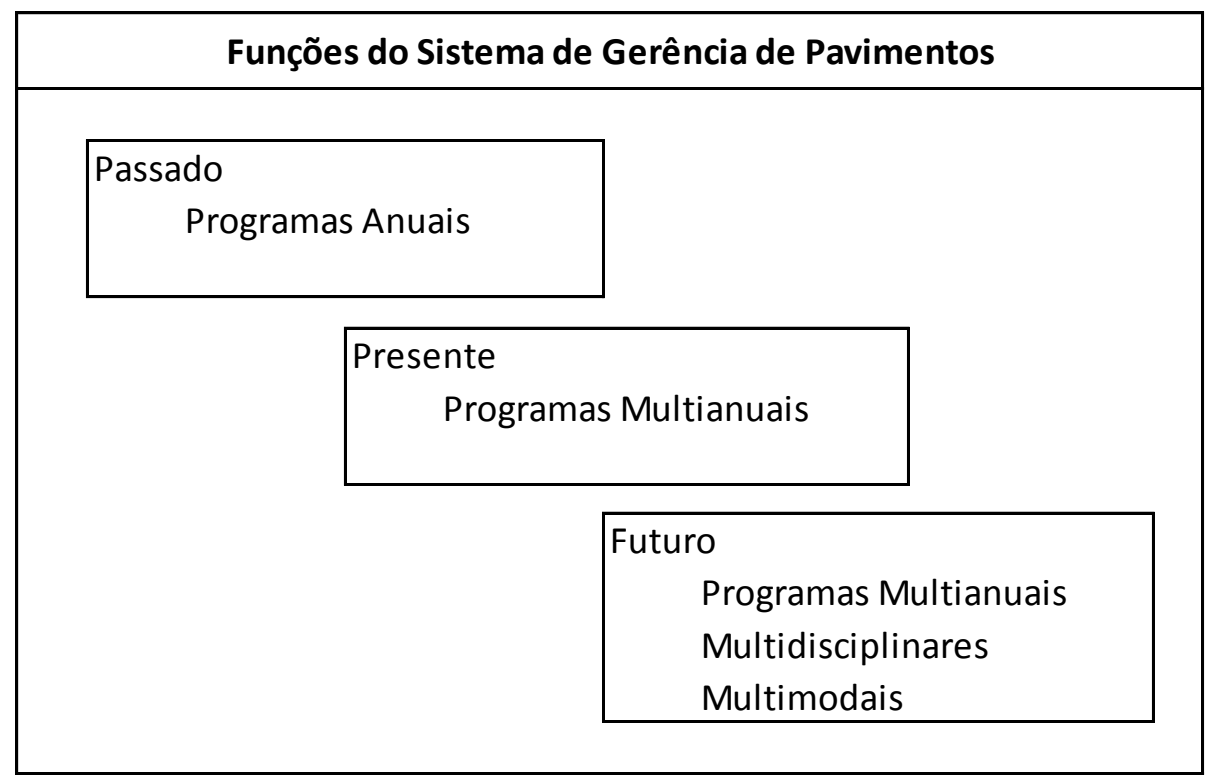

Figura 2.1 - Evolução da Abrangência das Funções de um Sistema de Gerência de Pavimentos (adaptada de KULKARNI \& MILLER, 2003)

Outras definições do Sistema de Gerência de Pavimentos apontam para cinco componentes chaves, que segundo Peterson (1987) são:

- Levantamento das condições do pavimento;

- Base de dados contendo toda a informação relacionada ao pavimento;

- Algoritmos de análise;

- Critérios de decisão;

- Implementação de procedimentos.

O Sistema de Gerência de Pavimentos apresenta componentes que devem interagir mutuamente: o planejamento, o projeto, a construção e a manutenção dos pavimentos (DNIT, 2011). Como principais fatores externos podem ser citados os recursos orçamentários, os dados necessários ao sistema e as diretrizes políticas e administrativas. A Figura 2.2 adaptada do manual supracitado, ilustra adequadamente como se estrutura um Sistema de Gerência de Pavimentos. 


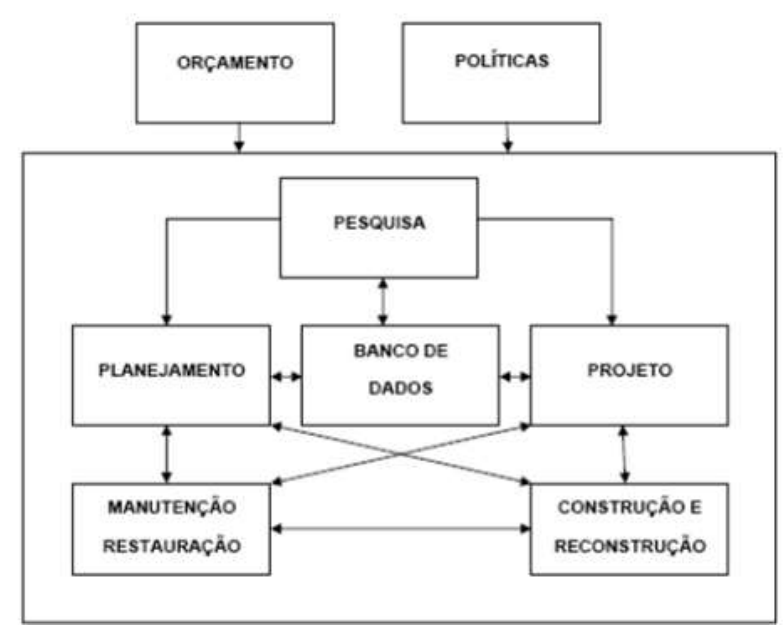

Figura 2.2 - Componentes que Interagem em um Sistema de Gerência de Pavimentos (adaptada de Manual de Gerência de Pavimentos, DNIT, 2011)

A estrutura de um sistema de gestão de pavimentos pode ser separada em dois níveis gerais: nível de rede e nível de projeto. O nível de rede refere-se à rede de pavimento como um todo e é geralmente relacionado com as decisões de alto nível relativas ao planejamento de toda a rede, política e orçamento (HAAS et al., 1994). Por exemplo, os gerentes, neste nível, podem comparar os custos e benefícios de vários programas alternativos e, em seguida, identificar o programa/orçamento que terá o maior relação custo-benefício da rede durante o período analisado.

O nível de projeto lida com seções constituintes menores dentro da rede e é geralmente relacionado com as decisões de baixo nível relativas à condição, manutenção, reconstrução e reabilitação do pavimento, bem como, seus custos unitários.

Abordagens para a gerência de pavimentos tendem a atacar o sistema de dois níveis ou de cima para baixo, por primeiro lidar com as decisões em nível de rede, ou de baixo para cima, por lidar primeiramente com as decisões em nível de projeto. Qualquer método pode ser bastante detalhado ou relativamente simples, dependendo da quantidade e qualidade de dados, além da capacidade analítica desejada (AASHTO, 1990). 


\subsubsection{Coleta de Dados do Gerenciamento de Pavimentos}

A coleta de dados da condição dos pavimentos é um componente primordial no gerenciamento de pavimentos. Os tipos de dados coletados em um SGP incluem condições de conforto, defeitos de superfície (afundamentos, trincas), propriedades de aderência da superfície (aderência pneu/pavimento, resistência à derrapagem e macrotextura) e condições estruturais do pavimento (bacias deflectométricas e resultados de ensaios destrutivos).

A maneira pela qual as agências e órgãos coletam, armazenam e analisam os dados tem evoluído juntamente com os avanços da tecnologia, com a utilização de computadores portáteis, sensores avançados, tecnologias de imagens, bancos de dados distribuídos e tecnologias espaciais de georreferenciamento. Essas tecnologias permitiram a coleta de dados e integração de procedimentos necessários para apoiar as análises abrangentes e processos de avaliação necessários para o gerenciamento (FLINTSCH e BRYANT, 2008).

No entanto, o uso das tecnologias mencionadas anteriormente, em alguns casos, faz com que os órgãos coletem grandes quantidades de dados que nem sempre são úteis ou necessários para apoiar os processos de decisão em nível de rede. Para evitar essa situação, três princípios são recomendados: coletar apenas os dados necessários; coletar dados com nível mínimo de detalhe, suficiente para tomar decisões apropriadas; e coletar dados apenas quando necessário (BENNETT e MCPHERSON, 2005). Para auxiliar na adaptação das práticas de coleta de informações para o uso dos dados, Paterson e Scullion (1990) introduziram o conceito de Níveis de Qualidade de Informação (NQI) para gerenciamento das rodovias.

O conceito dos NQI estrutura a informação do gerenciamento da rodovia em diferentes níveis, que se correlacionam com o grau de detalhamento necessário para a tomada de decisão, mostrando-se adequado para a coleta e tratamento dos dados. Dentro da estrutura proposta, elementos muito detalhados (dados de baixo nível) podem ser 
condensados ou agregados em formas progressivamente mais simples (dados de nível superior). Bennett e Paterson (2000) definiram cinco níveis, que variam de alto nível de detalhamento, em um NQI-1 (dados de pesquisa e referência para outros métodos de medição), para uma forma mais abrangente, em NQI-5 (dados de nível superior, tais como, medidas-chave para desempenho ou indicadores, que normalmente podem combinar atributos-chave de várias peças de informação). A Figura 2.3 ilustra a pirâmide dos Níveis da Qualidade de Informação (NQI).

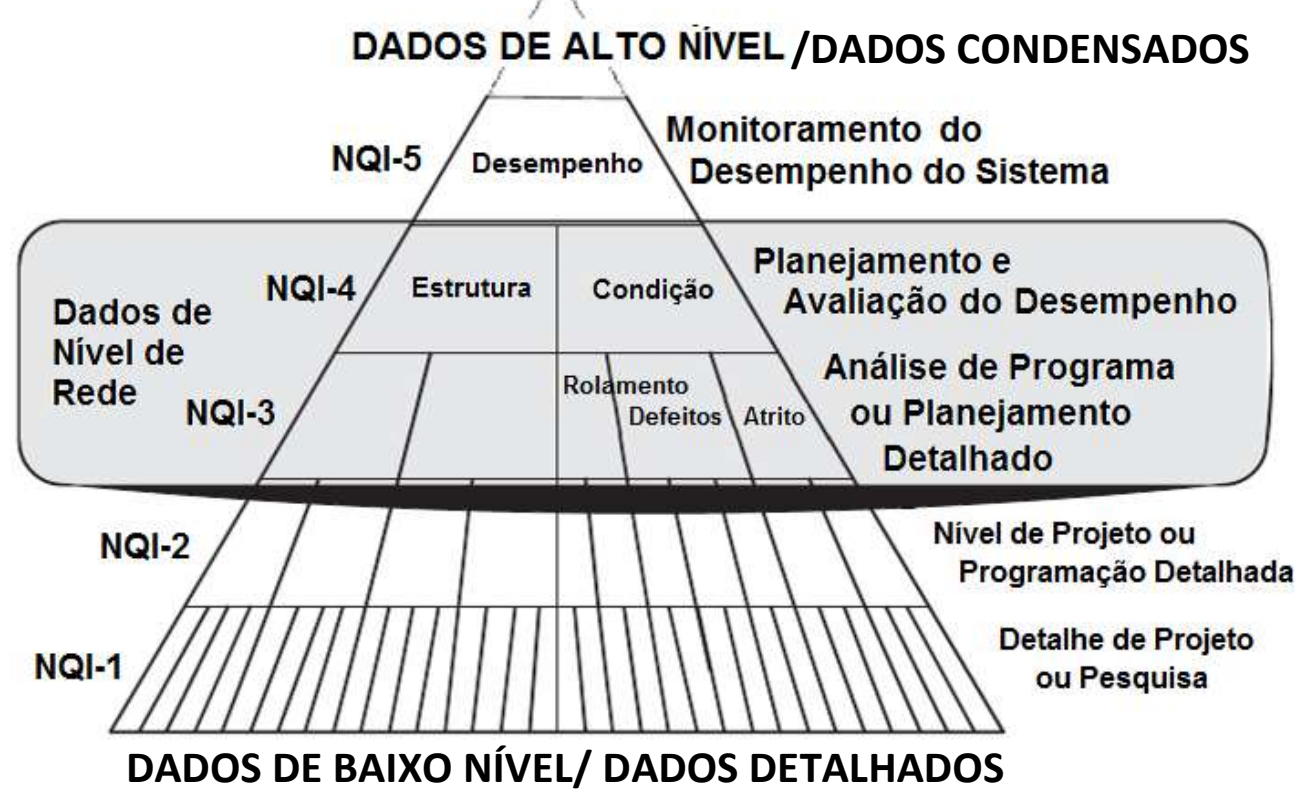

Figura 2.3 - Pirâmide dos Níveis de Qualidade de Informação (adaptada de Bennett e Paterson, 2000)

A coleta de dados para a tomada de decisão em nível de rede é geralmente diferente daquela utilizada em nível de projeto, portanto, os requisitos de qualidade para a condição do pavimento também são diferentes. A coleta em nível de rede envolve o levantamento de grandes quantidades de dados do estado do pavimento, que são convertidos em índices de condição. Devido à grande quantidade de informação necessária, os métodos de levantamento normalmente envolvem coletas automatizadas, que podem geralmente ser realizadas a altas velocidades, sem afetar o tráfego e garantindo segurança para os usuários da rodovia e para a equipe de levantamento. As informações são utilizadas para avaliar o estado global da rede, 
determinando estratégias de manutenção e de reabilitação, além de seus custos e orçamentos. Este nível de informação é o mais apropriado para mostrar os segmentos prioritários aos tomadores de decisão e para a realização de projeções plurianuais com respeito à condição geral da rede.

No nível de projeto, dados mais específicos são normalmente coletados em termos de identificação de defeitos e suas severidades. Medidas de atrito e avaliação estrutural são mais comuns neste nível de coleta de dados, pois são informações mais específicas para determinar os métodos de manutenção e requisitos orçamentários para projetos de pavimento. Este nível de informação é adequado para utilização em decisões técnicas.

A Figura 2.4 apresentada a seguir, resume o percentual de Estados e Províncias canadenses que fazem o inventário de cada tipo de levantamento da condição do pavimento no nível de rede e de projeto. $\mathrm{O}$ valor indicado acima de cada barra indica o percentual de agências que coletam os referidos indicadores de pavimento. Estes resultados são consistentes com os resultados relatados por Timm e McQueen (2004).

Questão: Qual dado de condição do pavimento a sua agência coleta?

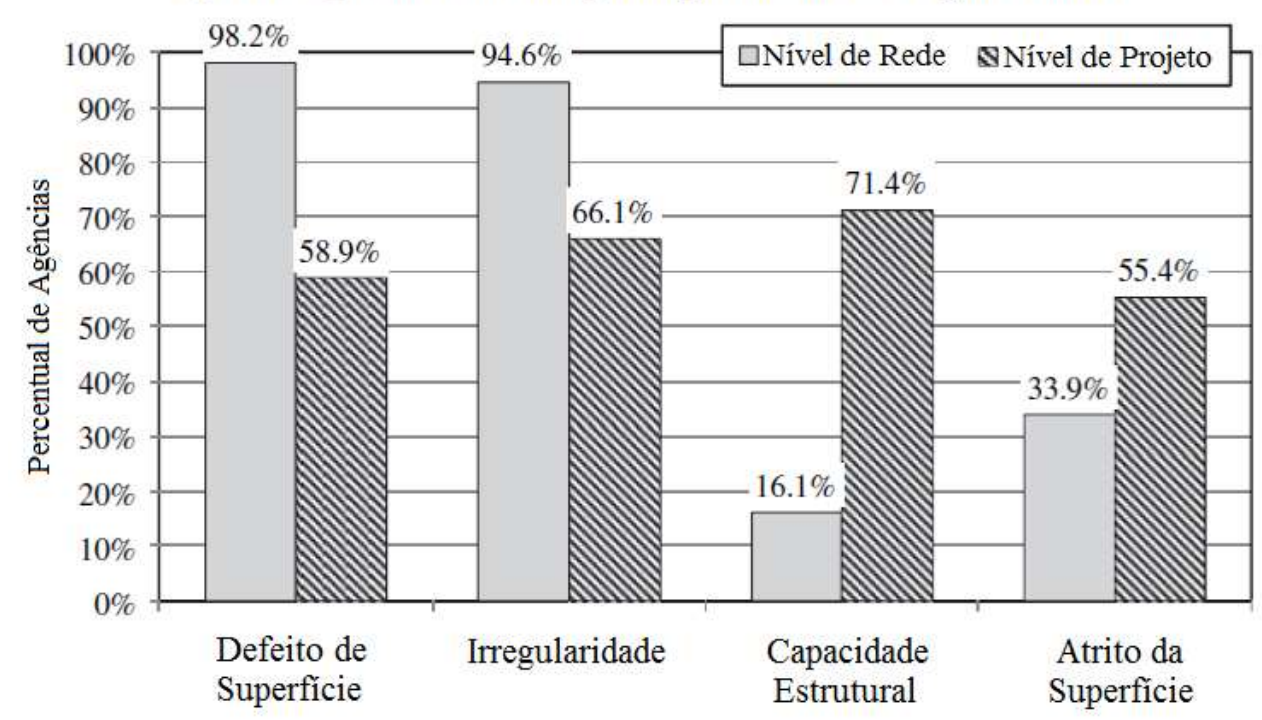

Figura 2.4 - Comparação entre o Nível de Rede e Nível de Projeto e os tipos de Levantamentos de Pavimento (adaptada de Timm e McQueen, 2004)

No nível de rede, os dados de levantamento de defeitos são coletados por quase todas as agências. Apenas uma agência (2\%) informou que não coletou dados de defeito no 
pavimento, e três (5\%) relataram que não estão coletando dados de irregularidade no nível de rede. A capacidade estrutural e propriedades de atrito são coletados no nível de projeto.

Essa análise mostra que em nível de rede a qualidade funcional do pavimento monitorado é o item mais importante, dado que conforme exposto anteriormente, é uma informação necessária para os tomadores de decisões conseguirem realizar seu planejamento de obras de manutenção ou reabilitação dos pavimentos.

Na implementação do SGP, a avaliação de pavimentos é uma das etapas mais importantes por ser o ponto de partida para as futuras decisões neste sistema, de acordo com Hudson e Haas (1978). Esta atividade possibilita que sejam estudadas as condições estruturais e funcionais dos pavimentos, adotando-se os procedimentos e as metodologias que melhor se adequem às características dos trechos de uma malha viária.

\subsection{Defeitos em Pavimentos Flexíveis}

Os pavimentos, segundo o Strategic Highway Research Program - SHRP (1993), podem apresentar por diversas razões uma variedade de patologias, que são denominadas de defeitos. Os defeitos nos pavimentos se refletem em danos na superfície e podem ser causados por imperfeições nas construções, pelo meio ambiente e pelas solicitações impostas pelo tráfego. Os defeitos afetam as capacidades funcionais e estruturais do pavimento, causando desconforto aos usuários.

O levantamento dos defeitos de superfície tem como finalidade a identificação e quantificação da extensão da área afetada, bem como, sua severidade. Estas informações possibilitam que sejam avaliadas e monitoradas as condições do pavimento em função do tempo, estabelecendo-se as causas da deterioração. Yshiba (2003) ressalta a importância da coleta de dados sobre a localização e a evolução de cada tipo de defeito para que possam ser estabelecidas e definidas as estratégias de intervenção e as atividades de manutenção e reabilitação. 
As trincas, por exemplo, são um tipo de defeito que se não forem devidamente seladas, podem comprometer estruturalmente e funcionalmente o pavimento. Elas têm um impacto significativo na evolução das deformações nas trilhas de roda e da irregularidade longitudinal. Desta forma, o trincamento se constitui, ao longo do tempo, em um critério importante para definição das intervenções de recuperação do pavimento (DNER, 1998).

Os defeitos verificados em pavimentos asfálticos estão relacionados, em sua maioria, às trincas, à deformação permanente nas trilhas de roda, às panelas, ao desgaste do agregado, ao bombeamento e à exsudação (HAAS et al., 1994). Os trincamentos nos pavimentos asfálticos podem ser originados por fadiga, envelhecimento, reflexão de trincas das camadas inferiores e pela retração térmica.

\subsubsection{Mecanismo e Terminologia dos Defeitos}

Vários manuais, catálogos e publicações sumarizam os tipos de defeitos nos revestimentos asfálticos. Apesar da diversidade de informações, existe uma analogia e boa padronização entre os defeitos apresentados nos manuais e publicações da SHRP (2003), AASHTO (1986), Domingues (1993) e DNER (1998), conforme o levantamento de defeitos apresentados por cada um:

- SHRP (1993) apresenta quinze tipos de defeitos em pavimentos flexíveis;

- AASHTO (1986) apresenta dezessete tipos de defeitos em pavimentos flexíveis;

- Domingues (1993) apresenta vinte e três tipos de defeitos em pavimentos flexíveis;

- DNER (1998) apresenta oito tipos de defeitos em pavimentos flexíveis.

Entretanto, o presente trabalho irá discorrer sobre os defeitos apresentados pelo DNER/DNIT. 
A nomenclatura e classificação de cada tipo específico de defeito está baseada na Norma DNIT 005/2003 - TER, que define os termos técnicos empregados em defeitos que ocorrem em pavimentos flexíveis e semi-rígidos, de forma a padronizar a linguagem adotada em normas e manuais.

Os tipos de defeitos catalogados pela norma brasileira são: fendas (F); afundamentos (A); corrugações e ondulações transversais $(\mathrm{O})$; panela ou buraco $(\mathrm{P})$; remendos $(\mathrm{R})$, definidos por Bernucci et al., (2008), conforme descrição apresentada a seguir:

\section{Fendas}

As fendas são aberturas na superfície asfáltica, sendo classificadas como fissuras, quando a abertura é perceptível a olho nu à uma distância inferior a 1,5m, ou como trincas quando a abertura é superior à da fissura.

Os revestimentos betuminosos tendem a trincar sob a ação combinada do tráfego e das condições ambientais. A trinca é um defeito de superfície que permite a entrada de água na estrutura do pavimento, que uma vez iniciado tende a aumentar a extensão e severidade, podendo conduzir à desintegração do revestimento e comprometimento estrutural do pavimento. A velocidade de deterioração do pavimento aumenta após o aparecimento das trincas, sendo por esse motivo, um critério importante para a deflagração de intervenções para a recuperação do pavimento (DNER,1998).

As fissuras estão geralmente atreladas aos excessos de finos no material do revestimento, compactação excessiva e má dosagem do ligante asfáltico (QUEIROZ, 1984).

Quanto à tipologia, as trincas apresentam-se de forma isolada ou interligada. As trincas isoladas podem ser:

- Transversais curtas ou longas;

- Longitudinais curtas ou longas; 
- De retração, que não podem ser atribuídas aos fenômenos de fadiga, mas sim, de retração térmica ou de camadas subjacentes trincadas.

A Figura 2.5 apresenta a seguir exemplos de trincamento isolado.

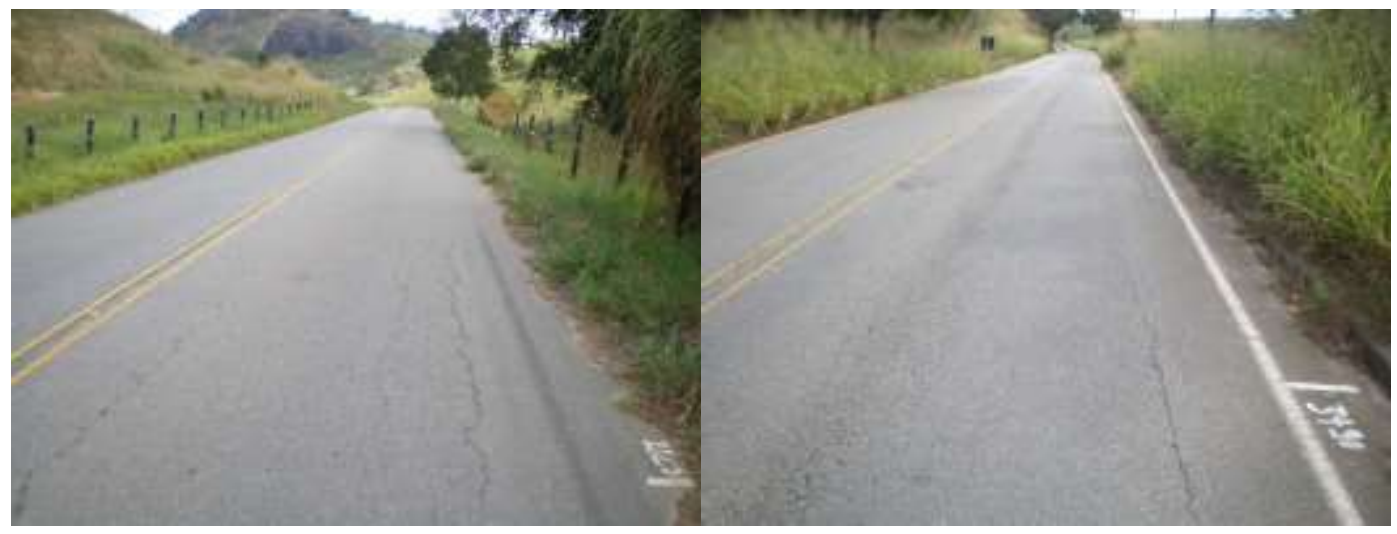

Figura 2.5 - Trincamento Isolado - Longitudinal Longo

Já as trincas interligadas podem ser do tipo:

- Trincas de bloco (tendem a uma regularidade geométrica), podendo apresentar ou não, erosão acentuada nas bordas, conforme apresentado na Figura 2.6 a seguir.

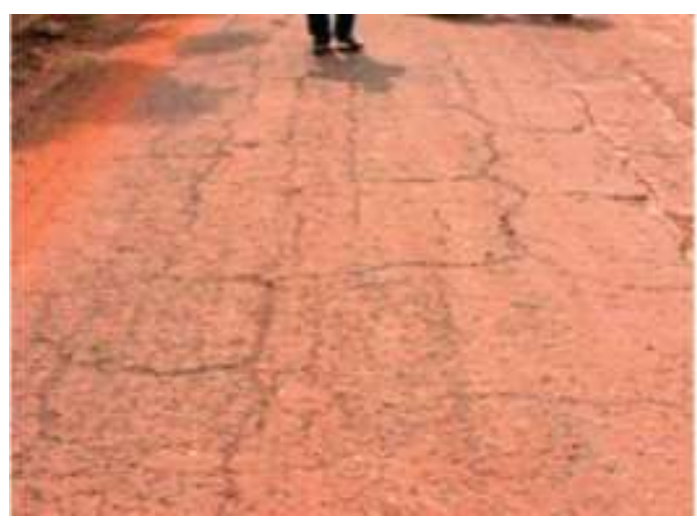

Figura 2.6 - Aspecto do Trincamento em Bloco (BERNUCCI et al., 2006)

- Trincas tipo couro de jacaré (não seguem um padrão de reflexão geométrico), podendo apresentar ou não, erosão acentuada nas bordas. Na Figura 2.7 é apresentada a imagem de uma rodovia com esse tipo de trincamento. 


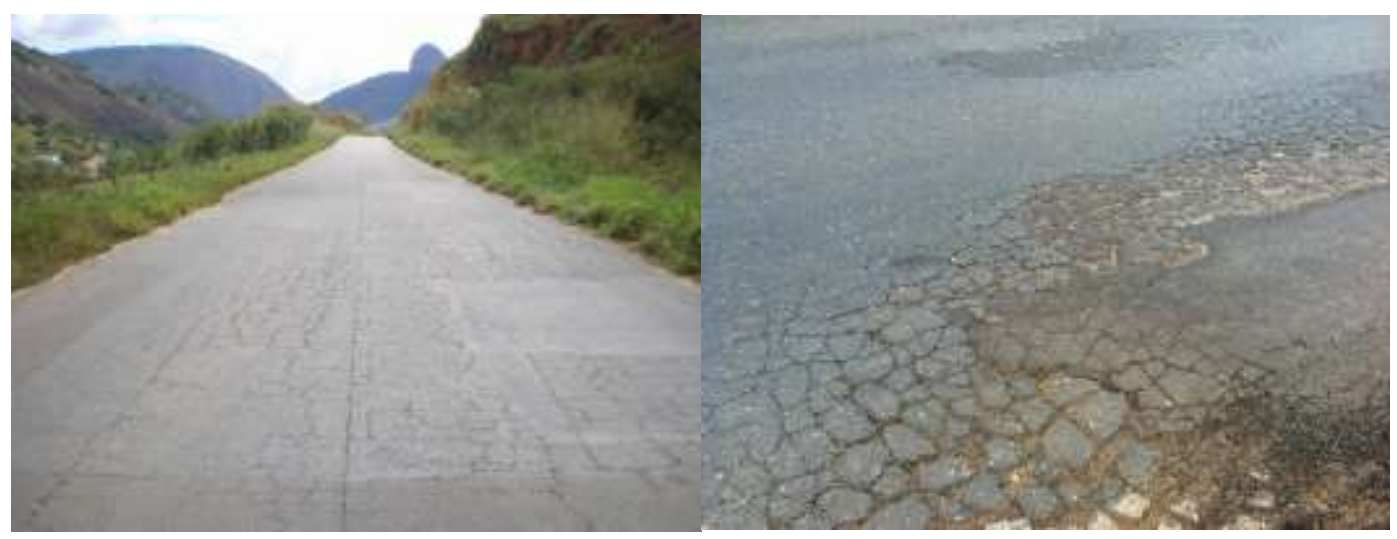

Figura 2.7 - Rodovia com Trincamento tipo Couro de Jacaré

Os trincamentos, conforme tabela do DNER supracitada podem estar relacionados ao tráfego ou fadiga, ao clima, à reflexão, além do envelhecimento do revestimento asfáltico. Os trincamentos devido à fadiga do revestimento resultam do carregamento excessivo. Este tipo de trincamento é caracterizado na sua fase final pelas trincas do tipo couro de jacaré.

Muitas trincas têm origem no mecanismo de reflexão das trincas das camadas inferiores de base ou sub-base, que propagam-se em direção ao revestimento asfáltico. A reflexão ocorre devido à concentração de tensões no entorno da região ocupada pela trinca existente. Elas podem surgir na forma de trincas longitudinais, transversais ou interligadas.

O trincamento por envelhecimento surge devido à oxidação do ligante asfáltico, que com o efeito do clima e do tempo, torna-se susceptível à ruptura com a perda de sua fração mais leve (maltenos), não suportando as deformações provenientes das variações diárias de temperatura e do tráfego. O processo de envelhecimento, com elevação do módulo de resiliência do revestimento, depende do tipo e qualidade do ligantes e das condições climáticas da região. Teores mais elevados de asfalto e menor volume de vazios da mistura tendem a promover maior dificuldade à oxidação da mistura e, consequentemente, ao envelhecimento. O trincamento em blocos, muitas vezes está atrelado ao processo de envelhecimento e retração térmica, podendo ser causado também pela retração das camadas cimentadas da base ou sub-base. 
O trincamento causado pela retração térmica ocorre devido a uma alta redução na temperatura, resultando na alta rigidez do ligante betuminoso. As trincas transversais são causadas pela retração térmica do revestimento asfáltico e pela presença de água nas camadas inferiores, além da retração causada pela presença de camadas cimentadas. As trincas longitudinais também estão atreladas à retração causada pelas camadas cimentadas, sendo que as trincas próximas ao bordo da faixa de rolamento estão geralmente associadas à umidade no acostamento, recalque da fundação ou rupturas dos aterros. Além disso, o alargamento da pista também pode gerar o fenômeno do trincamento longitudinal.

As trincas são classificadas em três distintos graus de severidade, de acordo com as características do trincamento. O trincamento classe FC-1, ou classe 1, é caracterizado pela presença de poucas trincas conectadas, sem erosão nos bordos e sem evidência de bombeamento. Os de classe FC-2, ou classe 2, apresentam trincamento conectados, enquanto que os FC-3, ou classe 3, apresentam erosão nas bordas.

De maneira resumida, é apresentada na Tabela 2.1 a seguir a simbologia e a descrição de cada tipo de defeito.

Tabela 2.1 - Resumo das Causas e tipo de Deformações Permanentes (DNER, 1998)

\begin{tabular}{|c|c|c|c|c|c|}
\hline Símbolo & & Tipo & \multicolumn{3}{|c|}{ Classe das Fendas } \\
\hline FI & Fissura & & - & - & - \\
\hline TTC & \multirow{4}{*}{ Trincas Isoladas } & Trincas Transversais Curtas & FC-1 & FC-2 & FC-3 \\
\hline TTL & & Trincas Transversais Longas & FC-1 & FC-2 & FC-3 \\
\hline TLC & & Trincas Longitudinais Curtas & FC-1 & FC-2 & FC-3 \\
\hline TLL & & Trincas Longitudinais Longas & FC-1 & FC-2 & FC-3 \\
\hline $\mathrm{J}$ & \multirow{2}{*}{ Trincas Interligadas } & Jacaré & - & FC-2 & - \\
\hline JE & & Jacaré com Erosão & - & - & FC-3 \\
\hline TRR & Trincas Isoladas & Trincas de Retração do Revestimento & FC-1 & FC-2 & FC-3 \\
\hline TB & \multirow{2}{*}{ Trincas Interligadas } & Trincas em Blocos & - & FC-2 & - \\
\hline TBE & & Trincas em Blocos com Erosão & - & - & FC-3 \\
\hline
\end{tabular}




\section{Afundamentos}

Os afundamentos são deformações permanentes caracterizadas pela depressão da superfície do pavimento, acompanhada ou não de solevamento, podendo-se apresentar sob a forma de afundamento plástico ou por consolidação.

O afundamento plástico (AP) ocorre devido à fluência de um ou mais materiais constituintes das camadas que compõem a superfície de terraplenagem. Se o afundamento plástico apresentar-se com extensão de até seis metros, recebe a denominação de afundamento plástico local (ALP). Caso se apresente com extensão superior a seis metros e pertença a um plano no qual também está inserida a trilha de roda, é denominado afundamento plástico na trilha de roda (ATP).

O afundamento de consolidação ocorre devido à consolidação diferenciada em uma ou mais camadas que compõem a superfície de terraplenagem. Se apresentar extensão de até seis metros é denominado afundamento de consolidação local (ALC), caso apresente extensão superior a seis metros e pertença a um plano no qual também está inserida trilha de roda, recebe o nome de afundamento de consolidação na trilha de roda (ATC). A Figura 2.8 apresenta exemplos de afundamento plástico e por consolidação.

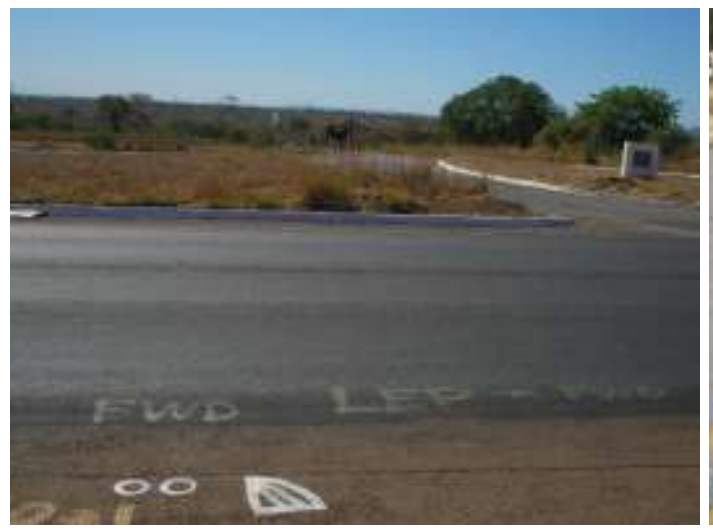

(a)

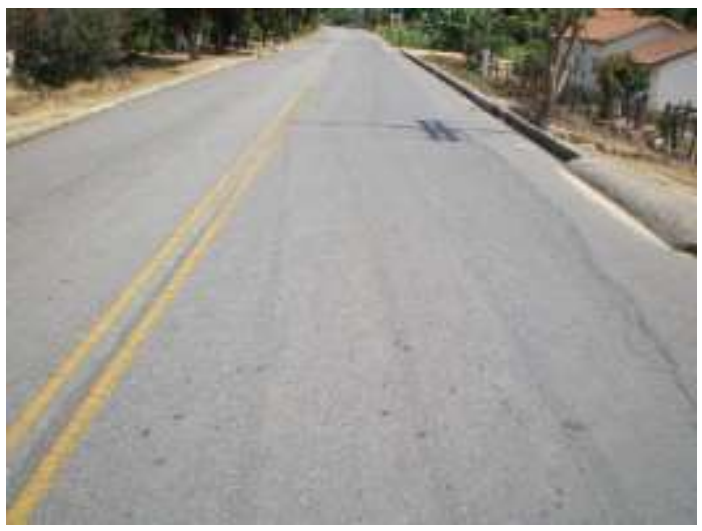

(b)

Figura 2.8 - Afundamento Plástico (a) e Afundamento por Consolidação (b)

Os afundamentos causam acréscimo na irregularidade longitudinal do pavimento, afetando a qualidade estrutural, o custo operacional dos veículos e, devido ao acúmulo 
de água, a segurança dos usuários. As deformações permanentes podem estar associadas ao carregamento ou tráfego, bem como, a outros fatores, conforme a Tabela 2.2, que apresenta o resumo das causas e tipos de deformações permanentes, segundo o Manual de Reabilitação dos Pavimentos Asfálticos (DNER, 1998).

Tabela 2.2 - Resumo das Causas e tipo de Deformações Permanentes (DNER, 1998)

\begin{tabular}{c|l|l}
\multicolumn{3}{c}{ Resumo das causas e tipos de deformação permanente } \\
\hline Causa geral & \multicolumn{1}{|c}{ Causa específica } & \multicolumn{1}{c}{ Exemplo de defeito } \\
\hline \multirow{4}{*}{$\begin{array}{c}\text { Associada com o } \\
\text { carregamento }\end{array}$} & $\begin{array}{l}\text { Carregamento concentrado } \\
\text { ou em excesso }\end{array}$ & $\begin{array}{l}\text { Fluência plástica (ruptura por } \\
\text { cisalhamento) }\end{array}$ \\
\cline { 2 - 3 } & $\begin{array}{l}\text { Carregamento de longa } \\
\text { duração ou estático }\end{array}$ & $\begin{array}{l}\text { Deformações ao longo do } \\
\text { tempo (creep) }\end{array}$ \\
\cline { 2 - 3 } & $\begin{array}{l}\text { Grande número de repetições } \\
\text { de carga }\end{array}$ & $\begin{array}{l}\text { Afundamento nas trilhas de } \\
\text { roda }\end{array}$ \\
\hline \multirow{2}{*}{$\begin{array}{c}\text { Não associada com o } \\
\text { carregamento }\end{array}$} & $\begin{array}{l}\text { Subleito constituido de solo } \\
\text { expansivo }\end{array}$ & Inchamento ou empolamento \\
\cline { 2 - 3 } & $\begin{array}{l}\text { Solos compressíveis na } \\
\text { fundação do pavimento }\end{array}$ & Recalque diferencial \\
\hline
\end{tabular}

Os carregamentos de tráfego causam deformações permanentes em três situações:

- Quando os esforços induzidos nos materiais do pavimento causam cisalhamento, promovendo deslizamentos no interior do material. Neste caso, o carregamento concentrado ou em excesso causam a fluência plástica, pois os esforços são superiores à resistência ao cisalhamento dos materiais;

- Carregamentos de longa duração ou estáticos podem causar afundamentos nos materiais viscosos;

- Grandes números de repetições de carga causam deformações nas trilhas de rodas que se acumulam ao longo do tempo.

A fluência plástica e a densificação são dois mecanismos associados à deformação que são causados pela influência do tráfego. A fluência plástica nos pavimentos pode ser controlada na fase de projeto pela seleção de materiais, de acordo com sua resistência ao cisalhamento, sendo que para solos pode ser utilizado o CBR e para misturas betuminosas, a estabilidade Marshall. 
A densificação é caracterizada pela diminuição do volume dos materiais constituintes do pavimento. Na fase de construção, a densificação pode ser controlada pela correta compactação das camadas do pavimento, pois quanto maior a sua compactação, maior sua resistência ao cisalhamento e menor a susceptibilidade à entrada de água.

\section{Ondulações e Corrugações}

Segundo Bernucci et al. (2008), as corrugações são deformações transversais ao eixo da pista, com depressões intercaladas de elevações, com comprimento de onda entre duas cristas de alguns centímetros. As ondulações também são deformações transversais ao eixo, em geral decorrentes da consolidação diferencial do subleito, com comprimento de onda da ordem de metros.

Ambos os defeitos apresentam a abreviação de "O", embora sejam decorrentes de fenômenos diferentes.

\section{Escorregamentos}

O escorregamento (E) pode ser definido como o deslocamento do revestimento em relação à camada subjacente do pavimento, com o aparecimento de fendas em forma de meia-lua. Podem se associar a afundamentos plásticos em trilhas de rodas.

Os escorregamentos podem ser gerados devido: à imprimação (excessiva ou insuficiente) do revestimento sobre a camada inferior, gerando deslocamentos transversais da mistura asfáltica, em especial nos trechos em curva; viscosidade inadequada do ligante; excesso de ligante na mistura por equívoco de dosagem ou ainda por falha na produção; emprego de misturas asfálticas ricas em betume e em agregados miúdos (BALBO,1997). A seguir é apresentada a Figura 2.9 que ilustra o referido defeito. 


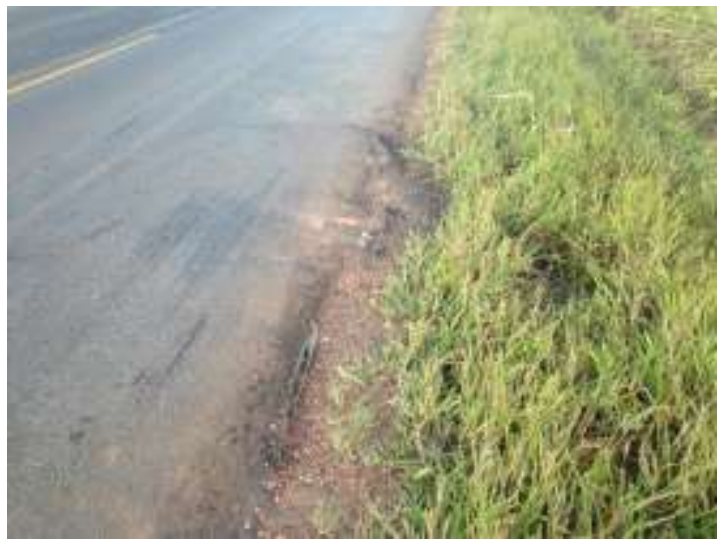

Figura 2.9 - Escorregamento do Revestimento Asfáltico

\section{Exsudação}

A exsudação (Ex) ocorre quando há migração do ligante através do revestimento. A migração do ligante para a superfície do pavimento leva ao aparecimento de manchas escuras na superfície do revestimento, conforme apresentado na Figura 2.10.

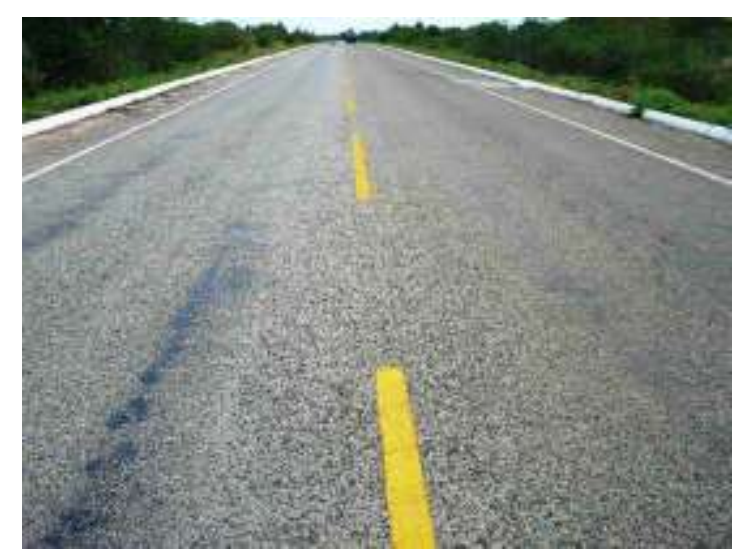

Figura 2.10 - Segmento com Exsudação

As causas prováveis da exsudação são o excesso de ligante betuminoso, o baixo índice de vazios da mistura asfáltica e a compactação pelo tráfego (dosagem inadequada da mistura asfáltica). 


\section{Desgaste}

O desgaste (D) pode ser definido como efeito do arrancamento progressivo do pavimento, caracterizado pela aspereza superficial do revestimento e provocado por esforços tangenciais causados pelo tráfego.

Entre as outras causas para o desgaste, destaca-se: a perda do envolvimento betuminoso e arrancamento progressivo do agregado; perda de adesividade liganteagregado por ação de abrasão, água ou produtos químicos; compactação inadequada; envelhecimento da mistura e endurecimento do ligante; abertura ao tráfego antes que o ligante tivesse aderido ao agregado. A Figura 2.11 ilustra o referido defeito.

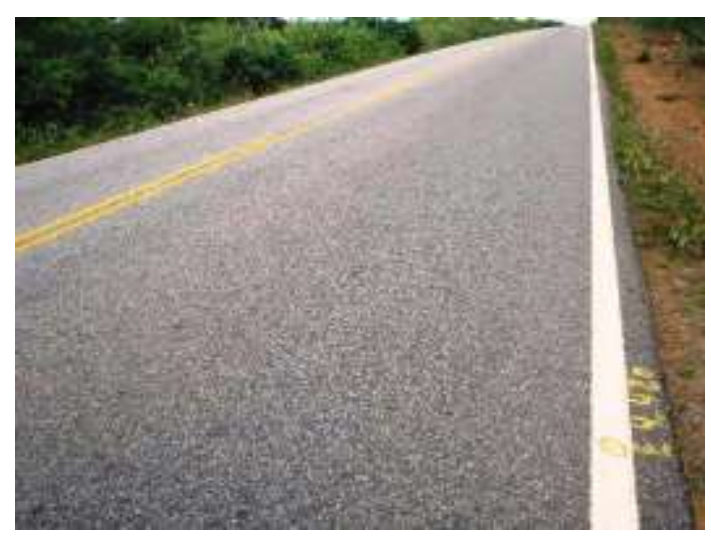

Figura 2.11 - Exemplo de Desgaste

\section{Buraco ou Panela}

O buraco ou panela $(\mathrm{P})$ é definido como uma cavidade que se forma no revestimento por diversos motivos (inclusive pela falta de aderência entre as camadas superpostas, causando o desplacamento de camadas), podendo alcançar as camadas inferiores do pavimento, provocando a desagregação dessas camadas.

É um defeito muito grave, pois afeta estruturalmente o pavimento, permitindo o acesso das águas superficiais ao interior da estrutura. Também é grave do ponto de vista funcional, já que afeta a irregularidade longitudinal (PINTO e PREUSSLER, 2010). 
As panelas podem ser geradas devido aos trincamentos em estágio terminal, desintegração localizada da superfície do pavimento (desgaste de severidade alta) e evolução de defeitos. A seguir é apresentada a Figura 2.12 que ilustra o referido defeito.

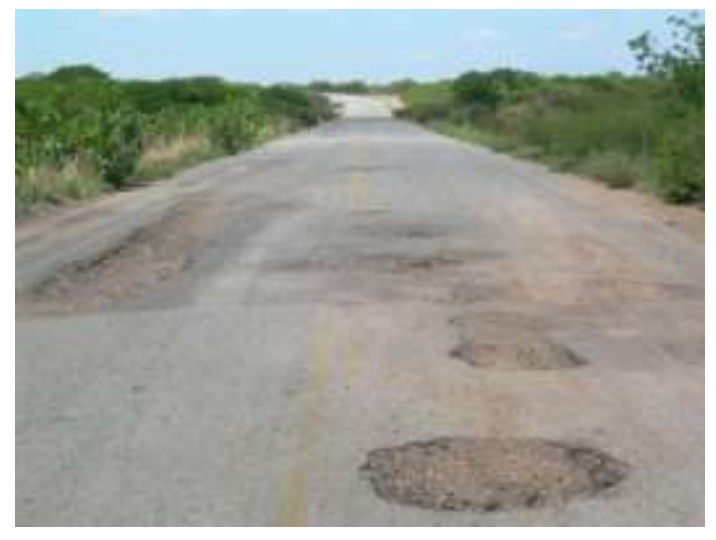

Figura 2.12 - Exemplo de Panela

\section{Remendos}

O remendo $(\mathrm{R})$ é um tipo de defeito que, apesar de estar relacionado a uma conservação da superfície, caracteriza-se pelo preenchimento de panelas, ou qualquer outro tipo de depressão com massa asfáltica.

Os remendos podem ser superficiais, quando o preenchimento das panelas é somente com a utilização de mistura betuminosa. No caso de remendos, em que há a necessidade de preenchimento até a camada de base, com a utilização de material granular da base, o remendo é denominado como profundo. A Figura 2.13 apresentada a seguir ilustra o referido defeito. 


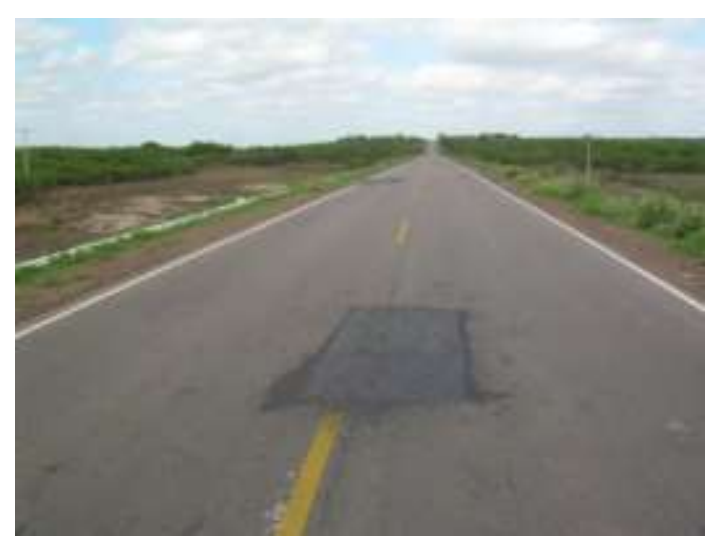

Figura 2.13 - Exemplo de Remendo

\subsection{Métodos de Avaliação da Superfície do Pavimento}

Existem vários métodos que se propõem a estabelecer um índice de qualidade para um segmento de pavimento, a partir da análise e estatísticas relacionadas aos diversos defeitos encontrados sobre a superfície do pavimento.

Os defeitos, levantados através do critério objetivo, podem gerar parâmetros considerados como qualitativos ou quantitativos, ou ainda ambos. Há ainda métodos que qualificam o pavimento sob o ponto de vista operacional, em especial, quanto ao conforto de rolamento como é o caso do Valor de Serventia Atual, ou VSA.

Os levantamentos podem ser realizados de forma manual ou mecanizada. Nos levantamentos manuais os segmentos são selecionados por amostragem, em intervalos predeterminados, utilizando-se procedimentos estatísticos. Haas et al. (1994) citam que o tamanho da amostra varia de 10 a $25 \%$ da extensão da rede, sendo função dos recursos disponíveis e dos tipos de defeitos.

Nesse tipo de coleta de dados, os levantamentos podem ser realizados a pé ou no interior de um veículo trafegando a velocidades que variam de 6,4 a $16 \mathrm{~km} / \mathrm{h}$ (HAAS et al., 1994) e de 3 a $10 \mathrm{~km} / \mathrm{h}$ (DNER, 1998). Na execução, os avaliadores descem do carro e efetuam as medidas de abertura de trincas e afundamentos em trilhas de roda. São examinadas as faixas de tráfego e os acostamentos. As características e dados são 
registrados em planilhas padronizadas empregando códigos alfanuméricos ou em planilhas eletrônicas utilizando teclados e computadores portáteis (laptops ou palm). O procedimento padrão usado no Brasil pelas concessionárias e órgãos federais é o Índice de Gravidade Global (IGG), preconizado pelo DNIT, no PRO-006/2003.

Nos levantamentos automatizados, os veículos são aparelhados com equipamentos especiais que podem ser instalados na região frontal ou traseira, apresentando velocidades que variam entre $30 \mathrm{~km} / \mathrm{h}$ e $110 \mathrm{~km} / \mathrm{h}$. O estado do pavimento é registrado por meio de câmeras e sensores a laser. Este levantamento permite que por meio de sensores computadorizados, sejam separados e codificados os defeitos quanto aos tipos, severidade e integridade, além da integração destas imagens com dados de construção dos pavimentos, tais como espessura e materiais das camadas, largura, número de faixas, sinalização e volume de tráfego.

\subsubsection{Procedimento - DNIT-PRO 006/2003}

Os defeitos exteriorizados pela superfície de um pavimento flexível ou semi-rígido, em razão de sua natureza ou intensidade, refletem um quadro sintomático do seu comportamento frente às cargas de tráfego e aos agentes intempéricos. As medidas de conservação requeridas estão vinculadas ao grau de deterioração do pavimento (PEREIRA, 1972).

O DNIT PRO 006/2003 fixa as condições exigíveis na avaliação objetiva da superfície de pavimentos flexíveis e semi-rígidos e tem como meta estabelecer uma forma de calcular o Índice de Gravidade Global (IGG), utilizando uma combinação de defeitos. O IGG é uma adaptação do chamado "Severity Index", proveniente de estudos experimentais americanos e canadenses, para as condições brasileiras.

A concepção do inventário do IGG no Brasil foi baseada em um estudo publicado pelo engenheiro Armando Pereira em 1972, sob o título de "Um Método de Avaliação de Pavimentos Flexíveis e Semi-Rígidos". Neste estudo é apresentado o Índice de Severidade Global, SG, que reflete o grau de deterioração do pavimento no momento 
do inventário. O referido procedimento para definição do SG foi baseado nos relatórios da AASHO Road Test.

O procedimento de inventário do IGG avalia a superfície do pavimento mediante a contagem e classificação de ocorrências de defeitos e a medida de deformações permanente nas trilhas de roda.

Os defeitos avaliados são as trincas, ondulações, remendos, desgastes, panela, afundamentos plásticos e exsudações. O parâmetro de avaliação é denominado, conforme citado anteriormente, Índice de Gravidade Global, que retrata o grau de deterioração atingido pela superfície do pavimento. A Tabela 2.3 apresentada a seguir descreve a escala de conceito do IGG.

Tabela 2.3 - Descrição da Escala de Conceito do IGG (DNIT, 2003)

\begin{tabular}{c|c}
\hline Conceito & Limites de IGG \\
\hline Ótimo & $0-20$ \\
\hline Bom & $20-40$ \\
\hline Regular & $40-80$ \\
\hline Ruim & $80-160$ \\
\hline Péssimo & 160 \\
\hline
\end{tabular}

A montagem do índice é feita a partir dos registros de defeitos inventariados sobre a superfície do pavimento e dos afundamentos em trilha de roda. O inventário de defeitos é realizado de maneira amostral, em estações de ensaios afastadas de $20 \mathrm{~m}$, alternando as faixas de tráfego direita e esquerda no caso de rodovia de pista simples. A amostragem é realizada em cada uma das estações ensaiadas, considerando-se a delimitação em comprimento de 3 metros em ré e 3 metros em avante em relação à estação e à largura da faixa inventariada, ou seja, uma área de aproximadamente $21 \mathrm{~m}^{2}$ (6 m por 3,5 m). Desta forma, aproximadamente $15 \%$ da área total do pavimento é analisada. Nas rodovias de pista dupla, analisa-se as faixas externas de tráfego mais críticas, dispondo de uma estação de ensaio a cada $20 \mathrm{~m}$. 
Embora não explicitado em norma, essas distâncias podem ser alteradas em função de uma pré-análise que demonstre uma constância em termos de patologia (BALBO, 1997).

O levantamento dos defeitos é realizado em cada estação ou estaca de ensaio, em que um operador anota em ficha de campo a presença ou não de cada um dos tipos de defeito, de acordo com a codificação normatizada. A anotação é realizada utilizandose o símbolo do "X", onde não é contado o número de defeitos em cada estação, mas apenas identificando-se a sua presença. $\mathrm{Na}$ Tabela 2.4 é apresentada a ficha padrão para inventário da superfície do pavimento, de acordo com a PRO-006/2003.

Tabela 2.4 - Ficha Padrão para Inventário da Superfície do Pavimento (DNIT, 2006)

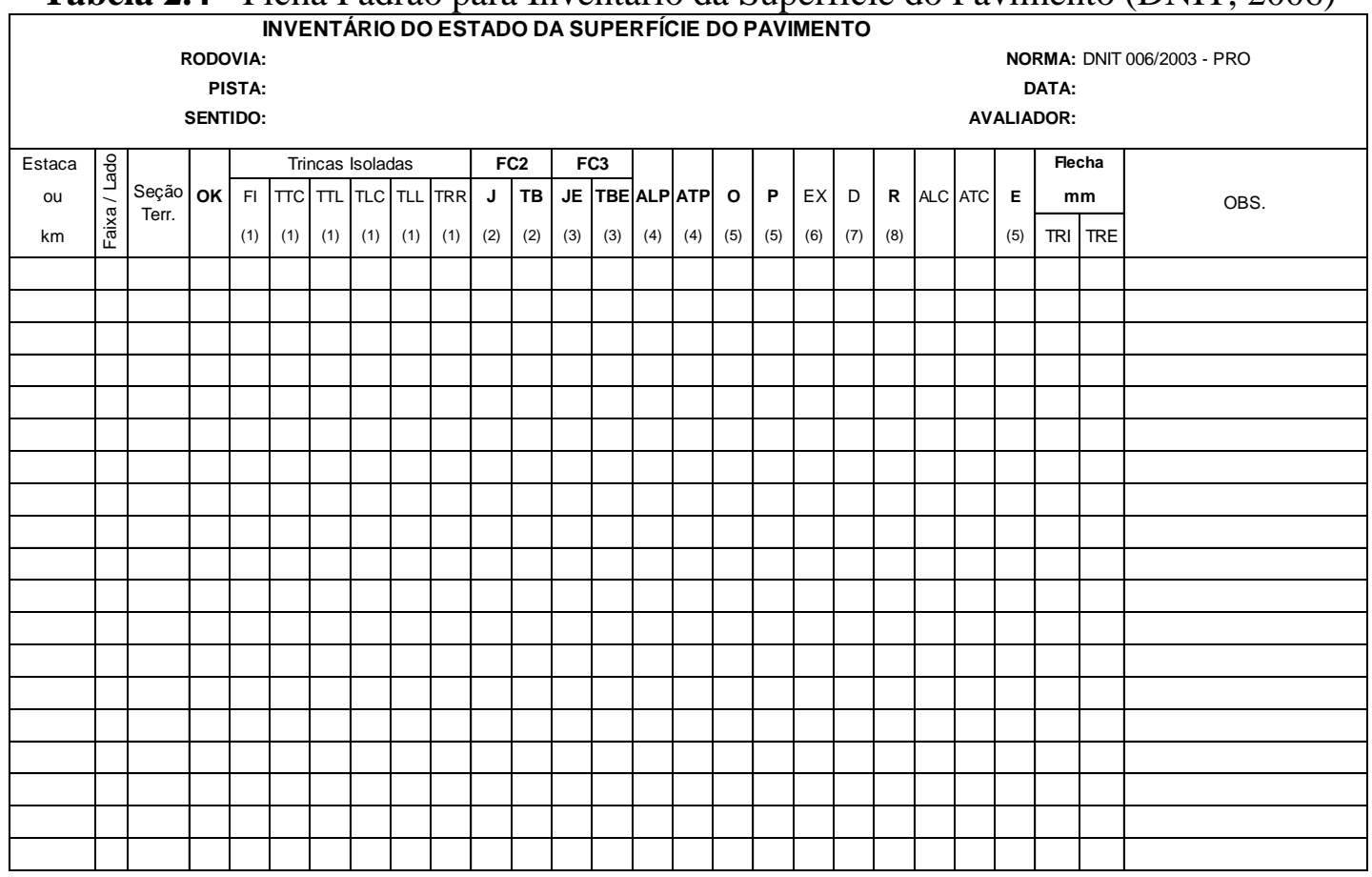

Conforme apresentado na tabela acima, é necessário medir os afundamentos nas trilhas de rodas internas e externas, que é realizado com o emprego de uma treliça de alumínio de base de 1,2 m, que possui uma régua corrediça localizada em sua posição central. Na Figura 2.14 é apresentada a treliça para o levantamento das trilhas de roda internas e externas. 

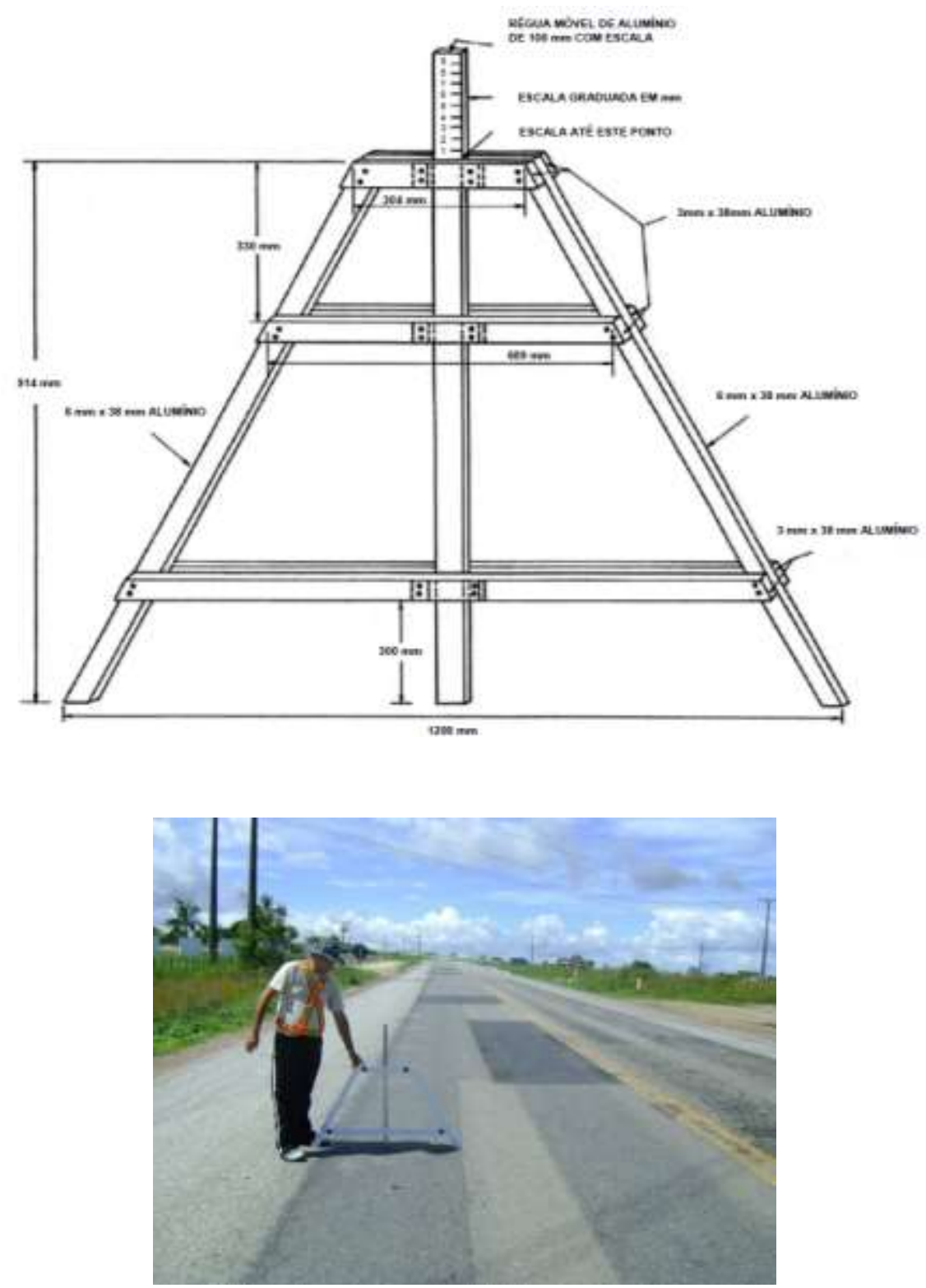

Figura 2.14 - Treliça Metálica para Medição da Trilha de Roda (DNIT, 2006)

Os dados levantados em campo são analisados em escritório, onde os defeitos são agrupados em 10 grupos para fins de ponderação do IGG. Para um certo segmento homogêneo, determina-se a frequência absoluta e relativa de ocorrência dos defeitos anotados, bem como a média e a variância das flechas nas trilhas de roda, conforme apresentado nas expressões (2.1) e (2.2), respectivamente. 


$$
\begin{gathered}
\bar{x}=\frac{\sum x_{i}}{n} \\
s=\sqrt{\frac{\sum\left(x_{i}-\bar{x}\right)^{2}}{n-1}}
\end{gathered}
$$

Em que,

$x_{i}$ - Valores individuais das trilhas de rodas $(\mathrm{mm})$;

$\bar{x}$ - Média aritmética das flechas medidas (TRI e TRE) (mm);

$s$ - Desvio padrão dos valores de flecha medida nas trilhas de rodas (mm);

$s^{2}-$ Variância (mm).

Para cada tipo de defeito é atribuído um fator de ponderação (fp) que expressa maior ou menor importância relativa em termos de serventia. Nos casos de estações em que são contabilizados defeitos do tipo FC-1, FC-2 e FC-3, considera-se somente o defeito mais grave entre os inventariados. A Tabela 2.5 retrata a planilha de ponderação para cálculo do IGG, de acordo com cada grupo.

Tabela 2.5 -Tabela de Ponderação para Cálculo do IGG (adaptada de DNIT, 2006)

\begin{tabular}{c|l|c}
\hline Ocorrência Tipo & \multicolumn{1}{|c}{ Defeitos } & \begin{tabular}{c}
$\mid c$ \\
\multicolumn{1}{|c}{ Fator de } \\
Ponderação (fp)
\end{tabular} \\
\hline 1 & Fissuras e Trincas Isoladas (FI, TTC, TTL, TLC, TLL e TRR) & 0,2 \\
\hline 2 & FC-2 (Jacaré e Trincas em Bloco) & 0,5 \\
\hline 3 & FC-3 (Jacaré com Erosão e Trincas em Bloco com Erosão) & 0,8 \\
\hline 4 & ALP e ATP, ALC e ATC & 0,9 \\
\hline 5 & O, P e E & 1,0 \\
\hline 6 & Ex & 0,5 \\
\hline 7 & D & 0,3 \\
\hline 8 & R & 0,6 \\
\hline 9 & Médias das Flechas & $4 / 3$ \\
\hline 10 & Média das Variâncias das Flechas & 1,0 \\
\hline
\end{tabular}

Para o cálculo do IGG são consideradas as $\mathrm{N}$ estações de inventário contidas no segmento homogêneo em estudo, calculando-se a frequência relativa $\left(f_{r}\right)$ de cada tipo 
de defeito observado, tomando-se o número de observações do mesmo nas estações de ensaio, com as frequências absolutas ( $\left.f_{a}\right)$, através da expressão (2.3):

$$
f_{r}=\left(\frac{f_{a}}{N}\right) \cdot 100
$$

O produto da frequência relativa de cada defeito, bem como, da média e da variância das flechas pelo seu respectivo fator de ponderação resulta no Índice de Gravidade Individual (IGI) imposto ao pavimento por cada tipo de defeito, através da expressão (2.4):

$$
I G I=f_{r} . f p
$$

O IGG é obtido pelo somatório de todos os valores de IGI impostos pelos tipos defeitos, conforme apresentado na expressão (2.5):

$$
I G G=\sum I G I
$$

A norma ainda limita um segmento homogêneo à extensão de 1000 m, porém essa consideração não é utilizada de maneira geral.

Na Figura 2.15 é apresentado um fluxograma que esquematiza todo o processo de inventário e cálculo para a obtenção do IGG, bem como, o diagnóstico de seus resultados. 


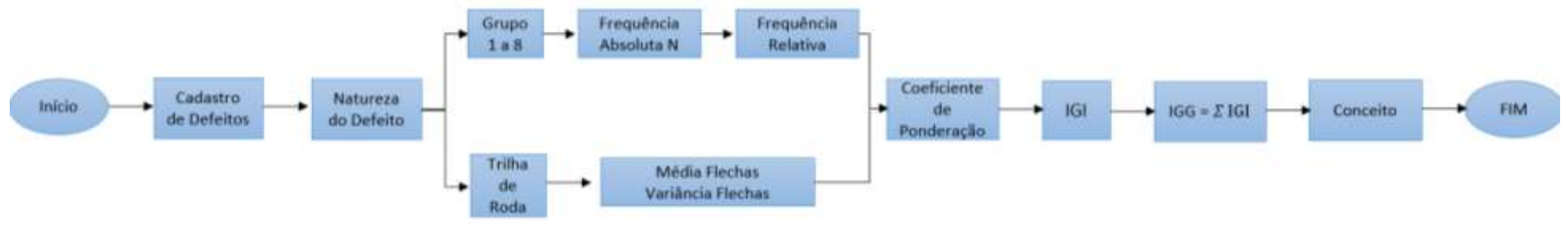

Pavimento Asfáltico (DNIT 006/2003 - TER):
1. Fissuras e Trincas Isoladas (FI, TTC, TTL, TLC, TLL e TRR)
2. FC-2 (Jacaré e Trincas em Bloco)
3. FC-3 (Jacaré com Erosalo e Trincas em Bloco com Erosalo)
4. ALP, ATP e ALC, ATC (Plastico ou por Consolidaçăo)
5. Ondulaçalo, Panela e Escorregamento
6. Exsudaçlo
7. Desgaste
8. Remendo

\begin{tabular}{|c|c|}
\hline Conceito & Limites de IGG \\
\hline Otimo & $0-20$ \\
\hline Bom & $20-40$ \\
\hline Regular & $40-80$ \\
\hline Ruim & $80-160$ \\
\hline Phaimo & 160 \\
\hline
\end{tabular}

Figura 2.15 - Fluxograma do Processo de Inventário e Cálculo para Obtenção do IGG 


\subsubsection{Irregularidade Longitudinal}

A irregularidade longitudinal de um pavimento é conceituada como o conjunto dos desvios da superfície viária em relação a um plano de referência, afetando a qualidade do rolamento e a dinâmica dos veículos, sendo um parâmetro muito utilizado para a avaliação funcional de um pavimento (PATERSON, 1987).

A irregularidade decorre tanto de problemas construtivos, quanto de pós-construção, como resultado do tráfego, clima e de deformação permanente nos subleitos e revestimento. Segundo Ksaibati et al. (1998), a irregularidade longitudinal é causada pelos seguintes fatores:

- Técnicas de construção que permitem algumas variações do perfil do projeto;

- Cargas repetidas, em áreas específicas;

- Não uniformidade da compactação das camadas inferiores, inclusive do subleito.

Haas et al. (1994) citam que a dinâmica dos veículos é afetada pelas distorções na superfície, e que estas causam desgaste, acréscimo no tempo de viagem e na manutenção. Portanto, a irregularidade tem grande influência no custo de operação de um veículo.

Dada a importância da irregularidade na percepção de conforto dos usuários, muitos países adotam índices de serventia baseados exclusivamente em parâmetros de irregularidade. Segundo Hudson e Haas (1978), a irregularidade longitudinal não é uma função só do perfil do pavimento, como também das características dos veículos, incluindo pneus, suspensão e também da sensibilidade dos usuários quanto às variações de velocidade e acelerações.

Estudos mostram que $95 \%$ das informações relativas à serventia de pavimentos nos testes originais da AASHO estão ligadas exclusivamente à irregularidade do perfil (HAAS et al., 1994). A importância da irregularidade tem sido também reconhecida 
como forma de controle de construção em pavimentos novos. Devido à difusão dos sistemas de gerência de pavimentos ocorrida na última década, tem sido crescente a conscientização nos órgãos públicos da real necessidade de medir as irregularidades longitudinais, mesmo com as diferentes formas de medir e distintos critérios de aceitação observados em diversos países (FARIAS e SOUZA, 2002).

As deformações plásticas de um pavimento, normalmente nas trilhas de rodas são verificadas no perfil transversal de um pavimento. Já o perfil longitudinal, pode ser entendido como uma linha imaginária paralela ao eixo da pista, que contém o greide da rodovia, as irregularidades longitudinais e a textura do pavimento. A condição do pavimento está diretamente relacionada com os dados obtidos na medida deste perfil. Só existe um perfil verdadeiro em cada linha imaginária que se escolha. $\mathrm{O}$ mesmo perfil longitudinal somente será obtido se a mesma linha imaginária for rigorosamente seguida, o que é de difícil obtenção na prática. Por isso, pode-se afirmar a quase impossibilidade de ser medido o perfil verdadeiro, pois ele depende da precisão dos equipamentos disponíveis para medi-lo, tanto no deslocamento horizontal, quanto na medida vertical (SAYERS E KARAMIHAS, 1998).

Variações no perfil longitudinal, relacionadas com o greide se apresentam como ondulações com grande amplitude e comprimento de onda, que segundo Oliveira (2002), a irregularidade pode ser dividida em categorias, de acordo com a amplitude (A) e o comprimento de onda $(\boldsymbol{\lambda})$, conforme Tabela 2.6.

Tabela 2.6 - Relação entre o Tipo de Onda, Comprimento e Amplitude (OLIVEIRA, 2002)

\begin{tabular}{c|c|c} 
Tipo de Onda & Amplitude & $\begin{array}{c}\text { Comprimento } \\
\text { de Onda }\end{array}$ \\
\hline Curta & $1 \mathrm{~mm} \leq \mathrm{A} \leq 20 \mathrm{~mm}$ & $0,5 \mathrm{~m} \leq \lambda<5 \mathrm{~m}$ \\
\hline Média & $5 \mathrm{~mm} \leq \mathrm{A} \leq 50 \mathrm{~mm}$ & $5 \mathrm{~m} \leq \lambda<15 \mathrm{~m}$ \\
\hline Longa & $10 \mathrm{~mm} \leq \mathrm{A} \leq 200 \mathrm{~mm}$ & $15 \mathrm{~m} \leq \lambda \leq 50 \mathrm{~m}$
\end{tabular}

As ondas com dimensões superiores aos intervalos anteriormente descritos não são consideradas como irregularidade, e as ondas com dimensões inferiores são consideradas 
somente na avaliação de microtextura e macrotextura. A Figura 2.16, adaptada de YODER e WITCZAK (1975), caracteriza as ondulações (distúrbios) longitudinais e transversais.
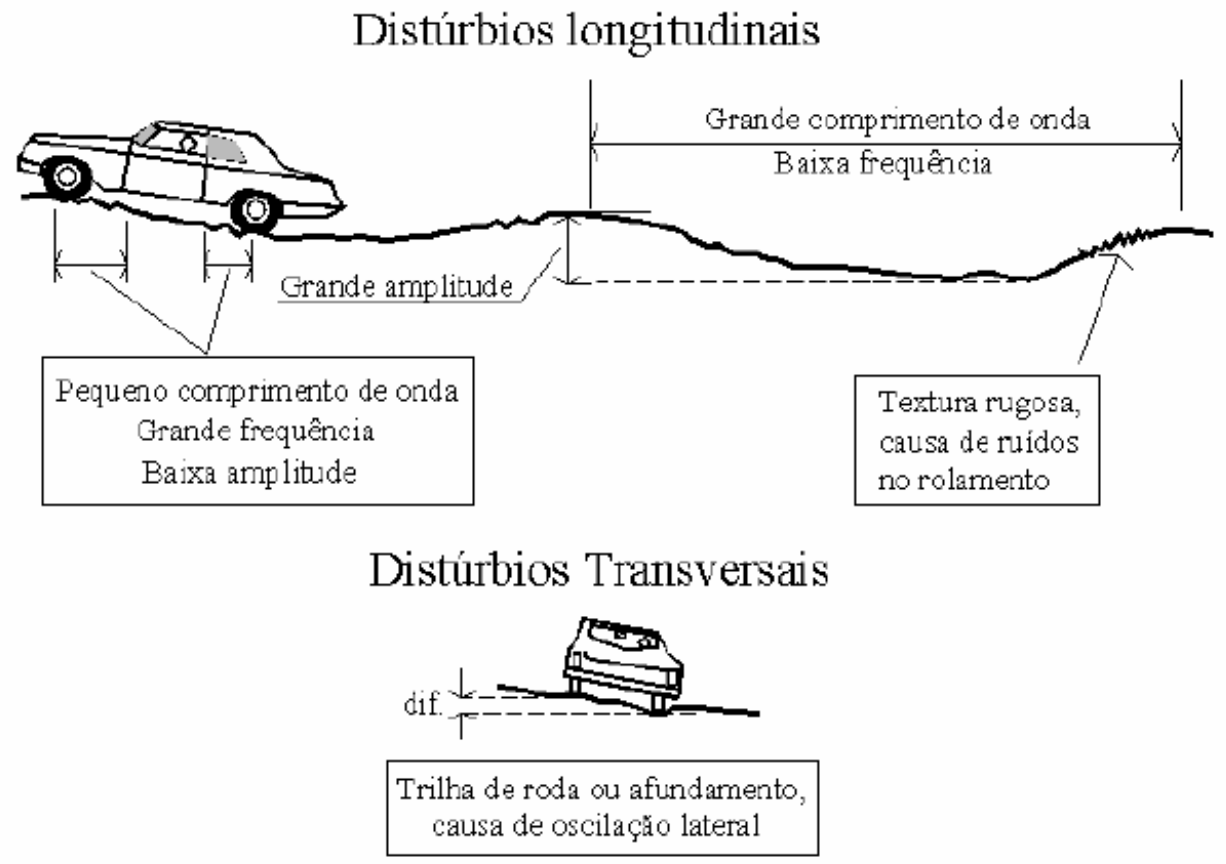

Figura 2.16 - Ondulação Longitudinal e Transversal (adaptada de YODER e WITCZAK, 1975)

Visando viabilizar a medida de parâmetros ligados à irregularidade longitudinal, diversos equipamentos ou processos foram concebidos, podendo genericamente ser enquadrados em quatro grupos fundamentais: os sistemas de medida direta do perfil, os sistemas de medida indireta do perfil, os sistemas do tipo-resposta e finalmente, os sistemas de medida de sonda sem contato.

Os sistemas de medidas direta do perfil são obtidos através das medidas diretas ou manuais da geometria vertical do pavimento com o emprego de instrumentos topográficos ou instrumentos adequados, em que a medida da irregularidade é processada estatisticamente em função dos dados. Alguns equipamentos utilizados são o nível e mira, Abay Beam do TRRL (Transport Road Research Laboratory). 
Nos sistemas de medidas indiretas do perfil, as medidas mecanizadas fornecem os coeficientes de irregularidade, amplitude e comprimento de onda. Alguns equipamentos utilizados são o Perfilômetro Dinâmico de Superfície - GMR, Perfilômetro CHLOE, Merlin do TRRL e Analisador do Perfil Longitudinal (APL) do LCPC (Laboratoire Central des Ponts et Chaussées).

Os sistemas tipo-resposta são baseados na reação do veículo. Nestes sistemas, as reações do veículo são medidas de maneira acumulativa pelos movimentos entre a carroceria e os eixos traseiro e dianteiro, ou seja, é a resposta à excitação dinâmica provocada pelo perfil. Alguns equipamentos utilizados são o rugosímetro BPR, Bump Integrator, Maysmeter e o Sistema IPR/USP.

Já os sistemas de medida de sonda sem contato são realizados através do contato óptico, ultra-sônico ou a laser, baseando-se na reflexão de uma onda sonora ou raio laser emitido por dispositivos situados no veículo. Estes aparelhos digitais coletam dados do perfil em pontos discretos, que servem de entrada para um programa de computador que calcula as elevações, distâncias e índices de irregularidade. Alguns equipamentos utilizados são o perfilômetro laser e perfilômetro acústico FELT.

Os sistemas mais difundidos a nível internacional e também no Brasil são os integradores do tipo-resposta e o perfilômetro laser. Os equipamentos do tipo-resposta se baseiam na reação da suspensão dos veículos às irregularidades existentes, sendo os únicos normatizados no Brasil, segundo as normas DNER-PRO 182/94, que discorre sobre a avaliação da irregularidade em si, a DNER-PRO 229/94, que trata sobre a manutenção do equipamento e a DNER-PRO 164/94 que contém o procedimento de calibração para esse tipo de equipamento.

Esses equipamentos realizam a avaliação da irregularidade dos pavimentos através da acumulação em um sentido, pelos deslocamentos entre a carroceria e o eixo traseiro de um veículo de passeio. Como esses deslocamentos são muito sensíveis à velocidade em que o veículo está trafegando, os equipamentos do tipo-resposta necessitam de uma calibração, muitas vezes chamada de calibração por correlação, onde objetiva-se 
estabelecer, para uma determinada velocidade de operação, a relação entre o valor de um índice de irregularidade e a quantidade de deslocamento vertical por deslocamento horizontal indicada pelo equipamento.

Para obter-se uma curva de calibração para uma determinada velocidade de operação do equipamento, que pode ser de 30,50 e $80 \mathrm{~km} / \mathrm{h}$, é necessário efetuar o processo descrito acima em diversos segmentos que representem bem os diferentes valores de irregularidade que poderão ser encontrados na medição real. Isto é previsto na própria norma de calibração.

De posse do modelo de correlação, o equipamento estaria em tese habilitado a realizar medições, que posteriormente serão convertidas pelo modelo para o quociente de irregularidade QI. As equações são apresentadas por meio da expressão (2.6):

$$
Q I=a+b \cdot L
$$

A cada lance, geralmente de $320 \mathrm{~m}$, o aparelho emite um sinal sonoro através de um mostrador que informa a leitura $\mathrm{L}$, representativa da irregularidade acumulada no lance em questão. O valor de QI é posteriormente calculado em escritório, aplicando-se a correlação correspondente.

Adota-se como escala padrão de irregularidade no Brasil o quociente de irregularidade - QI - expresso em contagens/km. A irregularidade pode ser medida em diversas escalas padronizadas, onde uma das escalas da irregularidade do pavimento é o International Roughness Index (IRI), que consiste num tratamento estatístico do perfil longitudinal na trilha de roda de uma superfície de pavimento. O índice é uma média retificada das variações computadas do perfil absoluto, sendo representativo dos movimentos verticais induzidos aos veículos por uma banda de frequência, percebida tanto nas respostas dos veículos quanto no conforto sentido por seus ocupantes.

O IRI é definido pela simulação matemática de um quarto-de-carro, isto é, uma roda associada às características dinâmicas da suspensão e os impactos da massa de um 
veículo de passeio típico. A escala de medida é adimensional e utiliza um fator de escala igual a 1000, podendo, portanto, ser representada em $\mathrm{m} / \mathrm{km}$.

Conforme apresentado anteriormente, a escala padrão de irregularidade no Brasil, o Quociente de Irregularidade (QI), é contagens $/ \mathrm{km}$, medida correlacionável com o International Roughness Index (IRI), expresso em m/km, através da expressão (2.7):

$$
I R I=\frac{Q I}{13}
$$

As equações matemáticas utilizadas para a definição do IRI foram adaptadas dos estudos da Pesquisa de Inter-relacionamento de Custos Rodoviários (PICR) desenvolvida pelo GEIPOT (1982) e é calculado de acordo com os procedimentos e especificações do documento técnico do Banco Mundial Número 46 "Diretrizes para construção e calibração de medições para irregularidade da rodovia".

As leituras das medições são registradas em planilhas com os resultados da irregularidade do pavimento, em conjunto de incidências registradas durante o levantamento, constando a identificação da rodovia, trecho, quilômetro inicial e final, faixa, sentido crescente ou decrescente, sistema de medição, operador e data de realização do levantamento.

Uma vez determinado o perfil longitudinal de qualquer trecho do pavimento - seja por meio de nível e mira ou com o auxílio de um perfilômetro laser - podem ser calculados os índices de irregularidade QI e IRI, que sintetizarão em um número apenas a condição de rolamento de determinado trecho de pavimento, que pode ser correlacionada por meio da Tabela 2.7. 
Tabela 2.7 - Relação entre a Condição do Pavimento e os Níveis de Irregularidade (PINTO e PREUSSLER, 2010)

\begin{tabular}{c|c|c}
\hline Condição & $\begin{array}{c}\text { QI } \\
(\text { contagem/km) }\end{array}$ & $\begin{array}{c}\text { IRI } \\
(\mathbf{m} / \mathbf{k m})\end{array}$ \\
\hline Excelente & $13-25$ & $1-1,9$ \\
\hline Boa & $25-35$ & $1,9-2,7$ \\
\hline Regular & $35-45$ & $2,7-3,5$ \\
\hline Ruim & $45-60$ & $3,5-4,6$ \\
\hline Péssima & $>60$ & $>4,6$ \\
\hline
\end{tabular}

\subsubsection{Método do PCI do NYSDOT}

O método do PCI (Pavement Condition Index), conhecido no Brasil como ICP (Índice da Condição do Pavimento) foi desenvolvido por Shahin e pelo US Army Construction Engineering Research Laboratory (CERL), em 1979 (APS et al., 1998). É um índice muito utilizado no exterior, fornecendo a capacidade de incluir a qualidade de uma rodovia na tomada de decisão tanto em nível de projeto, como em nível de rede. É considerado uma ferramenta eficaz na gerência de pavimentos e, como consequência, nas tomadas de decisão. (NYSDOT, 2010).

Segundo Shahin e Kohn (1979), o objetivo principal do método do PCI é o desenvolvimento de um índice numérico de condição de pavimento para estacionamentos, ruas e rodovias, sejam eles rígidos ou flexíveis, destinados a fornecer ao engenheiro um método padrão para:

- Avaliação da condição estrutural e da condição da superfície de uma seção do pavimento;

- Determinação das necessidades de manutenção e de reparação, em função da condição do pavimento;

- Determinação do desempenho do pavimento, em função de avaliação contínua do PCI. 
O método fornece um valor numérico do PCI, que varia de 0 (zero) a 100 (cem), baseados nas informações da inspeção visual. O valor máximo, ou 100, corresponde a um pavimento de excelente qualidade, enquanto que o nível mínimo, ou 0 , refere-se a um pavimento de péssima qualidade, conforme apresentado na Tabela 2.8.

Tabela 2.8 - Classificação do Pavimento pelo Método do PCI

\begin{tabular}{c|c}
\hline Classificação & Valor de PCI \\
\hline Excelente & $100-86$ \\
\hline Muito Boa & $85-71$ \\
\hline Boa & $70-56$ \\
\hline Regular & $55-41$ \\
\hline Ruim & $40-26$ \\
\hline Muito Ruim & $25-11$ \\
\hline Péssima & $10-0$ \\
\hline
\end{tabular}

Os defeitos em pavimentos flexíveis considerados pelo método do PCI tradicional são:

- Trincamento tipo couro de jacaré - medido em área;

- Exsudação - medido em área;

- Trinca em Blocos - medido em área;

- Ondulação;

- Depressão;

- Erosão;

- Trincamento longitudinal ou transversal;

- Contaminação por óleo;

- Remendo;

- Panela;

- Agregado polido;

- Envelhecimento;

- Afundamento em trilha de roda. 
Para a inspeção dos defeitos, o pavimento deve ser dividido em unidades amostrais. Há dois métodos sugeridos para esta inspeção: método de inspeção total e método de inspeção por amostragem. Na inspeção total, todas as unidades amostrais do trecho selecionado são avaliadas e na inspeção por amostragem, apenas uma porção das unidades amostrais do trecho são avaliadas (SHAHIN, 2005).

Em ambos os métodos, o avaliador caminha sobre cada unidade amostral medindo cada tipo de defeito e verificando sua severidade. Os dados de cada unidade amostral são registrados em um formulário, conforme apresentado na Figura 2.17 a seguir: 


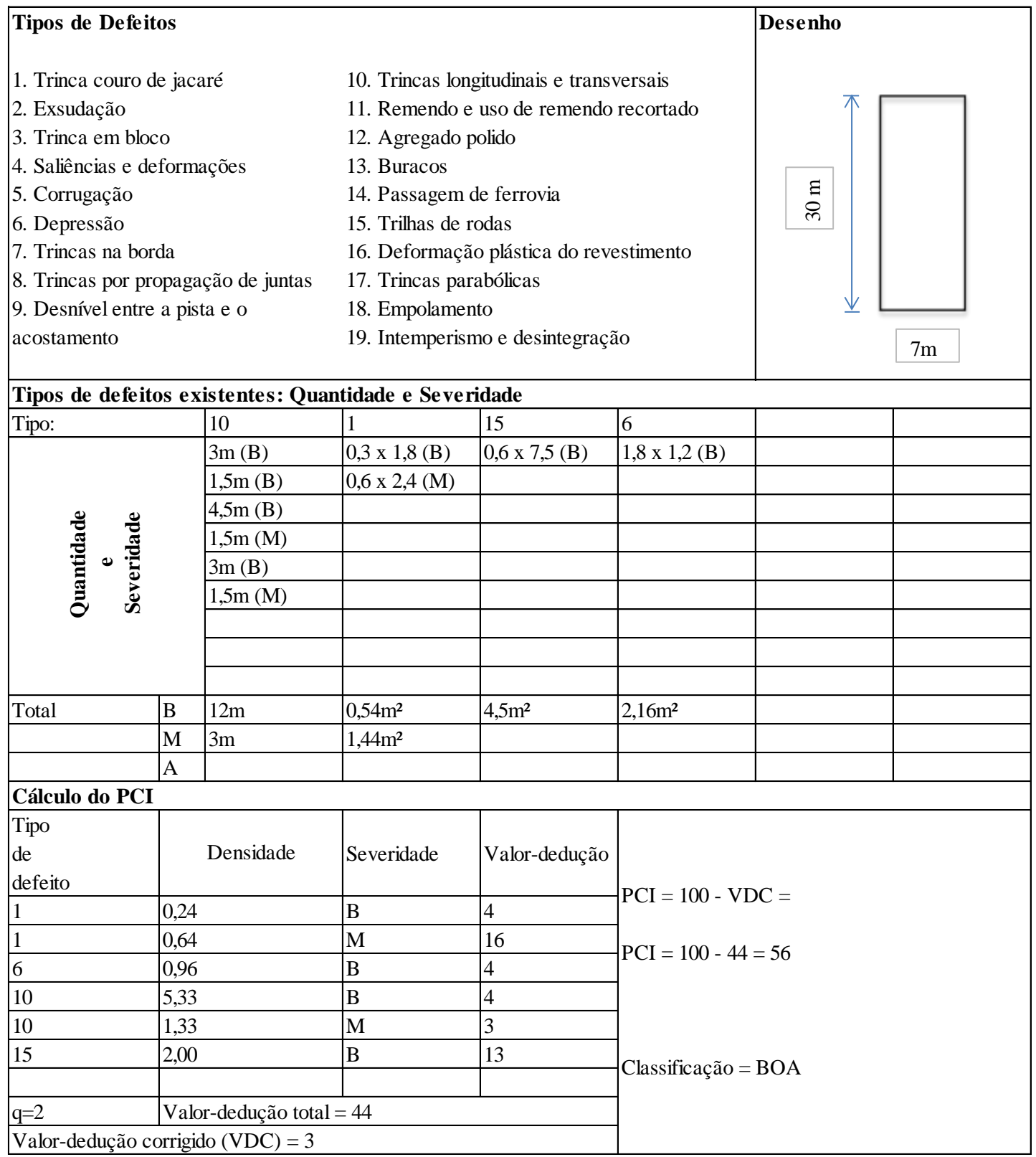

Figura 2.17 - Formulário para Inspeção de Pavimento (Adaptado do HEADQUARTERS DEPARTAMENT OF THE ARMY, 1982)

Após o registro total dos defeitos da unidade amostral (UA), a densidade de cada um deles é calculada em função da sua incidência na área analisada (razão entre a quantidade do defeito e a área da unidade amostral). O valor densidade (d) é obtido por meio da expressão (2.8).

$$
d=\frac{\text { áreal extensãodefeito }}{\text { áreaUA }} * 100
$$


Em que,

d: densidade;

UA: unidade amostral.

Em função da densidade e da severidade é possível determinar os valores-dedução individuais (VDi), através das curvas valores-dedução existentes para cada tipo de defeito. Em seguida, obtém-se o valor-dedução total (VDT). Em função do VDT e do número de deduções individuais maiores que 5 determina-se o valor-dedução corrigido (VDC). Por fim, para o cálculo do PCI, utiliza-se a expressão (2.9):

$$
P C I=100-V D C
$$

Em que,

VDC: valor-dedução corrigido.

Órgãos do governo americano desenvolveram outras formas de cálculo do PCI, diferentemente do modelo proposto incialmente por Shahin e Kohn (CHEETHAM et al., 2001). O Departamento de Transportes do Estado de New York - NYSDOT desenvolveu em 2003 uma metodologia mais simplificada para o cálculo do PCI, em que uma comissão composta por uma equipe de vários níveis no processo de tomada de decisão avaliou uma seção transversal de rodovia, de maneira a definir os parâmetros de importância para o cálculo do PCI.

Foram definidos os fatores funcionais que afetam o desempenho do pavimento, a serem considerados no cálculo do PCI do NYSDOT:

- Classificação da Superfície;

- Qualidade ao rolamento (IRI);

- Afundamentos;

- Falhas e defeitos dominantes. 
A Classificação da Superfície baseia-se na gravidade e extensão do trincamento na superfície do pavimento, devendo ser realizada com um motorista e um avaliador operando no limite da velocidade da rodovia. $\mathrm{O}$ avaliador deve realizar duas avaliações de cada segmento de pavimento:

1. Atribuir uma classificação da condição de "1" (ruim) até "10" (excelente), com base nos defeitos da superfície do pavimento, conforme apresentado resumidamente na Tabela 2.9;

2. Identificar a presença de tipos específicos de defeitos, chamados defeitos dominantes. Os defeitos dominantes são os trincamentos couro de jacaré.

Tabela 2.9 - Resumo da Classificação da Superfície e suas Condições (adaptado de NYSDOT, 2010)

\begin{tabular}{c|c}
\hline $\begin{array}{c}\text { Classificação } \\
\text { da Superfície }\end{array}$ & Condição/Descrição \\
\hline $9-10$ & $\begin{array}{c}\text { Excelente - sem defeito de } \\
\text { superfície }\end{array}$ \\
\hline $7-8$ & $\begin{array}{c}\text { Bom - início de defeitos de } \\
\text { superfície }\end{array}$ \\
\hline 6 & $\begin{array}{c}\text { Regular - defeitos de superfície são } \\
\text { claramente visíveis }\end{array}$ \\
\hline $1-5$ & $\begin{array}{c}\text { Ruim - defeitos frequentes e } \\
\text { severos }\end{array}$ \\
\hline$U$ & Em construção - Não avaliado \\
\hline
\end{tabular}

A seguir são apresentadas as Tabelas 2.10 e 2.11 que detalham a classificação, as descrições e as características, tais como, frequência, severidade e aparência de cada segmento de pavimento avaliado. 
Tabela 2.10 - Classificação Detalhada da Superfície e suas Características (adaptado de NYSDOT, 2010)

\begin{tabular}{|c|c|c|c|c|}
\hline \multirow{2}{*}{$\begin{array}{l}\text { Classificação da } \\
\text { Superfície }\end{array}$} & \multirow{2}{*}{ Decrição Geral } & \multicolumn{3}{|c|}{ Caracte rísticas } \\
\hline & & Frequência & Severidade & Aparência \\
\hline 10 & $\begin{array}{l}\text { sem defeito de superfície - recém } \\
\text { construído ou reabilitado }\end{array}$ & sem defeitos & & $\begin{array}{l}\text { pavimento novo, escuro } \\
\text { com um ano ou menos }\end{array}$ \\
\hline 9 & sem defeitos significantes & $\begin{array}{c}\text { quase todo o pavimento está } \\
\text { livre defeitos, um único } \\
\text { defeito ou trinca por } 160 \mathrm{~m} \text { é } \\
\text { permitido }\end{array}$ & $\begin{array}{c}\text { o defeito é superficial ou o } \\
\text { trincamento é pequeno }\end{array}$ & $\begin{array}{l}\text { superfície está oxidada } \\
\text { para cor cinza, } \\
\text { variando de } 1 \text { a } 3 \text { anos }\end{array}$ \\
\hline 8 & defeitos raros com gravidade leve & $\begin{array}{c}\text { a maioria do pavimento está } \\
\text { livre de trincas, facilidade } \\
\text { para contagem do número de } \\
\text { trincas em alta velocidade }\end{array}$ & \begin{tabular}{|c|} 
trincas pequenas \\
espaçadas, \\
sem trincamento classe 2, \\
sem defeitos dominantes \\
\end{tabular} & $\begin{array}{l}\text { superfície uniforme, } \\
\text { pode haver selagem de } \\
\text { trincas }\end{array}$ \\
\hline 7 & $\begin{array}{l}\text { defeitos raros para ocasionais com } \\
\text { gravidade pequena }\end{array}$ & $\begin{array}{c}\text { grande parte do pavimento } \\
\text { está livre de trincas, mais } \\
\text { dificuldade para contagem do } \\
\text { número de trincas em alta } \\
\text { velocidade }\end{array}$ & $\begin{array}{c}\text { maioria do trincamento } \\
\text { com menos de } 3 \mathrm{~mm} \text { de } \\
\text { largura, } \\
\text { aparecimento de trincas } \\
\text { classe } 2, \\
\text { pode haver defeitos } \\
\text { dominantes }\end{array}$ & $\begin{array}{c}\text { aspecto bom, mas o } \\
\text { trincamento é } \\
\text { perceptível, } \\
\text { trincamento adicional foi } \\
\text { desenvolvido desde a } \\
\text { última selagem de trinca, } \\
\text { necessidade de } \\
\text { recapeamento }\end{array}$ \\
\hline 6 & $\begin{array}{c}\text { defeitos ocasionais para frequentes } \\
\text { com gravidade moderada }\end{array}$ & $\begin{array}{l}\text { maior parte do pavimento } \\
\text { está trincada, } \\
\text { trincamento são espaçados } \\
\text { com alguns metros de } \\
\text { distância ou menos }\end{array}$ & \begin{tabular}{|} 
trincamento com mais de \\
$3 \mathrm{~mm}$ de largura, \\
maioria de trincas classe 2, \\
trincamento interligado, \\
comum a presença de \\
defeitos dominantes
\end{tabular} & $\begin{array}{l}\text { condição parece } \\
\text { "regular", } \\
\text { necessidades de } \\
\text { restauração }\end{array}$ \\
\hline 5 & $\begin{array}{l}\text { defeitos frequentes com gravidade } \\
\text { moderada para severa }\end{array}$ & $\begin{array}{l}\text { quase todo o pavimento ou } \\
\text { trilhas de roda tem } \\
\text { trincamento bem } \\
\text { desenvolvido }\end{array}$ & $\begin{array}{c}\text { trincamento são largos e } \\
\text { desenvolvido com classe } 2, \\
\text { muitos trincamentos } \\
\text { interligados, presença de } \\
\text { panela e remendos }\end{array}$ & $\begin{array}{c}\text { condição parece "ruim", } \\
\text { necessidades de uma } \\
\text { restauração maior }\end{array}$ \\
\hline 4 & $\begin{array}{l}\text { defeitos frequentes com gravidade } \\
\text { severa }\end{array}$ & $\begin{array}{l}\text { o pavimento está na sua } \\
\text { maioria trincado, } \\
\text { viagem é prejudicada }\end{array}$ & $\begin{array}{c}\text { trincamentos são largos e } \\
\text { interligados, presença de } \\
\text { panela e remendos }\end{array}$ & $\begin{array}{l}\text { necessidade de } \\
\text { reconstrução }\end{array}$ \\
\hline
\end{tabular}


Tabela 2.11 - Classificação Detalhada da Superfície e suas Características (adaptado de NYSDOT, 2010)

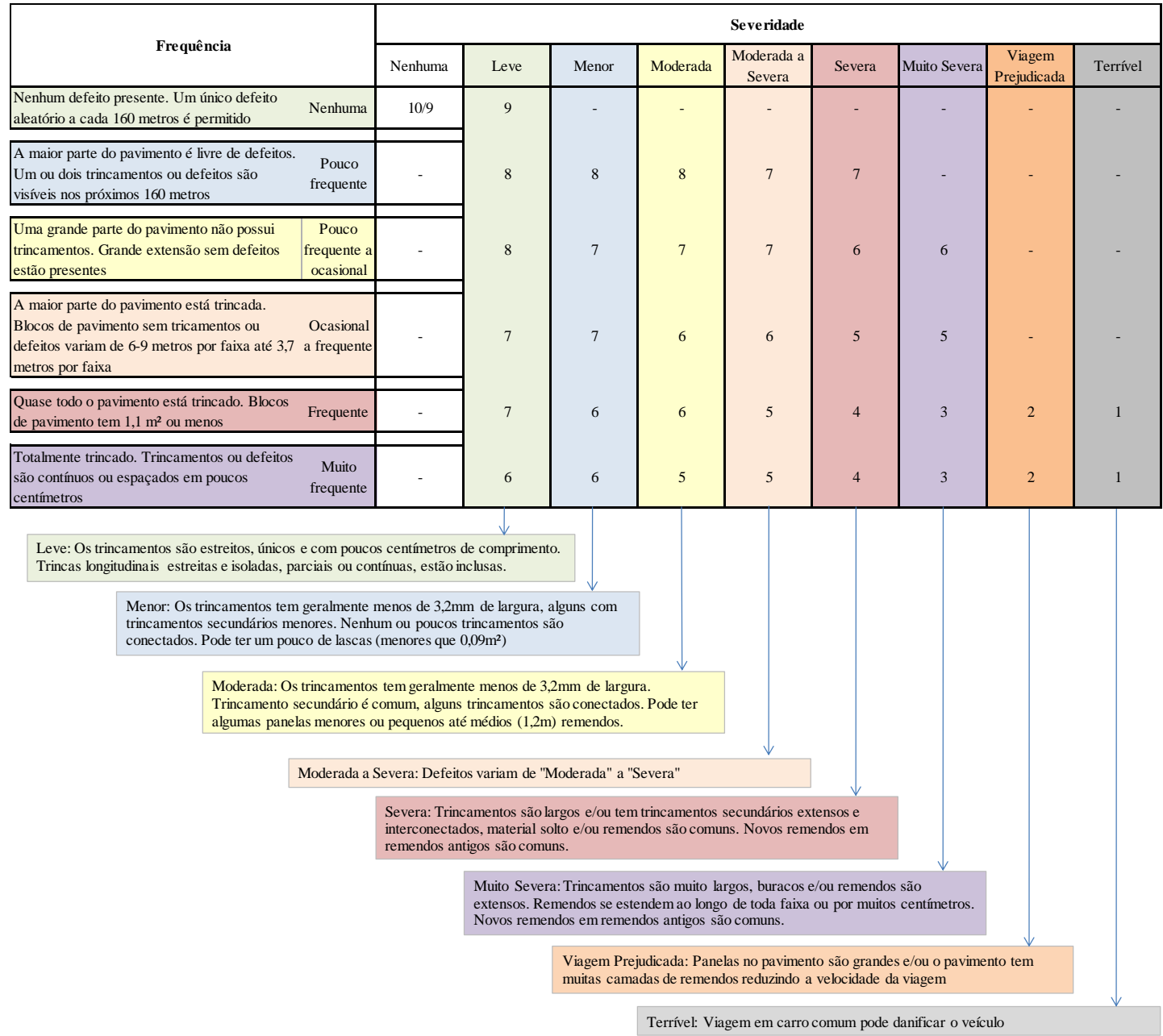

Na classificação da superfície do pavimento são realizadas considerações especiais para os remendos, as selagens de trincas e desplacamento.

Para os remendos, é necessário avaliar os que se apresentam em boas e em más condições. Remendos em boas condições não são considerados defeitos, mas sim, parte integrante do pavimento, enquanto que os em condições ruins são considerados defeitos.

As fissuras e trincas na superfície do pavimento tornam-se substancialmente mais visíveis após a selagem, fato que pode causar uma classificação inferior dos avaliados. Para evitar uma queda brusca na classificação após a selagem, o pavimento é avaliado 
na mesma classificação do ano anterior. O segmento mantém mesma classificação de trincamento até que um trincamento adicional se desenvolva.

Quanto ao desplacamento, para fins de avaliação, o referido defeito é classificado como trincamento com alta severidade.

Assim como descrito na norma ASTM D6433-03 "Prática Padrão para Pesquisa do PCI para Rodovias e Estacionamentos", o comitê decidiu utilizar o mesmo sistema para deduzir o PCI, onde os pontos para cada defeito do pavimento são subtraídos, a partir de uma avaliação classificada como "excelente", com o valor 100. A abordagem da dedução foi escolhida pela simplificada compreensão, por oferecer flexibilidade nos fatores e ponderações utilizadas e pela relativa facilidade de cálculo. A abordagem do NYSDOT para PCI é muito mais simples, mas compartilha uma filosofia semelhante de incorporação de múltiplos fatores ponderados em uma única classificação.

A ponderação de cada fator no PCI é controlada pelo número de pontos disponíveis para a dedução para a faixa de gravidade do defeito. O comitê utilizou sua experiência para incluir o máximo de pontos a deduzir para cada fator, determinando assim, a sua importância relativa.

Após ser realizada a análise e avaliação dos cálculos do PCI utilizando dados de produção, a dedução máxima para cada fator de defeitos para o pavimento flexível foi definida conforme apresentado na Tabela 2.12. 
Tabela 2.12 - Dedução Máxima Relativa a cada Tipo de Defeito para o Cálculo do PCI (adaptado de NYSDOT, 2010)

\begin{tabular}{c|c}
$\begin{array}{c}\text { Tipo de } \\
\text { Defeito/Levantamento }\end{array}$ & $\begin{array}{c}\text { Fator Máximo } \\
\text { de De dução }\end{array}$ \\
\hline $\begin{array}{c}\text { Classificação da Superfície } \\
\text { Irregularidade Longitudinal } \\
\text { (IRI) }\end{array}$ & 35 pontos \\
\hline Afundamento & 15 pontos \\
\hline Trincamento Jacaré & 15 pontos \\
\hline
\end{tabular}

Apesar da Classificação da Superfície e IRI representarem 35\% da classificação total, o PCI em geral é composto de $65 \%$ de deduções atribuíveis a defeitos superfície. Isso representa um equilíbrio razoável entre defeitos e qualidade de rolamento na avaliação da condição do pavimento.

Todos os dados necessários para o cálculo do PCI são coletados pelas atividades de campo, tais como: classificação de superfície, trincamento tipo couro de jacaré, pesquisas anuais de IRI, além da profundidade do afundamento.

Durante o desenvolvimento inicial do PCI, o Comitê criou curvas para deduzir valores para a faixa de classificação de cada fator. As curvas foram projetadas para sensibilizar os valores de dedução para faixas de classificação que fornecem o maior impacto na condição e desempenho do pavimento. Por exemplo, a dedução para valores IRI entre 1,6 e $2,7 \mathrm{~m} / \mathrm{km}$ aumenta de forma relativamente rápida a cada aumento no valor do IRI, mas a dedução aumenta mais lentamente para os valores de IRI abaixo de 1,6 $\mathrm{m} / \mathrm{km}$ e acima de $3,1 \mathrm{~m} / \mathrm{km}$, em que as alterações relativas na rugosidade têm menos impacto aos usuários das rodovias.

Duas equações são utilizadas para deduzir o valor IRI, devido à dificuldade em obter uma única equação para se ajustar bem à curva. As curvas-dedução para cada fator e as correspondentes equações de regressão estão apresentadas na Figura 2.18. 


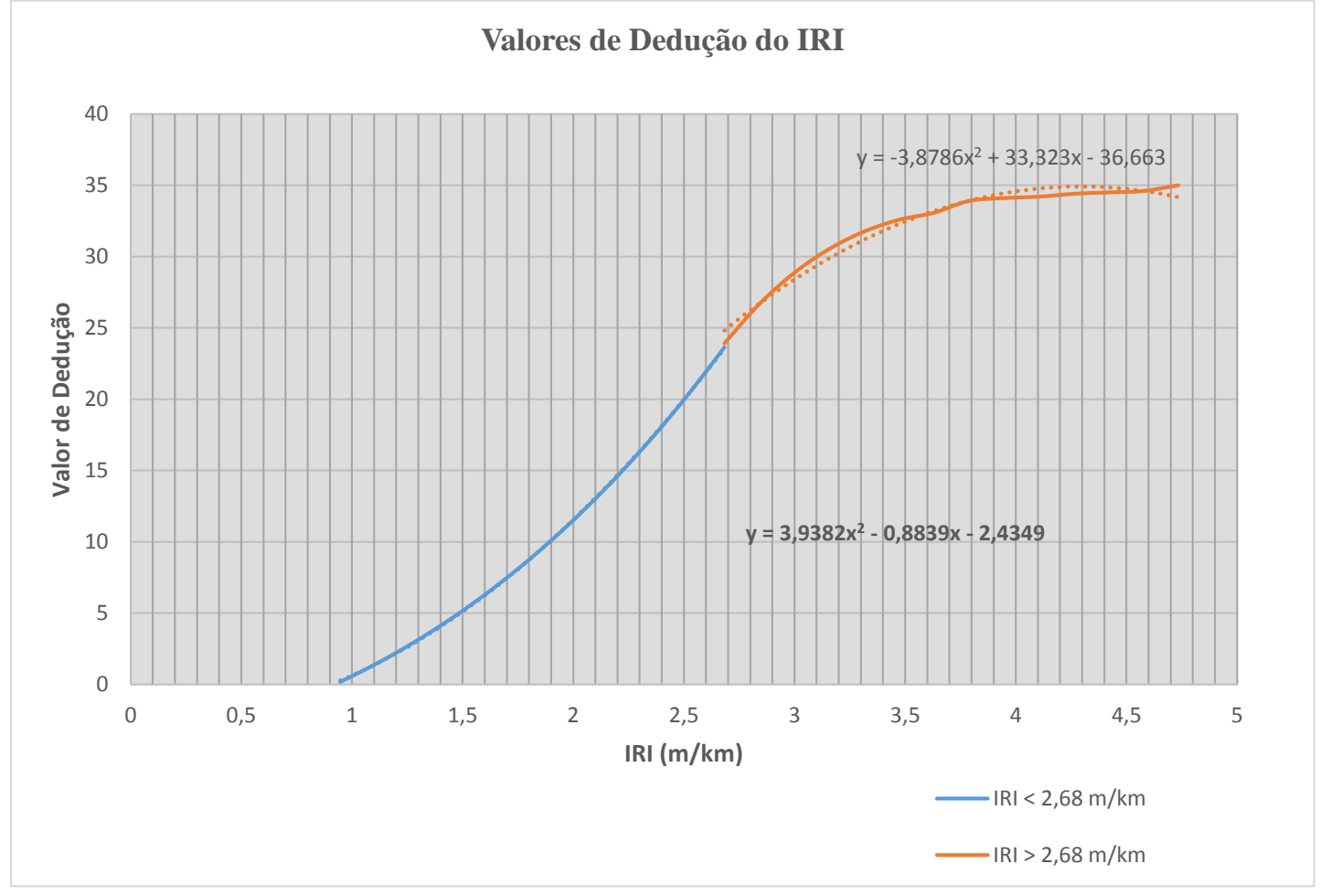

Figura 2.18 - Gráfico da Curva de Dedução do IRI (adaptado de NYSDOT, 2010)

Na Figura 2.19 é apresentada a curva de dedução do afundamento para o cálculo do PCI.

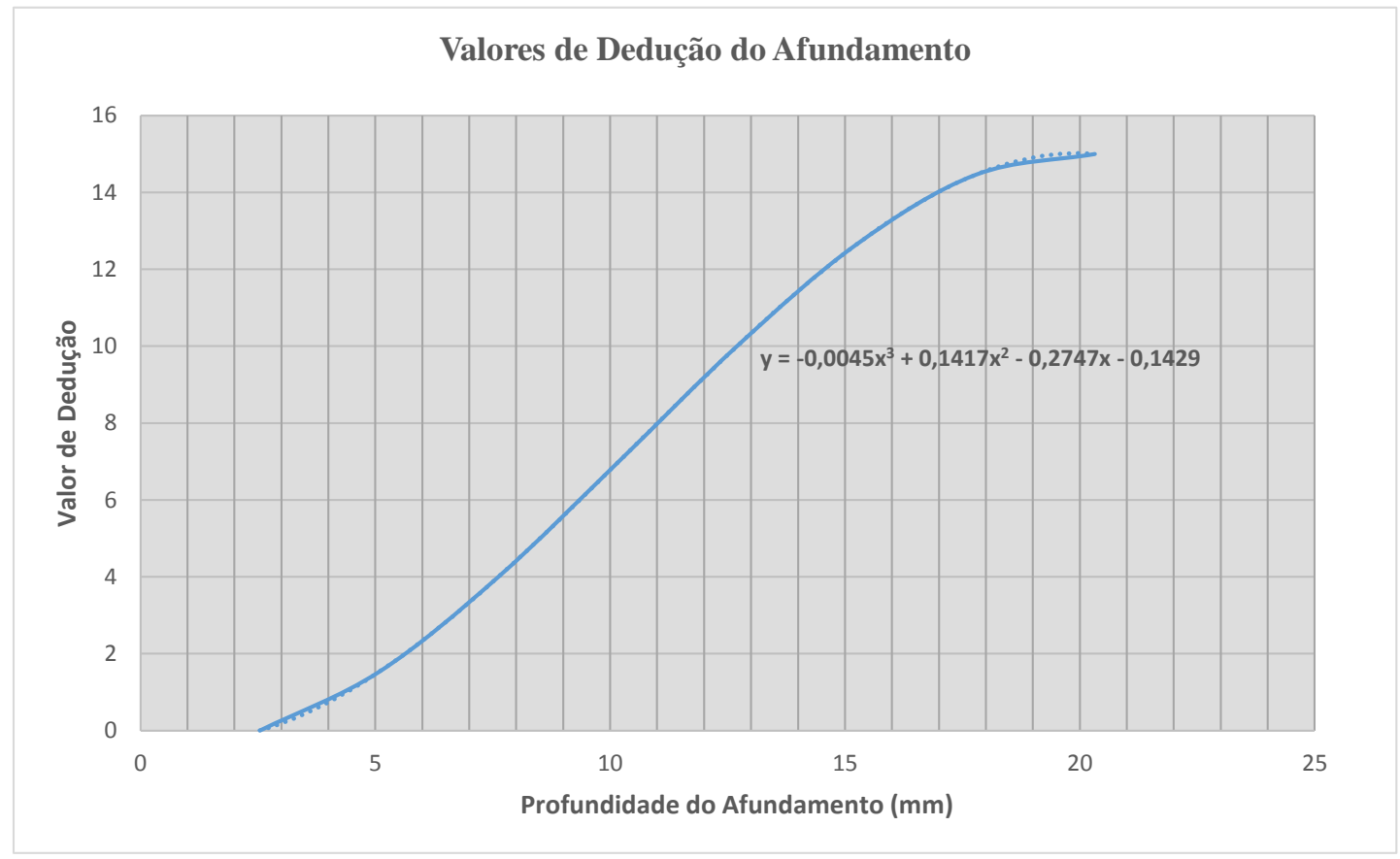

Figura 2.19 - Gráfico da Curva de Dedução do Afundamento (adaptado de NYSDOT, 2010) 
Para determinar os valores de dedução para a avaliação da superfície, o comitê novamente utilizou pareceres de peritos e atribuiu a dedução de pontos para cada valor de Classificação da Superfície. No entanto, a Classificação da Superfície é sempre um número inteiro, portanto, a curva resultante e o seu efeito sobre a classificação PCI provocaram um grande passo ou queda repentina na zona de transição entre cada valor de classificação da superfície.

Segundo o NYSDOT (2010), é intuitivo que a classificação da superfície deteriora-se gradualmente, embora o sistema de pontuação não permita classificações intermediárias. Para ajudar a reduzir a aparência de uma queda brusca na classificação (e, finalmente, no PCI), a quantidade a deduzir no primeiro ano da classificação é reduzida em alguns pontos. Na maioria dos casos isso ajuda a suavizar a curva e reduz quedas bruscas no PCI. A Tabela 2.13 apresenta a classificação da superfície e o valor da dedução no primeiro ano de análise e o valor de dedução completa.

Tabela 2.13 - Classificação da Superfície Correlacionada aos Valores de Dedução no $1^{\text {o }}$ Ano de Análise e a Dedução Completa (adaptado de NYSDOT, 2010)

\begin{tabular}{c|c|c}
\hline $\begin{array}{c}\text { Classificação da } \\
\text { Superficie }\end{array}$ & $\begin{array}{c}\text { Dedução } \\
\mathbf{1}^{\mathbf{0}} \text { ano }\end{array}$ & $\begin{array}{c}\text { Dedução } \\
\text { Completa }\end{array}$ \\
\hline 10 & 0 & 0 \\
\hline 9 & 1 & 2 \\
\hline 8 & 3 & 5 \\
\hline 7 & 8 & 10 \\
\hline 6 & 17 & 20 \\
\hline 5 & 27 & 30 \\
\hline 4 ou menos & 33 & 35 \\
\hline
\end{tabular}

O mesmo conceito de dedução diferenciada entre o primeiro ano e os demais é aplicado para deduzir os valores dos defeitos dominantes. Como não há classificação graduada 
para o trincamento couro de jacaré, utiliza-se as designações "isolado" (Ai) e "geral" (Ag), conforme ilustrado na Tabela 2.14.

Tabela 2.14 - Defeitos Dominantes do tipo Trincamento Couro de Jacaré Correlacionados aos Valores de Dedução no $1^{\circ}$ ano de Análise e a Dedução Completa (adaptado de NYSDOT, 2010)

\begin{tabular}{c|c|c}
\hline $\begin{array}{c}\text { Defeito } \\
\text { Dominante }\end{array}$ & $\begin{array}{c}\text { Dedução } \\
\mathbf{1}^{\mathbf{0}} \text { ano }\end{array}$ & $\begin{array}{c}\text { Dedução } \\
\text { Comple ta }\end{array}$ \\
\hline $\mathrm{Ai}$ & 5 & 8 \\
\hline $\mathrm{Ag}$ & 12 & 15 \\
\hline
\end{tabular}

\subsection{Equipamentos de Avaliação Funcional}

Os levantamentos das condições do pavimento desempenham um papel vital no sistema de gestão de uma rede rodoviária, fornecendo informações importantes sobre o desempenho do pavimento, de maneira a prever e antecipar necessidades de manutenção e reabilitação. Portanto, é essencial que os dados sejam coletados de maneira precisa, eficiente e segura.

No passado, o único método de pesquisa sobre a condição do pavimento era a pé ou de carro pela rodovia, coletando os dados manualmente. Este método consome tempo, é perigoso e subjetivo. Portanto, ao longo das últimas três décadas percebeu-se um esforço para automatizar totalmente o processo de coleta de dados (TIMM e MCQUEEN; 2004).

Um levantamento automatizado da condição do pavimento é realizado trafegando-se na rodovia em uma velocidade estabelecida, coletando os dados. Os veículos utilizados para os levantamentos são equipados com vários sistemas tecnologicamente complexos. Cada sistema foi concebido para coletar dados e alguns dos sistemas trabalham em conjunto com o outro. Algumas das informações que são normalmente coletadas são os trincamentos, macrotextura, panela, afundamento, flecha na trilha de roda, remendos e irregularidade longitudinal. 
Ressalta-se a tendência na utilização de equipamentos automatizados para a coleta de dados de pavimento. Bennett (1998) cita que há uma grande variedade destes tipos de equipamentos, produzidos em diversos países, com diferentes tecnologias, com variabilidade de custos e de características. Destaca-se também que os principais problemas que têm sido encontrados pelos usuários referem-se à verificação e à avaliação do desempenho destes instrumentos, bem como, à correta identificação dos defeitos.

Os principais equipamentos para levantamentos automatizados da avaliação funcional são:

- ARAN (Automatic Road Analyser);

- ROMDAS - TPL (Road Measurement Data Acquisition System - Transverse Profile Logger);

- PASCO;

- Perfilômetro laser;

- AMAC.

Adicionalmente, também será apresentado e descrito detalhadamente o equipamento Pavement Scanner, que é o objeto desta pesquisa.

\subsubsection{ARAN (Automatic Road Analyser)}

O “Automatic Road Analyser" (ARAN) é um equipamento montado sobre um veículo adaptado para avaliação rodoviária integrada, dispondo de três filmadoras assim dispostas: uma câmera fotográfica de alta resolução voltada para a parte dianteira do veículo para uma visão panorâmica do local e duas outras na porção traseira capazes de fotografar uma largura de até $4 \mathrm{~m}$ do pavimento, de forma a permitir a determinação do seu grau de deterioração superficial. A Figura 2.20 ilustra o equipamento ARAN. 


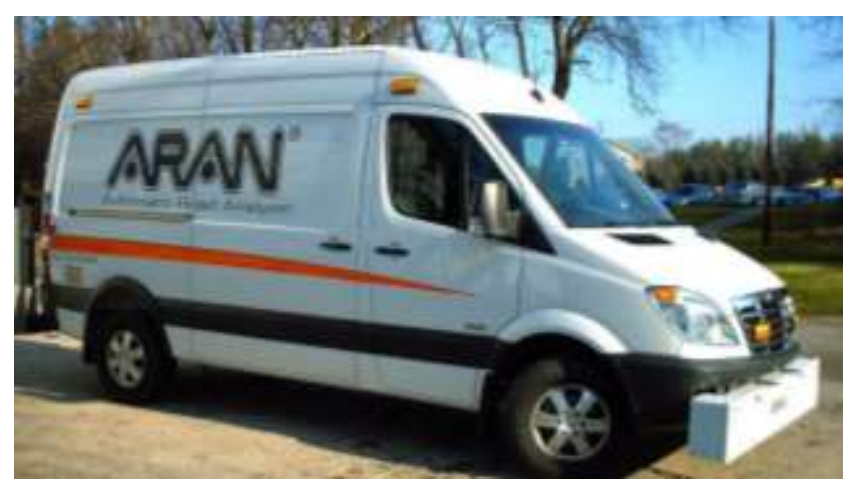

Figura 2.20 - Equipamento ARAN

O foto-registro pela câmera traseira, de cada faixa de tráfego individualmente, é a base para a inspeção visual, assim como para a determinação das áreas deterioradas do pavimento. As imagens são coletadas no campo com elevada resolução e o grau de trincamento do pavimento processado automaticamente, sendo determinadas em escritório somente as demais ocorrências de defeitos de superfície, com total possibilidade de retorno a pontos duvidosos (HAAS et al.,1994).

Há ainda um perfilômetro laser de elevado rendimento composto por dois sensores laser e dois acelerômetros na dianteira do veículo, que permitem a determinação do perfil longitudinal dos pavimentos e dos parâmetros de irregularidade em termos de IRI (International Roughness Index).

Há um perfilômetro traseiro com dois sensores laser de varredura que permitem a determinação do perfil transversal de elevada resolução por varredura (e não pontuais como os sensores de avaliação de perfil longitudinal), além de um conjunto de sensores de GPS e de sensor inercial para determinação do traçado da rodovia em planta e perfil, bem como a declividade longitudinal e transversal da pista.

\subsubsection{ROMDAS - TPL (Road Measurement Data Acquisition System - Transverse Profile Logger)}

Segundo Bennett (1998), o ROMDAS é um equipamento projetado para registrar o perfil transversal dos pavimentos (TPL) utilizando cinco sensores ultrasônicos instalados em um veículo com espaçamento de $100 \mathrm{~mm}$. Ele é um componente do 
sistema ROMDAS que mede também a irregularidade e a condição visual em vídeo. A seção principal do TPL contém 20 (vinte) sensores.

$\mathrm{Na}$ execução dos levantamentos um "controlador mestre" ligado a um computador dispara os sensores e armazena os dados, juntamente com a linha de eixo onde os levantamentos foram realizados. Entretanto, os desencontros dos disparos podem complicar os respectivos registros dos sensores. Os disparos dos sensores levam um tempo de aproximadamente $0,125 \mathrm{~s}$. A distância longitudinal entre os sensores de $1 \mathrm{a}$ 5 de cada grupo varia com a velocidade de operação do veículo. A Figura 2.21, obtida diretamente do catálogo do fornecedor, ilustra o equipamento.

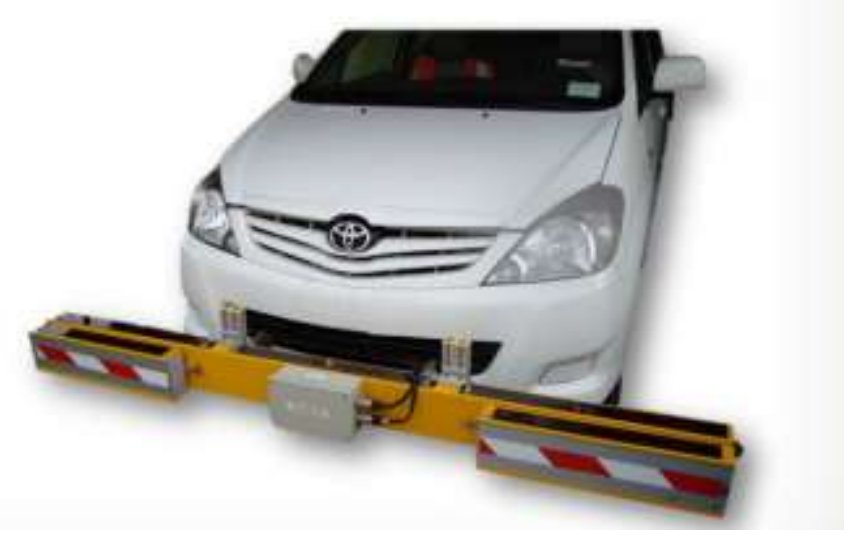

Figura 2.21 - Equipamento ROMDAS - TPL

\subsubsection{PASCO}

O equipamento da PASCO é instalado em um veículo que pode trafegar com velocidade superior a $80 \mathrm{~km} / \mathrm{h}$ e fotografar áreas com 4,80 m de largura, tendo sido utilizado no programa Long-Term Pavement Performance (LTPP). O sistema é equipado com duas câmeras fotográficas, cujas fotografias são capturadas à noite, de maneira a não ter influência da frequência de raios ultravioletas. A primeira câmera levanta os defeitos de forma contínua, sendo necessária a interpretação manual das fotos, enquanto que a segunda fotografa, de uma forma ininterrupta, o pavimento, para estimar o afundamento das trilhas de roda, utilizando uma linha ótica como referência (FEDERAL HIGHWAY ADMINISTRATION, 1998). 


\subsubsection{Perfilômetro Laser}

O perfilômetro laser foi projetado para determinar, com grande precisão, os perfis longitudinal e transversal das rodovias. Além destes parâmetros, o equipamento é capaz de avaliar as inclinações horizontais e verticais da rodovia, raios de curvatura, o Quociente de Irregularidade (QI) ou o International Roughness Index (IRI), e os afundamentos nas trilhas de roda externa e interna.

Alguns dos tipos mais modernos de perfilômetros laser é o DYNATEST $5051 \mathrm{Mk}-\mathrm{III}$ RSP (Road Surface Profiler). O sistema RSP foi desenvolvido para ser bastante flexível, incorporando um conceito modular que permite uma variedade de combinação de sensores e configurações. Essas combinações podem variar de um a três acelerômetros e de dois até vinte e um sensores a laser.

O equipamento é composto por três sensores lasers para medição de "altura" ou "profundidade" da pista, dois acelerômetros para compensação de esforços inerciais e um sensor óptico de partida assentados em uma barra transdutora. Há também um hodômetro de precisão montado na roda dianteira para definição da posição longitudinal. Todos estes sensores são ligados à unidade de processamento (DPU Data Processing Unit) através de módulos de conexão, sendo as informações processadas, armazenadas e visualizadas em "tempo real" em um notebook posicionado na cabine do veículo.

Os parâmetros de medição são calculados em tempo real e apresentados em intervalos mínimos de $25 \mathrm{~mm}$ (1 polegada) até um máximo de 1,6 km (1 milha).

Apesar da complexidade do equipamento, a operação é bastante simples, uma vez que seu funcionamento interno é comandado por um sistema informatizado, tornando a execução dos levantamentos de campo simples.

A Figura 2.22 ilustra uma das opções de perfilômetros laser. 


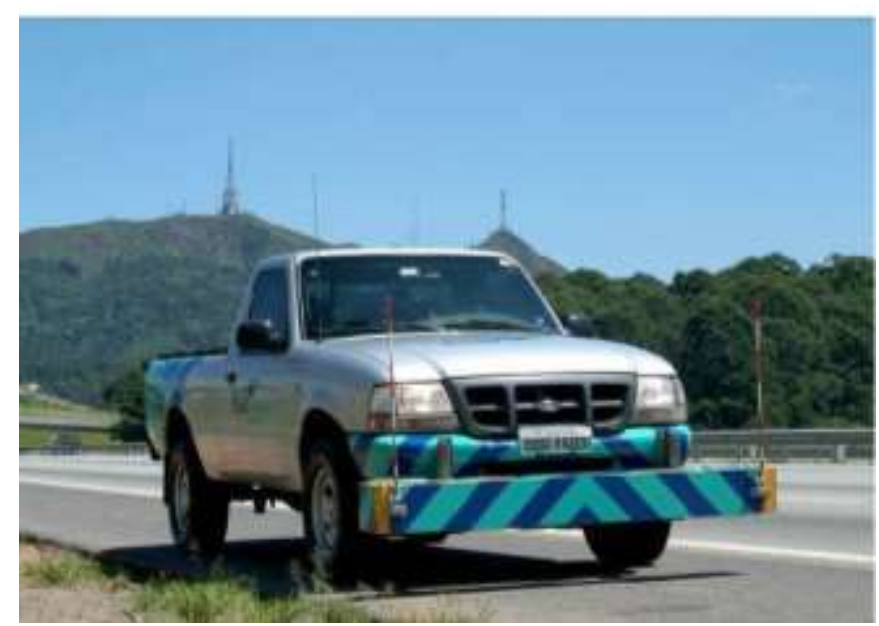

Figura 2.22 - Perfilômetro Laser Dynatest

O equipamento permite ainda alcançar grande produtividade, uma vez que ele pode percorrer a rodovia em estudo a uma velocidade de operação de até $80 \mathrm{~km} / \mathrm{h}$, dependendo das condições do trecho, o que torna o seu uso extremamente atraente para:

- Monitorar as condições da rodovia, alimentando um sistema de gerência de pavimentos;

- Avaliar a qualidade de rodovias recém construídas ou de operações de restauração executadas em pavimentos já existentes;

- Diagnosticar as condições de uma rodovia existente, determinando as operações de manutenção e/ou restauração que se façam necessárias.

\subsubsection{AMAC - Vectra}

O AMAC é um equipamento de avaliação funcional de pavimentos desenvolvido pela Association des Sociétés Françaises d'Autoroutes e implementado pelo grupo da Vectra Road Engineering, na França. A Figura 2.23 ilustra o equipamento AMAC. 


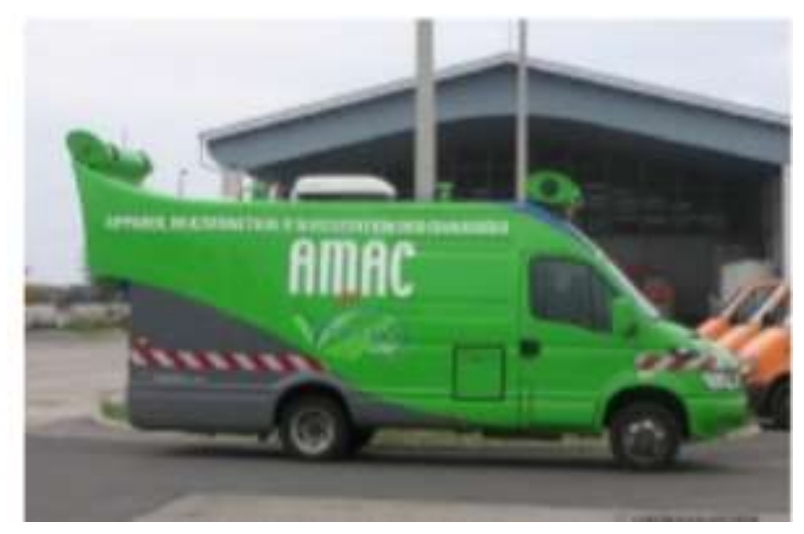

Figura 2.23 - Equipamento AMAC - VECTRA (NGUYEN et al., 2010)

A aquisição de dados é realizada por duas linhas de escaneamento, com dois lasers, de maneira similar ao Pavement Scanner. O veículo trabalha em uma velocidade média de $80 \mathrm{~km} / \mathrm{h}$. A resolução adquirida da imagem é um milímetro por pixel; o tamanho da imagem capturada é 3,9 $\mathrm{m}$ de largura e $4 \mathrm{~m}$ de comprimento, correspondente ao tamanho de imagem no nível de cinza de 4096x4096 pixels.

Há estudos realizados com os dados extraídos do AMAC na análise da detecção de trincamento utilizando as medidas de anisotropia, onde a idéia principal foi encontrar medidas diferentes de trincamento em diversas direções (NGUYEN et al., 2010).

\subsubsection{Pavement Scanner}

\subsubsection{Introdução}

Nos últimos 10 anos tem sido desenvolvida e testada a tecnologia 3D do Pavement Scanner. O sistema foi testado em uma série de rodovias americanas e canadenses para se avaliar o desempenho na tarefa de detecção automatizada e classificação de defeitos dos pavimentos. Os dados foram então comparados com os resultados obtidos através da inspeção humana de mais de 9000 km e apresentavam coerência na classificação geral de defeitos em 95\% dos casos (SAVARD et al., 2013). 
O sistema utilizado no Pavement Scanner, o Laser Cracking Measurement System LCMS, foi concluído em três fases principais. A primeira, em 2002, teve como objetivo avaliar os perfis de laser 3D e foi validado por meio de levantamento de seções de rodovia contendo trincas artificiais criadas por cortes de serra. A segunda, em 2005, validou os algoritmos para a detecção e classificação de trincas em segmentos de 400 metros de rodovia. A terceira fase foi destinada a aperfeiçoar o sistema e os softwares de processamento (LAURENT e HÉBERT; 2002).

O Pavement Scanner utiliza linhas de projeção de laser, câmeras de alta potência e óptica avançada para adquirirem o perfil 3D da rodovia em alta definição. Esta exclusiva tecnologia permite visão 3D para avaliação automática do estado do pavimento, seja ele flexível ou rígido. O Pavement Scanner adquire dados de imagem em 3D e 2D da superfície da rodovia com resolução de $1 \mathrm{~mm}$, sobre uma largura de 4 $\mathrm{m}$ em pista, com velocidades de até $100 \mathrm{~km} / \mathrm{h}$.

Os dados do Pavement Scanner são adquiridos e comprimidos em tempo real no veículo de levantamento, de modo a minimizar as necessidades de armazenamento (aproximadamente 1GB por $\mathrm{km}$ ).

O perfil transversal da rodovia é um conjunto de pontos de um plano levantados ao longo do eixo transversal da rodovia, sendo captado cada vez que o controlador do Pavement Scanner recebe um sinal de disparo, a partir do hodômetro do veículo. Tipicamente, o sistema pode capturar um perfil da rodovia a cada poucos milímetros $(5 \mathrm{~mm}$ a $100 \mathrm{~km} / \mathrm{h})$. Cada perfil consiste de até 4160 pontos de dados.

O perfil longitudinal da rodovia é gerado pela medição da sua forma ao longo de uma linha imaginária, fornecendo dados para o cálculo de vários índices de irregularidade, tais como o IRI.

Uma seção da rodovia é um conjunto de perfis consecutivos que são unidos e salvos em um arquivo comum, podendo ser visto como um conjunto de coordenadas 3D (X, $\mathrm{Y}, \mathrm{Z}$ ), onde $\mathrm{X}$ é a coordenada ao longo do eixo transversal da rodovia, $\mathrm{Y}$ ao longo do 
eixo longitudinal, e $\mathrm{Z}$ é o eixo de profundidade. O comprimento da seção da rodovia é configurável e pode ser definido pelo usuário antes de iniciar o levantamento, apresentando um comprimento típico de 5 a $10 \mathrm{~m}$. O formato de cada arquivo salvo pelo usuário inclui todos os dados necessários para a biblioteca de processamento:

- Mapa de profundidade da superfície da via (também referida como dados de alcance, ou imagem XYZ);

- Intensidade de imagem da superfície da via (isto é, a intensidade do feixe de laser, em cada ponto de dados);

- Aceleração vertical que irá ser utilizada para gerar o perfil longitudinal da via (opcional);

- Data e hora associada a cada perfil da seção da rodovia.

A Figura 2.24 ilustra o perfil transversal, longitudinal e a seções de rodovia.

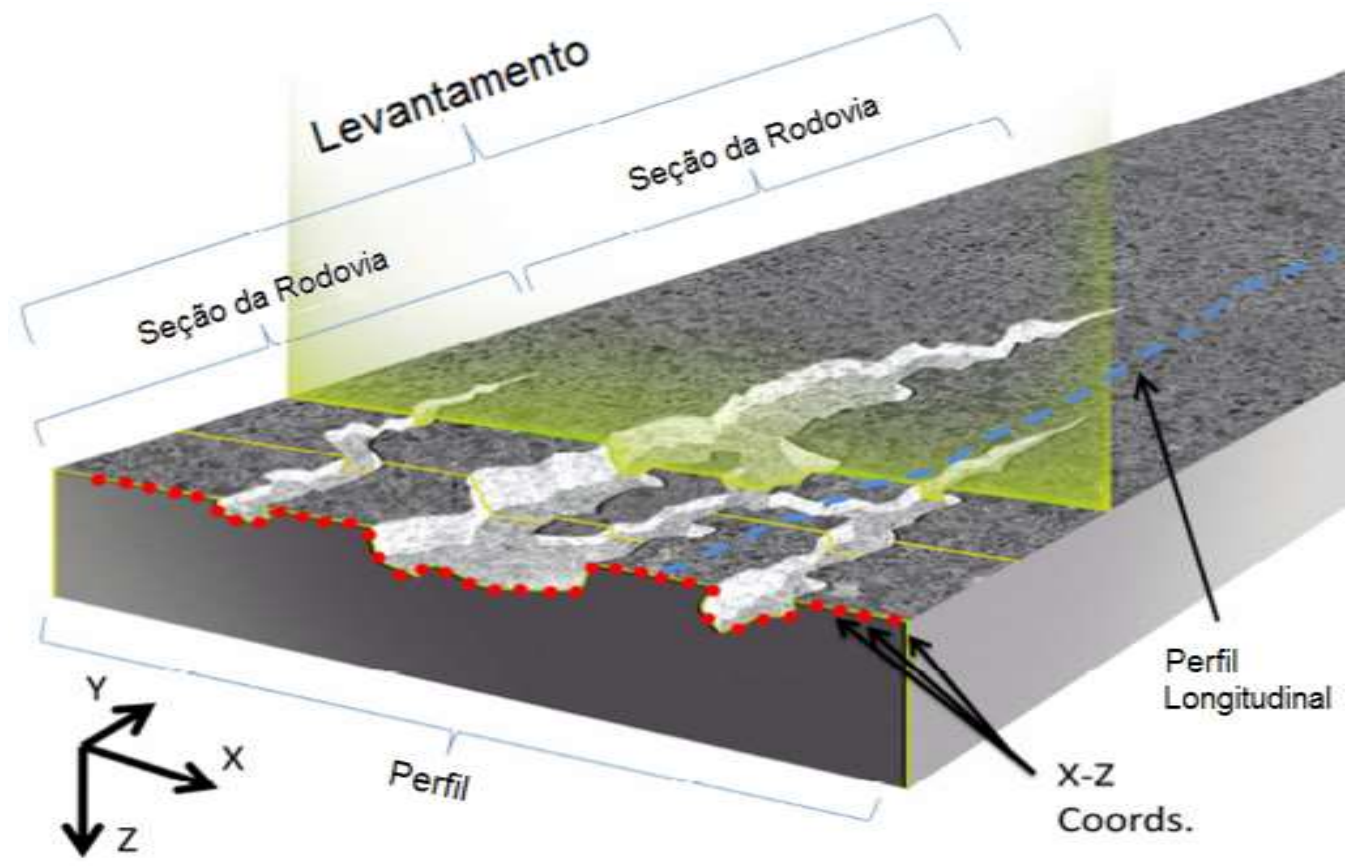

Figura 2.24 - Caracterização do Perfil Transversal, Longitudinal e Seção de Rodovia (adaptado do LCMS Manual, 2013)

Os dados coletados são processados, podendo-se determinar os trincamentos, sinalização horizontal, degrau entre pista e acostamento, panela, exsudação, remendos 
e desagregação. É possível medir os perfis longitudinais, IRI, declividade e inclinação transversal, bem como, a definição da macrotextura. $\mathrm{O}$ afundamento na trilha de roda também é medido e caracterizado utilizando mais de 4.000 pontos na seção transversal analisada. No caso de rodovias com pavimento rígido, suas pistas podem ser escaneadas para se avaliar as juntas e falhas entre as placas de concreto.

\subsubsection{Estrutura do Equipamento}

O Pavement Scanner é composto por duas unidades idênticas de sensores lasers 3D de alta performance, que são capazes de medir o perfil transversal completo do pavimento com a resolução de $1 \mathrm{~mm}$ em velocidade de tráfego. Os dados em alta resolução $2 \mathrm{D}$ e 3D que são adquiridos pelo sistema são processados utilizando algoritmos que foram desenvolvidos para identificar os defeitos com suas severidades, afundamentos, macrotextura, irregularidade longitudinal.

A faixa de luz é projetada pelo laser no pavimento e sua imagem é capturada enquanto o veículo de inspeção trafega ao longo da rodovia. A Figura 2.25 (a) demonstra a disposição dos sensores a laser e a Figura 2.25 (b), o detalhe do sensor a laser levantando o trincamento.

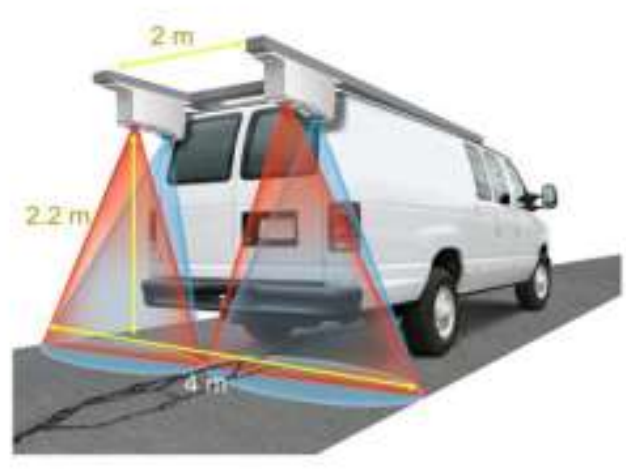

(a)

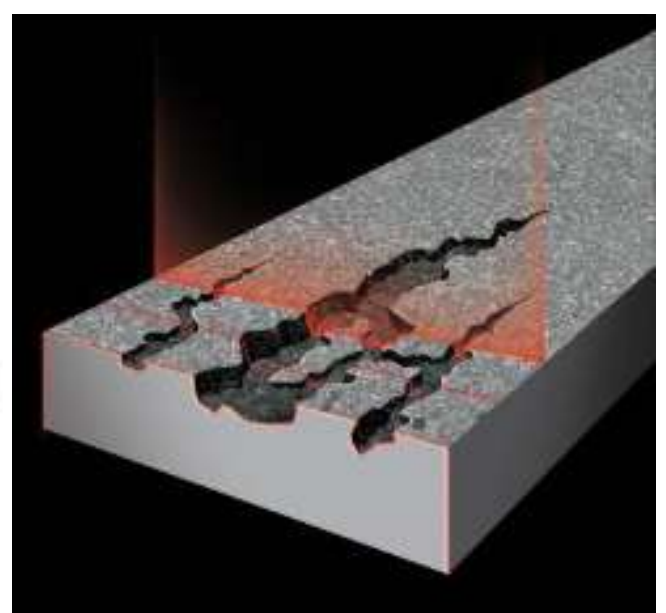

(b)

Figura 2.25 - Disposição dos Sensores a Laser (a). Detalhe do Laser Levantando o Trincamento (b) (adaptado do LCMS Manual, 2013) 
Cada unidade de sensor possui um tipo específico de câmera de alta velocidade e um módulo de emissão que projeta uma linha de laser. O principal componente de cada projetor de linha de laser é um diodo laser semicondutor de alta potência que emite em sua saída cerca de $7 \mathrm{~W}$ a $10 \mathrm{~W}$. Antes de atravessar pela janela de saída da linha do projetor do laser, o feixe a laser emitido passa por um sistema óptico adequadamente concebido para moldá-lo e, em seguida, o projeta sob a forma de uma linha fina alongada. A "linha de laser" tem uma espessura de cerca de $7 \mathrm{~mm}$, enquanto o seu comprimento é de cerca de $7 \mathrm{~cm}$, ambas dimensões referenciando-se à janela de saída. A linha de laser, ao se afastar da janela de saída, se espalha tornando o feixe mais alongado. Com a altura nominal de cerca de 2,2 m, o feixe de laser entra em contato com o pavimento apresentando cerca de $2 \mathrm{~m}$ de comprimento e espessura de $1 \mathrm{~mm}$. As linhas de laser projetadas a partir das duas unidades de sensores se sobrepõem, iluminando uma zona de cerca de $4 \mathrm{~m}$ de comprimento sobre o pavimento da rodovia. A vista esquemática frontal e lateral apresentada na Figura 2.26 ilustra os principais parâmetros relacionados com a geometria e com as dimensões definidos para cada unidade de sensor laser do Pavement Scanner.

Vista Esquemática Frontal

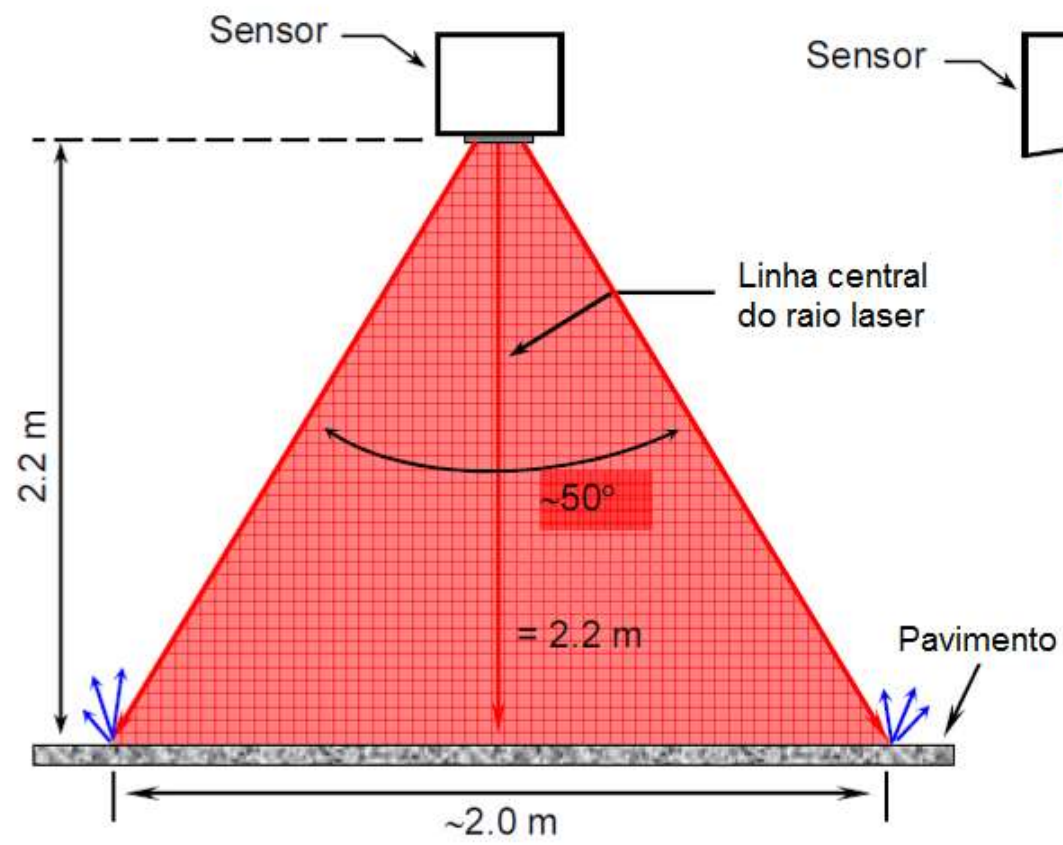

Vista Esquemática Lateral

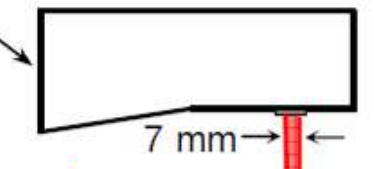

Figura 2.26 - Vista Esquemática Frontal e Lateral da Geometria da Linha de Laser (adaptado do LCMS Manual, 2013) 
Conforme configuração de instalação do Pavement Scanner ilustrada na Figura 2.27, as duas unidades de sensores de laser idênticos são fixadas a uma estrutura de montagem horizontal ligada ao teto do veículo de inspeção. Durante a operação do Pavement Scanner, a radiação a laser invisível é emitida a partir do projetor de laser, sendo as zonas em que se propaga radiação laser representadas esquematicamente na cor vermelha. A parte inferior da figura mostra também uma fotografia de um sensor de laser, em que as janelas de saída da câmara e do projetor de linha a laser são claramente identificadas. Nota-se que a janela de saída da câmara é arredondada, enquanto que a do projetor de linha do laser é retangular.
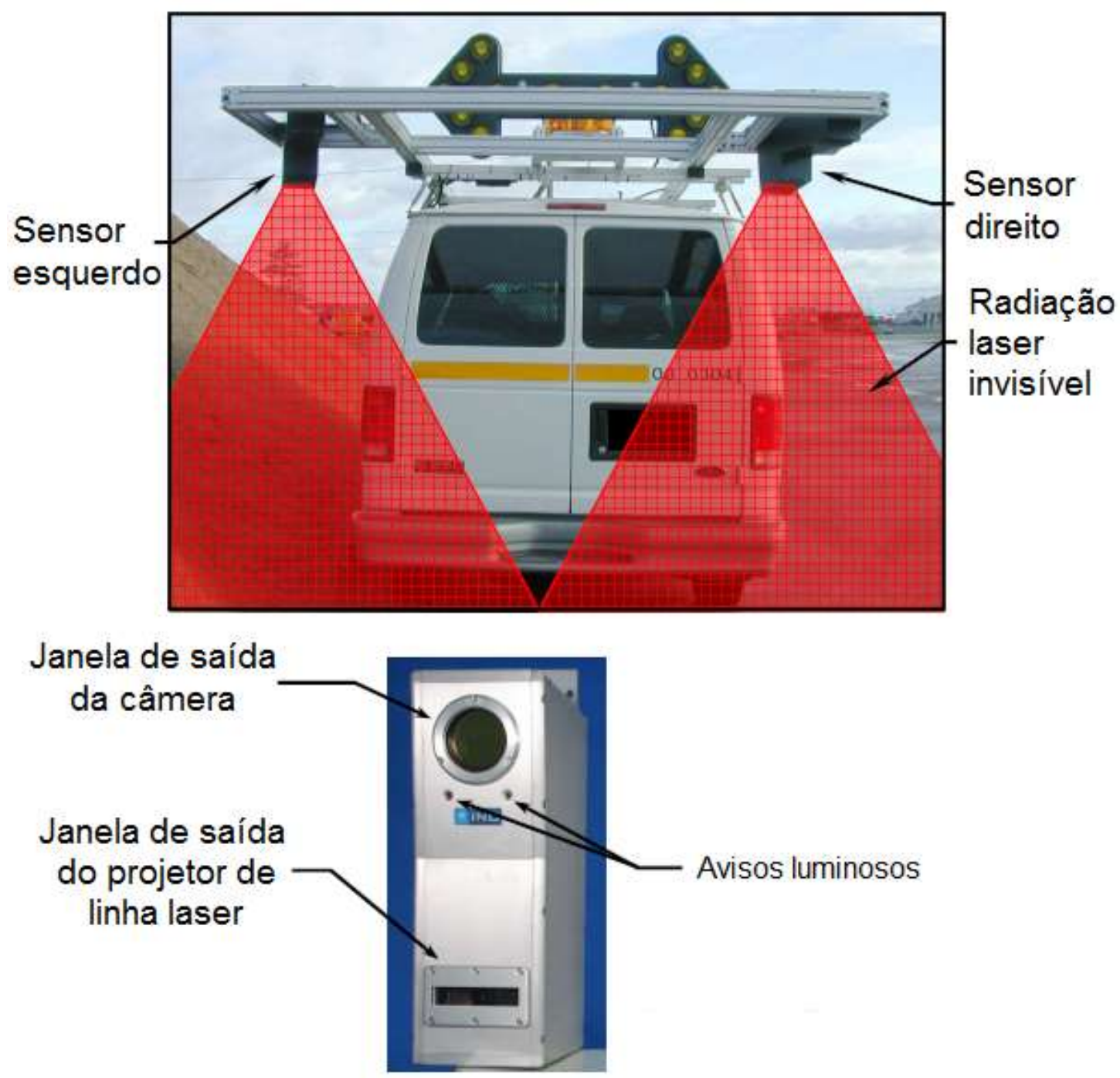

Figura 2.27 - Veículo de Inspeção com Unidades de Sensores a Laser (foto superior). Imagem de uma Unidade de Sensor a Laser, com o Projetor a Laser e Câmera (foto inferior) (adaptado do LCMS Manual, 2013) 
Um sinal do hodômetro é utilizado para sincronizar os dados adquiridos pelo sistema. Todas as imagens provenientes das câmeras são digitalizadas e então processadas pelo computador. Salvar as imagens brutas implicaria em um armazenamento de 30GB/km em uma velocidade de $100 \mathrm{~km} / \mathrm{h}$, mas utilizando algoritmos de compressão sem perda de dados na informação 3D e rápida compressão JPEG nos dados de intensidade, o armazenamento diminui para $720 \mathrm{MB} / \mathrm{km}$.

Os sensores do Pavement Scanner adquirem simultaneamente o perfil 3D e de intensidade da rodovia. A Figura 2.28 ilustra como os diversos tipos de dados são coletados pelo sistema do Pavement Scanner e podem ser explorados para identificar os diversos tipos de características do pavimento. Observa-se que a informação 3D e de intensidade servem para propósitos diferentes. Os dados de intensidade são necessários para a detecção da sinalização horizontal e de trincas seladas da pista, enquanto os dados 3D são utilizados para a detecção da maioria das outras características.

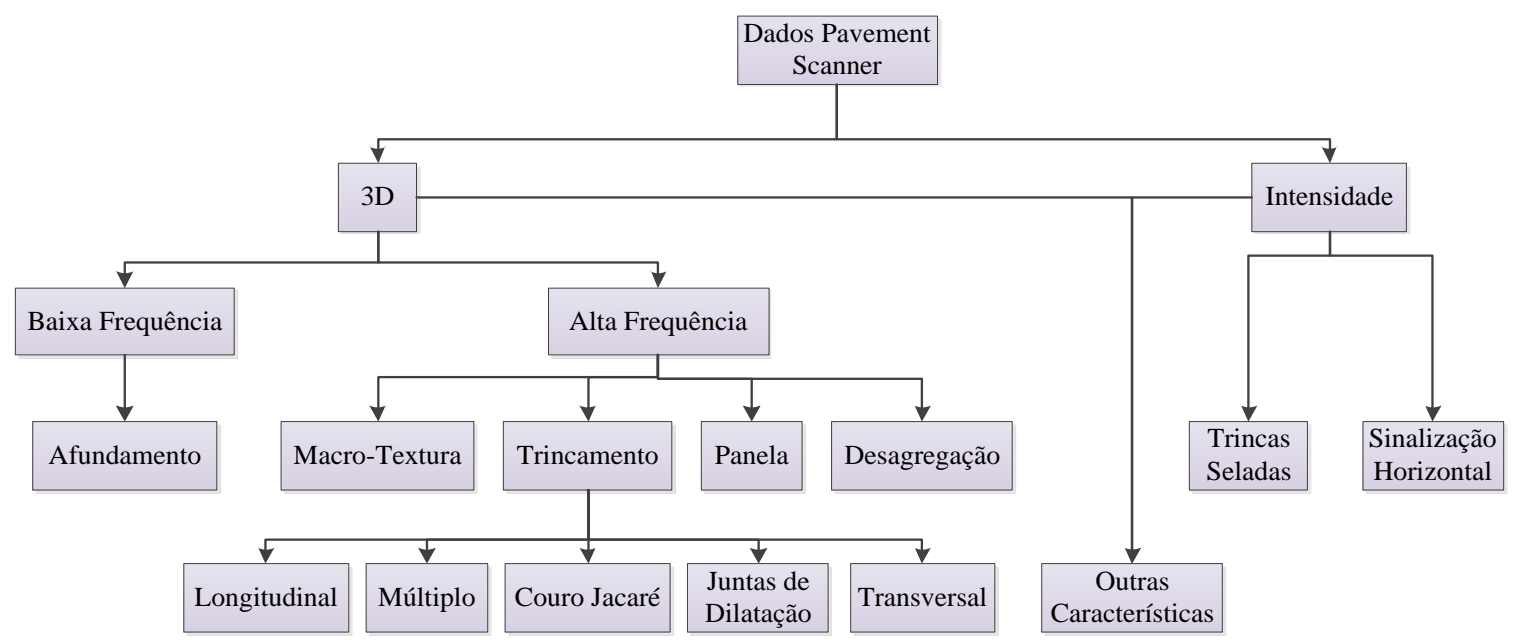

Figura 2.28 - Diagrama dos Resultados do 3D e da Intensidade no Pavement Scanner (adaptado do LCMS Manual, 2013)

O perfil de intensidade provisionado pelo sistema do Pavement Scanner é utilizado para formar uma imagem contínua da superfície da rodovia. Faixas altamente refletivas são muito mais fáceis de serem identificadas em $2 \mathrm{D}$ já que aparecem altamente contrastadas nas imagens. 
O primeiro propósito da informação de intensidade é a detecção dos limites de rodovia, através de algoritmo de identificação das linhas utilizadas na sinalização para se determinar a largura e a posição da faixa da rodovia com intuito de compensar os desvios do motorista. As informações de posição da faixa são então utilizadas por outros algoritmos de detecção para circunscrever a análise dentro da região de interesse de forma a evitar a análise de defeitos fora pista. No caso de rodovias em que não há sinalização horizontal, a delimitação é realizada a partir dos dados processados de degrau entre pista e acostamento.

Os dados 3D obtidos pelo sistema do Pavement Scanner medem a distância entre o sensor e superfície para cada ponto avaliado na rodovia. A Figura 2.29 (a) mostra a modelagem dos dados adquiridos pelos sensores. Nesta imagem, a elevação foi convertida para uma escala de cinza, em que quanto mais escuro o ponto, menor é a cota da superfície. Na modelagem, a altura pode variar ao longo da seção transversal da rodovia. As áreas da trilha de roda podem ser mais profundas do que as áreas adjacentes e assim, aparecerem mais escuras, podendo corresponder à presença de afundamentos. A maioria das funcionalidades que têm de ser detectadas estão localizadas na porção de alta frequência espacial da modelagem, contudo, variações de altura também podem ser observadas na direção longitudinal devido às variações nos perfis longitudinais da rodovia, causando movimentos na suspensão do veículo, correspondendo ao conteúdo de baixa frequência espacial das informações da modelagem no sentido longitudinal. 


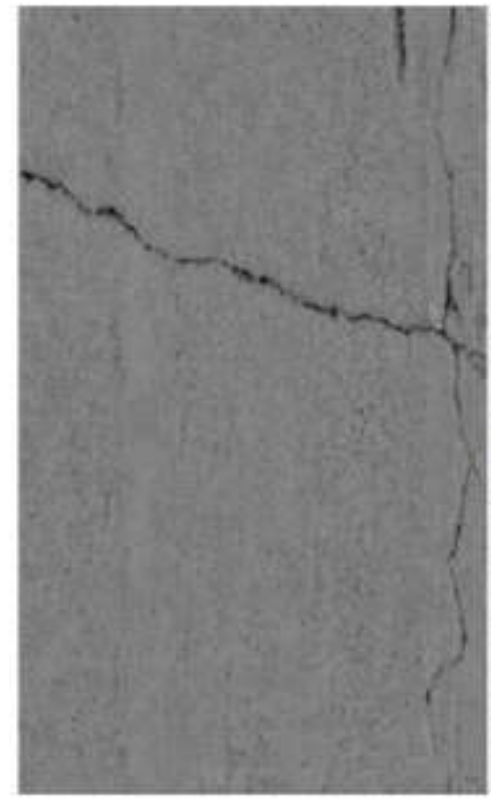

(a)

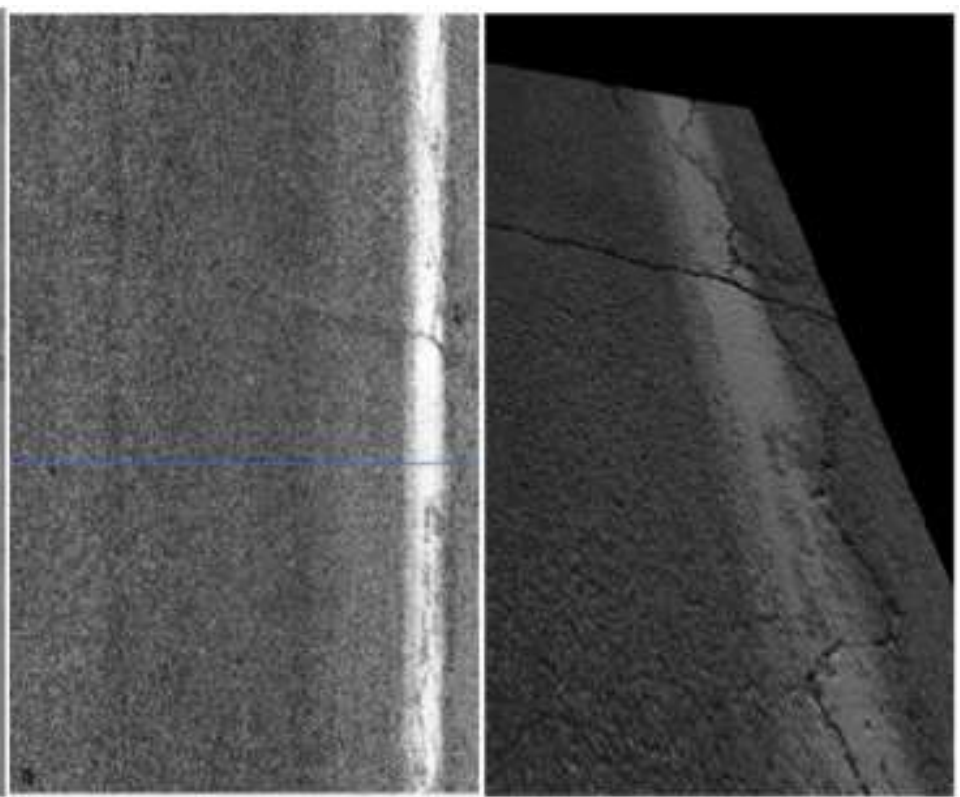

(b)

(c)

Figura 2.29 - Dados da Modelagem (a), Dados de Intensidade (b), Mistura dos Dois Dados (c)

Com o intuito de medir o perfil longitudinal, inclinação e declividade com um alto grau de precisão foram adicionados unidades de medidas inerciais - IMU aos sensores. Os IMU são compostos por três eixos acelerômetros e giroscópios, em que o eixo vertical do IMU (gravidade) é cuidadosamente alinhado ao mesmo plano que os lasers dos sensores 3D. Este alinhamento permite uma referência direta do sistema de coordenadas do IMU com os sensores 3D, permitindo a fusão dos dados de ambos os tipos de sensores. A Figura 2.30 ilustra o IMU no sensor.

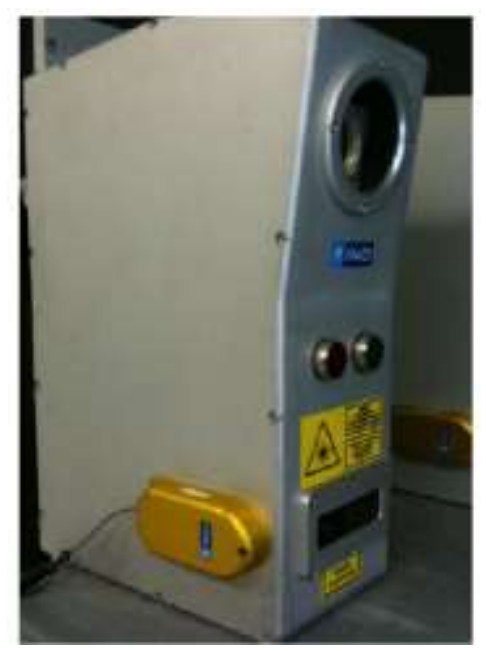

Figura 2.30 - IMU (dourado) Inserido nos Sensores do Pavement Scanner 
O perfil longitudinal é medido por meio da integração do sinal vertical (G) e do acelerômetro (eixo z), com o intuito de medir o deslocamento vertical total do veículo e o perfil da estrada, enquanto subtrai as variações da distância entre o veículo e a estrada, como medido diretamente pelos sensores 3D. $\mathrm{O}$ acelerômetro permite a remoção das variações no perfil longitudinal, que são causadas pela suspensão do veículo, quando o veículo atinge solavancos na estrada. Esses sensores e o IMU também devem ser cuidadosamente sincronizados para que todo o processo funcione com precisão.

As principais características do Pavement Scanner são:

- Detecção automática de fissuras e severidade;

- $\quad$ Medidas de macrotextura;

- $\quad$ Detecção de defeitos em superfícies asfálticas e de concreto;

- $\quad$ Alta resolução (1 mm);

- $\quad$ Perfil longitudinal (IRI - International Roughness Index);

- Inclinação transversal e longitudinal.

As especificações do sistema, segundo o manual do LCMS são:

- $\quad$ Número de perfis a laser: 2;

- Velocidade de aquisição: de 5600 perfis/segundo até 11200 perfis/segundo;

- 4096 pontos na trilha de roda;

- Dados 3D e 2D para caracterização: fissuras, panelas, desagregação, trincamentos, juntas no concreto, etc.;

- Velocidade do veículo: de $0 \mathrm{~km} / \mathrm{h}$ até $100 \mathrm{~km} / \mathrm{h}$;

- $\quad$ Espaço entre os perfis: de 1 até $5 \mathrm{~mm}$ (ajustável);

- $\quad$ Largura transversal de visão: 4 m;

- $\quad$ Precisão transversal: $1 \mathrm{~mm}$;

- $\quad$ Resolução transversal: 4096 pontos/perfil;

- $\quad$ Profundidade de visão: $250 \mathrm{~mm}$ (ajustável);

- $\quad$ Precisão (em profundidade): 0,5 mm; 
- $\quad$ Dimensões do perfil do laser: $428 \mathrm{~mm}$ (altura) x $265 \mathrm{~mm}$ (largura) x $139 \mathrm{~mm}$ (profundidade);

- $\quad$ Peso: $10 \mathrm{~kg}$ (por sensor);

- $\quad$ Consumo de energia (máx.): $150 \mathrm{~W}$ a 120/240 VAC.

\subsubsection{Descrição dos Módulos de Processamento do Pavement Scanner}

O Pavement Scanner possui uma biblioteca de processamento automatizada, o LCMS, entretanto alguns parâmetros de processamento podem ser configurados pelo usuário com base em suas necessidades específicas. Podem ser alterados os parâmetros relativos ao trincamento (área, largura e espessura do trincamento), marcas no pavimento, macrotextura, afundamento e degrau. O tempo para o processamento dos dados é variável de acordo com o grau de detalhamento dos arquivos de saída, conforme apresentado a seguir, em que os tempos consideram a alocação de uma equipe para tratamento dos dados:

- Tempo 1 - processamento dos arquivos originais: $3 \mathrm{~h}$ para cada $100 \mathrm{~km}$ (contínuos);

- Tempo 2 - análise dos dados processados e processamento no programa excel: 10 a $16 \mathrm{~h}$ para cada $100 \mathrm{~km}$ (contínuos);

- Tempo 3 - montagem das fichas de campo (IGG, LVC, LVD, IRI): 6 a $8 \mathrm{~h}$ para cada 100 km (contínuos);

- Tempo 4 - conferência com fotos (quando necessário): varia de 8 a $12 \mathrm{~h}$ para cada $100 \mathrm{~km}$ (contínuos).

\section{Trincamento}

O módulo de detecção do trincamento é, certamente, o módulo de processamento mais complexo. Para qualquer seção de rodovia, a biblioteca irá identificar a lista de trincamento existente e associar sua gravidade através da largura. A detecção deste 
defeito é realizada a partir da imagem (3D) dos dados, para o qual é aplicado um limite de profundidade de forma a identificar potenciais trincamentos.

O parâmetro de limite de profundidade é determinado automaticamente pela biblioteca utilizando a informação da textura local da superfície da via. A imagem resultante de potenciais trincamentos é então processada para remover falsas trincas isoladas, que normalmente são causadas por asperezas nas superfícies da rodovia. $\mathrm{O}$ último passo do algoritmo de detecção de trincas é juntar as trincas remanescentes, a fim de formar segmentos contínuos.

Os dados do perfil em 3D precisam ser separados em efeitos do trincamento e em movimentos do veículo. A macrotextura é também um problema, pois as vias têm macrotextura muito variável de uma seção para outra, ou mesmo a partir de um lado da faixa para a outra. Por exemplo, em rodovias com menor valor de macrotextura, pode-se esperar detectar trincas bem pequenas, as quais seriam dificilmente observáveis em pavimentos mais texturizados. Assim, é necessário avaliar e adaptar as operações de processamento com base na macrotextura e tipo de superfície do pavimento.

Uma vez que a operação de detecção é realizada, uma imagem binária é obtida onde pixels ativos restantes são possíveis fissuras. Esta imagem binária é então filtrada para remover as detecções falsas, que são causadas por asperezas e outras características da superfície do pavimento que não sejam fissuras no pavimento. Neste ponto, no processamento, a maioria dos pixels restantes pode ser corretamente identificada como trincas existentes, no entanto muitos destes trincamentos precisam ser agrupados para evitar detecções múltiplas do mesmo trincamento. Os trincamentos são agrupados em duas categorias principais: trincamentos longitudinais e transversais. Além disso, trincas longitudinais são ainda refinadas em três subcategorias: simples, múltiplas e jacaré.

Após o processo de detecção, o passo seguinte consiste na caracterização do trincamento. O nível de gravidade de um trincamento é determinado através da 
avaliação da sua largura (abertura), sendo separados em graus de severidade baixo, médio e alto.

Segundo Laurent e Hébert (2008), foi realizado um levantamento em uma malha de 10.000 km no Canadá, sob o gerenciamento e supervisão do Ministério de Transportes de Quebéc (MTQ), onde o pavimento foi levantado pelo Pavement Scanner e então seus resultados de trincamento foram analisados visualmente e manualmente em seções de $10 \mathrm{~m}$, sendo a compatibilidade categorizada em três classes (bom, médio e ruim), além de uma classe não disponível (ND) utilizada quando não havia possibilidade de se avaliar corretamente uma seção. A Tabela 2.15 apresenta os resultados da compilação da avaliação manual, em que os resultados finais são considerados excelentes, já que a classificação geral "Bom” chega a 96,5\%.

Tabela 2.15 - Resultados Finais dos $10.000 \mathrm{~km}$ Inventariados pelo Pavement Scanner e Posteriormente Classificado Manualmente (adaptado de LAURENT e HÉBERT; 2008)

\begin{tabular}{|c|c|c|c|c|c|c|c|c|c|}
\hline \multirow[b]{3}{*}{ Distrito } & \multirow{3}{*}{$\begin{array}{c}\text { Total } \\
\text { (seções } \\
10 \mathrm{~m})\end{array}$} & \multicolumn{8}{|c|}{ Resultados (classificação manual) } \\
\hline & & \multicolumn{4}{|c|}{ Número de imagens (seções 10m) } & \multicolumn{4}{|c|}{ Proporção (\%) } \\
\hline & & Bom & Média & Ruim & $\begin{array}{c}\text { Não } \\
\text { disponível } \\
\text { (ND) }\end{array}$ & Bom & Média & Ruim & \begin{tabular}{|c|} 
Não \\
disponível \\
(ND)
\end{tabular} \\
\hline 84 & 35.288 & 34.144 & 310 & 144 & 690 & 96,8 & 0,9 & 0,4 & 2,0 \\
\hline 85 & 4.243 & 4.101 & 53 & 51 & 38 & 96,7 & 1,2 & 1,2 & 0,9 \\
\hline 86 & 147.903 & 144.040 & 516 & 1.520 & 1.827 & 97,4 & 0,3 & 1,0 & 1,2 \\
\hline 87 & 149.926 & 138.453 & 1.170 & 5.728 & 4.575 & 92,3 & 0,8 & 3,8 & 3,1 \\
\hline 88 & 189.097 & 183.010 & 1.064 & 2.002 & 3.021 & 96,8 & 0,6 & 1,1 & 1,6 \\
\hline 89 & 125.003 & 121.835 & 442 & 2.015 & 711 & 97,5 & 0,4 & 1,6 & 0,6 \\
\hline 90 & 123.653 & 116.930 & 2.980 & 2.434 & 1.309 & 94,6 & 2,4 & 2,0 & 1,1 \\
\hline $91 \& 92$ & 215.513 & 213.142 & 197 & 956 & 1.218 & 98,9 & 0,1 & 0,4 & 0,6 \\
\hline Total & 990.626 & 955.655 & 6.732 & 14.850 & 13.389 & 96,5 & 0,7 & 1,5 & 1,4 \\
\hline
\end{tabular}

Uma segunda avaliação foi realizada em 770 quilômetros da rede rodoviária do MTQ, utilizando 77.000 imagens de 10m, seções adquiridas pelo sistema LCMS que foram comparadas a imagens das mesmas seções levantada por vídeo-registro. Neste estudo, uma análise mais detalhada foi realizada para avaliar a capacidade do LCMS para detectar e classificar corretamente os seguintes defeitos: trincas longitudinais, trincas transversais, remendos e panelas. Novamente, cada seção $10 \mathrm{~m}$ foi analisada visualmente e os resultados de detecção foram classificados da seguinte forma: Muito menos (faltando duas ou mais trincas), Menos (faltando uma trinca), Bom, Mais (1 ou mais detecções falsas). A Tabela 2.16 resume estes resultados. 
Tabela 2.16 - Resultados Finais dos $770 \mathrm{~km}$ Inventariados pelo Pavement Scanner e Comparados aos Dados de Vídeo-Registro (adaptado de LAURENT e HÉBERT; 2008)

\begin{tabular}{l|c|c|c|c|c|c|c|c}
\hline \multirow{2}{*}{\begin{tabular}{c}
\multirow{2}{*}{$\begin{array}{c}\text { Tipo de } \\
\text { defeito }\end{array}$} \\
\cline { 2 - 9 }
\end{tabular}} & \multicolumn{6}{c}{ Númesultados (classificação manual de 77.000 imagens) } \\
\cline { 2 - 9 } & $\begin{array}{c}\text { Muito } \\
\text { menos }\end{array}$ & Menos & Bom & Mais & $\begin{array}{c}\text { Muito } \\
\text { menos }\end{array}$ & Menos & Bom & Mais \\
\hline $\begin{array}{l}\text { Trincamentos } \\
\text { longitudinais }\end{array}$ & 632 & 1.040 & 53.429 & 854 & 1,1 & 1,9 & 95,5 & 1,5 \\
\hline $\begin{array}{l}\text { Trincamentos } \\
\text { transversais }\end{array}$ & 1.426 & 5.948 & 13.962 & 744 & 6,5 & 26,9 & 63,2 & 3,4 \\
\hline $\begin{array}{l}\text { Remendos } \\
\text { Panelas }\end{array}$ & 430 & 1.210 & 4.926 & 95 & 6,5 & 18,2 & 74,0 & 1,4 \\
\hline
\end{tabular}

Em geral, os resultados se apresentaram muito bons, exceto para o que poderia ser esperado para a detecção de trincas transversais. A tabela indica que um grande número de trincas transversais não foram levantadas $(33,4 \%)$, no entanto, a maioria dessas trincas ausentes foram trincas transversais completas que foram detectadas como trincamento incompleto $(80 \%)$.

\section{Macrotextura}

O módulo de processamento da macrotextura mede a textura da superfície do pavimento em cada uma das cinco bandas AASHTO: a faixa central, as duas bandas da trilha de roda, e as duas bandas externas. $\mathrm{O}$ algoritmo baseia-se em um "método de mancha de areia digital" que calcula o volume de vazios de ar contido entre uma superfície digital 3D e a própria superfície do pavimento. A saída é um valor de profundidade média da textura, ou mean texture depth (MTD), que é semelhante ao método de mancha de areia manual descrita na norma ASTM E965: “Método de teste padrão para medição da profundidade de textura do pavimento de profundidade utilizando uma técnica volumétrica".

O sistema do Pavement Scanner obtém dados suficientes para não apenas medir o padrão MTD, mas também avaliar a textura usando modelo digital do método de 
correção de areia (ASTM E965). O modelo de correção de areia é calculado usando o índice de porosidade de rodovia (RPI). O índice RPI é definido como o volume de vazios na superfície da rodovia que seria ocupado por areia (a partir do método de correção de areia) dividido pela área de superfície. Este modelo permite que a textura seja avaliada continuamente por toda a superfície da rodovia, ao invés de medir apenas em um ponto único dentro da trilha de roda.

\section{Afundamento}

O módulo de processamento do afundamento permite ao usuário recuperar as informações do referido defeito (profundidade e largura da seção transversal) para uma seção de rodovia específica. O cálculo do afundamento é baseado na norma ASTM E1703 "Método de Teste Padrão para Medição da Profundidade do Afundamento utilizando uma Régua". Este método bem conhecido mede a profundidade do sulco do afundamento em uma localização escolhida na superfície do pavimento usando uma régua e uma escala.

A biblioteca de processamento do Pavement Scanner calcula dois sulcos por perfil: os sulcos da trilha de roda esquerda e direita. O número de medidas de afundamento que devem ser calculados por seção de rodovias pode ser configurado pelo usuário. A Figura 2.31 (a), (b) e (c) ilustra os afundamentos com raio grande e médio, além do pavimento com múltiplos afundamentos. 

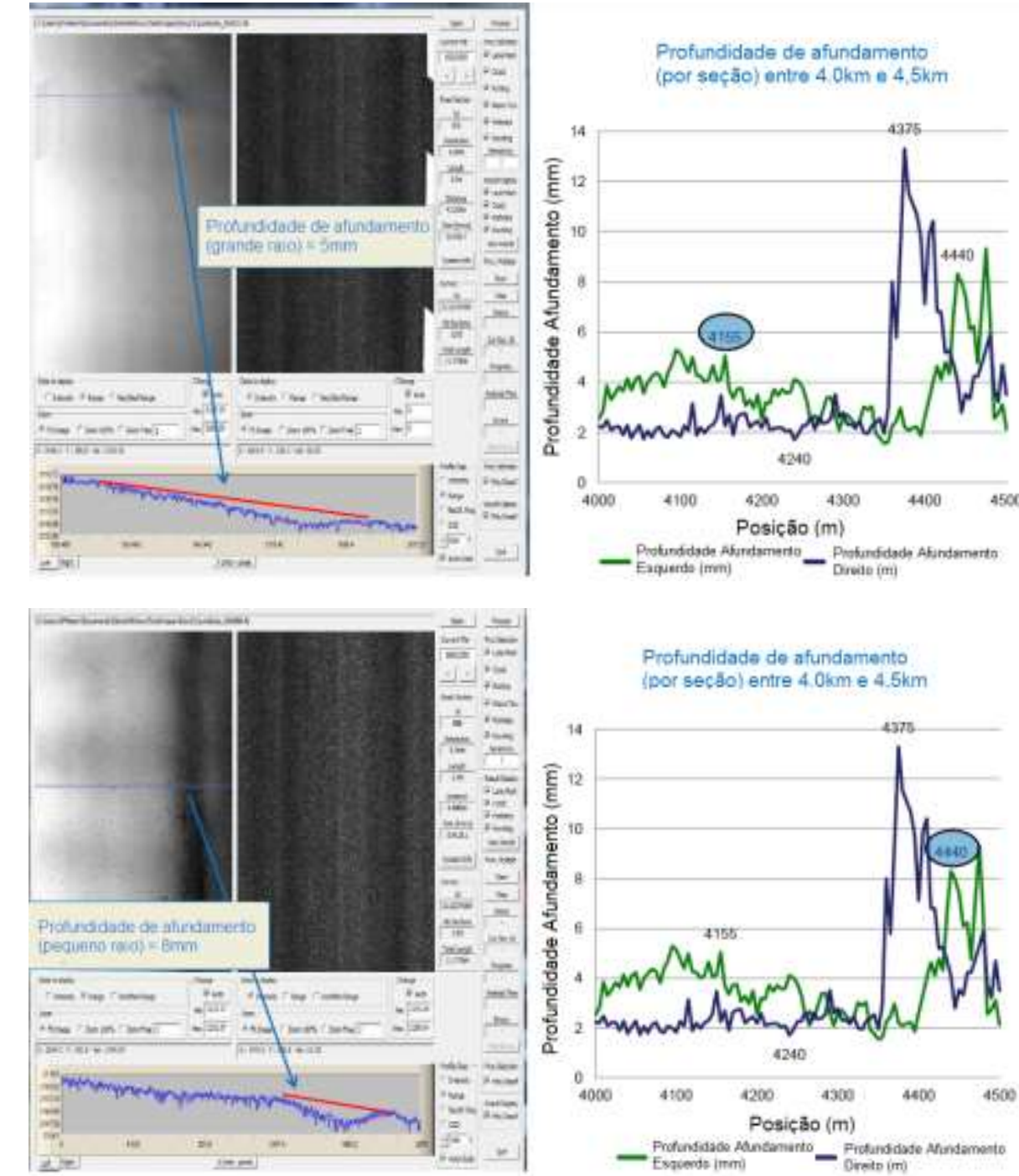

(a)
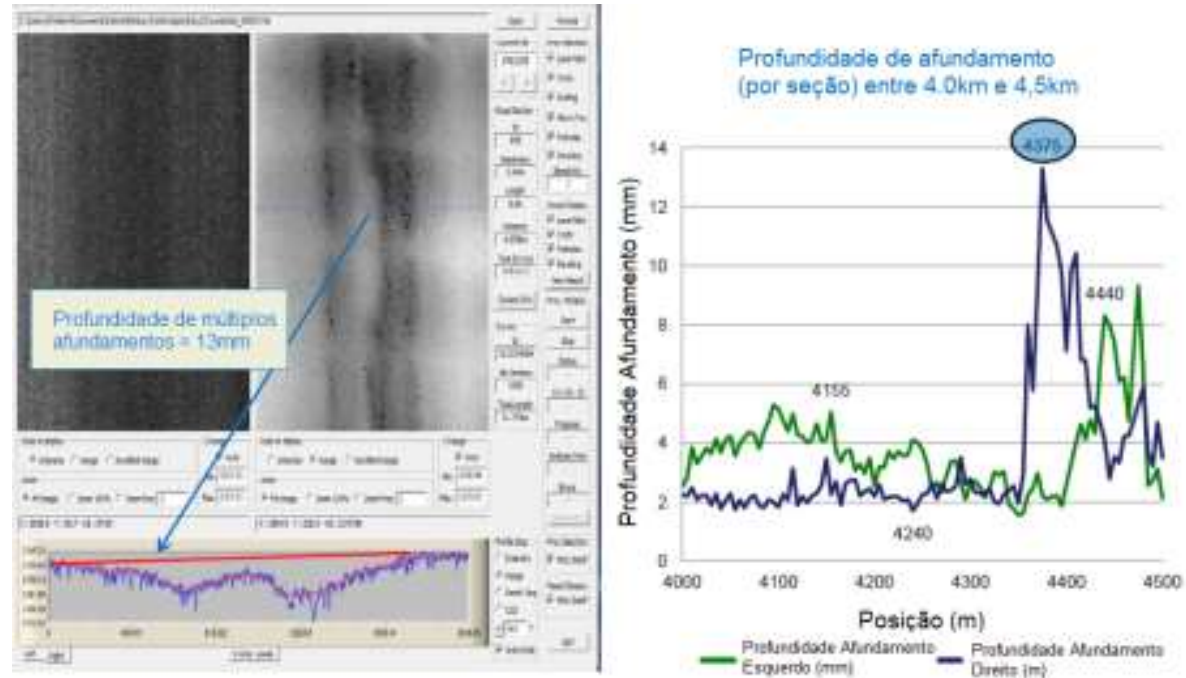

(b)

Figura 2.31 - Exemplo de Afundamentos Processados no Pavement Scanner (a) Afundamento de Raio Grande, (b) Afundamento de Raio Pequeno, (c) Múltiplos Afundamentos. (adaptado do LCMS Manual, 2013) 
Está sendo utilizado um algoritmo de processamento do afundamento na trilha de roda, adaptado às normas brasileiras, que considera o afundamento localizado no ponto médio de uma régua de 1,2 m de largura, ou seja, na mesma dimensão da treliça metálica.

\section{Sinalização Horizontal}

O módulo de detecção da sinalização da pista retorna as posições das sinalizações/marcas da pista esquerda e direita da rodovia. Outros módulos de análise dos parâmetros do Pavement Scanner exploram a informação de faixa de sinalização. Por exemplo, a localização da sinalização horizontal é utilizada pelo módulo do afundamento, de modo que ambas trilhas de roda não excedam a largura da seção transversal da faixa de rodagem. Da mesma forma, o módulo de detecção de trincas mapeia apenas os trincamentos dentro das duas faixas de marcação. Além disso, as posições de marcação de pista são necessárias para determinar as posições utilizadas para as medições da macrotextura.

A Figura 2.32 exemplifica a utilização dos marcadores de faixa para corrigir desvios do motorista do veículo de levantamento.

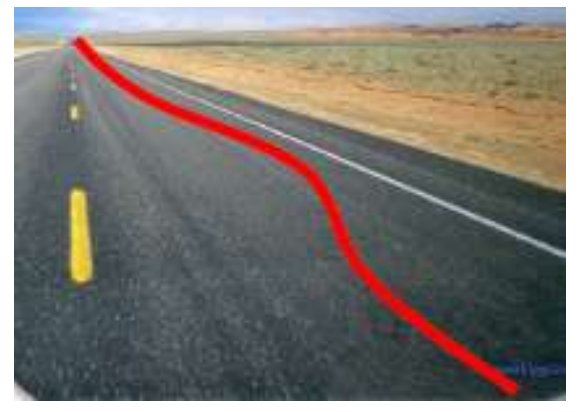

(a)

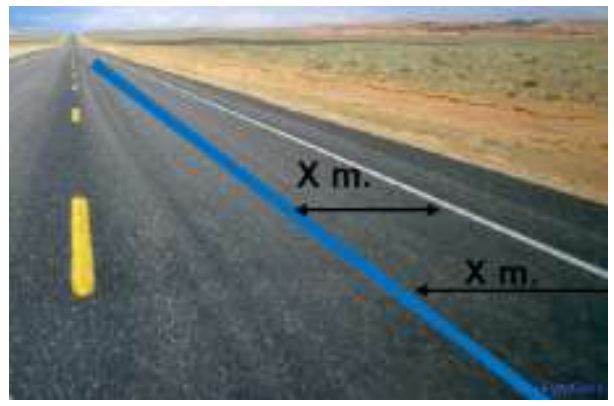

(b)

Figura 2.32 - Imagem do Sistema Clássico de Levantamento Dependendo da Trajetória do Veículo (a). Imagem do sistema do Pavement Scanner que utiliza as marcações de faixa para compensar desvios do motorista (b) (LCMS Manual, 2013) 


\section{Panelas}

Este módulo de processamento detecta as panelas na superfície do pavimento, podendo ser caracterizadas pela profundidade máxima, severidade, delimitação da área, diâmetro e perímetro.

O padrão de severidade da panela é determinado de acordo com os critérios definidos pela Federal Highway Administration - FHWA em seu "Manual de Identificação de Defeitos para o Programa de Desempenho a do Pavimento a Longo Prazo". Entretanto, como nos outros defeitos estudados, o padrão desse módulo pode ser modificado de acordo com as regulamentações de cada órgão. A Figura 2.33 mostra a detecção das panelas pelo Pavement Scanner.

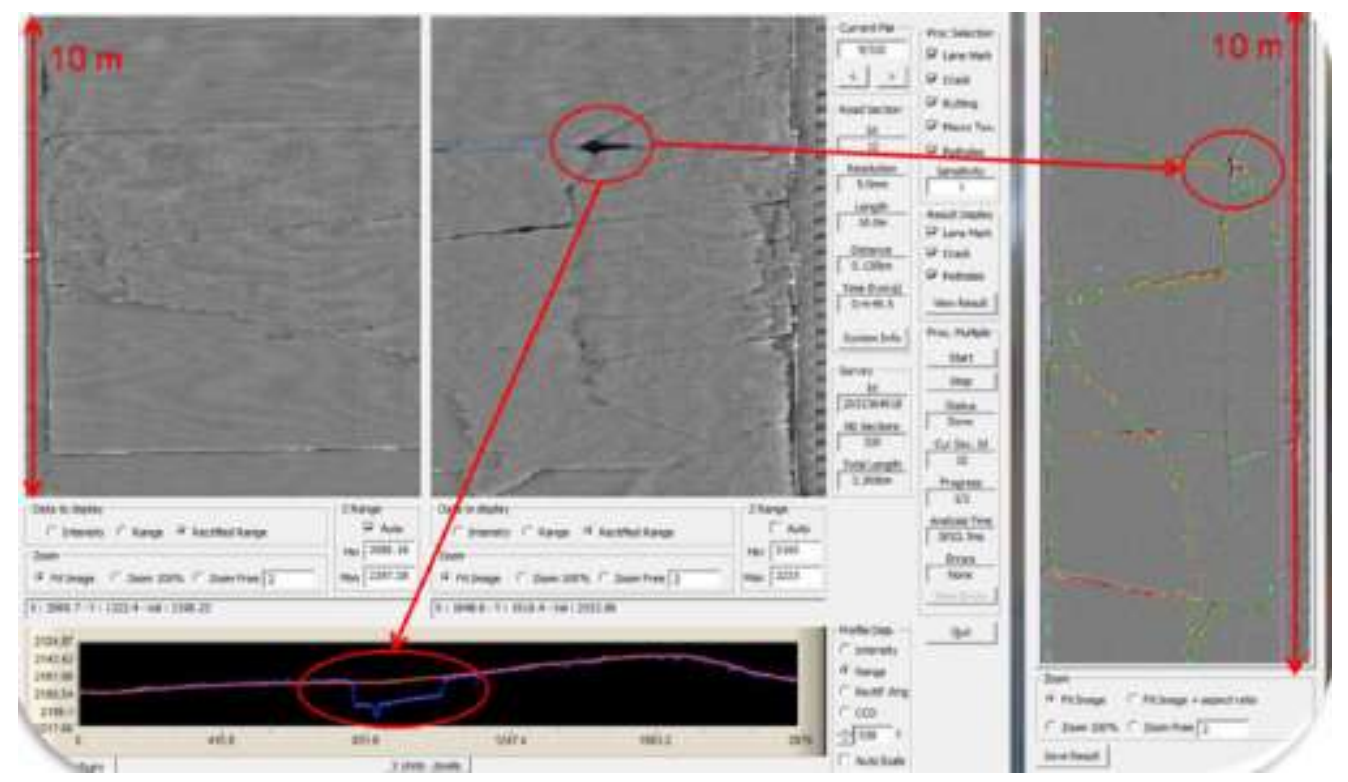

Figura 2.33 - Exemplo da Detecção de Panelas pelo Pavement Scanner

Nota-se que as áreas em que são detectadas as panelas são excluídas dos resultados do trincamento. 


\section{Degrau}

O módulo de degrau detecta e retorna a posição e altura do degrau existente entre a pista e o acostamento. Bem como no caso da sinalização horizontal, a informação de degrau também pode ser explorada por outros módulos de processamento. Os locais de degrau são utilizados para posicionar a largura da seção transversal da faixa de rolamento, comparando-as com as posições das marcas de pista.

\section{Desagregação}

A fim de detectar e quantificar as condições de desagregação é proposto um índice desagregação (RI, do inglês Ravelling Index). O RI é calculado através da medição da perda de volume de agregado (redução de volume devido a ausência de agregados) por unidade de área de superfície (metro quadrado). A elevada resolução dos dados em 3D permite a detecção de agregados ausentes. Algoritmos concebidos para detectar especificamente a perda de agregados foram desenvolvidos a fim de avaliar o RI automaticamente. A Figura 2.34 demonstra os resultados de detecção agregado (em azul) em imagens de profundidade.

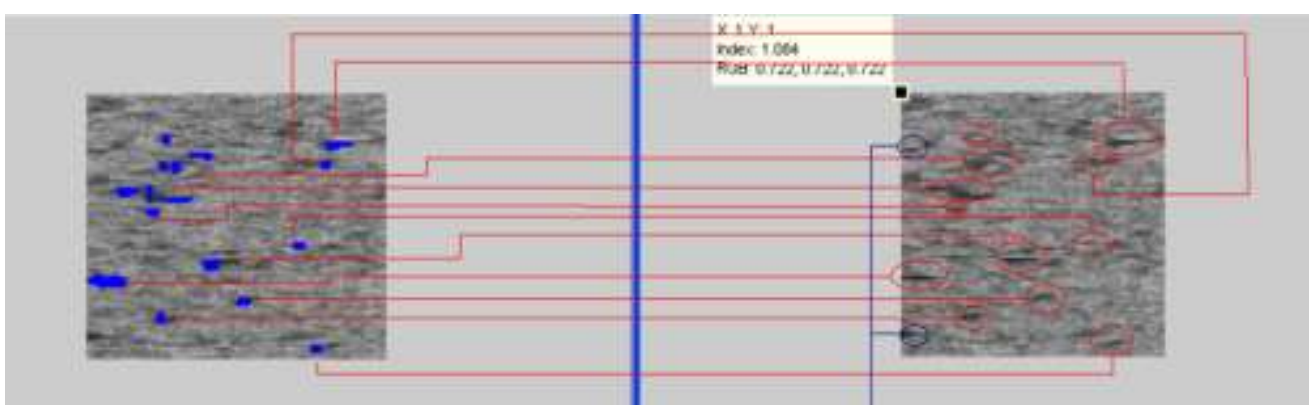

Figura 2.34 - Exemplo da Detecção Automática de Perdas de Agregado pelo Pavement Scanner 


\section{IRI (Índice de Irregularidade Internacional)}

O módulo para detecção da irregularidade pode ser utilizado para computar e salvar os dados dos perfis longitudinais da rodovia, bem como, para calcular o Índice de Irregularidade Internacional (IRI) a partir dos perfis longitudinais medidos.

Assim, os usuários têm duas opções: podem calcular os valores do IRI para os perfis longitudinais utilizando o software do Pavement Scanner ou podem recuperar os perfis longitudinais crus e, em seguida, calcular seu próprio índice de rugosidade (que pode ser diferente do IRI conhecido) utilizando qualquer software ou método.

O Pavement Scanner calcula dois perfis longitudinais da via, geralmente nas trilhas de roda, utilizando os pontos de dados 3D e das acelerações verticais. 


\section{METODOLOGIA DA PESQUISA}

\subsection{Definição da Metodologia da Pesquisa}

A pesquisa consiste na análise da aplicabilidade técnica e operacional do emprego do equipamento Pavement Scanner na avaliação funcional de pavimentos em rodovias brasileiras. O estudo busca uma solução de monitoramento de pavimentos que conjugue a coleta de informações de forma automática, sem a interferência do profissional encarregado pela atividade de inventário de superfície, em curto intervalo de tempo e processamento de dados também sistematizados, reduzindo-se as interferências com o tráfego e garantindo-se informações de rápida restituição e confiabilidade

Para tanto foram definidas e materializadas seções-teste ao longo de vias, inspecionadas utilizando os métodos usuais de avaliação de pavimentos estabelecidos nas normas e especificações nacionais, empregando-se para cada método equipes independentes nos levantamentos de campo. Com isso, objetiva-se não somente caracterizar cada uma das seções-teste, mas também verificar as possíveis discrepâncias que podem ser observadas em função de eventuais dependências dos resultados em relação aos profissionais que realizam as avaliações em pista.

Paralelamente foi disponibilizado um equipamento Pavement Scanner e treinadas duas equipes para utilização do mesmo nos levantamentos de campo, além de adaptadas as ferramentas de processamento de dados para gerar resultados conforme exigido nas normas nacionais. As duas equipes em questão procederam às avaliações das seçõesteste para estudo comparativo dos resultados entre si e em relação aos métodos "tradicionais".

Adicionalmente, foram aplicados os resultados obtidos pelo equipamento Pavement Scanner no cálculo do PCI (Pavement Condition Index) definido pelo método da NYSDOT (2003), onde os segmentos estudados foram classificados de acordo com o 
referido índice, podendo variar de zero (pavimento de péssima qualidade) a cem (pavimento excelente).

As etapas da pesquisa são compostas da seguinte forma:

1. Definição e demarcação de seção-teste de $320 \mathrm{~m}$ para dois diferentes tipos revestimentos: concreto betuminoso usinado a quente (CBUQ) e microrrevestimento a frio; distintas condições funcionais das vias avaliadas visualmente: rodovia com característica boa e de regular a ruim e diferentes características geométricas: pista simples e dupla.

2. Caracterização das seções-teste com emprego dos seguintes procedimentos:

- Avaliação de superfície nas faixas crescentes e decrescentes, 1 e 2, empregando-se os procedimentos da norma rodoviária DNIT 06/2003 PRO, com duas equipes distintas e utilização de formulário em papel;

- Avaliação de superfície nas faixas crescentes e decrescentes, 1 e 2, empregando-se os procedimentos da norma rodoviária DNIT 06/2003 PRO, porém de forma detalhada a cada 1 metro, com três equipes distintas e utilização de formulário em papel;

- Cadastro fotográfico do trecho para caracterização das estações de avaliação do pavimento, para cada uma das equipes de forma independente;

- Realização de três medidas de irregularidade longitudinal dos pavimentos em cada uma das seções-teste com equipamento tipo laser por três equipes distintas;

3. Testes e configuração do Pavement Scanner de forma a gerar resultados em conformidade com as normas brasileiras, bem como treinamento de duas equipes distintas para operação do equipamento;

4. Realização de duas avaliações utilizando-se o Pavement Scanner nas seçõesteste por duas equipes distintas; 
5. Repetição da etapa 4 supracitada por mais duas vezes, no dia e noite subsequente. Cada avaliação sendo realizada em três velocidades distintas (60, 70 e $80 \mathrm{~km} / \mathrm{h})$.

6. Estudo dos resultados de IGG entre as distintas técnicas de levantamento;

7. Estudo dos resultados de trincamento obtidos entre as distintas técnicas de levantamento;

8. Estudo dos resultados de afundamento na trilha de roda obtidos entre as distintas técnicas de levantamento;

9. Estudo dos resultados de irregularidade longitudinal obtidos pelo Pavement Scanner e pelo Perfilômetro Laser;

10. Análise da influência da velocidade nos levantamentos mecanizados;

11. Análise da influência da luminosidade nos levantamentos mecanizados;

12. Análise da influência do tipo de revestimento;

13. Análise da repetitividade de defeitos dos métodos tradicionais e mecanizados;

14. Resultados de repetitividade e reprodutividade entre as distintas técnicas de levantamento em conformidade com a ISO 5725-2 (1994);

15. Correlação entre o IGG e o PCI;

16. Análise do IGG em relação ao percentual amostral;

17. Análise da variabilidade do IGG com relação à posição inicial. 


\subsection{Definição das Seções-teste}

As seções-teste foram definidas tendo em vista diferentes combinações possíveis de variáveis, de forma que seja possível avaliar características diversas de rodovias. Assim, buscou-se pistas com 320 metros de extensão, seguindo-se os seguintes critérios de seleção:

- Diferentes tipos de Geometria: Pista Simples (faixa crescente e decrescente) e Pista Dupla (faixa 01 e 02);

- Diferentes tipos de revestimento: CBUQ e Microrrevestimento;

- Diferentes tipos de condição: boa e regular a ruim.

O interesse pelos diferentes tipos de geometria de pista objetiva avaliar se há diferença nos resultados obtidos pela avaliação mecanizada e tradicional, onde será considerada a dificuldade para levantamento na faixa 01 devido à alta velocidade dos veículos que nela trafegam, bem como, à dificuldade para se realizar o levantamento tradicional da referida faixa pelo acostamento.

Dois diferentes tipos de revestimentos foram avaliados objetivando a verificação se os resultados alcançados pelos diferentes métodos de levantamento serão compatíveis entre si.

A condição das seções-teste estudadas é uma variável importante, dado que as pistas em boas condições podem apresentar maior facilidade para a realização do ensaio mecanizado ou o tradicional, enquanto que as ruins, poderão demonstrar maior dificuldade. Além disso, foram avaliados os resultados para os mesmos operadores de ensaio para as diferentes pistas.

Desta forma, após visitas ao campo, foi possível selecionar 08 seções-teste (ST) no interior do estado de São Paulo, conforme numeração de ST-01 a ST-08 na Tabela 3.1 e mapa de situação apresentado na Figura 3.1. 
Tabela 3.1 - Planejamento das Seções-Teste para Ensaios

\begin{tabular}{|c|c|c|c|}
\hline \multicolumn{4}{|c|}{ Seções Teste } \\
\hline \multirow{2}{*}{$\begin{array}{c}\text { Tipo de } \\
\text { Revestimento }\end{array}$} & \multirow{2}{*}{ Condição } & \multicolumn{2}{|c|}{ Caracte rísticas Geométricas } \\
\hline & & Pista Simples & Pista Dupla \\
\hline \multirow{2}{*}{ CBUQ } & Boa & $\begin{array}{c}\text { Seção-Teste } \\
01\end{array}$ & $\begin{array}{c}\text { Seção-Teste } \\
02\end{array}$ \\
\hline & $\begin{array}{l}\text { Regular a } \\
\text { Ruim }\end{array}$ & $\begin{array}{c}\text { Seção-Teste } \\
03\end{array}$ & $\begin{array}{c}\text { Seção-Teste } \\
04\end{array}$ \\
\hline \multirow{2}{*}{ Micro } & Boa & $\begin{array}{c}\text { Seção-Teste } \\
05\end{array}$ & $\begin{array}{c}\text { Seção-Teste } \\
06\end{array}$ \\
\hline & $\begin{array}{l}\text { Regular a } \\
\text { Ruim }\end{array}$ & $\begin{array}{c}\text { Seção-Teste } \\
07\end{array}$ & $\begin{array}{c}\text { Seção-Teste } \\
08\end{array}$ \\
\hline
\end{tabular}




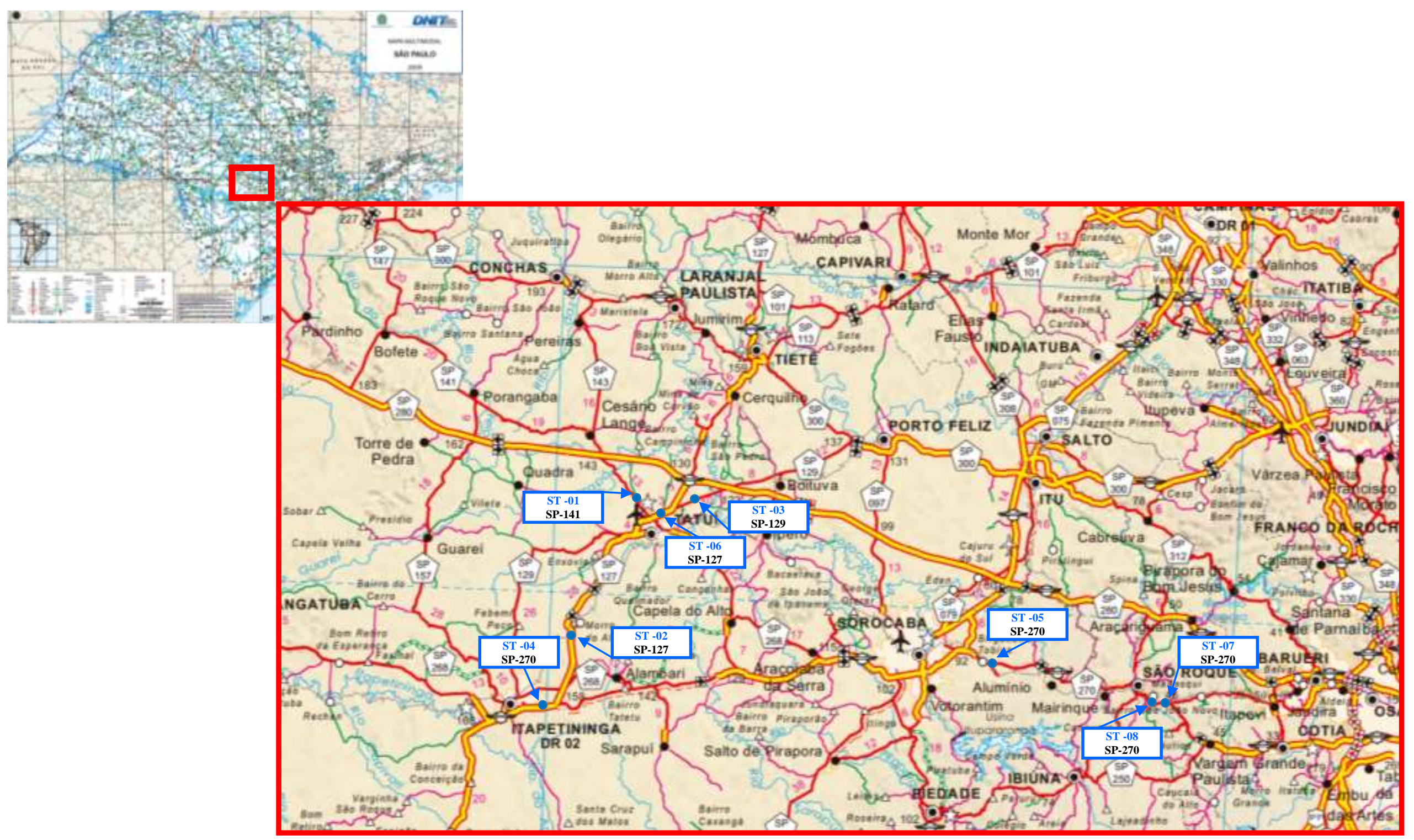

Figura 3.1 - Mapa de Situação das Seções-teste 
A seção-teste ST-01 está localizada na Rodovia SP-141 (Rodovia Mario Batista Mori), as seções-teste ST-04, ST-05, ST-07 e ST-08 estão localizadas na Rodovia SP-270 (Rodovia Raposo Tavares), as seções-teste ST-02 e ST-06 estão localizadas na Rodovia SP-127 (Rodovia Antônio Schincariol) e finalmente, a ST-03 está localizada na Rodovia SP-129 (Rodovia Gladys Bernardes). A Tabela 3.2 resume a localização, características geométricas, tipo de revestimento e condição de cada seção-teste avaliada.

Tabela 3.2 - Localização das Seções-Teste para Ensaios

\begin{tabular}{|c|c|c|c|}
\hline \multicolumn{4}{|c|}{ Seções-Testes } \\
\hline \multirow{2}{*}{$\begin{array}{c}\text { Tipo de } \\
\text { Revestimento }\end{array}$} & \multirow{2}{*}{ Condição } & \multicolumn{2}{|c|}{ Características Geométricas } \\
\hline & & Pista Simples & Pis ta Dupla \\
\hline \multirow{2}{*}{ CBUQ } & Boa & $\begin{array}{c}\text { Seção-Teste } 01 \\
\text { SP-141 } \\
\text { km } 34,50 \text { ao } 34,82\end{array}$ & $\begin{array}{c}\text { Seção-Teste } 02 \\
\text { SP-127 } \\
\text { km 137,00 ao 137,32 } \\
\text { Crescente }\end{array}$ \\
\hline & $\begin{array}{c}\text { Regular a } \\
\text { Ruim }\end{array}$ & $\begin{array}{c}\text { Seção-Teste } 03 \\
\text { SP-129 } \\
\text { km 27,30 ao } 27,62\end{array}$ & $\begin{array}{c}\text { Seção-Teste } 04 \\
\text { SP-270 } \\
\text { km 169,80 ao 169,48 } \\
\text { Decrescente }\end{array}$ \\
\hline \multirow{2}{*}{ Micro } & Boa & $\begin{array}{c}\text { Seção-Teste } \mathbf{0 5} \\
\text { SP-270 } \\
\text { km } 87,78 \text { ao } 88,10\end{array}$ & $\begin{array}{c}\text { Seção-Teste } 06 \\
\text { SP-127 } \\
\text { km 111,00 ao 111,32 } \\
\text { Crescente }\end{array}$ \\
\hline & $\begin{array}{c}\text { Regular a } \\
\text { Ruim }\end{array}$ & $\begin{array}{c}\text { Seção-Teste } 07 \\
\text { SP-270 } \\
\text { km 55,80 ao } 56,12\end{array}$ & $\begin{array}{c}\text { Seção-Teste } 08 \\
\text { SP-270 } \\
\text { km 57,00 ao 56,68 } \\
\text { Decrescente }\end{array}$ \\
\hline
\end{tabular}

As seções-teste acima relacionadas foram inventariadas pelo método tradicional e mecanizado na primeira semana de agosto de 2014, com extensão de pista de $320 \mathrm{~m}$ e 
de $640 \mathrm{~m}$ de faixa. Para as pistas simples, foram estudados os sentidos crescente e decrescente, já para as pistas duplas, foram estudadas as faixas 01 e 02.

O tráfego não foi considerado como um critério de seleção dos locais estudados, no entanto, seções com tráfego que variam de médio a elevado em muitos casos podem dificultar certos tipos de levantamentos, especialmente os tradicionais, devido à dificuldade de acesso à pista com segurança. Desta forma, a Tabela 3.3 descreve os volumes médios diários (VDM) extraídos juntos ao site de Departamento de Estradas de Rodagem do Estado de São Paulo (DER) para o ano de 2014. Não foram obtidos dados de tráfego da seção-teste 03 , porém pela percepção dos levantamentos realizados em campo, seu tráfego é baixo, inferior a 2.000 veículos por dia. 
Tabela 3.3 - VDM das Seções-Teste (Adaptado de DER - SP - Estatística do Volume Médio Diário da Rodovias, 2014)

\begin{tabular}{|c|c|c|c|}
\hline \multicolumn{4}{|c|}{ Seções-Testes } \\
\hline \multirow{2}{*}{$\begin{array}{c}\text { Tipo de } \\
\text { Revestimento }\end{array}$} & \multirow{2}{*}{ Condiçãa } & \multicolumn{2}{|c|}{ Caracterís ticas Geométricas } \\
\hline & & Pista Simples & Pista Dupla \\
\hline \multirow{2}{*}{ CBUQ } & $\begin{array}{c}\text { Boa a } \\
\text { Regular }\end{array}$ & $\begin{array}{c}\text { Seção-Teste } 01 \\
\text { VDM 4.078 } \\
(3.359 \text { pass }+719 \text { com })\end{array}$ & $\begin{array}{c}\text { Seção-Teste } 02 \\
\text { VDM } 3.226 \\
(2.143 \text { pass }+1.083 \text { com })\end{array}$ \\
\hline & Ruim & $\begin{array}{c}\text { Seção-Teste } 03 \\
\text { Sem dados de VDM } \\
\text { BAIXO }\end{array}$ & $\begin{array}{c}\text { Seção-Teste } 04 \\
\text { VDM } 9.069 \\
(6.885 \text { pass }+2.184 \text { com })\end{array}$ \\
\hline \multirow{2}{*}{ Micro } & $\begin{array}{c}\text { Boa a } \\
\text { Regular }\end{array}$ & $\begin{array}{c}\text { Seção-Teste } \mathbf{0 5} \\
\text { VDM } 9.365 \\
(7.942 \text { pass }+1.423 \text { com })\end{array}$ & $\begin{array}{c}\text { Seção-Teste } 06 \\
\text { VDM } 7.442 \\
(5.062 \text { pass }+2.380 \mathrm{com})\end{array}$ \\
\hline & Ruim & $\begin{array}{c}\text { Seção-Teste } 07 \\
\text { VDM } 28.050 \\
(25.561 \text { pass }+2.489 \mathrm{com})\end{array}$ & $\begin{array}{c}\text { Seção-Teste } 08 \\
\text { VDM } 28.050 \\
(25.561 \text { pass }+2.489 \mathrm{com})\end{array}$ \\
\hline
\end{tabular}

As Figuras 3.2 (a) a (h) ilustram os locais estudados. 


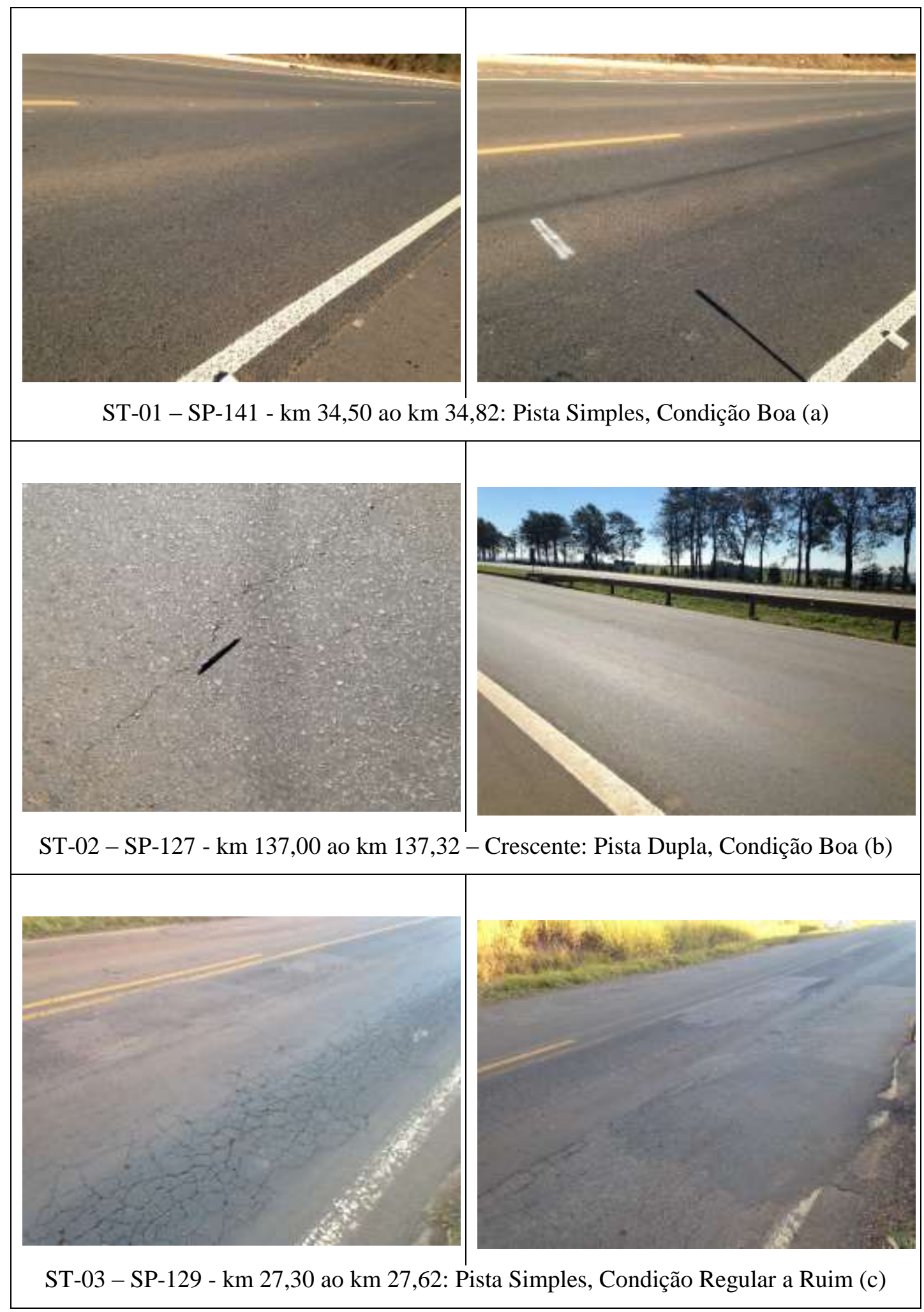

Figura 3.2 - Locais das Seções-teste para Ensaios 


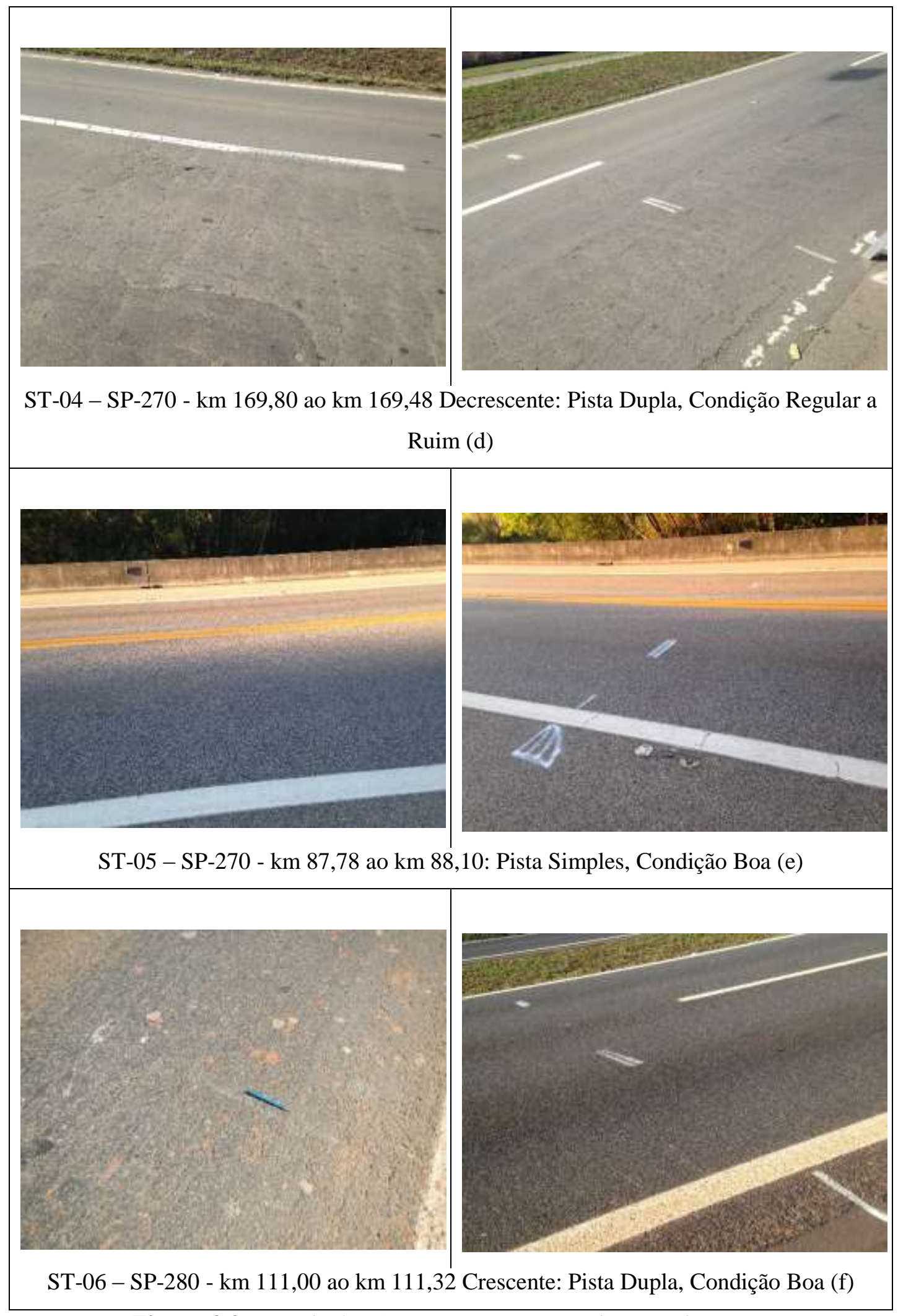

Figura 3.2 - Locais das Seções-teste para Ensaios (continuação) 


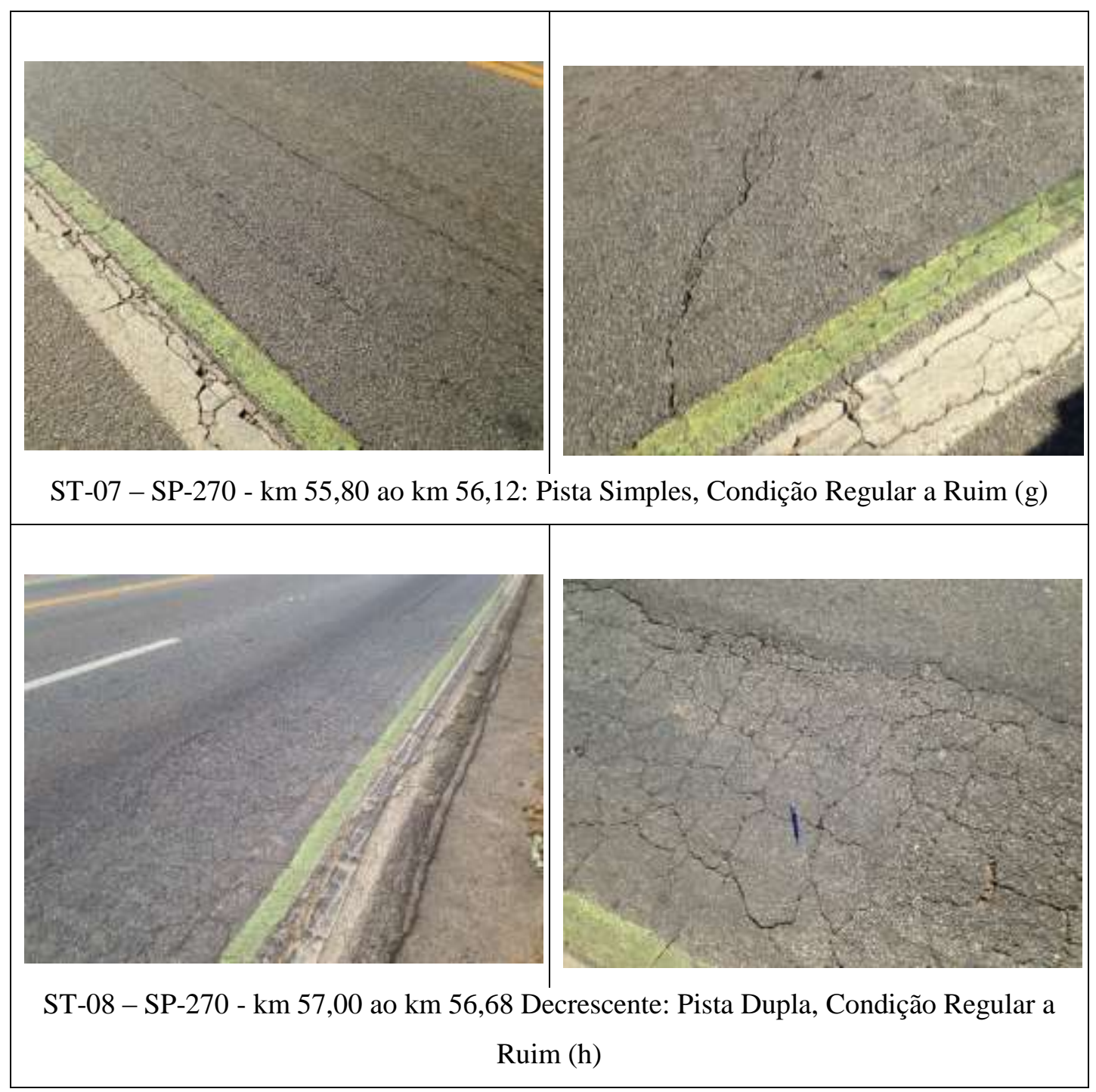

Figura 3.2 - Locais das Seções-teste para Ensaios (continuação)

\subsection{Levantamentos de Campo}

Após a seleção das seções-teste, foi realizada a marcação com tinta branca na pista (em ambas as faixas analisadas). Para as análises em pistas simples, a marcação foi realizada no início e fim de cada faixa, já para a pista dupla, somente no início de cada faixa. Essa marcação tem por objetivo definir o início de cada seção a ser analisada, visando a evitar distorções na análise e verificação dos dados levantados pela forma tradicional ou mecanizada. 
As Figuras 3.3 e 3.4 ilustram a marcação de faixa em algumas das seções-teste estudadas.

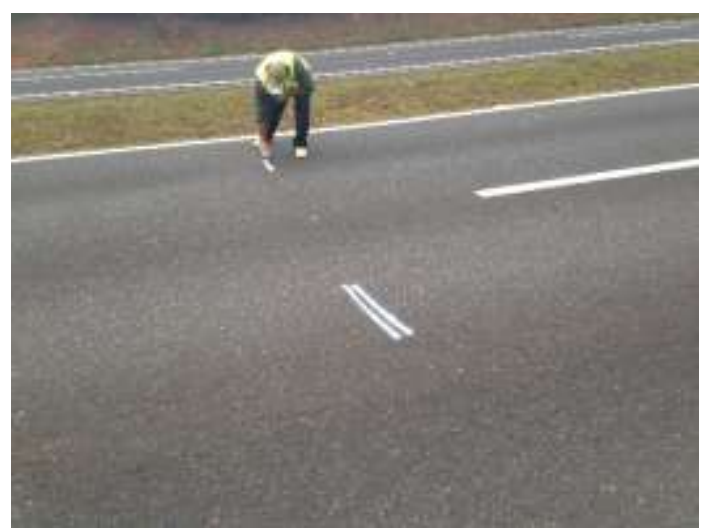

Figura 3.3 - Marcação com Tinta Branca em Pista Dupla

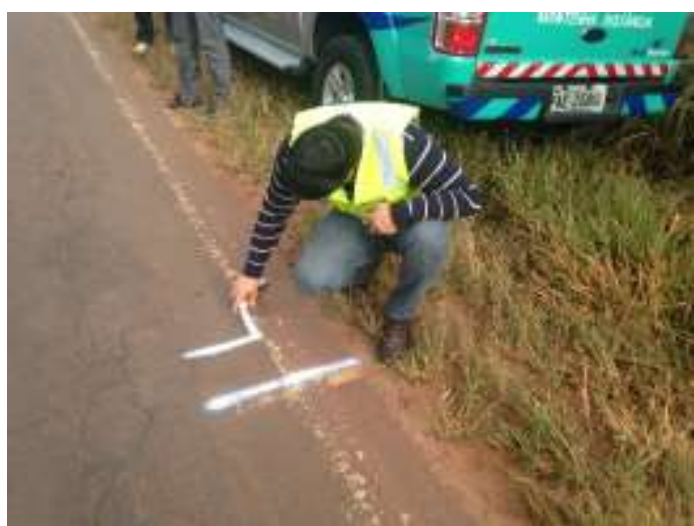

Figura 3.4 - Marcação com Tinta Branca em Pista Simples

Posteriormente, foram realizados os levantamentos, seguindo-se ordem cronológica listada:

1. Levantamento com Pavement Scanner;

2. Levantamento com Perfilômetro Laser;

3. Levantamento visual dos defeitos.

\subsubsection{Levantamentos com Pavement Scanner}

Foram realizados os levantamentos mecanizados com a utilização do Pavement Scanner, conforme apresentados na Figura 3.5. 


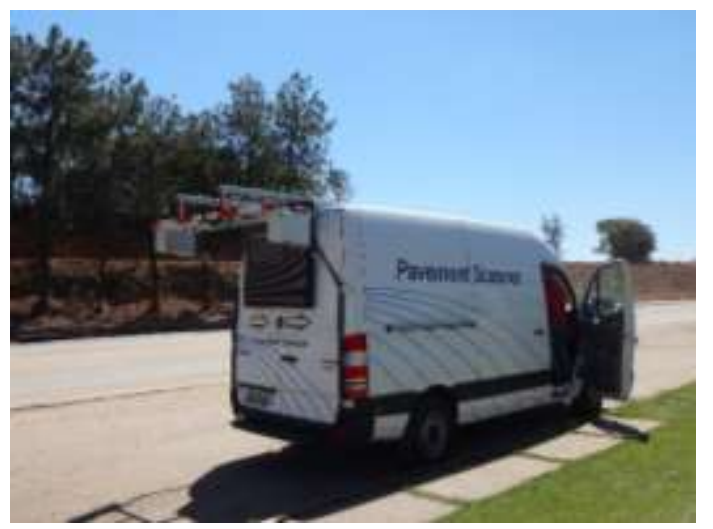

(a)

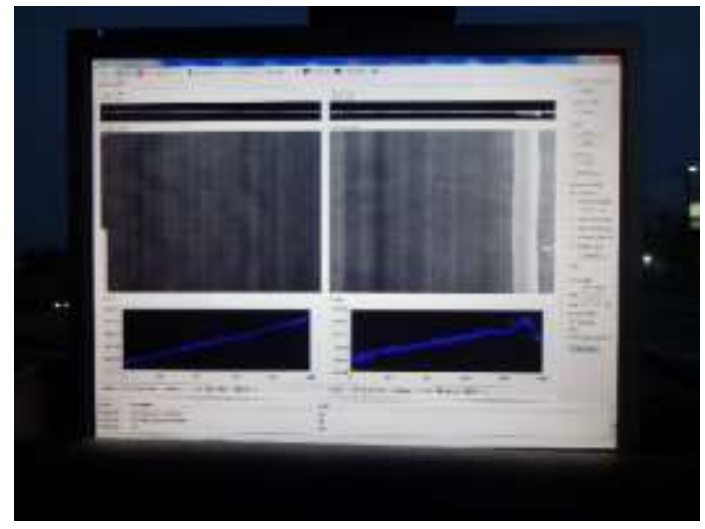

(b)

Figura 3.5 - Levantamento com Pavement Scanner. Imagem do Equipamento (a). Imagem da Tela de Levantamento no Interior do Veículo do Equipamento (b).

O inventário foi executado por duas equipes distintas em uma mesma campanha (campanha 01), durante o dia, na velocidade de $70 \mathrm{~km} / \mathrm{h}$. Adicionalmente, foi realizada outra campanha (campanha 02), em três velocidades distintas, 60, 70 e $80 \mathrm{~km} / \mathrm{h}$, no dia e noite. A Tabela 3.4 descreve as campanhas realizadas.

Tabela 3.4 - Descrição das Campanhas Realizadas com o Pavement Scanner

\begin{tabular}{c|c|c|c|c|c|c|c}
\hline \multirow{2}{*}{ Equipe } & \multicolumn{6}{|c}{ Número de Avaliações } \\
\cline { 2 - 8 } & Campanha 01 & \multicolumn{5}{c}{ Dia } & \multicolumn{4}{c}{ Noite } \\
\cline { 2 - 8 } & $\begin{array}{c}\text { Deção-Teste } \\
(70 \mathrm{~km} / \mathrm{h})\end{array}$ & $\begin{array}{c}\text { Seção-Teste } \\
(60 \mathrm{~km} / \mathrm{h})\end{array}$ & $\begin{array}{c}\text { Seção-Teste } \\
(70 \mathrm{~km} / \mathrm{h})\end{array}$ & $\begin{array}{c}\text { Seção-Teste } \\
(80 \mathrm{~km} / \mathrm{h})\end{array}$ & $\begin{array}{c}\text { Seção-Teste } \\
(60 \mathrm{~km} / \mathrm{h})\end{array}$ & $\begin{array}{c}\text { Seção-Teste } \\
(70 \mathrm{~km} / \mathrm{h})\end{array}$ & $\begin{array}{c}\text { Seção-Teste } \\
(80 \mathrm{~km} / \mathrm{h})\end{array}$ \\
\hline A & 1 & 1 & 1 & 1 & 1 & - & - \\
\hline B & 2 & - & - & - & - & 1 & 1 \\
\hline
\end{tabular}

Após a finalização das campanhas com o Pavement Scanner iniciaram-se os tratamentos de dados em escritório. Para isso, as imagens e informações de cada seçãoteste foram processadas de forma a se obter as seguintes informações:

- Localização e percentual de áreas trincadas;

- Localização, altura e perfil de afundamentos, inclusive em trilhas de roda;

- Localização, altura e perfil de ondulações;

- Localização e área de panelas; 
- Localização e área de remendos;

- Localização e área de exsudação;

- Localização e área de desgaste;

- Valores de irregularidade longitudinal.

Durante o processamento, as informações obtidas e gravadas com os dois lasers do Pavement Scanner são extraídas como imagem em arquivo .jpeg, e como banco de dados, em arquivo .xml. Para a obtenção dos dados brutos são utilizados todos os módulos internos de processamento do equipamento, tais como: trincamento, afundamento, IRI, panela e exsudação.

Há duas configurações distintas para processamento dos dados, uma utiliza parâmetro de revestimento comum (como é o caso do CBUQ), já a outra, revestimento com maior porosidade (como é o caso do microrrevestimento). No segundo caso, a configuração do processamento tende a eliminar possíveis sulcos da macrotextura do microrrevestimento, que erroneamente poderiam ser detectados como trincas.

O Pavement Scanner realiza o levantamento dos dados de maneira objetiva, em que os resultados do tratamento dos dados brutos são representados por pontos, que apresentam informações de coordenadas (x,y) em plano local, bem como, a abertura em milímetros. Os pontos levantados com suas informações de coordenadas e espessura da abertura foram detalhadamente mapeados em uma malha com dimensões 1,0 metro (extensão) e 0,2 metros (largura) em arquivo .xls.

A partir dos dados mapeados na malha, foi possível identificar os defeitos existentes no pavimento através do emprego de algoritmos para o mapeamento de trincas de classes diferentes, afundamentos, panela, exsudação e remendo.

A delimitação da área a ser levantada os defeitos foi definida a partir da sinalização da linha de bordo e da linha de separação de faixas, com base nas informações do laser que detecta a intensidade. A Figura 3.6 ilustra o mapeamento dos defeitos em uma mesma seção, sendo que a imagem à direita foi extraída do laser 3D e a imagem à 
esquerda, extraída a partir do laser de intensidade. À esquerda desta figura é ilustrada a linha representada na cor rosa, que determina os limites a serem analisados em cada faixa, a partir da pintura de faixa. A linha amarela representa a localização do perfil longitudinal para a detecção do IRI. As trincas são representadas pelas cores vermelha, amarela e verde, de acordo com a classe. À direita desta figura são apresentadas as imagens em 3D com mapeamento dos defeitos no excel, representados por retângulos coloridos com dimensão de 1metro por $20 \mathrm{~cm}$, cujos valores internos correspondem à abertura de cada defeito em milímetro.

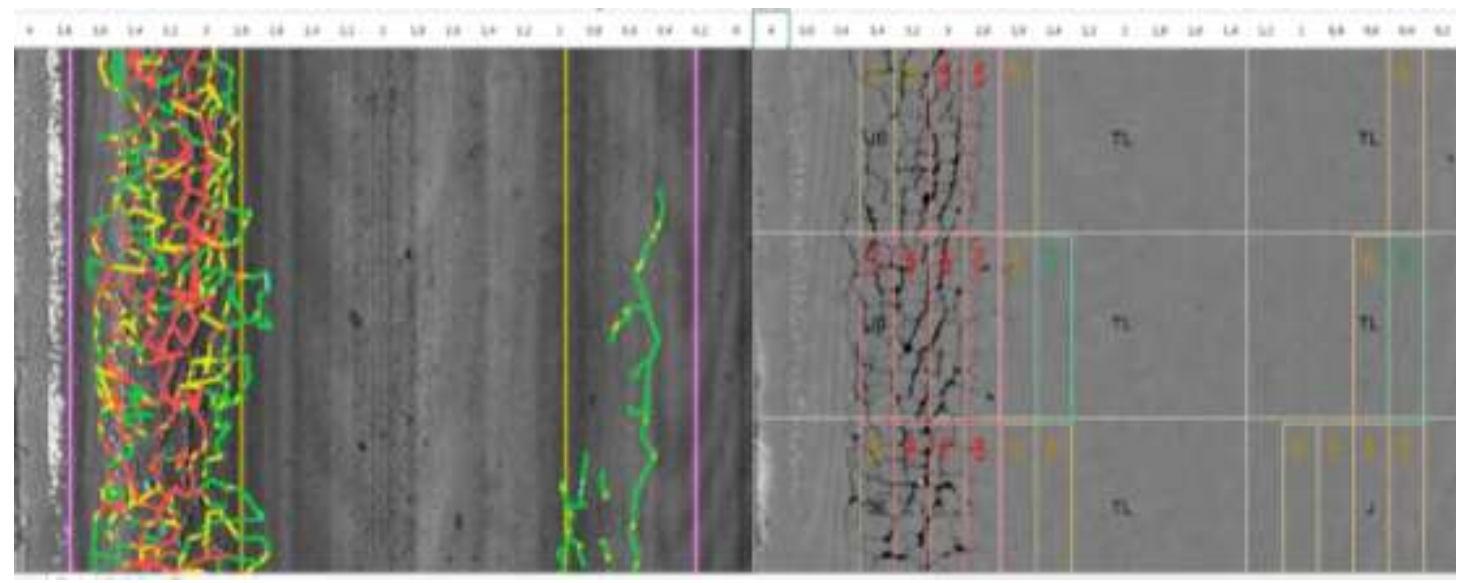

(b)

(b)

Figura 3.6 - Mapeamento dos Trincamentos em uma Mesma Seção. Imagem de Fundo em 3D (b). Imagem de Fundo da Intensidade (a)

A Figura 3.7 ilustra o mapeamento dos remendos, cujo perímetro inicialmente é detectado como trincamento, conforme pode ser verificada na imagem à esquerda. Posteriormente é realizado um refinamento visual dos módulos de detecção do remendo, de forma a garantir se este defeito foi detectado corretamente. 


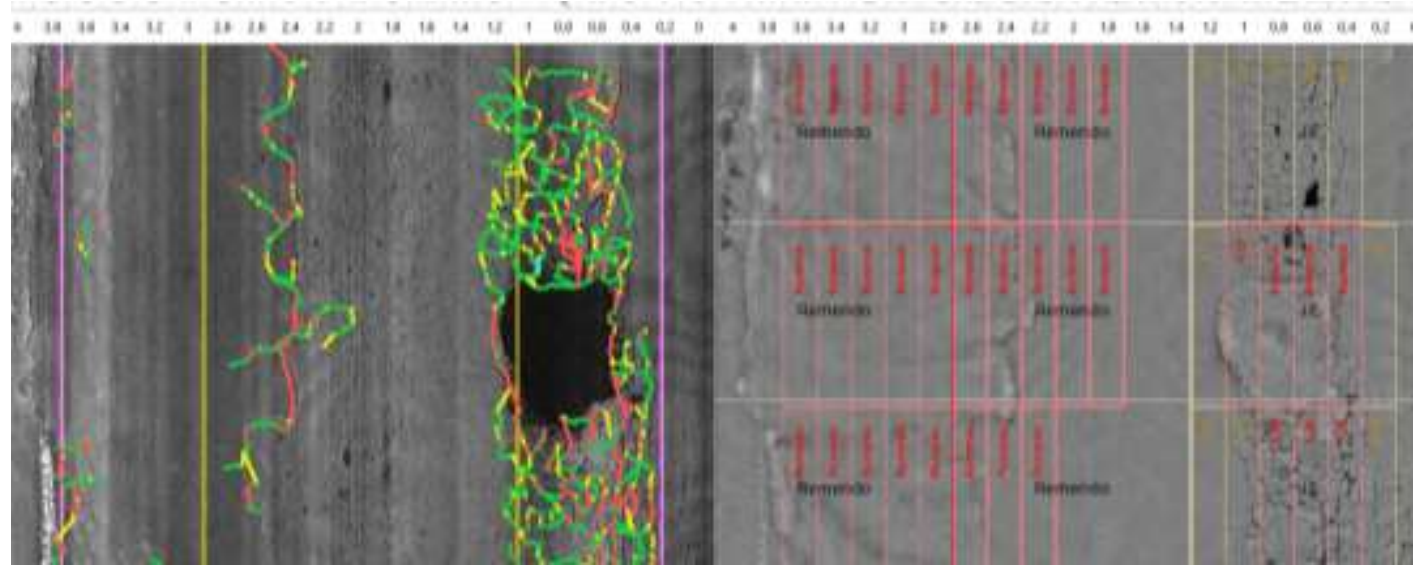

(c)

(b)

Figura 3.7 - Mapeamento do Remendo em uma mesma seção. Imagem de Fundo em 3D (b). Imagem de Fundo da Intensidade (a)

\subsubsection{Levantamentos com Metodologia Tradicional}

Foram realizados os levantamentos utilizando-se a metodologia tradicional definida na norma DNIT-PRO 006/2003, além de levantamentos mecanizados para a definição da irregularidade longitudinal com a utilização do Perfilômetro Laser, conforme apresentados nas 3.8 a 3.16 .
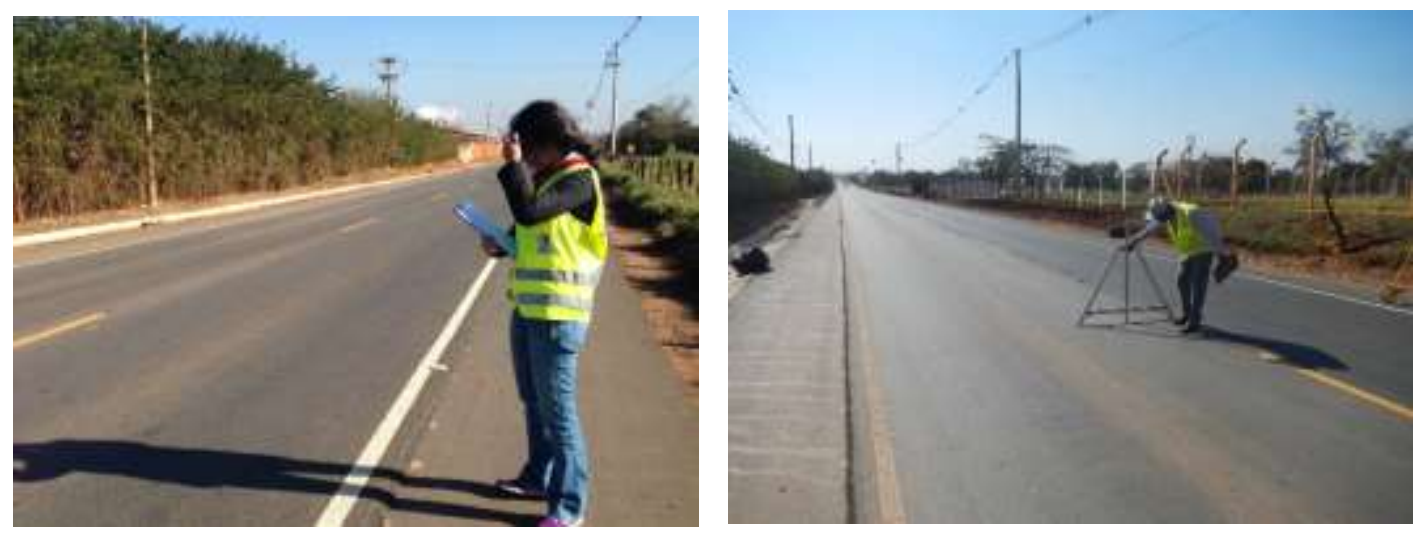

Figura 3.8 - Levantamentos Tradicionais na Seção-Teste 01 

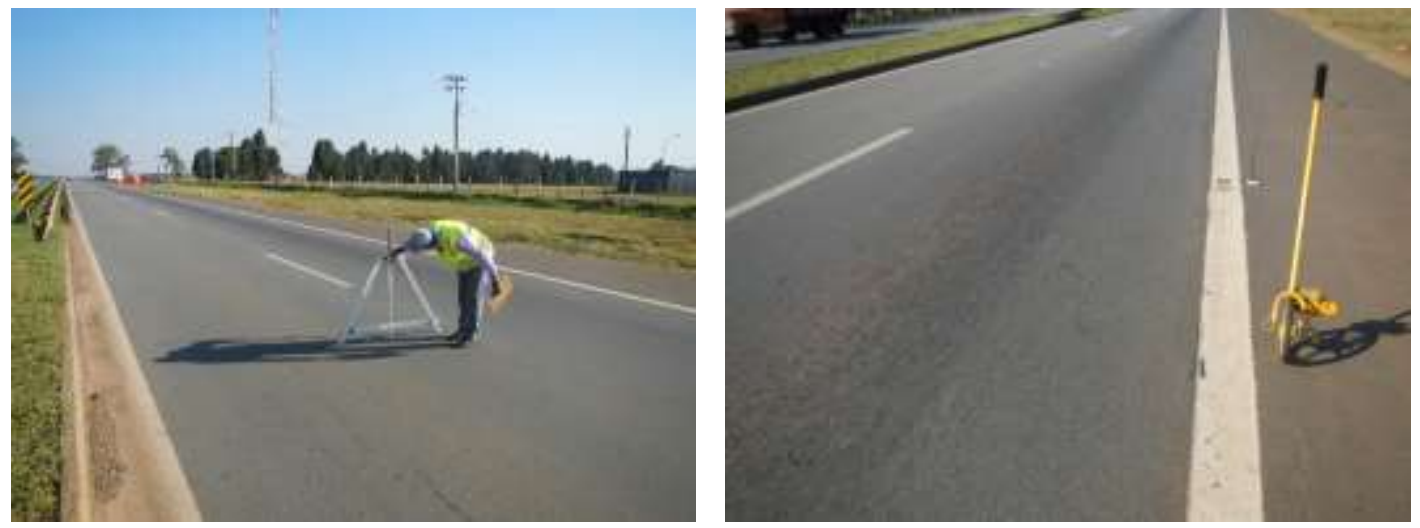

Figura 3.9 - Levantamentos Tradicionais na Seção-Teste 02
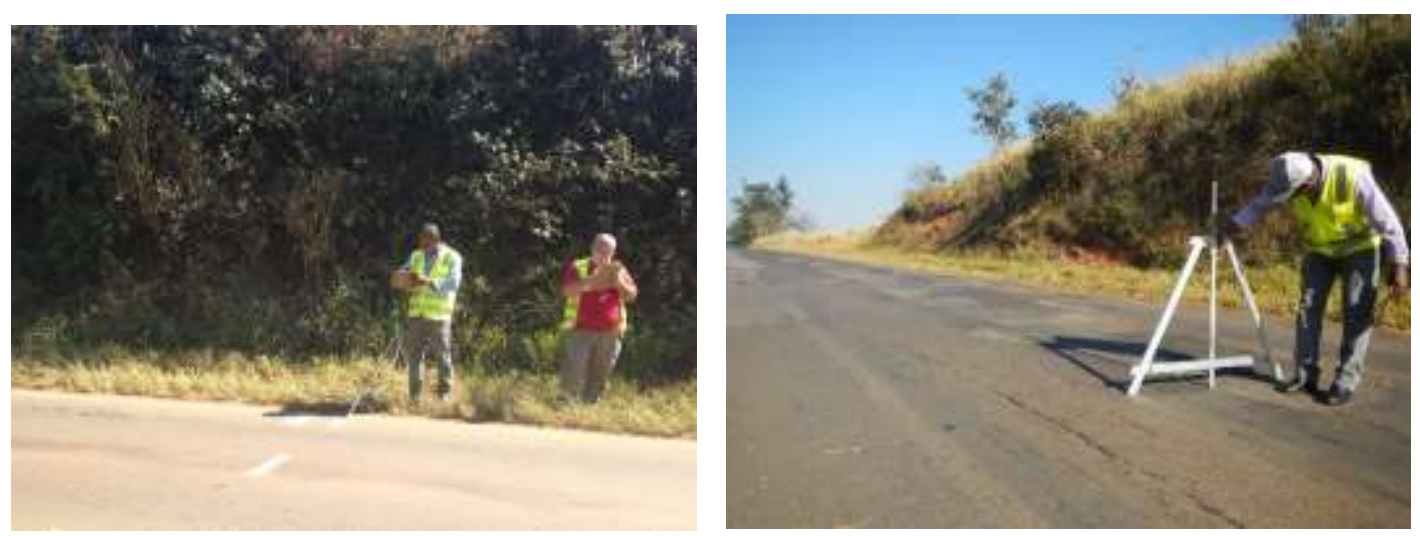

Figura 3.10 - Levantamentos Tradicionais na Seção-Teste 03
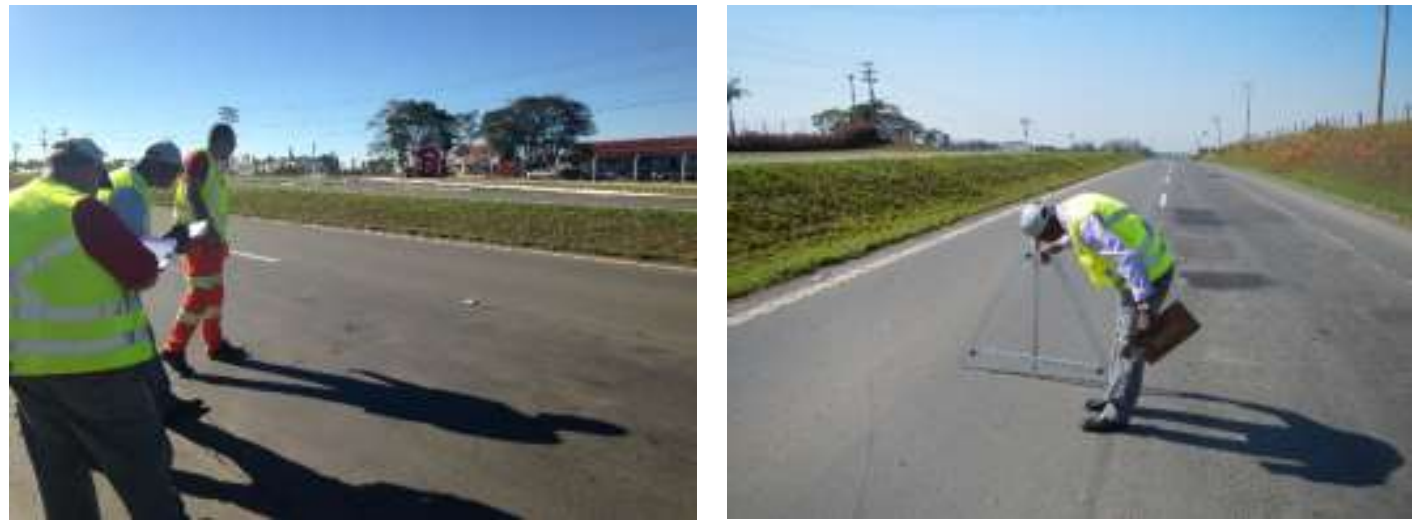

Figura 3.11 - Levantamentos Tradicionais na Seção-Teste 04 

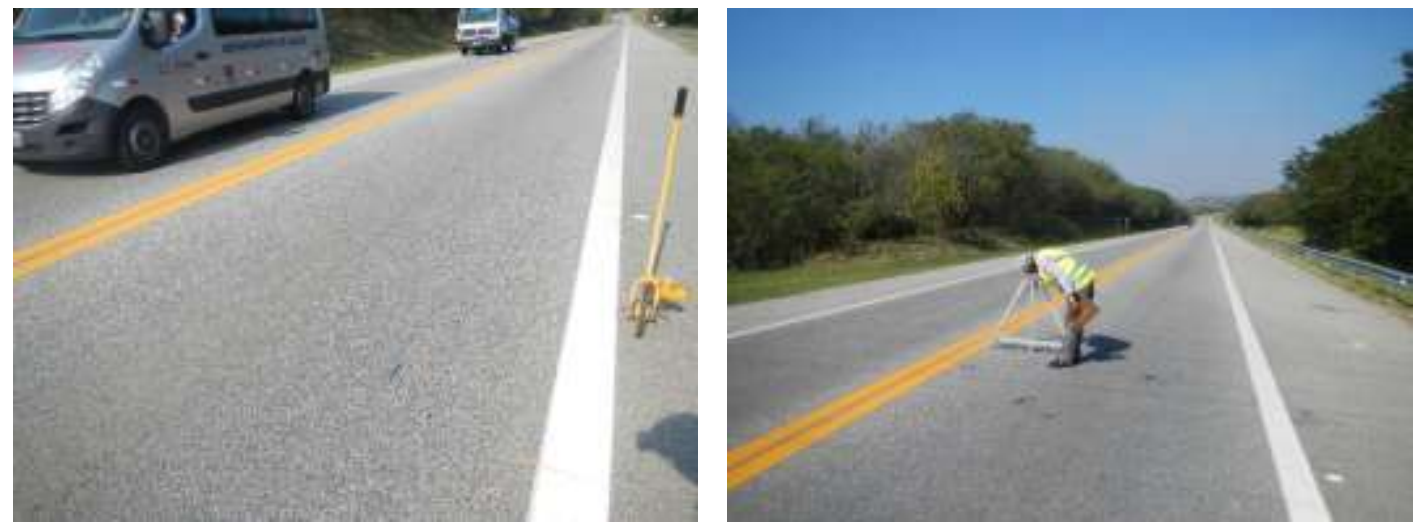

Figura 3.12 - Levantamentos Tradicionais na Seção-Teste 05
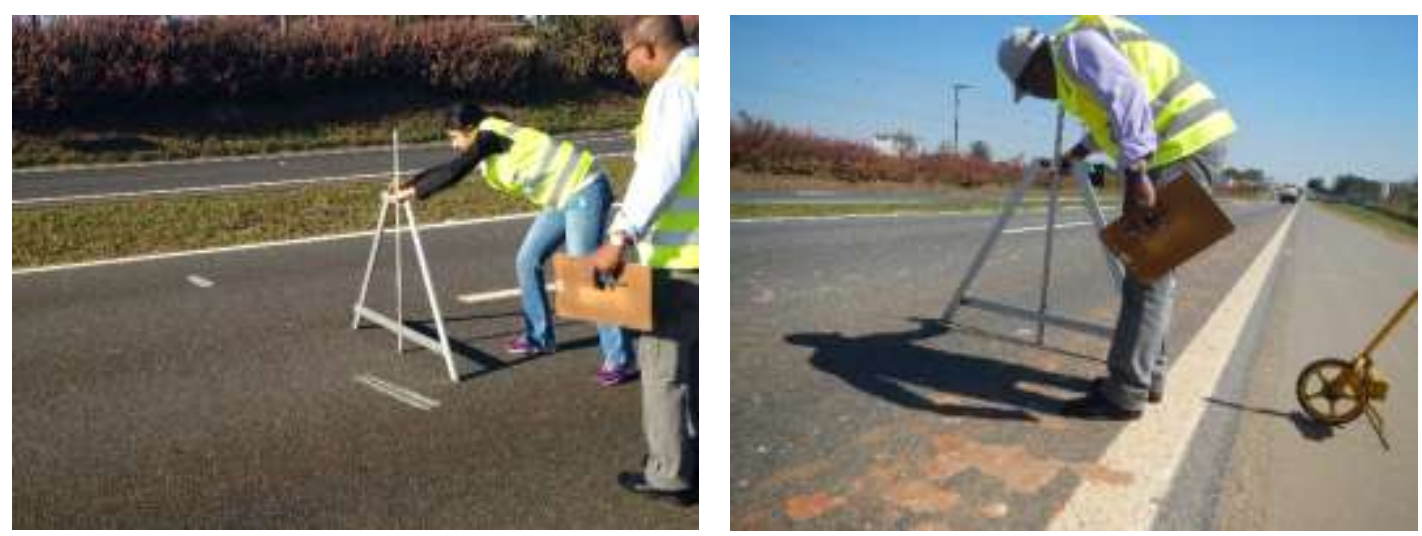

Figura 3.13 - Levantamentos Tradicionais na Seção-Teste 06
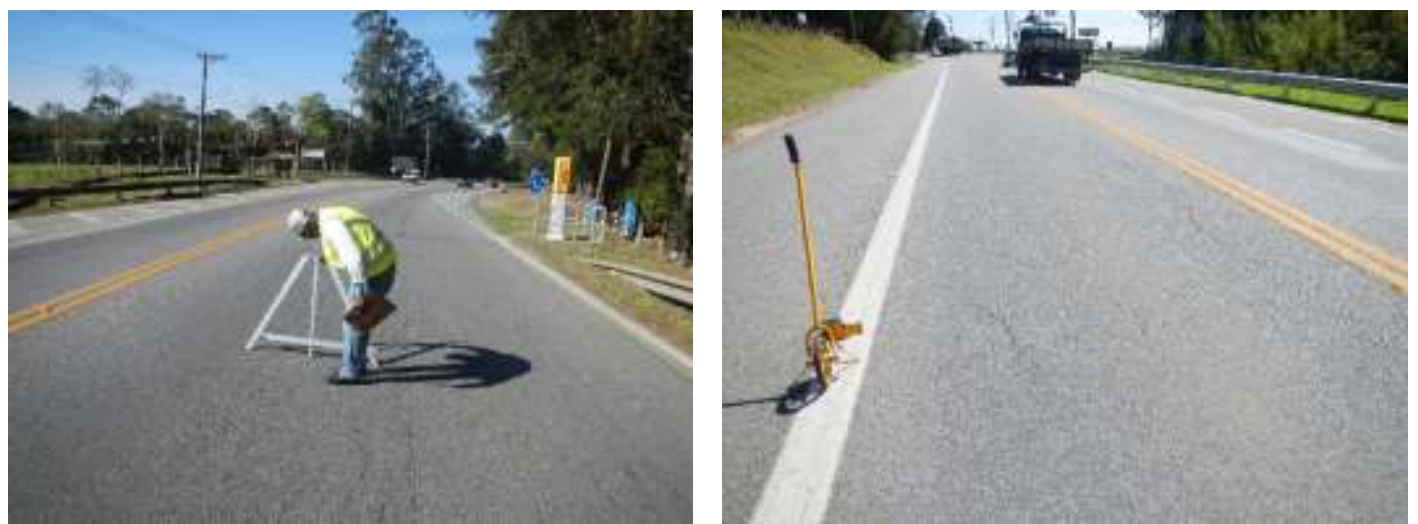

Figura 3.14 - Levantamentos Tradicionais na Seção-Teste 07 

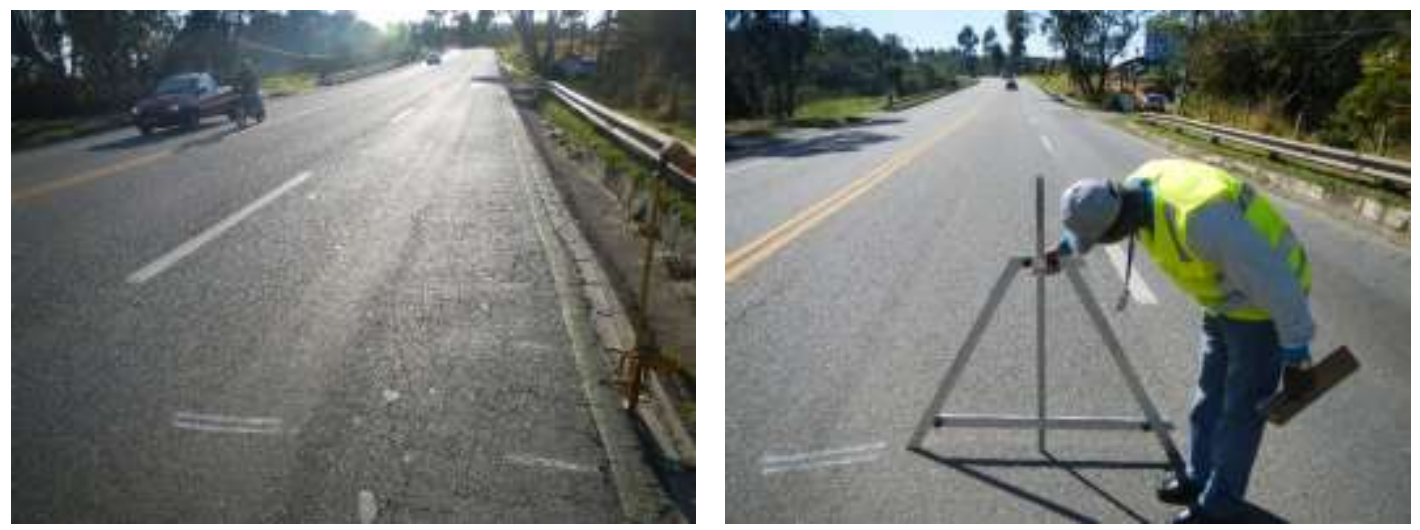

Figura 3.15 - Levantamentos Tradicionais na Seção-Teste 08

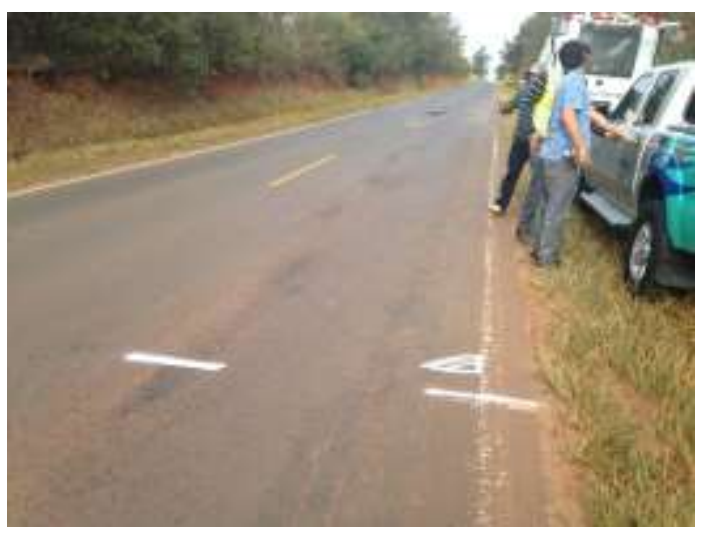

(a)

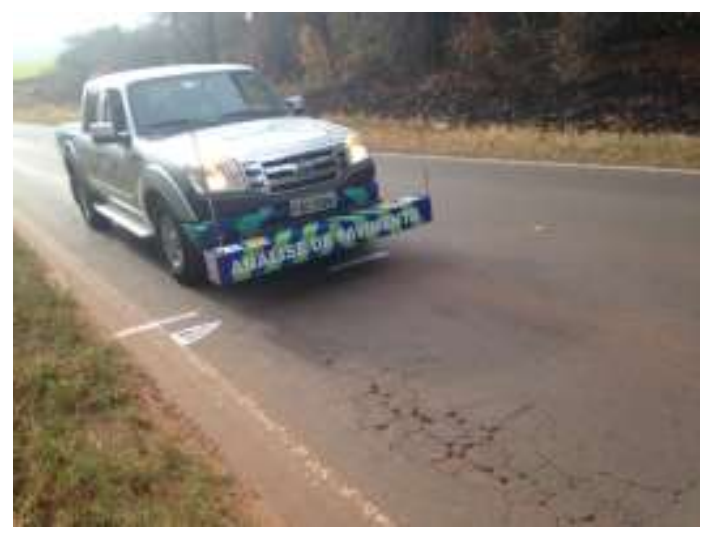

(b)

Figura 3.16 - Levantamento com Perfilômetro Laser. Equipe preparando-se para início do levantamento (a). Preparação para início do levantamento com o equipamento (b).

Os levantamentos tradicionais de campo seguiram as normativas do DNIT PRO006/2003 com relação às ocorrências e classificação de defeitos. No entanto, tendo em vista a obtenção de informação mais detalhadas ao longo de todas as seções-teste, foi realizado o levantamento contínuo, ou seja, com levantamento a cada 1 metro, sob uma forma de "IGG detalhado". Adicionalmente, foram realizadas em quatro seções-teste o IGG da forma tradicional, com a finalidade de se avaliar possíveis discrepâncias com relação à forma mais detalhada. Também foram levantadas visualmente informações detalhadas com relação às áreas de defeitos. As informações coletadas são de suma importância para a comparação dos resultados das metodologias de avaliação de defeitos pelos métodos tradicionais e mecanizados, além da avaliação crítica do cálculo do IGG. 
Os levantamentos tradicionais foram realizados em quatro campanhas, sendo que a avaliação objetiva (IGG) foi realizada com sete repetições, por duas equipes distintas na campanha 03; a avaliação objetiva por metro (IGG "detalhado") e o IRI foram executados por três equipes diferentes em uma mesma campanha (campanha 04). Adicionalmente, foi realizada a campanha 05 , composta de apenas uma equipe, para a realização destes levantamentos. A Tabela 3.5 detalha as campanhas realizadas.

Tabela 3.5 - Descrição das Campanhas Realizadas pelas Metodologias Tradicionais

\begin{tabular}{|c|c|c|c|c|}
\hline \multirow[b]{3}{*}{ Equipe } & \multicolumn{4}{|c|}{ Número de Avaliações } \\
\hline & \multirow{2}{*}{$\begin{array}{c}\text { Campanha } 03 \\
\text { Método PRO- } \\
006 / 2003\end{array}$} & \multicolumn{2}{|c|}{ Campanha 04} & \multirow[b]{2}{*}{$\begin{array}{c}\text { Campanha 05 } \\
\text { Método PRO- } \\
\text { 006/2003 } \\
\text { (detalhado) }\end{array}$} \\
\hline & & $\begin{array}{c}\text { Método PRO- } \\
006 / 2003 \\
\text { (detalhado) }\end{array}$ & IRI & \\
\hline A & $7^{*}$ & 1 & 1 & 3 \\
\hline B & $7^{*}$ & 1 & 1 & \\
\hline C & & 1 & 1 & \\
\hline
\end{tabular}

*Realizado nas ST-01, ST-03, ST-04 e ST-06

Após a finalização das referidas campanhas iniciaram-se os tratamentos de dados em escritório. Através do levantamento detalhado dos defeitos foi possível obter os seguintes dados:

- Localização e percentual de áreas trincadas;

- Localização e altura de afundamentos, inclusive em trilhas de roda;

- Localização e área de ondulações;

- Localização e área de panelas;

- Localização e área de remendos;

- Localização e área de desgaste;

Já com os dos dados coletados pelo Perfilômetro Laser foram obtidos os valores de irregularidade longitudinal. 


\section{RESULTADOS E ESTUDOS COMPARATIVOS}

\subsection{Resultados Gerais de IGG}

A Tabela 4.1 apresenta os resultados de IGG para pistas simples, enquanto que a Tabela 4.2, para pistas duplas. Os referidos resultados foram obtidos a partir dos levantamentos tradicionais e mecanizados, em metodologia de cálculo em conformidade com a apresentada pelo DNIT-PRO 006/2003, sendo que para o levantamento tradicional foram realizadas 14 repetições na ST-01, ST-03, ST-04 e ST-

06, para o detalhado, realizadas 5 repetições em todas as seções-teste e para o mecanizado, 9 repetições. 
Tabela 4.1 - Resultados de IGG para Pista Simples

\begin{tabular}{|c|c|c|c|c|c|c|c|c|c|c|c|c|c|c|c|c|c|c|c|c|}
\hline \multirow{2}{*}{\multicolumn{2}{|c|}{ IGG }} & \multicolumn{14}{|c|}{ Amostra } & \multirow{2}{*}{ Média } & \multirow{2}{*}{$\begin{array}{l}\text { Desvio } \\
\text { Padrão }\end{array}$} & \multirow{2}{*}{\begin{tabular}{|l|} 
Coef. de \\
Variação
\end{tabular}} & \multirow{2}{*}{ Variância } & \multirow{2}{*}{$\begin{array}{c}\text { Máx } \\
\text { Mín }\end{array}$} \\
\hline & & 1 & 2 & 3 & 4 & 5 & 6 & 7 & 8 & 9 & 10 & 11 & 12 & 13 & 14 & & & & & \\
\hline \multirow{3}{*}{$\begin{array}{c}\text { Seção Teste } \\
01\end{array}$} & Tradicional & 0 & 0 & 0 & 0 & 1 & 1 & 0 & 0 & 0 & 0 & 0 & 0 & 0 & 0 & 0,3 & 0,1 & $41 \%$ & 0,0 & 0,4 \\
\hline & Tradicional Detalhado & 0 & 0 & 0 & 0 & 0 & & & & & & & & & & 0,2 & 0,1 & $33 \%$ & 0,0 & 0,1 \\
\hline & Pavement Scanner & 1 & 1 & 1 & 1 & 1 & 1 & 1 & 1 & 0 & & & & & & 0,8 & 0,2 & $29 \%$ & 0,1 & 0,6 \\
\hline \multirow{3}{*}{$\begin{array}{c}\text { Seção Teste } \\
03\end{array}$} & Tradicional & 246 & 232 & 226 & 246 & 257 & 252 & 258 & 220 & 222 & 244 & 237 & 235 & 240 & 232 & 238,9 & 14,9 & $6 \%$ & 221,6 & 37,5 \\
\hline & Tradicional Detalhado & 231 & 228 & 254 & 242 & 198 & & & & & & & & & & 230,6 & 20,8 & $9 \%$ & 431,9 & 55,6 \\
\hline & Pavement Scanner & 228,5 & 228,2 & 230,5 & 232,7 & 228,8 & 228,3 & 228,1 & 224,7 & 225,5 & & & & & & 228,4 & 2,4 & $1 \%$ & 5,7 & 8,1 \\
\hline \multirow{3}{*}{$\begin{array}{c}\text { Seção Teste } \\
05\end{array}$} & Tradicional & & & & & & & & & & & & & & & & & & & 0,0 \\
\hline & Tradicional Detalhado & 14 & 5 & 6 & 7 & 12 & & & & & & & & & & 8,8 & 4,0 & $46 \%$ & 16,0 & 9,0 \\
\hline & Pavement Scanner & 4 & 5 & 5 & 4 & 4 & 4 & 4 & 4 & 4 & & & & & & 4,2 & 0,4 & $9 \%$ & 0,1 & 1,1 \\
\hline \multirow{3}{*}{$\begin{array}{c}\text { Seção Teste } \\
07\end{array}$} & Tradicional & & & & & & & & & & & & & & & & & & & 0,0 \\
\hline & Tradicional Detalhado & 51 & 41 & 38 & 47 & 40 & & & & & & & & & & 43,4 & 5,6 & $13 \%$ & 30,9 & 13,5 \\
\hline & Pavement Scanner & 39 & 39 & 36 & 34 & 37 & 37 & 35 & 36 & 36 & & & & & & 36,5 & 1,8 & $5 \%$ & 3,2 & 5,4 \\
\hline
\end{tabular}


Tabela 4.2 - Resultados de IGG para Pista Dupla

\begin{tabular}{|c|c|c|c|c|c|c|c|c|c|c|c|c|c|c|c|c|c|c|c|c|}
\hline \multirow{2}{*}{\multicolumn{2}{|c|}{ IGG }} & \multicolumn{14}{|c|}{ Amostra } & \multirow{2}{*}{ Média } & \multirow{2}{*}{$\begin{array}{l}\text { Desvio } \\
\text { Padrão }\end{array}$} & \multirow{2}{*}{$\begin{array}{l}\text { Coef. de } \\
\text { Variação }\end{array}$} & \multirow{2}{*}{ Variância } & \multirow{2}{*}{$\begin{array}{c}\text { Máx - } \\
\text { Mín }\end{array}$} \\
\hline & & 1 & 2 & 3 & 4 & 5 & 6 & 7 & 8 & 9 & 10 & 11 & 12 & 13 & 14 & & & & & \\
\hline \multirow{3}{*}{$\begin{array}{c}\text { Seção Teste } \\
02 \\
\text { Faixa } 1 \\
\end{array}$} & Tradicional & & & & & & & & & & & & & & & & & & & \\
\hline & Tradicional Detalhado & 2 & 1 & 2 & 1 & 1 & & & & & & & & & & 1,5 & 0,3 & $23 \%$ & 0,1 & 0,7 \\
\hline & Pavement Scanner & 1 & 1 & 1 & 2 & 1 & 1 & 1 & 1 & 1 & & & & & & 1,3 & 0,1 & $11 \%$ & 0,0 & 0,4 \\
\hline \multirow{3}{*}{\begin{tabular}{c|} 
Seção Teste \\
02 \\
Faixa 2 \\
\end{tabular}} & Tradicional & & & & & & & & & & & & & & & & & & & \\
\hline & Tradicional Detalhado & 10 & 17 & 17 & 6 & 7 & & & & & & & & & & 11,3 & 5,0 & $45 \%$ & 25,2 & 10,2 \\
\hline & Pavement Scanner & 5 & 5 & 4 & 5 & 5 & 6 & 5 & 5 & 4 & & & & & & 4,8 & 0,6 & $12 \%$ & 0,3 & 1,8 \\
\hline \multirow{3}{*}{$\begin{array}{c}\text { Seção Teste } \\
04 \\
\text { Faixa } 1 \\
\end{array}$} & Tradicional & 49 & 49 & 56 & 38 & 39 & 30 & 63 & 38 & 47 & 31 & 34 & 42 & 38 & 37 & 42,3 & 10,2 & $24 \%$ & 104,0 & 32,8 \\
\hline & Tradicional Detalhado & 52 & 38 & 50 & 28 & 39 & & & & & & & & & & 41,3 & 9,6 & $23 \%$ & 91,9 & 23,6 \\
\hline & Pavement Scanner & 29 & 31 & 33 & 26 & 33 & 27 & 31 & 26 & 33 & & & & & & 29,8 & 2,8 & $10 \%$ & 8,1 & 7,0 \\
\hline \multirow{3}{*}{$\begin{array}{c}\text { Seção Teste } \\
06 \\
\text { Plataforma }\end{array}$} & Tradicional & 5 & 7 & 6 & 8 & 7 & 5 & 5 & 6 & 5 & 7 & 6 & 7 & 6 & 9 & 6,3 & 1,0 & $16 \%$ & 1,0 & 2,7 \\
\hline & Tradicional Detalhado & 6 & 5 & 7 & 6 & 5 & & & & & & & & & & 5,6 & 0,8 & $14 \%$ & 0,6 & 2,0 \\
\hline & Pavement Scanner & 5 & 4 & 5 & 5 & 5 & 5 & 5 & 5 & 5 & & & & & & 5,0 & 0,3 & $6 \%$ & 0,1 & 1,0 \\
\hline \multirow{3}{*}{$\begin{array}{c}\text { Seção Teste } \\
06 \\
\text { Faixa } 1\end{array}$} & Tradicional & 5 & 6 & 4 & 6 & 5 & 4 & 5 & 5 & 5 & 6 & 5 & 5 & 5 & 5 & 5,0 & 0,5 & $10 \%$ & 0,3 & 1,5 \\
\hline & Tradicional Detalhado & 4 & 2 & 3 & 3 & 3 & & & & & & & & & & 3,1 & 0,7 & $23 \%$ & 0,5 & 2,0 \\
\hline & Pavement Scanner & 6 & 5 & 6 & 5 & 6 & 5 & 6 & 6 & 6 & & & & & & 5,8 & 0,6 & $10 \%$ & 0,4 & 1,6 \\
\hline \multirow{3}{*}{\begin{tabular}{c|} 
Seção Teste \\
06 \\
Faixa 2 \\
\end{tabular}} & Tradicional & 6 & 9 & 7 & 9 & 9 & 6 & 5 & 7 & 5 & 8 & 8 & 8 & 6 & 12 & 7,5 & 1,6 & $22 \%$ & 2,6 & 4,3 \\
\hline & \begin{tabular}{|l|} 
Tradicional Detalhado \\
\end{tabular} & 7 & 8 & 10 & 8 & 7 & & & & & & & & & & 8,1 & 1,4 & $17 \%$ & 1,9 & 3,5 \\
\hline & Pavement Scanner & 4 & 4 & 4 & 4 & 4 & 5 & 4 & 4 & 4 & & & & & & 4,2 & 0,2 & $6 \%$ & 0,1 & 0,7 \\
\hline \multirow{3}{*}{\begin{tabular}{c|} 
Seção Teste \\
08 \\
Faixa 1 \\
\end{tabular}} & \begin{tabular}{|l|} 
Tradicional \\
\end{tabular} & & & & & & & & & & & & & & & & & & & \\
\hline & Tradicional Detalhado & 20 & 28 & 30 & 18 & 22 & & & & & & & & & & 23,5 & 5,3 & $23 \%$ & 28,0 & 12,2 \\
\hline & Pavement Scanner & 16 & 20 & 20 & 20 & 17 & 17 & 18 & 17 & 15 & & & & & & 17,7 & 1,7 & $10 \%$ & 3,0 & 4,6 \\
\hline \multirow{3}{*}{\begin{tabular}{c|} 
Seção Teste \\
08 \\
Faixa 2 \\
\end{tabular}} & Tradicional & & & & & & & & & & & & & & & & & & & \\
\hline & \begin{tabular}{|l|} 
Tradicional Detalhado \\
\end{tabular} & 108 & 121 & 143 & 111 & 80 & & & & & & & & & & 112,5 & 22,9 & $20 \%$ & 523,2 & 63,1 \\
\hline & Pavement Scanner & 104 & 101 & 94 & 96 & 84 & 101 & 95 & 102 & 93 & & & & & & 96,8 & 6,0 & $6 \%$ & 36,0 & 19,6 \\
\hline
\end{tabular}


Verifica-se que em todas as seções-teste estudadas o coeficiente de variação do IGG com base no levantamento mecanizado é inferior em comparação ao levantamento tradicional. Para as pistas em condições regulares e ruim o coeficiente de variação tende a ser menor, já que os valores de média dos resultados são mais elevados. No caso em questão, as seções-teste ST-03, ST-04 Faixa 2, ST-07 e ST-08 Faixa 2 apresentaram para o levantamento mecanizado coeficientes de variação de $1 \%$ a $6 \%$. Nestas mesmas seções, no levantamento tradicional e tradicional detalhado o coeficiente de variação obtido oscilou entre $6 \%$ e $24 \%$. No levantamento com o Pavement Scanner, todos os coeficientes de variação do IGG foram inferiores a 13\%, com única exceção da ST-01 que possui valor de IGG médio muito baixo (inferior a 1) e qualquer variação torna o coeficiente de variação alto.

A Figura 4.1 ilustra o coeficiente de variação dos resultados de IGG obtidos para os três levantamentos. Observa-se que em todas as seções-teste o coeficiente de variação do Pavement Scanner apresentou-se inferior aos resultados tradicionais, denotando uma variabilidade maior de resultados nos levantamentos tradicionais atualmente utilizados para análise de malha rodoviária.

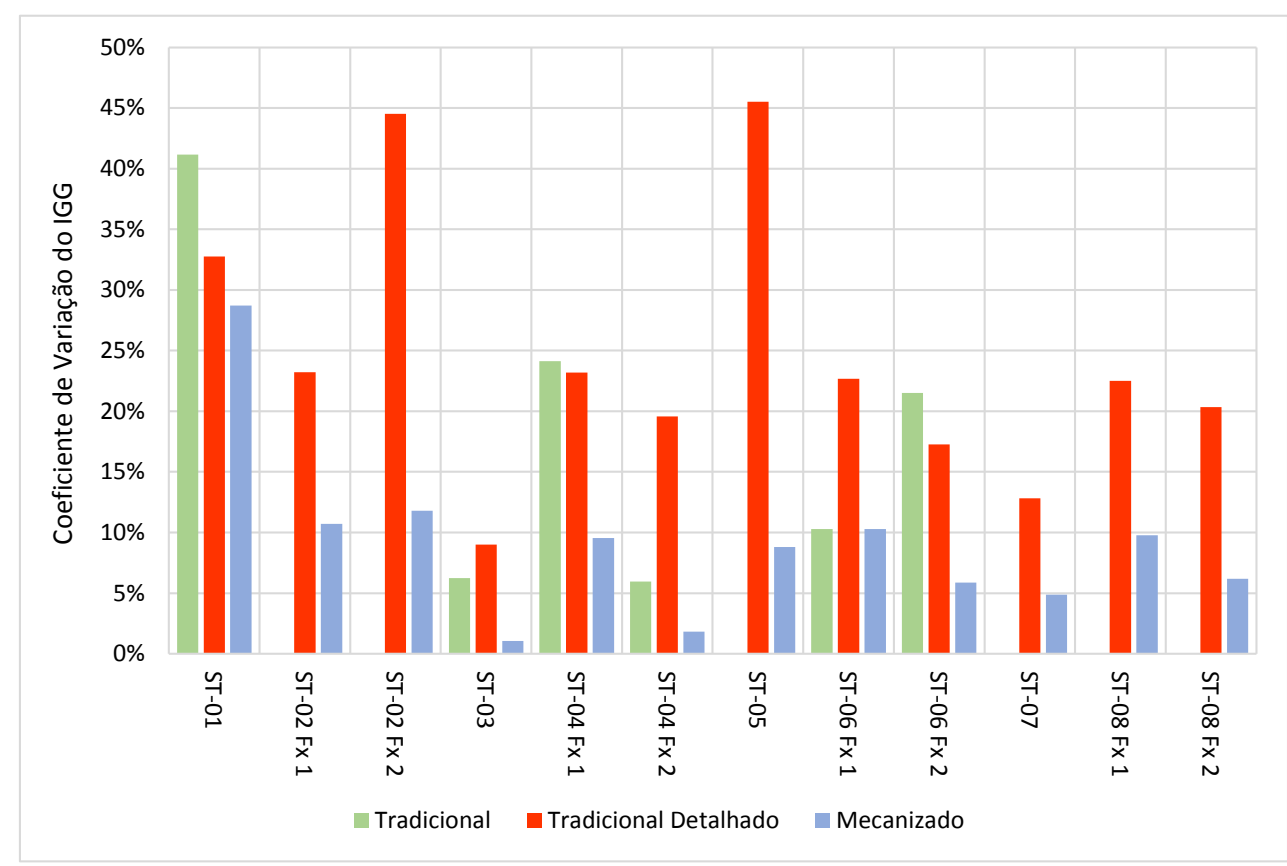

Figura 4.1 - Coeficiente de Variação dos Resultados de IGG 
De maneira a ilustrar a variação dos resultados de IGG para cada tipo de levantamento foram plotados gráficos ilustrativos, indicando-se com uma seta vermelha os pontos de elevada variação em cada método, conforme apresentado nas Figuras 4.2 a 4.13.

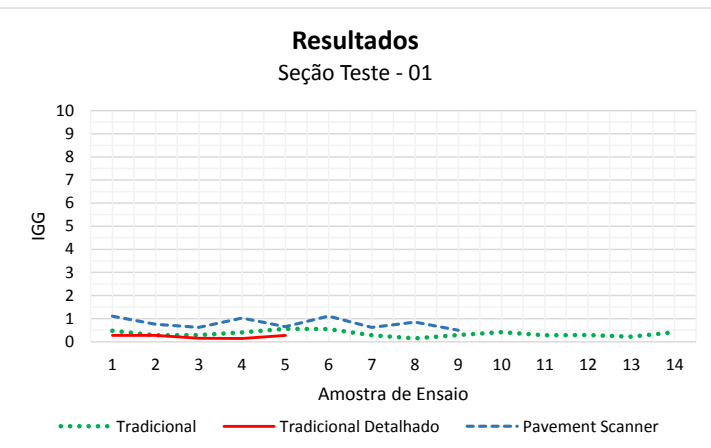

Figura 4.2 - Resultados do IGG - ST-01

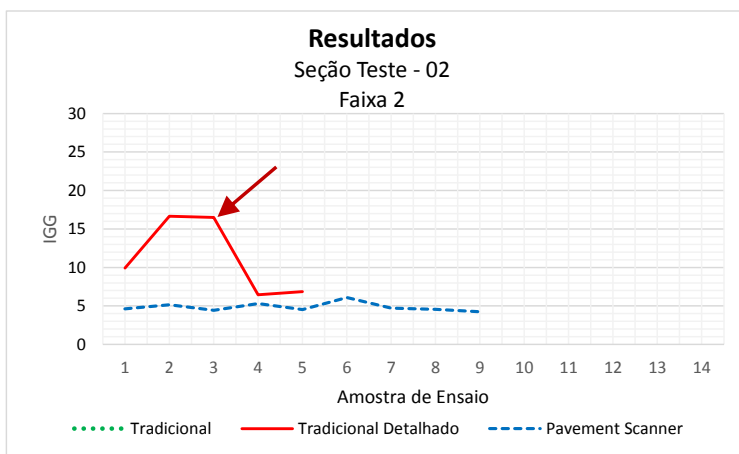

Figura 4.4 - Resultados do IGG - ST-02 Faixa 2

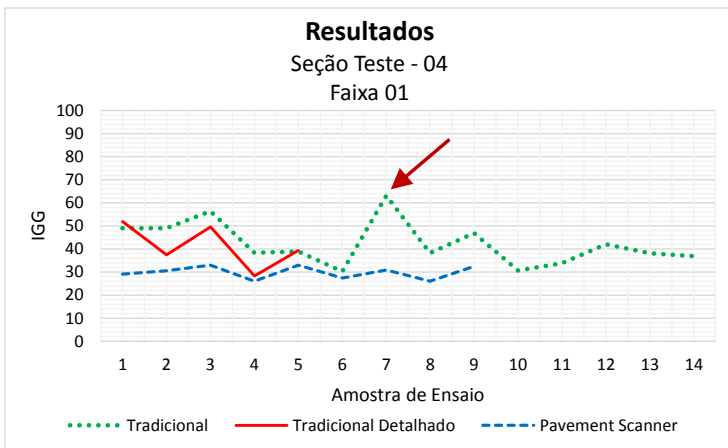

Figura 4.6 - Resultados do IGG - ST-04 Faixa 1

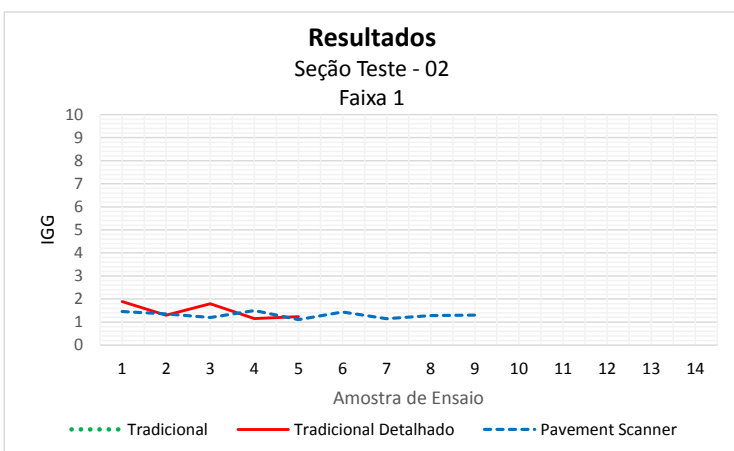

Figura 4.3 - Resultados do IGG - ST-02 Faixa 1

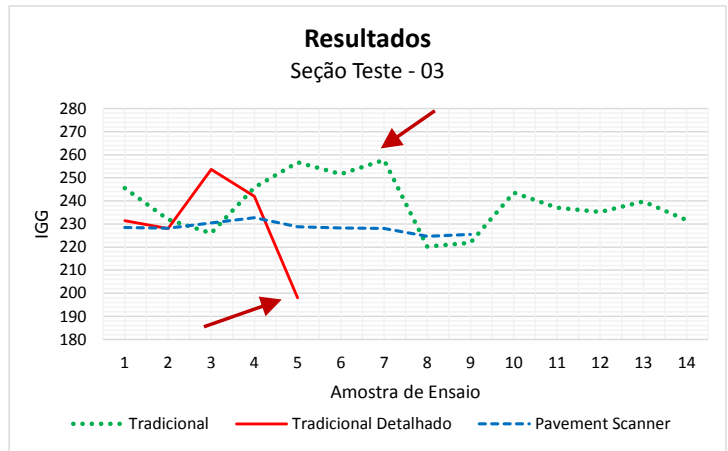

Figura 4.5 - Resultados do IGG - ST-03

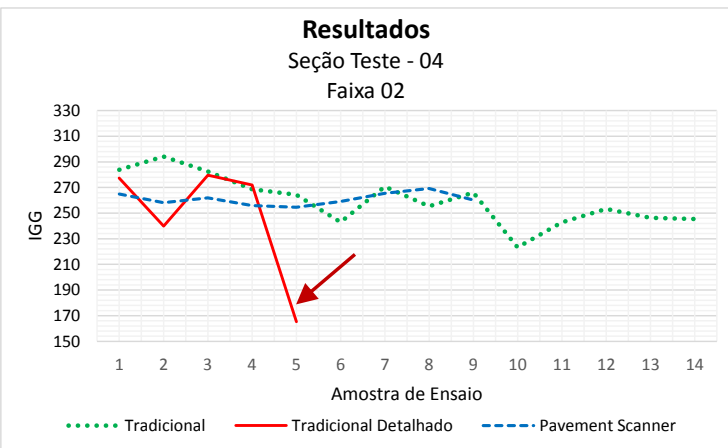

Figura 4.7 - Resultados do IGG - ST-04

Faixa 2 


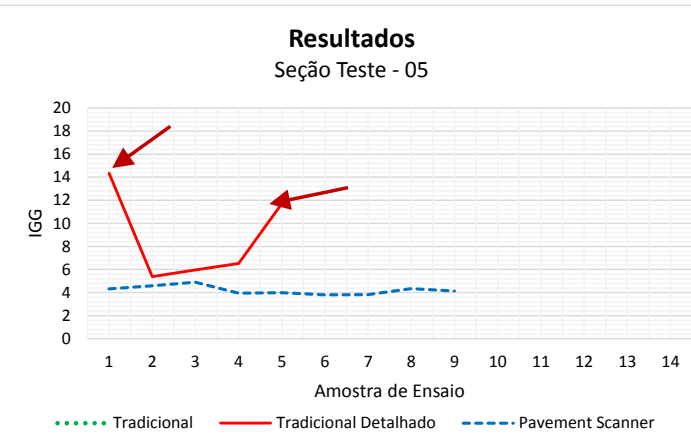

Figura 4.8 - Resultados do IGG - ST-05

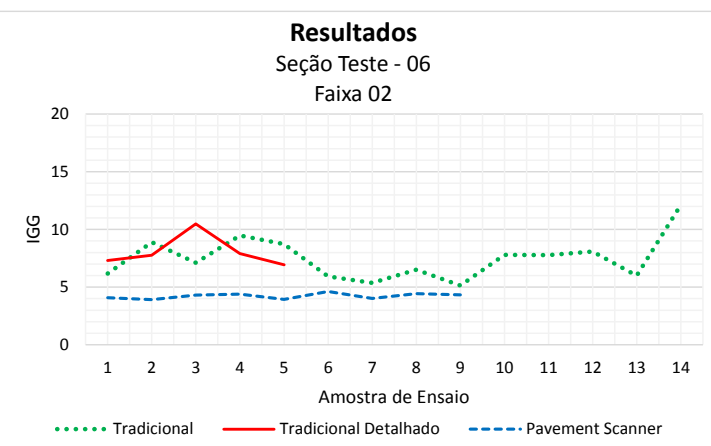

Figura 4.10 - Resultados do IGG - ST-06

Faixa 2

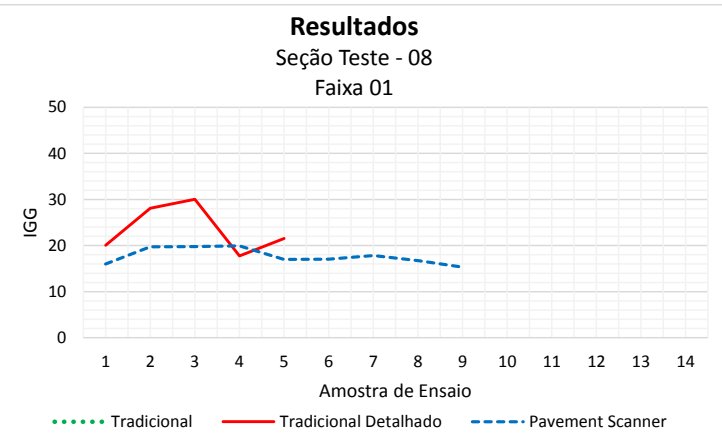

Figura 4.12 - Resultados do IGG - ST-08 Faixa 1

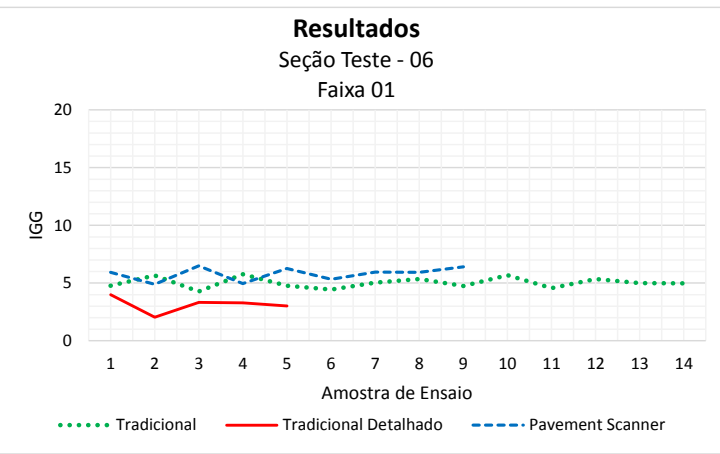

Figura 4.9 - Resultados do IGG - ST-06 Faixa 1

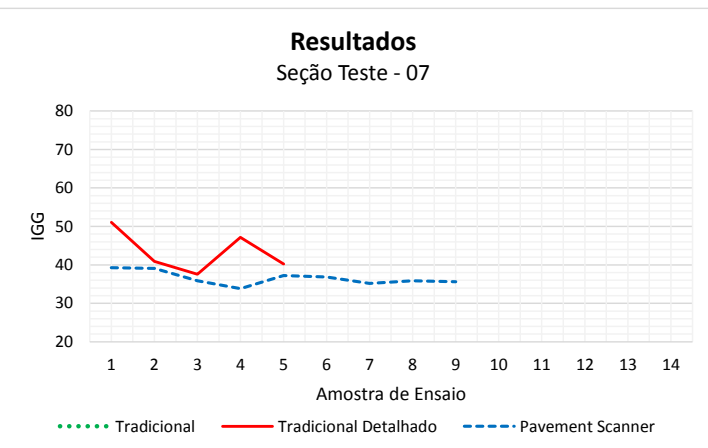

Figura 4.11 - Resultados do IGG - ST-07

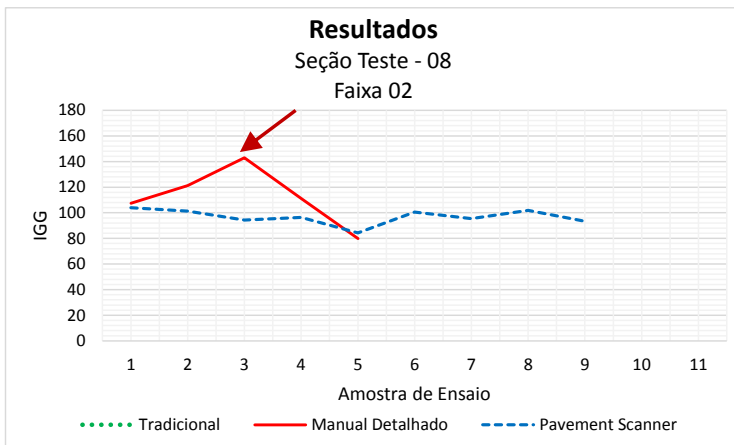

Figura 4.13 - Resultados do IGG - ST-08 Faixa 2

Analisando-se os gráficos apresentados, percebe-se que o os valores de IGG obtidos com o Pavement Scanner apresentam-se mais constantes e horizontais, com menor variação em relação aos levantamentos tradicionais. 
Além disso, os dados dos levantamentos tradicionais detalhados são mais discrepantes, apresentando uma diferença máxima no valor do IGG de 114, na ST-04, faixa 2. Essa discrepância possivelmente é dada pelo fato deste levantamento ter sido realizado por três diferentes operadores. O levantamento tradicional foi realizado por 2 operadores diferentes, apresentando também variação considerável, principalmente ST-03 e ST04, faixa 1.

A Figura 4.14 apresenta o gráfico de correlação entre a média dos resultados dos ensaios realizados pelo equipamento Pavement Scanner e a média dos resultados dos ensaios realizados pelo método tradicionalmente utilizado no Brasil para todas as seções-teste.

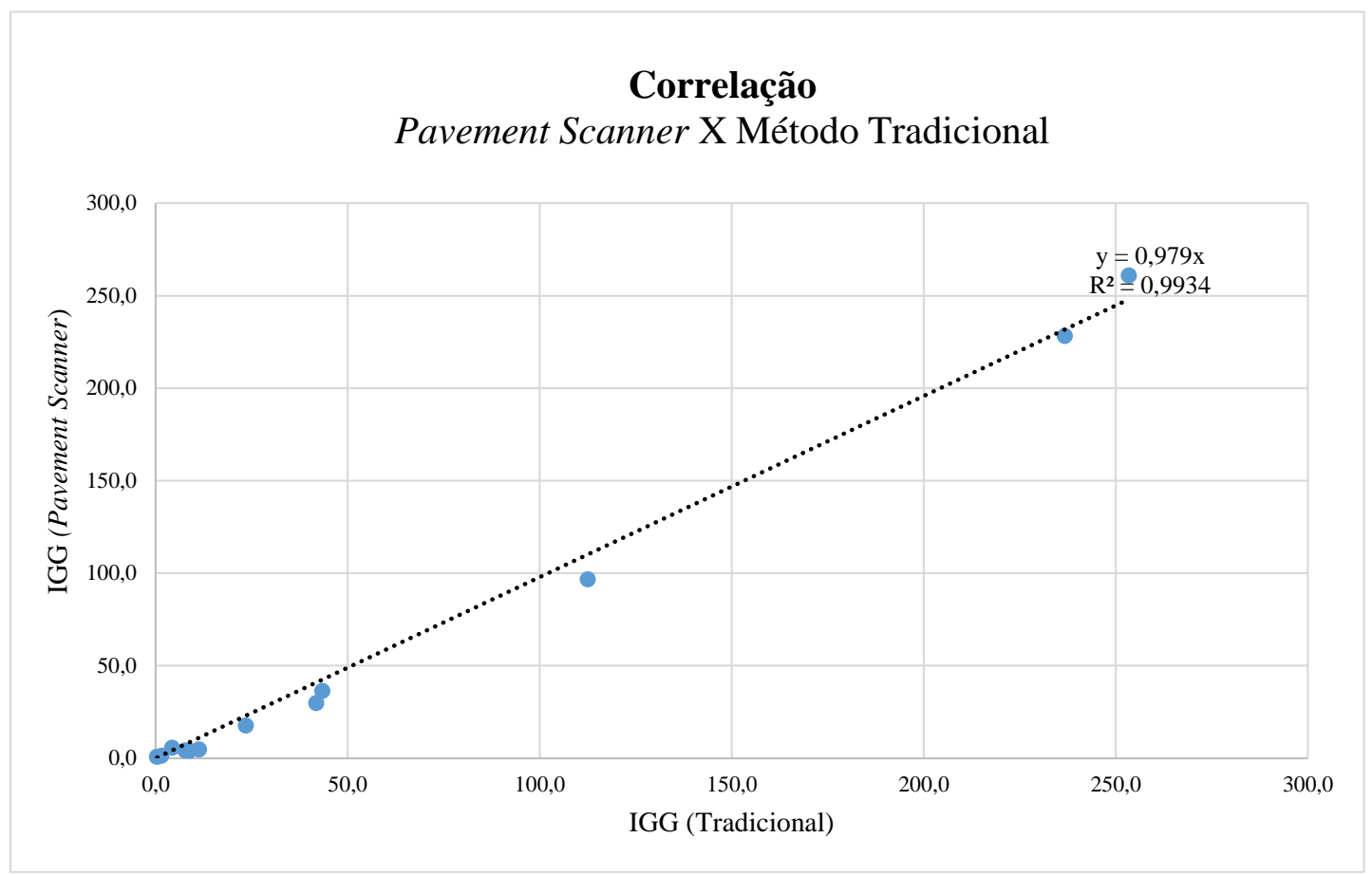

Figura 4.14 - Correlação das médias de IGG obtido com o Pavement Scanner e o obtido pelo Método Tradicional

O gráfico apresentado demonstra uma boa correlação entre o IGG pelo método tradicional e o IGG pelo Pavement Scanner com $\mathrm{R}^{2}$ de 0,99 . O resultado da correlação conduz a valores de IGG pelo Pavement Scanner inferiores em aproximadamente 2\% em relação ao tradicional. 
Os dados apresentados no gráfico da Figura 4.14 referem-se à correlação dos valores médios dos resultados do IGG. No entanto, buscando-se apresentar uma melhor relação dos pontos estudados, demonstrando possíveis discrepâncias de valores que a média não evidencia, plotou-se na Figura 4.15 os pontos de resultado do IGG tradicional e mecanizado.

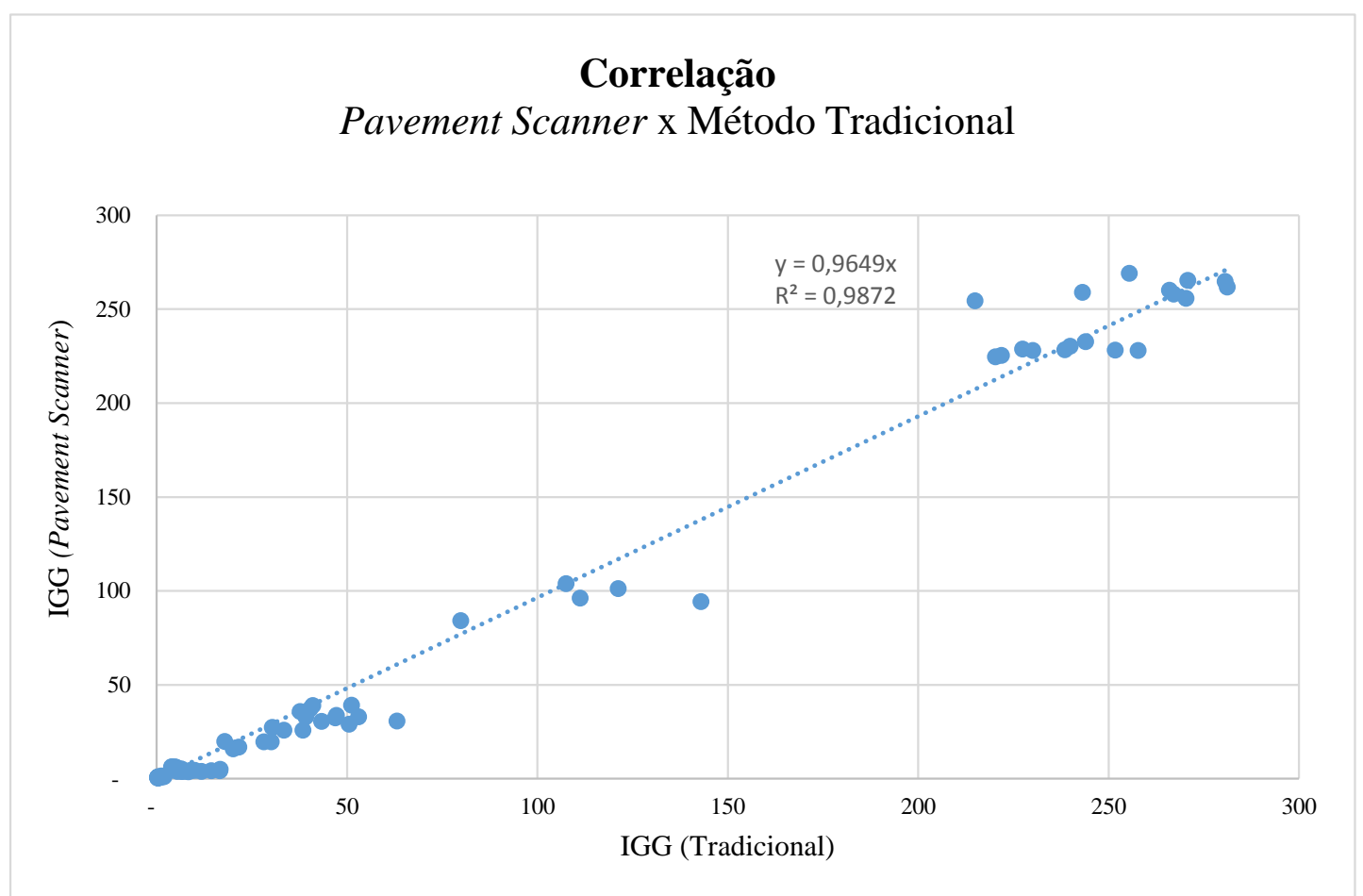

Figura 4.15 - Correlação do IGG do Pavement Scanner e o obtido pelo Método Tradicional

O gráfico apresentado demonstra valores de IGG mecanizados aproximadamente 3,5\% inferiores aos tradicionais. Verifica-se que os resultados do IGG com Pavement Scanner apresentam uma tendência "horizontal", ou seja, a variação no eixo das abscissas, que refere-se ao levantamento tradicional é muito maior para cada seçãoteste, se comparada aos valores representados no eixo y, que referem-se aos mecanizados. Além disso, o método tradicional apresenta coeficiente de variação superior aos 3,5\% obtidos pela curva de correlação.

É importante pontuar que a coleta de dados usual para a tomada de decisão em nível de rede é geralmente diferente daquela utilizada em nível de projeto, portanto, os requisitos de qualidade para a condição do pavimento também são diferentes. A coleta 
em nível de rede tradicionalmente envolve o levantamento de grandes quantidades de dados do estado do pavimento, que são convertidos em índices de condição, sendo usualmente realizada por métodos mecanizados. No nível de projeto, dados mais específicos são normalmente coletados em termos de identificação de defeitos e suas severidades, sendo o nível de informação adequado para utilização em decisões técnicas. Tendo em vista os resultados obtidos com o Pavement Scanner, percebe-se que os dados são de rápida restituição, sendo possível coleta de grandes extensões de rodovia, em curto intervalo de tempo, porém com o nível de detalhamento necessário para decisões também em nível de projeto.

\subsection{Resultados de Trincamento}

A Tabela 4.3 apresenta os resultados de trincamento para pistas simples, enquanto que a Tabela 4.4 para pistas duplas. Os referidos resultados foram obtidos a partir dos levantamentos tradicionais e mecanizados, sendo que para o levantamento tradicional foram realizadas 14 repetições na ST-01, ST-03, ST-04 e ST-06, para o tradicional detalhado, realizadas 5 repetições em todas as seções-teste e para o mecanizado, 9 repetições. 
Tabela 4.3 - Resultados de Trincamento para Pista Simples

\begin{tabular}{|c|c|c|c|c|c|c|c|c|c|c|c|c|c|c|c|c|c|c|c|c|}
\hline \multirow{2}{*}{\multicolumn{2}{|c|}{ Trincamento $(\%)$}} & \multicolumn{14}{|c|}{ Amostra } & \multirow{2}{*}{ Média } & \multirow{2}{*}{$\begin{array}{l}\text { Desvio } \\
\text { Padrão }\end{array}$} & \multirow{2}{*}{\begin{tabular}{|l|} 
Coef. de \\
Variação
\end{tabular}} & \multirow{2}{*}{ Variância } & \multirow{2}{*}{$\begin{array}{l}\text { Máx - } \\
\text { Mín }\end{array}$} \\
\hline & & 1 & 2 & 3 & 4 & 5 & 6 & 7 & 8 & 9 & 10 & 11 & 12 & 13 & 14 & & & & & \\
\hline \multirow{3}{*}{$\begin{array}{c}\text { Seção Teste } \\
01\end{array}$} & Tradicional & 0,0 & 0,0 & 0,0 & 0,0 & 0,0 & 0,0 & 0,0 & 0,0 & 0,0 & 0,0 & 0,0 & 0,0 & 0,0 & 0,0 & 0,0 & 0,0 & - & 0,0 & 0,0 \\
\hline & Tradicional Detalhado & 0,0 & 0,0 & 0,0 & 0,0 & 0,0 & & & & & & & & & & 0,0 & 0,0 & - & 0,0 & 0,0 \\
\hline & Pavement Scanner & 0,0 & 0,0 & 0,0 & 0,0 & 0,0 & 0,0 & 0,0 & 0,0 & 0,0 & & & & & & 0,0 & 0,0 & - & 0,0 & 0,0 \\
\hline \multirow{3}{*}{$\begin{array}{c}\text { Seção Teste } \\
03\end{array}$} & Tradicional & 51,2 & 39,1 & 41,5 & 40,6 & 38,8 & 42,1 & 42,7 & 42,4 & 44,7 & 58,8 & 44,7 & 51,2 & 48,2 & 41,8 & 44,8 & 3,7 & $8 \%$ & 3,7 & 20,0 \\
\hline & Tradicional Detalhado & 72,7 & 62,2 & 67,7 & 46,4 & 49,2 & & & & & & & & & & 59,6 & 11,5 & $19 \%$ & 131,3 & 26,3 \\
\hline & Pavement Scanner & 36,4 & 37,3 & 36,4 & 36,2 & 34,4 & 35,7 & 35,4 & 35,5 & 33,9 & & & & & & 35,7 & 1,0 & $3 \%$ & 1,1 & 3,3 \\
\hline \multirow{3}{*}{$\begin{array}{c}\text { Seção Teste } \\
05\end{array}$} & Tradicional & & & & & & & & & & & & & & & & & - & & \\
\hline & Tradicional Detalhado & 0,9 & 0,8 & 0,9 & 0,3 & 1,1 & & & & & & & & & & 0,8 & 0,3 & $36 \%$ & 0,1 & 0,8 \\
\hline & Pavement Scanner & 0,0 & 0,0 & 0,0 & 0,0 & 0,0 & 0,0 & 0,0 & 0,0 & 0,0 & & & & & & 0,0 & 0,0 & - & 0,0 & 0,0 \\
\hline \multirow{3}{*}{$\begin{array}{c}\text { Seção Teste } \\
07\end{array}$} & Tradicional & & & & & & & & & & & & & & & & & - & & \\
\hline & Tradicional Detalhado & 8,9 & 8,6 & 7,8 & 5,0 & 10,5 & & & & & & & & & & 8,2 & 2,0 & $25 \%$ & 4,1 & 5,5 \\
\hline & Pavement Scanner & 6,4 & 7,5 & 6,9 & 7,5 & 7,4 & 7,5 & 7,1 & 6,6 & 6,8 & & & & & & 7,1 & 0,4 & $6 \%$ & 0,2 & 0,9 \\
\hline
\end{tabular}


Tabela 4.4 - Resultados de Trincamento para Pista Dupla

\begin{tabular}{|c|c|c|c|c|c|c|c|c|c|c|c|c|c|c|c|c|c|c|c|c|}
\hline \multirow{2}{*}{\multicolumn{2}{|c|}{ Trincamento $(\%)$}} & \multicolumn{14}{|c|}{ Amostra } & \multirow{2}{*}{ Média } & \multirow{2}{*}{$\begin{array}{l}\text { Desvio } \\
\text { Padrão } \\
\end{array}$} & \multirow{2}{*}{$\begin{array}{l}\text { Coef. de } \\
\text { Variação }\end{array}$} & \multirow{2}{*}{ Variância } & \multirow{2}{*}{$\begin{array}{l}\text { Máx - } \\
\text { Mín }\end{array}$} \\
\hline & & 1 & 2 & 3 & 4 & 5 & 6 & 7 & 8 & 9 & 10 & 11 & 12 & 13 & 14 & & & & & \\
\hline \multirow{3}{*}{\begin{tabular}{c|} 
Seção Teste \\
02 \\
Faixa 1 \\
\end{tabular}} & Tradicional & & & & & & & & & & & & & & & & & - & & 0,0 \\
\hline & Tradicional Detalhado & 0,0 & 0,0 & 0,0 & 0,0 & 0,0 & & & & & & & & & & 0,0 & 0,0 & - & 0,0 & 0,0 \\
\hline & Pavement Scanner & 0,1 & 0,1 & 0,1 & 0,1 & 0,1 & 0,1 & 0,1 & 0,1 & 0,1 & & & & & & 0,1 & 0,0 & $7 \%$ & 0,0 & 0,0 \\
\hline \multirow{3}{*}{$\begin{array}{c}\text { Seção Teste } \\
02 \\
\text { Faixa } 2 \\
\end{array}$} & Tradicional & & & & & & & & & & & & & & & & & - & & \\
\hline & Tradicional Detalhado & 0,6 & 1,7 & 2,0 & 0,9 & 1,2 & & & & & & & & & & 1,3 & 0,6 & $46 \%$ & 0,3 & 1,5 \\
\hline & Pavement Scanner & 0,8 & 0,8 & 0,8 & 0,8 & 0,8 & 0,8 & 0,7 & 0,7 & 0,8 & & & & & & 0,8 & 0,0 & $6 \%$ & 0,0 & 0,1 \\
\hline \multirow{3}{*}{$\begin{array}{c}\text { Seção Teste } \\
04 \\
\text { Faixa } 1 \\
\end{array}$} & Tradicional & 11,7 & 9,4 & 11,1 & 10,1 & 5,6 & 6,6 & 7,9 & 5,0 & 7,8 & 7,8 & 10,0 & 8,9 & 7,8 & 8,9 & 8,5 & 2,4 & $28 \%$ & 5,7 & 6,7 \\
\hline & \begin{tabular}{|l|} 
Tradicional Detalhado \\
\end{tabular} & 8,0 & 5,1 & 9,3 & 3,0 & 2,4 & & & & & & & & & & 5,6 & 3,0 & $54 \%$ & 9,2 & 6,9 \\
\hline & Pavement Scanner & 2,6 & 3,5 & 2,8 & 2,6 & 3,8 & 3,5 & 4,2 & 2,9 & 4,0 & & & & & & 3,3 & 0,6 & $19 \%$ & 0,4 & 1,6 \\
\hline \multirow{3}{*}{$\begin{array}{c}\text { Seção Teste } \\
04 \\
\text { Faixa } 2\end{array}$} & Tradicional & 80,6 & 70,0 & 75,0 & 79,4 & 78,9 & 91,7 & 75,6 & 83,3 & 82,2 & 69,0 & 77,7 & 77,2 & 85,0 & 78,9 & 78,9 & 6,1 & $8 \%$ & 37,2 & 21,7 \\
\hline & Tradicional Detalhado & 98,0 & 81,0 & 95,0 & 93,0 & 70,0 & & & & & & & & & & 87,4 & 11,7 & $13 \%$ & 136,3 & 28,0 \\
\hline & Pavement Scanner & 54,2 & 52,3 & 50,5 & 49,6 & 55,5 & 52,5 & 57,5 & 56,7 & 53,4 & & & & & & 53,6 & 2,7 & $5 \%$ & 7,1 & 7,9 \\
\hline \multirow{3}{*}{$\begin{array}{c}\text { Seção Teste } \\
06 \\
\text { Faixa } 1\end{array}$} & Tradicional & 0,0 & 0,0 & 0,0 & 0,0 & 0,0 & 0,0 & 0,0 & 0,0 & 0,0 & 0,0 & 0,0 & 0,0 & 0,0 & 0,0 & 0,0 & 0,0 & - & 0,0 & 0,0 \\
\hline & \begin{tabular}{|l|} 
Tradicional Detalhado \\
\end{tabular} & 0,0 & 0,0 & 0,0 & 0,0 & 0,0 & & & & & & & & & & 0,0 & 0,0 & - & 0,0 & 0,0 \\
\hline & Pavement Scanner & 0,0 & 0,0 & 0,0 & 0,0 & 0,0 & 0,0 & 0,0 & 0,0 & & & & & & & 0,0 & 0,0 & - & 0,0 & 0,0 \\
\hline \multirow{3}{*}{$\begin{array}{c}\text { Seção Teste } \\
06 \\
\text { Faixa } 2\end{array}$} & Tradicional & 0,1 & 0,1 & 0,1 & 0,1 & 0,1 & 0,0 & 0,0 & 0,1 & 0,0 & 0,1 & 0,1 & 0,1 & 0,0 & 0,2 & 0,1 & 0,1 & - & 0,0 & 0,1 \\
\hline & \begin{tabular}{|l|} 
Tradicional Detalhado \\
\end{tabular} & 0,0 & 0,0 & 0,2 & 0,1 & 0,3 & & & & & & & & & & 0,1 & 0,1 & - & 0,0 & 0,3 \\
\hline & Pavement Scanner & 0,0 & 0,0 & 0,0 & 0,0 & 0,0 & 0,0 & 0,0 & 0,0 & & & & & & & 0,0 & 0,0 & - & 0,0 & 0,0 \\
\hline \multirow{3}{*}{$\begin{array}{c}\text { Seção Teste } \\
08 \\
\text { Faixa } 1 \\
\end{array}$} & Tradicional & & & & & & & & & & & & & & & & & - & & \\
\hline & Tradicional Detalhado & 0,4 & 0,3 & 0,5 & 0,7 & 0,7 & & & & & & & & & & 0,5 & 0,2 & $38 \%$ & 0,0 & 0,5 \\
\hline & \begin{tabular}{|l|} 
Pavement Scanner \\
\end{tabular} & 1,0 & 1,4 & 1,3 & 1,2 & 1,3 & 1,3 & 1,3 & 1,0 & 0,9 & & & & & & 1,2 & 0,2 & $16 \%$ & 0,0 & 0,5 \\
\hline \multirow{3}{*}{$\begin{array}{c}\text { Seção Teste } \\
08 \\
\text { Faixa } 2 \\
\end{array}$} & Tradicional & & & & & & & & & & & & & & & & & - & & \\
\hline & \begin{tabular}{|l|} 
Tradicional Detalhado \\
\end{tabular} & 33,0 & 41,0 & 33,8 & 19,4 & 21,8 & & & & & & & & & & 29,8 & 9,0 & $30 \%$ & 81,0 & 21,6 \\
\hline & Pavement Scanner & 20,6 & 19,9 & 21,3 & 19,1 & 20,8 & 21,0 & 20,0 & 19,0 & 17,7 & & & & & & 19,9 & 1,2 & $6 \%$ & 1,3 & 3,6 \\
\hline
\end{tabular}


Verifica-se que em todas as seções-teste estudadas o coeficiente de variação do trincamento nos levantamentos mecanizados são inferiores aos dos levantamentos tradicionais, inclusive nos casos de incidência muito baixa, em que o coeficiente de variação tende a ser alto.

Para as seções-teste mais críticas, o Pavement Scanner apresentou baixa variabilidade de resultados (3\% a 6\%), enquanto que o tradicional apresentou variabilidade maior $(8 \%$ a $38 \%)$.

No caso de pistas duplas, tornou-se importante analisar principalmente o coeficiente de variação para as faixas 1 , já que para os levantamentos tradicionais a detecção de trincamento nesta faixa poderia ser menos precisa, pois o operador realiza o levantamento no bordo do acostamento. A faixa 1, nos levantamentos tradicionais, apresentou coeficiente variação alto de até $54 \%$, sendo este a maior variação em todo o levantamento.

De maneira a ilustrar a variação dos resultados do percentual de trincamento para cada tipo de levantamento, foram plotados gráficos ilustrativos, indicando-se com uma seta vermelha pontos de elevada variação em cada levantamento, conforme apresentado nas Figuras 4.16 a 4.27.

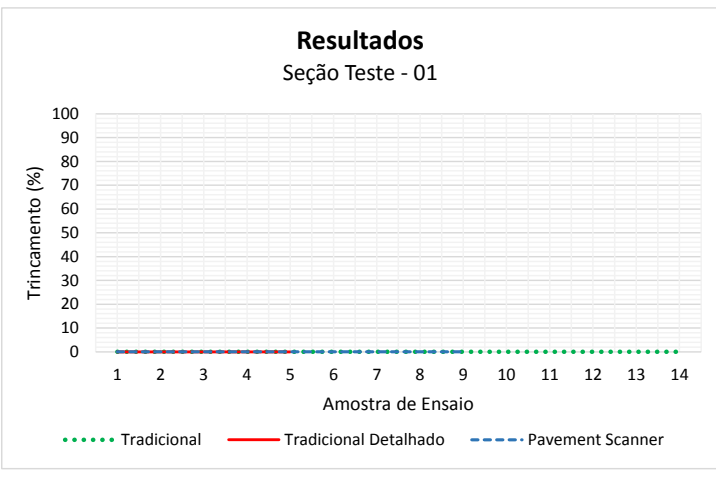

Figura 4.16 - Resultados do Trincamento ST-01

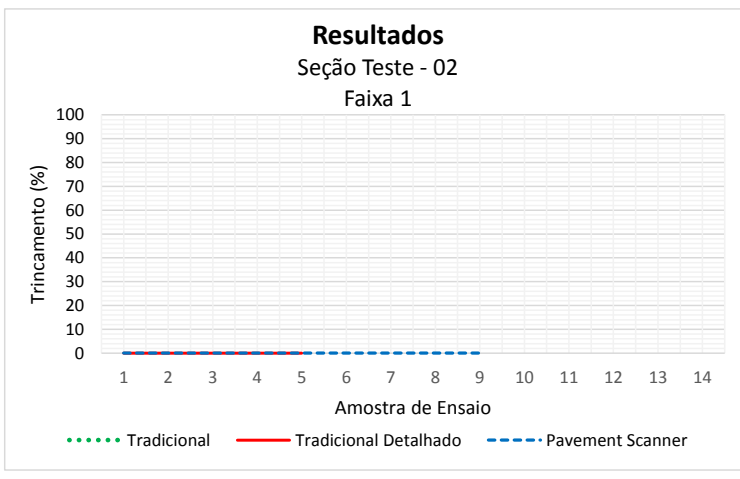

Figura 4.17 - Resultados do Trincamento ST-02 Faixa 1 


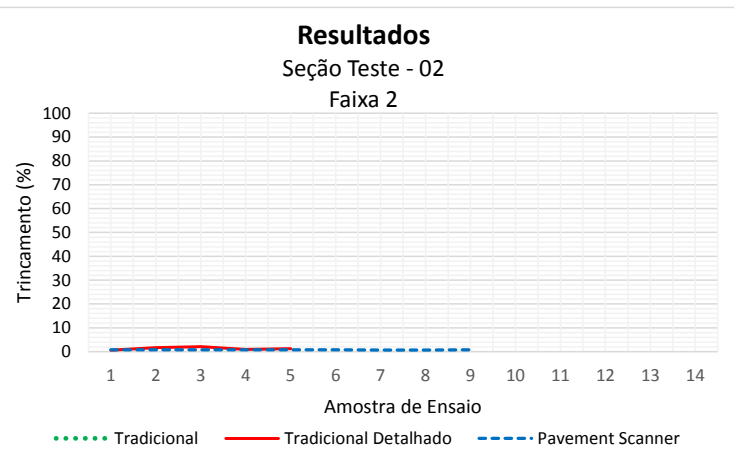

Figura 4.18 - Resultados do Trincamento ST-02 Faixa 2

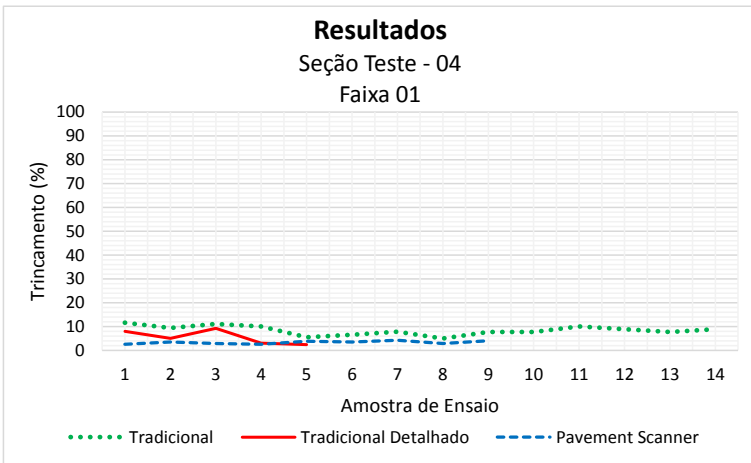

Figura 4.20 - Resultados do Trincamento ST-04 Faixa 1

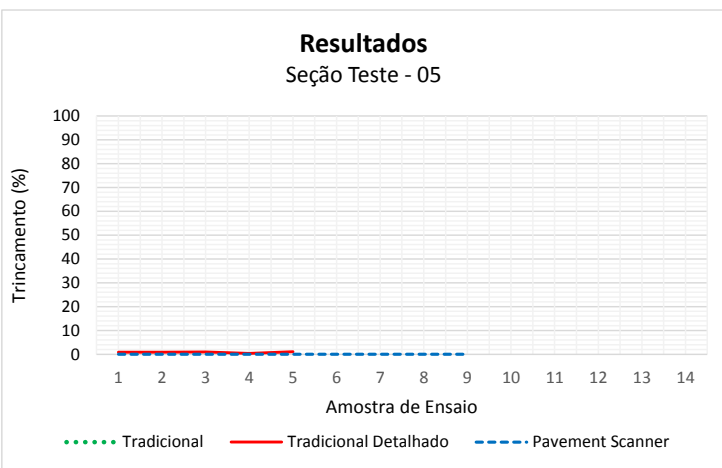

Figura 4.22 - Resultados do Trincamento ST-05

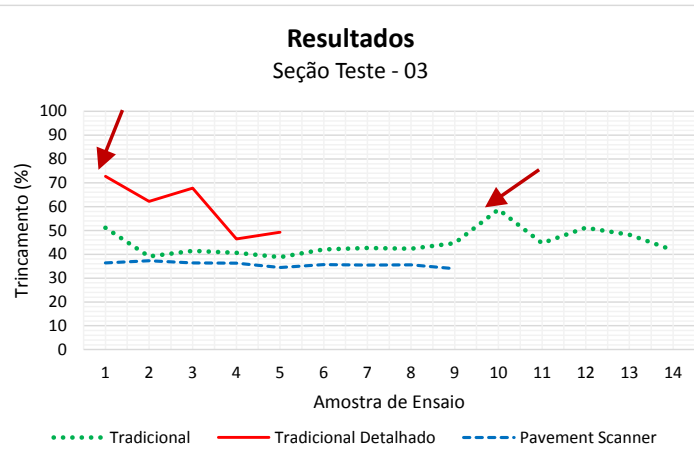

Figura 4.19 - Resultados do Trincamento ST-03

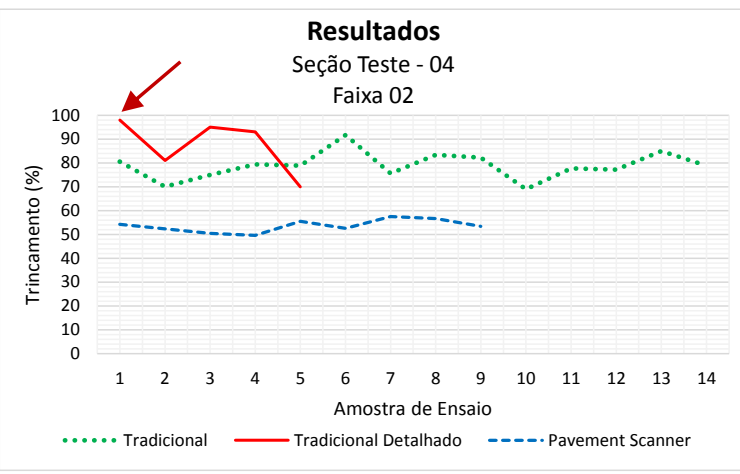

Figura 4.21 - Resultados do Trincamento ST-04 Faixa 2

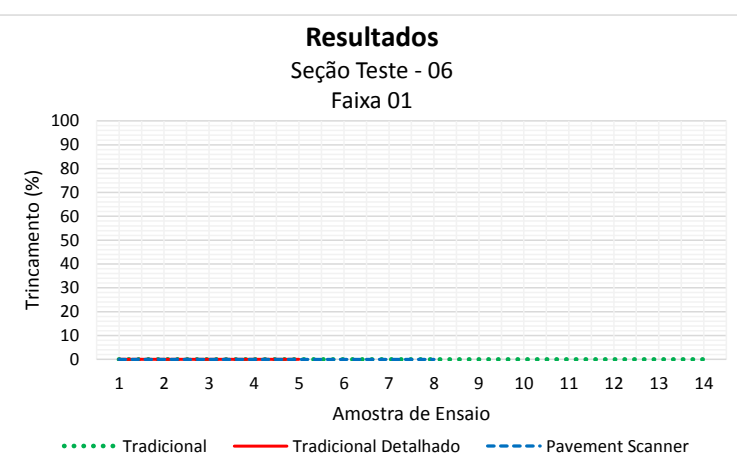

Figura 4.23 - Resultados do Trincamento ST-06 Faixa 1 


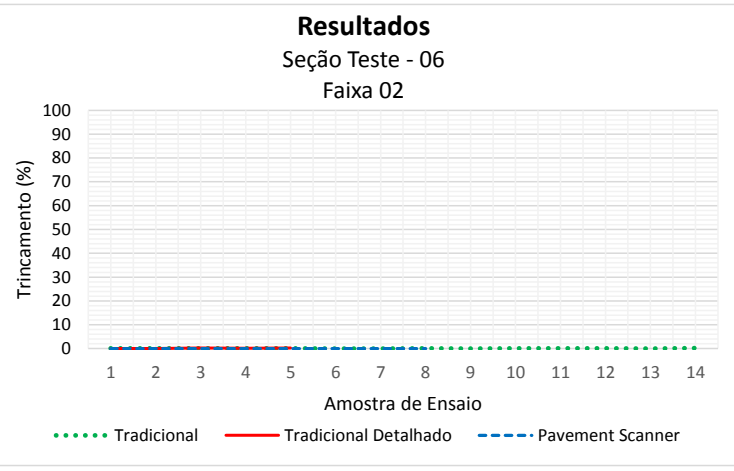

Figura 4.24 - Resultados do Trincamento ST-06 Faixa 2

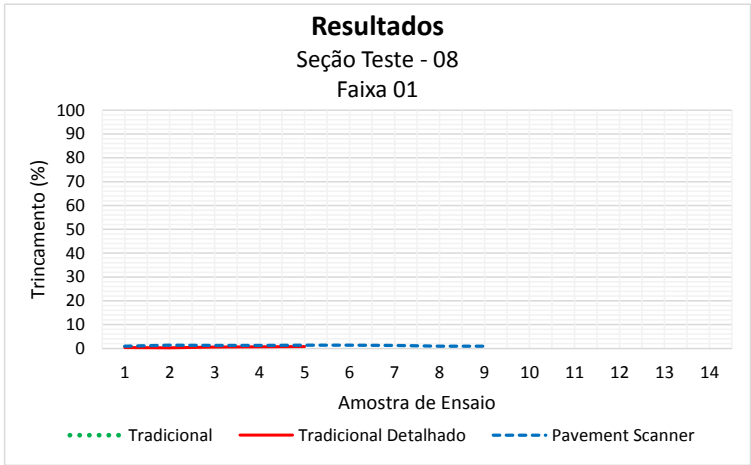

Figura 4.26 - Resultados do Trincamento ST-08 Faixa 1

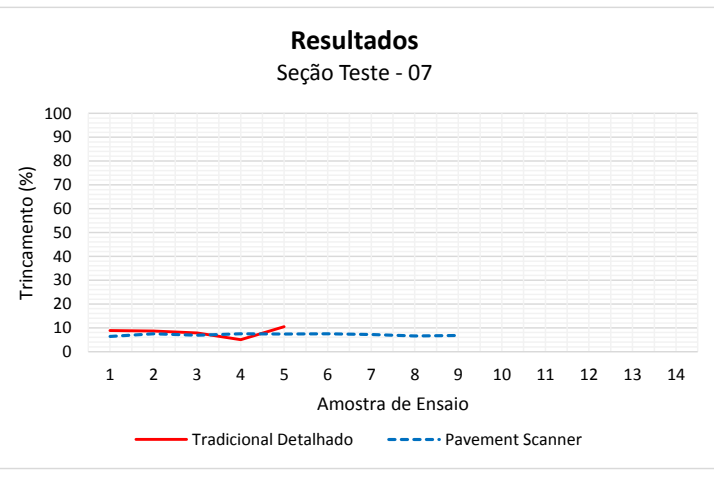

Figura 4.25 - Resultados do Trincamento ST-07

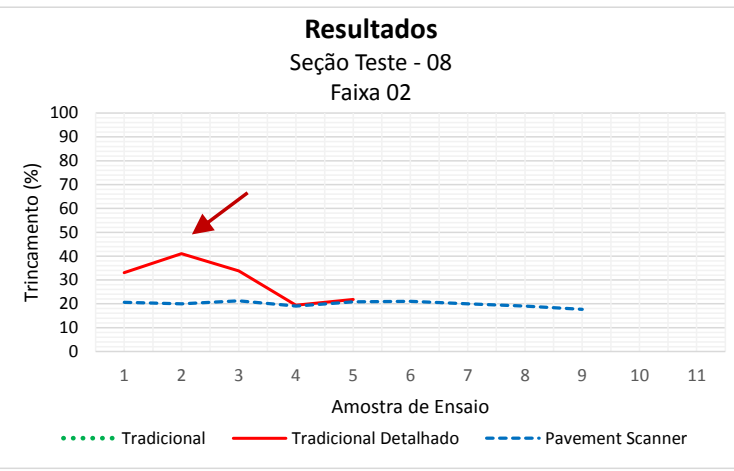

Figura 4.27 - Resultados do Trincamento ST-08 Faixa 2

Pelos gráficos é possível verificar que os resultados do levantamento tradicional ou visual apresentam elevada variabilidade. Além disso, nota-se que os percentuais de trincamento obtidos por este método apresentam-se mais altos que os mecanizados. Essa diferença entre os inventários é explicada pelo fato do levantamento mecanizado ser objetivo, ou seja, o defeito é mapeado conforme identificado pelo laser, sendo a sua área delimitada nos locais em que realmente há trincamento. No caso do levantamento tradicional, a área trincada é definida visualmente, sendo muitas vezes superestimada, já que o operador tem a tendência de dividir a faixa em três bandas de trincamento (interna, intermediária e externa), atribuindo a cada uma das bandas o percentual aproximado de $33 \%$ de área, ou seja, a resolução do levantamento visual é menor que a do levantamento mecanizado. As Figuras 4.28 a 4.30 demonstram alguns exemplos das diferenças entre as resoluções dos dois tipos de levantamentos. Verificase que o mecanizado apresenta resolução de $1 \mathrm{~m}$ x $0,2 \mathrm{~m}$, já o visual detalhado possui 
resolução em média de $1 \mathrm{~m}$ x 1,2m. Ressalta-se que a diferença tende a ser ainda maior no levantamento tradicional amostral (o IGG convencional), já que a resolução do levantamento é pior, de aproximadamente $6 \mathrm{~m}$ x 1,2m. 

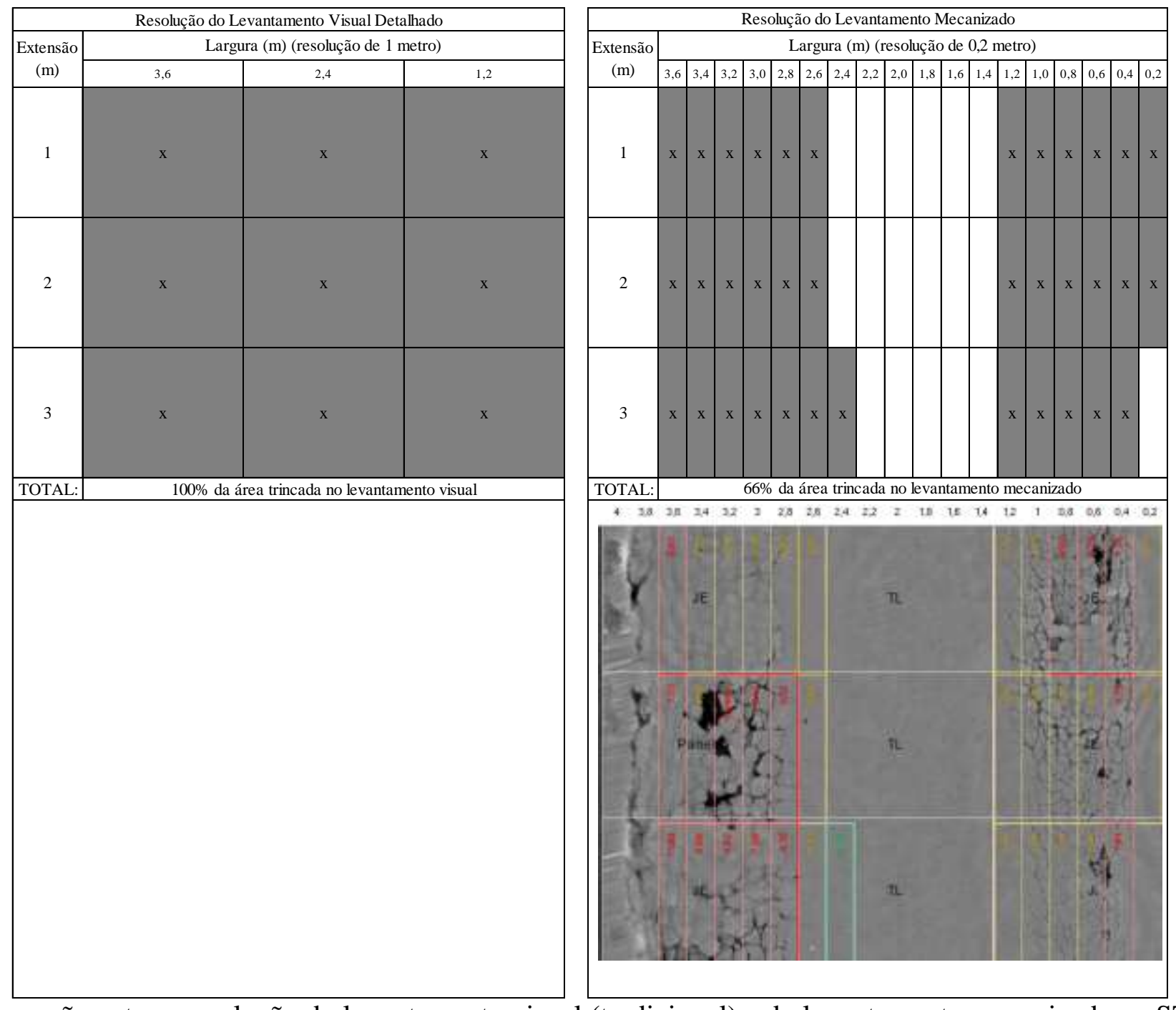

Figura 4.28 - Comparação entre a resolução do levantamento visual (tradicional) e do levantamento mecanizado na ST-03 entre a posição 0,040 e $0,043 \mathrm{~m}$. 

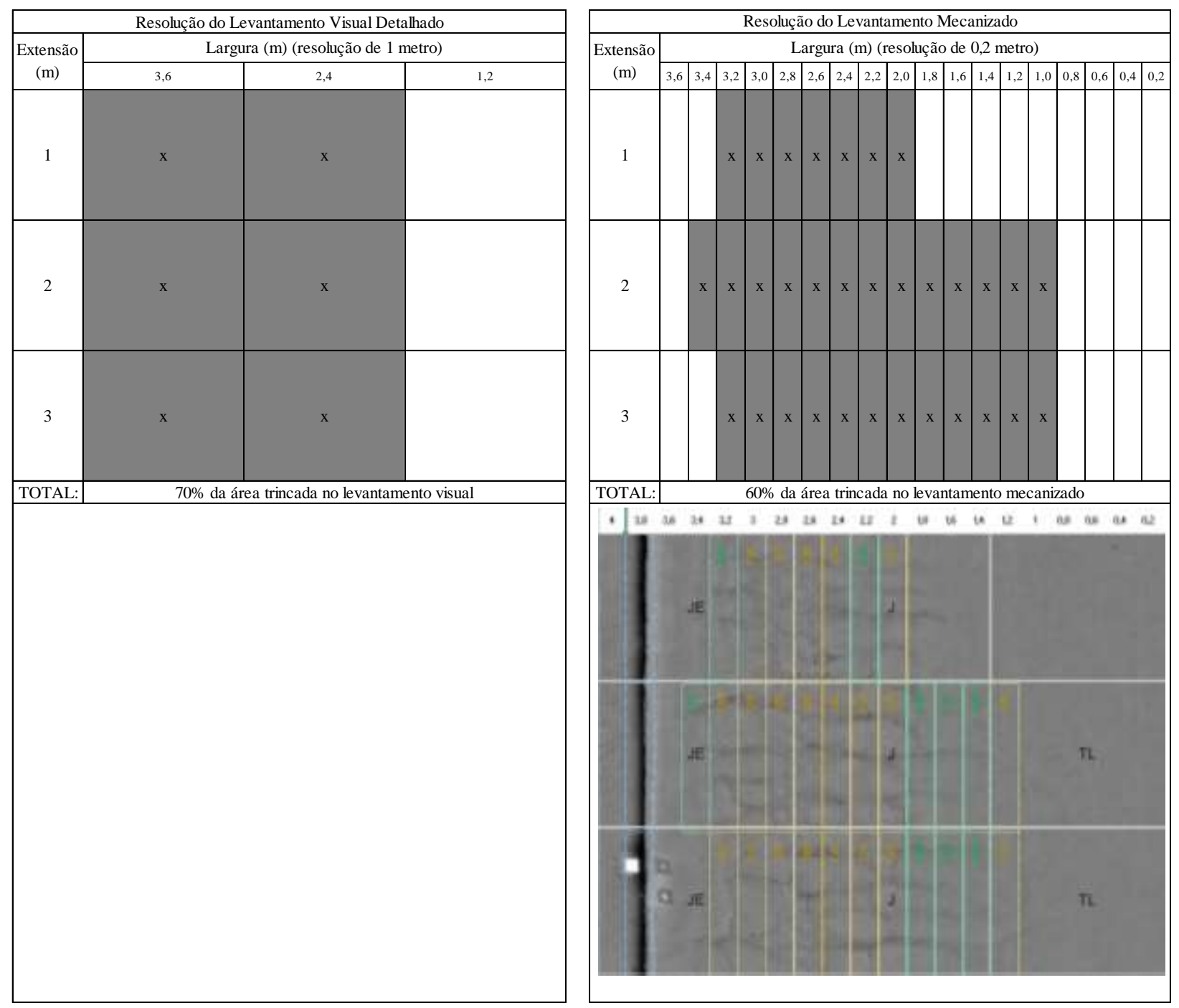

Figura 4.29 - Comparação entre a resolução do levantamento visual (tradicional) e do levantamento mecanizado na ST-04, faixa 2 entre a posição 0,261 e $0,263 \mathrm{~m}$. 

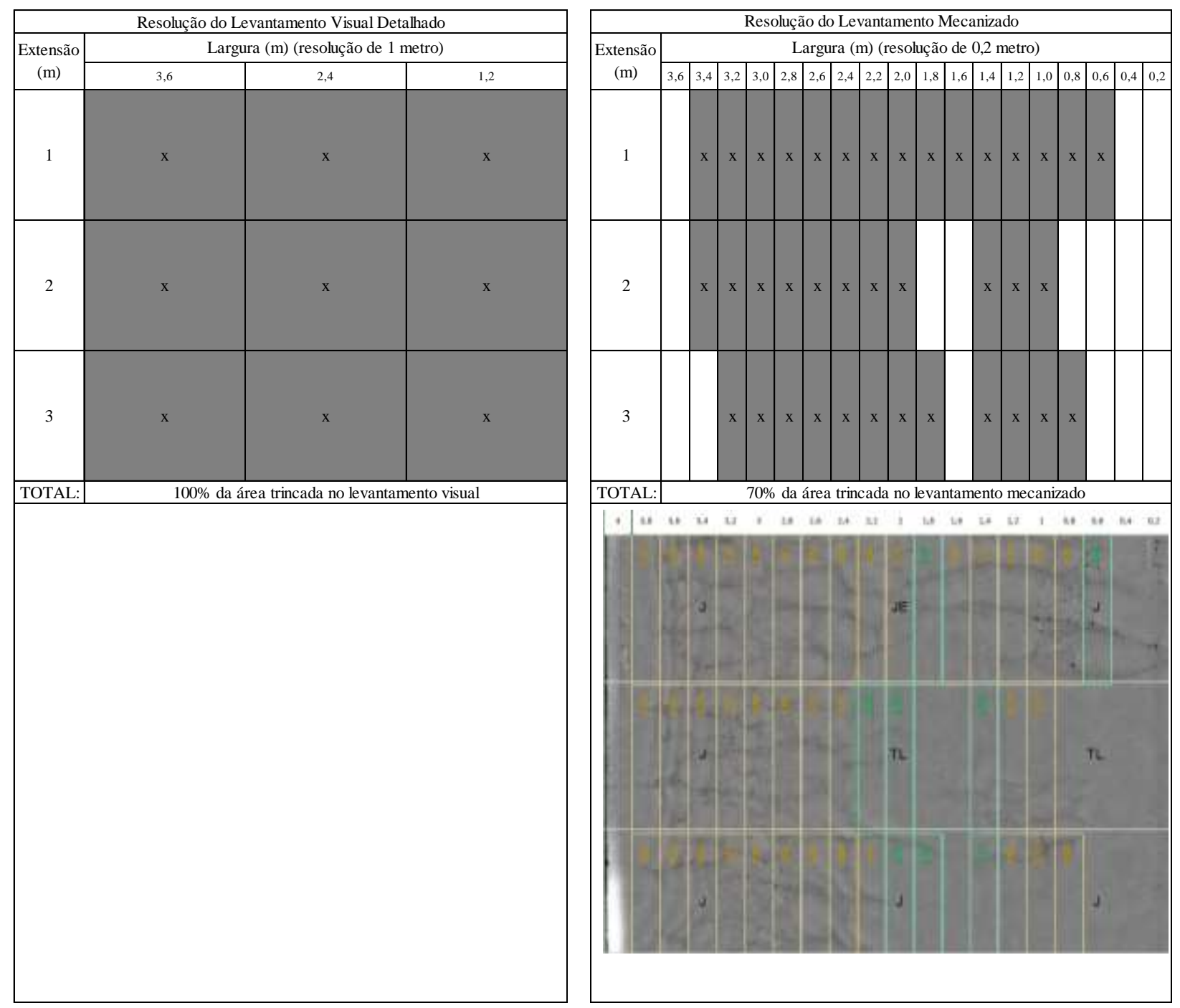

Figura 4.30 - Comparação entre a resolução do levantamento visual (tradicional) e do levantamento mecanizado na ST-04, faixa 2 entre a posição 0,300 e $0,303 \mathrm{~m}$. 
É possível verificar pelos exemplos apresentados que a diferença de resolução de cada tipo levantamento culmina em diferentes percentuais de trincamento, já que o levantamento visual apresenta um resultado menos refinado e detalhado que o obtido no Pavement Scanner. Vale destacar que a baixa resolução do levantamento visual ou tradicional tende a aumentar o percentual de trincamento, bem como, a variação de resultados, apresentando um desvio padrão e variância muito superior se comparado ao do levantamento mecanizado.

\subsection{Resultados do Afundamento na Trilha de Roda}

A Tabela 4.5 apresenta os resultados de afundamento na trilha de roda para pistas simples, enquanto que a Tabela 4.6 para pistas duplas. Os referidos resultados foram obtidos a partir dos levantamentos tradicionais e mecanizados, sendo que para o levantamento tradicional foram realizadas 14 repetições na ST-01, ST-03, ST-04 e ST06, para o tradicional detalhado, realizadas 5 repetições em todas as seções-teste e para o mecanizado, 9 repetições. 
Tabela 4.5 - Resultados de Afundamento na Trilha de Roda para Pista Simples

\begin{tabular}{|c|c|c|c|c|c|c|c|c|c|c|c|c|c|c|c|c|c|c|c|c|}
\hline \multirow{2}{*}{\multicolumn{2}{|c|}{$\begin{array}{c}\text { Trilha de Roda Média } \\
\text { (mm) }\end{array}$}} & \multicolumn{14}{|c|}{ Amostra } & \multirow{2}{*}{ Média } & \multirow{2}{*}{$\begin{array}{l}\text { Desvio } \\
\text { Padrão }\end{array}$} & \multirow{2}{*}{\begin{tabular}{|l|} 
Coef. de \\
Variação
\end{tabular}} & \multirow{2}{*}{ Variância } & \multirow{2}{*}{$\begin{array}{l}\text { Máx - } \\
\text { Mín }\end{array}$} \\
\hline & & 1 & 2 & 3 & 4 & 5 & 6 & 7 & 8 & 9 & 10 & 11 & 12 & 13 & 14 & & & & & \\
\hline \multirow{3}{*}{$\begin{array}{c}\text { Seção Teste } \\
01\end{array}$} & Tradicional & 0,2 & 0,1 & 0,1 & 0,1 & 0,3 & 0,2 & 0,1 & 0,1 & 0,1 & 0,2 & 0,1 & 0,1 & 0,1 & 0,2 & 0,2 & 0,1 & $37 \%$ & 0,0 & 0,2 \\
\hline & \begin{tabular}{|l|} 
Tradicional Detalhado \\
\end{tabular} & 0,1 & 0,1 & 0,1 & 0,1 & 0,1 & & & & & & & & & & 0,1 & 0,0 & $26 \%$ & 0,0 & 0,1 \\
\hline & Pavement Scanner & 0,4 & 0,3 & 0,3 & 0,3 & 0,3 & 0,4 & 0,2 & 0,3 & 0,2 & & & & & & 0,3 & 0,1 & $17 \%$ & 0,0 & 0,1 \\
\hline \multirow{3}{*}{$\begin{array}{c}\text { Seção Teste } \\
03\end{array}$} & Tradicional & 13,4 & 12,3 & 12,4 & 12,3 & 13,0 & 12,7 & 12,9 & 10,8 & 10,2 & 12,0 & 10,6 & 10,5 & 10,9 & 9,6 & 11,7 & 1,0 & $9 \%$ & 1,1 & 3,8 \\
\hline & \begin{tabular}{|l|} 
Tradicional Detalhado \\
\end{tabular} & 11,3 & 11,3 & 11,1 & 10,3 & 10,4 & & & & & & & & & & 10,9 & 0,5 & $4 \%$ & 0,2 & 1,0 \\
\hline & Pavement Scanner & 10,5 & 11,0 & 11,0 & 11,0 & 11,0 & 10,5 & 11,0 & 10,6 & 10,6 & & & & & & 10,8 & 0,2 & $2 \%$ & 0,1 & 0,5 \\
\hline \multirow{3}{*}{$\begin{array}{c}\text { Seção Teste } \\
05\end{array}$} & Tradicional & 0,0 & 0,0 & 0,0 & 0,0 & 0,0 & 0,0 & 0,0 & 0,0 & 0,0 & 0,0 & 0,0 & 0,0 & 0,0 & 0,0 & & & & & \\
\hline & Tradicional Detalhado & 1,9 & 1,7 & 1,9 & 1,8 & 1,8 & & & & & & & & & & 1,8 & 0,1 & $4 \%$ & 0,0 & 0,1 \\
\hline & Pavement Scanner & 1,8 & 1,8 & 1,7 & 1,6 & 1,5 & 1,6 & 1,5 & 1,8 & 1,8 & & & & & & 1,7 & 0,1 & $8 \%$ & 0,0 & 0,4 \\
\hline \multirow{3}{*}{$\begin{array}{c}\text { Seção Teste } \\
07\end{array}$} & Tradicional & 0,0 & 0,0 & 0,0 & 0,0 & 0,0 & 0,0 & 0,0 & 0,0 & 0,0 & 0,0 & 0,0 & 0,0 & 0,0 & 0,0 & & & & & \\
\hline & Tradicional Detalhado & 2,9 & 2,6 & 3,5 & 3,5 & 3,1 & & & & & & & & & & 3,1 & 0,4 & $13 \%$ & 0,2 & 0,4 \\
\hline & Pavement Scanner & 3,2 & 2,8 & 2,7 & 2,8 & 2,9 & 3,0 & 2,6 & 2,7 & 2,7 & & & & & & 2,8 & 0,2 & $6 \%$ & 0,0 & 0,5 \\
\hline
\end{tabular}


Tabela 4.6 - Resultados de Afundamento na Trilha de Roda para Pista Dupla

\begin{tabular}{|c|c|c|c|c|c|c|c|c|c|c|c|c|c|c|c|c|c|c|c|c|}
\hline \multirow{2}{*}{\multicolumn{2}{|c|}{$\begin{array}{c}\text { Trilha de Roda Média } \\
\text { (mm) }\end{array}$}} & \multicolumn{14}{|c|}{ Amostra } & \multirow{2}{*}{ Média } & \multirow{2}{*}{$\begin{array}{l}\text { Desvio } \\
\text { Padrão }\end{array}$} & \multirow{2}{*}{\begin{tabular}{|l} 
Coef. de \\
Variação
\end{tabular}} & \multirow{2}{*}{ Variância } & \multirow{2}{*}{$\begin{array}{l}\text { Máx - } \\
\text { Mín }\end{array}$} \\
\hline & & 1 & 2 & 3 & 4 & 5 & 6 & 7 & 8 & 9 & 10 & 11 & 12 & 13 & 14 & & & & & \\
\hline \multirow{3}{*}{$\begin{array}{c}\text { Seção Teste } \\
02 \\
\text { Faixa } 1\end{array}$} & Tradicional & & & & & & & & & & & & & & & & & & & 0,0 \\
\hline & Tradicional Detalhado & 0,7 & 0,6 & 0,7 & 0,4 & 0,4 & & & & & & & & & & 0,6 & 0,1 & $26 \%$ & 0,0 & 0,3 \\
\hline & Pavement Scanner & 0,7 & 0,9 & 0,7 & 1,0 & 0,7 & 0,8 & 0,7 & 0,7 & 0,7 & & & & & & 0,8 & 0,1 & $14 \%$ & 0,0 & 0,3 \\
\hline \multirow{3}{*}{\begin{tabular}{c|} 
Seção Teste \\
02 \\
Faixa 2 \\
\end{tabular}} & Tradicional & & & & & & & & & & & & & & & & & & & 0,0 \\
\hline & Tradicional Detalhado & 1,8 & 1,9 & 1,8 & 1,3 & 1,3 & & & & & & & & & & 1,6 & 0,3 & $19 \%$ & 0,1 & 0,7 \\
\hline & Pavement Scanner & 1,2 & 1,4 & 1,3 & 1,6 & 1,2 & 1,6 & 1,3 & 1,4 & 1,3 & & & & & & 1,4 & 0,2 & $11 \%$ & 0,0 & 0,4 \\
\hline \multirow{3}{*}{$\begin{array}{c}\text { Seção Teste } \\
\text { 04 } \\
\text { Faixa } 1\end{array}$} & Tradicional & 3,7 & 3,7 & 3,8 & 4,7 & 2,8 & 2,8 & 4,2 & 2,3 & 2,6 & 0,8 & 1,4 & 1,7 & 1,8 & 1,4 & 2,7 & 0,8 & $31 \%$ & 0,7 & 2,4 \\
\hline & Tradicional Detalhado & 2,4 & 2,9 & 3,1 & 1,7 & 2,1 & & & & & & & & & & 2,4 & 0,6 & $23 \%$ & 0,3 & 1,4 \\
\hline & Pavement Scanner & 2,2 & 2,4 & 2,1 & 2,0 & 2,1 & 2,2 & 2,1 & 1,6 & 2,0 & & & & & & 2,1 & 0,2 & $11 \%$ & 0,1 & 0,9 \\
\hline \multirow{3}{*}{$\begin{array}{c}\text { Seção Teste } \\
04 \\
\text { Faixa } 2 \\
\end{array}$} & Tradicional & 18,7 & 18,1 & 17,7 & 17,5 & 17,4 & 15,4 & 17,2 & 16,6 & 16,1 & 15,8 & 16,1 & 14,9 & 15,9 & 16,6 & 16,7 & 1,0 & $6 \%$ & 1,0 & 3,3 \\
\hline & Tradicional Detalhado & 18,0 & 17,4 & 18,1 & 17,2 & 18,2 & & & & & & & & & & 17,8 & 0,4 & $2 \%$ & 0,2 & 1,0 \\
\hline & Pavement Scanner & 17,0 & 16,9 & 16,4 & 18,6 & 15,9 & 17,6 & 16,5 & 16,9 & 15,2 & & & & & & 16,8 & 1,0 & $6 \%$ & 0,9 & 3,4 \\
\hline \multirow{3}{*}{$\begin{array}{c}\text { Seção Teste } \\
06 \\
\text { Faixa } 1 \\
\end{array}$} & Tradicional & 2,3 & 2,0 & 2,2 & 2,3 & 2,3 & 2,3 & 2,1 & 2,7 & 2,9 & 2,4 & 2,3 & 2,4 & 2,3 & 2,3 & 2,3 & 0,3 & $12 \%$ & 0,1 & 0,9 \\
\hline & Tradicional Detalhado & 1,7 & 0,8 & 1,7 & 1,5 & 1,4 & & & & & & & & & & 1,4 & 0,4 & $26 \%$ & 0,1 & 0,9 \\
\hline & Pavement Scanner & 2,2 & 2,1 & 2,2 & 2,6 & 2,3 & 2,5 & 2,2 & 2,3 & 2,1 & & & & & & 2,3 & 0,2 & $7 \%$ & 0,0 & 0,5 \\
\hline \multirow{3}{*}{$\begin{array}{c}\text { Seção Teste } \\
06 \\
\text { Faixa } 2 \\
\end{array}$} & Tradicional & 3,5 & 3,7 & 3,3 & 3,4 & 3,8 & 3,4 & 3,8 & 2,2 & 3,1 & 3,1 & 3,3 & 2,6 & 3,3 & 3,7 & 3,3 & 0,5 & $15 \%$ & 0,2 & 1,6 \\
\hline & Tradicional Detalhado & 2,9 & 3,6 & 3,8 & 3,1 & 2,8 & & & & & & & & & & 3,2 & 0,4 & $13 \%$ & 0,2 & 1,0 \\
\hline & Pavement Scanner & 2,8 & 3,3 & 2,9 & 3,3 & 2,7 & 3,2 & 2,7 & 2,9 & 2,8 & & & & & & 3,0 & 0,2 & $8 \%$ & 0,1 & 0,6 \\
\hline \multirow{3}{*}{\begin{tabular}{c|} 
Seção Teste \\
08 \\
Faixa 1 \\
\end{tabular}} & Tradicional & & & & & & & & & & & & & & & & & & & \\
\hline & Tradicional Detalhado & 3,2 & 3,9 & 6,7 & 3,3 & 4,3 & & & & & & & & & & 4,3 & 1,4 & $33 \%$ & 2,1 & 3,6 \\
\hline & Pavement Scanner & 3,0 & 3,3 & 3,4 & 3,7 & 3,3 & 3,4 & 3,2 & 3,5 & 3,3 & & & & & & 3,3 & 0,2 & $5 \%$ & 0,0 & 0,7 \\
\hline \multirow{3}{*}{$\begin{array}{c}\text { Seção Teste } \\
08 \\
\text { Faixa } 2\end{array}$} & Tradicional & & & & & & & & & & & & & & & & & & & \\
\hline & Tradicional Detalhado & 5,5 & 5,9 & 8,9 & 7,2 & 6,9 & & & & & & & & & & 6,9 & 1,3 & $20 \%$ & 1,8 & 3,4 \\
\hline & Pavement Scanner & 4,3 & 4,6 & 4,4 & 4,1 & 4,0 & 4,5 & 3,9 & 4,3 & 4,2 & & & & & & 4,3 & 0,2 & $5 \%$ & 0,1 & 0,7 \\
\hline
\end{tabular}


Verifica-se que na maioria das seções-teste estudadas o coeficiente de variação do afundamento médio na trilha de roda do Pavement Scanner foi inferior ao do levantamento tradicional. Isso é devido à imprecisão do levantamento com a treliça metálica, principalmente com relação ao ponto de levantamento, já que qualquer variação de poucos centímetros no local de coleta de dados pode alterar razoavelmente o resultado.

Outro fator para a maior variabilidade do levantamento tradicional é dado pela dificuldade de levantamento da trilha de roda em rodovias com VDM elevado, pois o intervalo para coleta de informação é curto quando não há fechamento da pista (situação usual nos levantamentos visuais), havendo pouco tempo para conferência, em função do risco de acidente para o avaliador.

De maneira a ilustrar a variação dos resultados do afundamento médio em trilha de roda para cada tipo de levantamento, foram plotados gráficos ilustrativos, indicandose com uma seta vermelha pontos de elevada variação em cada levantamento, conforme apresentado nas Figuras 4.31 a 4.42.

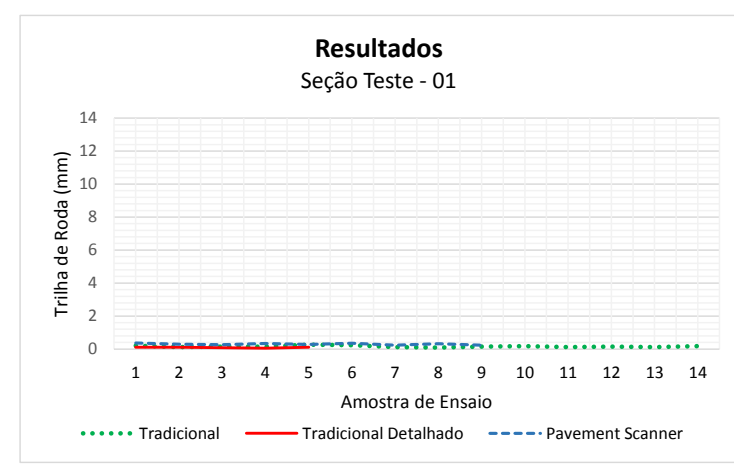

Figura 4.31 - Resultados do Afundamento médio na Trilha de Roda - ST-01

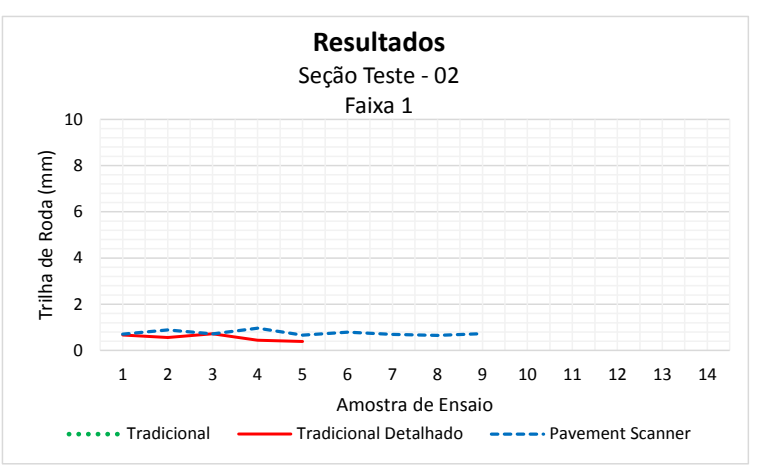

Figura 4.32 - Resultados do Afundamento médio na Trilha de Roda - ST-02 Faixa 1 


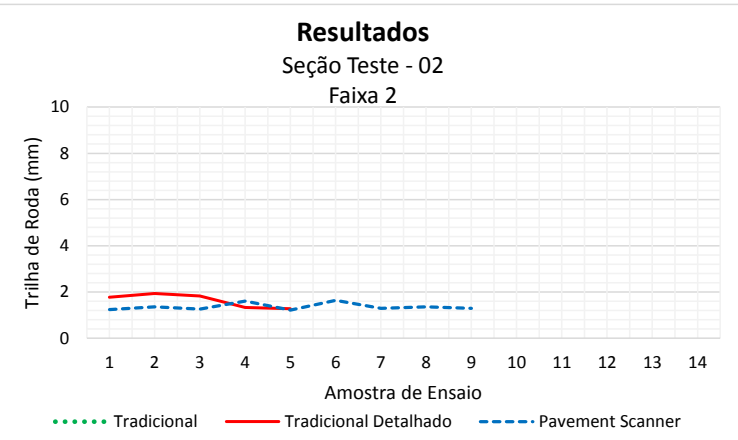

Figura 4.33 - Resultados do Afundamento médio na Trilha de Roda - ST-02 Faixa 2

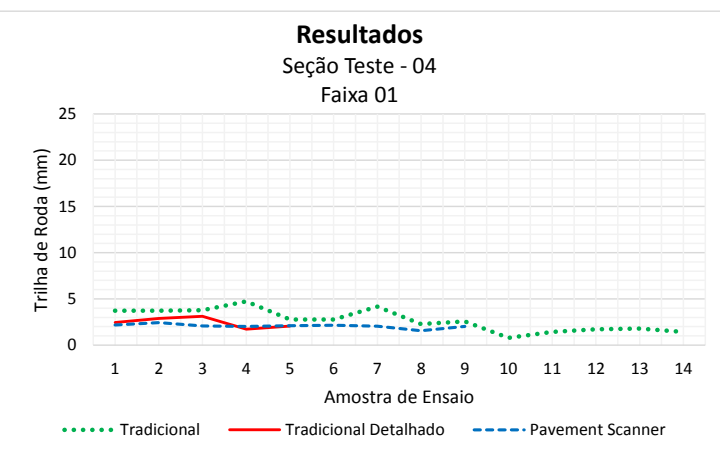

Figura 4.35 - Resultados do Afundamento médio na Trilha de Roda - ST-04 Faixa 1

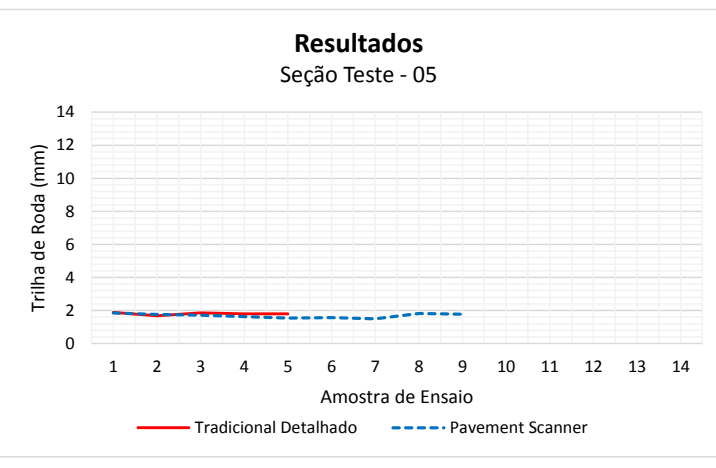

Figura 4.37 - Resultados do Afundamento médio na Trilha de Roda - ST-05

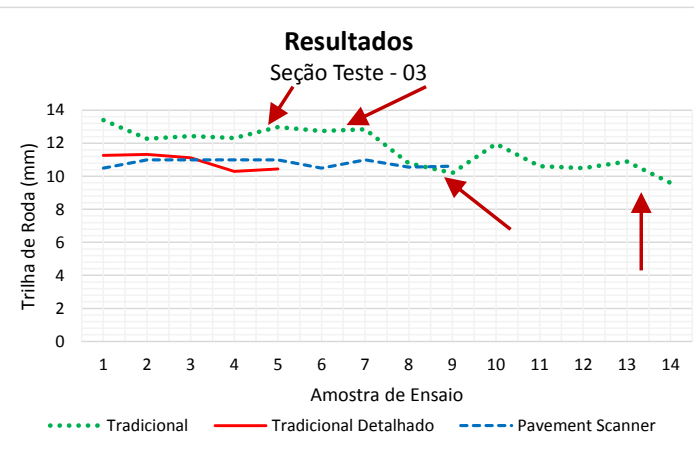

Figura 4.34 - Resultados do Afundamento médio na Trilha de Roda - ST-03

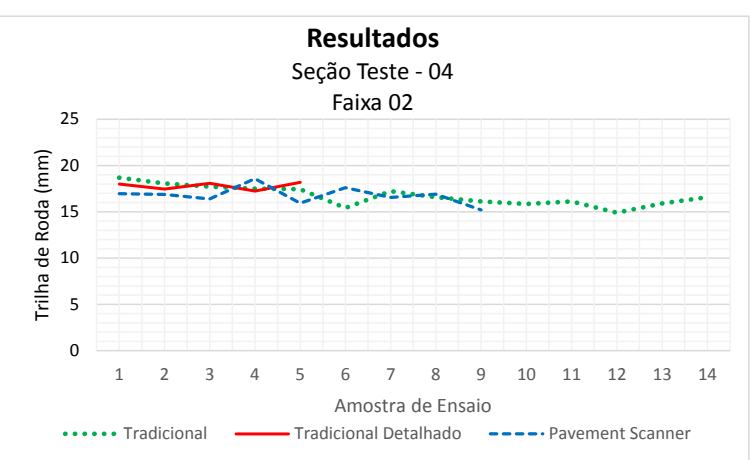

Figura 4.36 - Resultados do Afundamento médio na Trilha de Roda - ST-04 Faixa 2

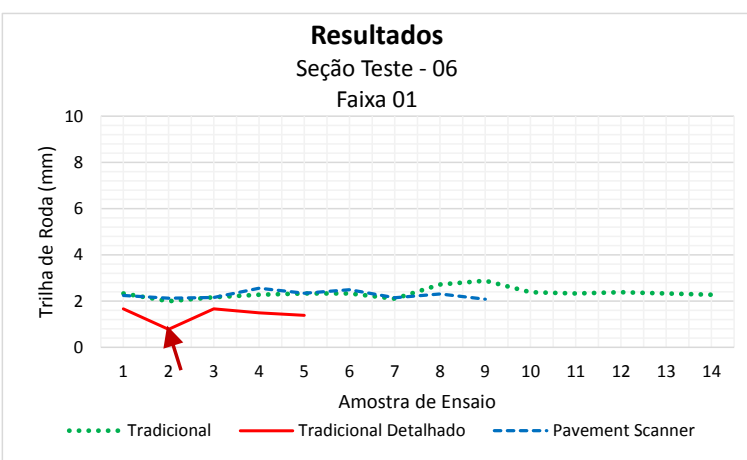

Figura 4.38 - Resultados do Afundamento médio na Trilha de Roda - ST-06 Faixa 1 


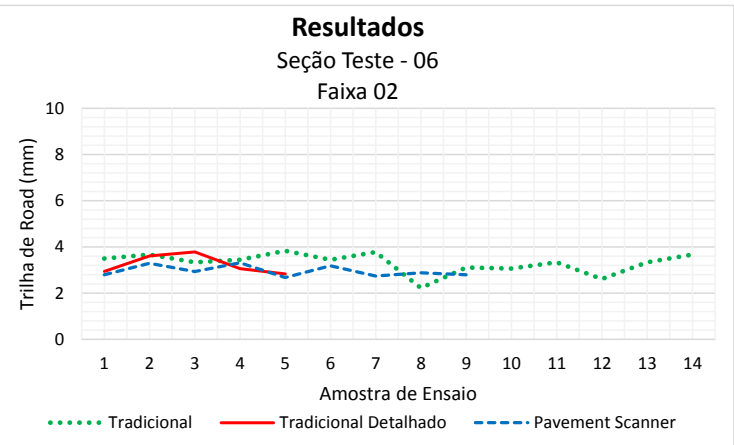

Figura 4.39 - Resultados do Afundamento médio na Trilha de Roda - ST-06 Faixa 2

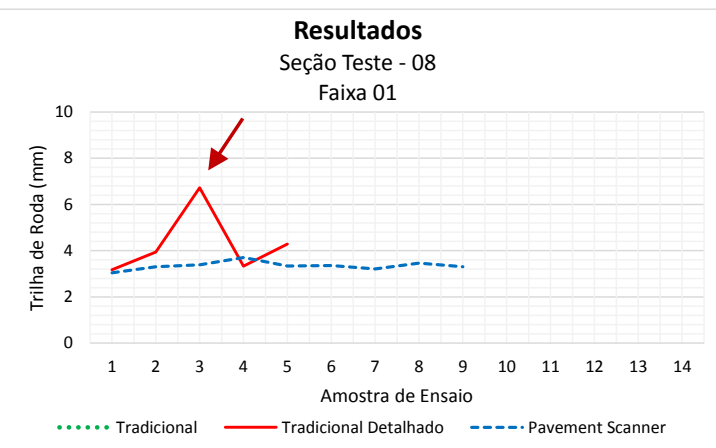

Figura 4.41 - Resultados do Afundamento médio na Trilha de Roda - ST-08 Faixa 1

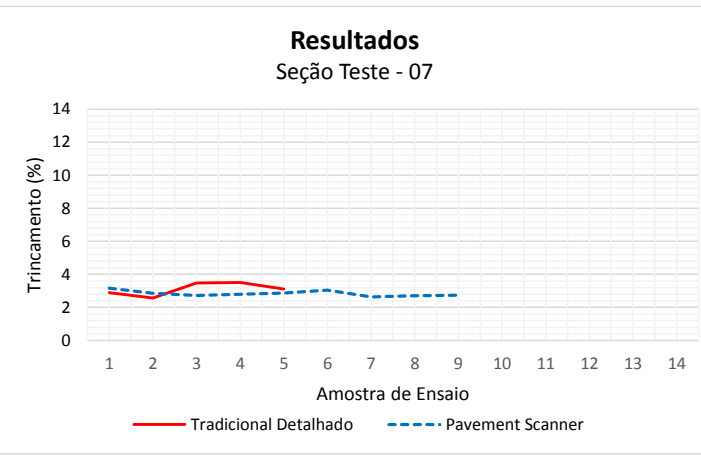

Figura 4.40 - Resultados do Afundamento médio na Trilha de Roda - ST-07

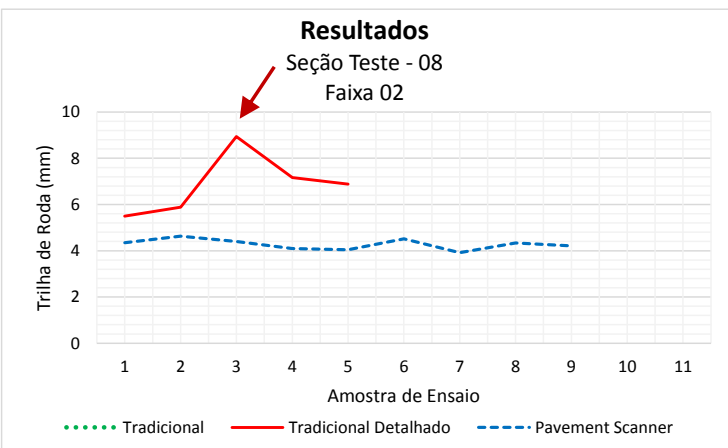

Figura 4.42 - Resultados do Afundamento médio na Trilha de Roda - ST-08 Faixa 2

Pelos gráficos é possível verificar que os resultados do levantamento tradicional apresentam maior variabilidade. Na seção-teste 08 há um pico no levantamento tradicional na amostra 3, em ambas as faixas. Isso possivelmente ocorreu devido ao tráfego intenso na data da coleta, dificultando o levantamento. Vale pontuar que para realizar inventários de IGG nas rodovias brasileiras, muitas vezes as medidas de afundamento na trilha de roda são estimadas visualmente e não com a treliça metálica, diminuindo ainda mais a precisão do levantamento.

A Figura 4.43 apresenta o gráfico de correlação entre a média dos resultados dos ensaios realizados pelo equipamento Pavement Scanner e a média dos resultados dos ensaios realizados tradicionalmente com a utilização da treliça metálica para todas as seções-teste. 


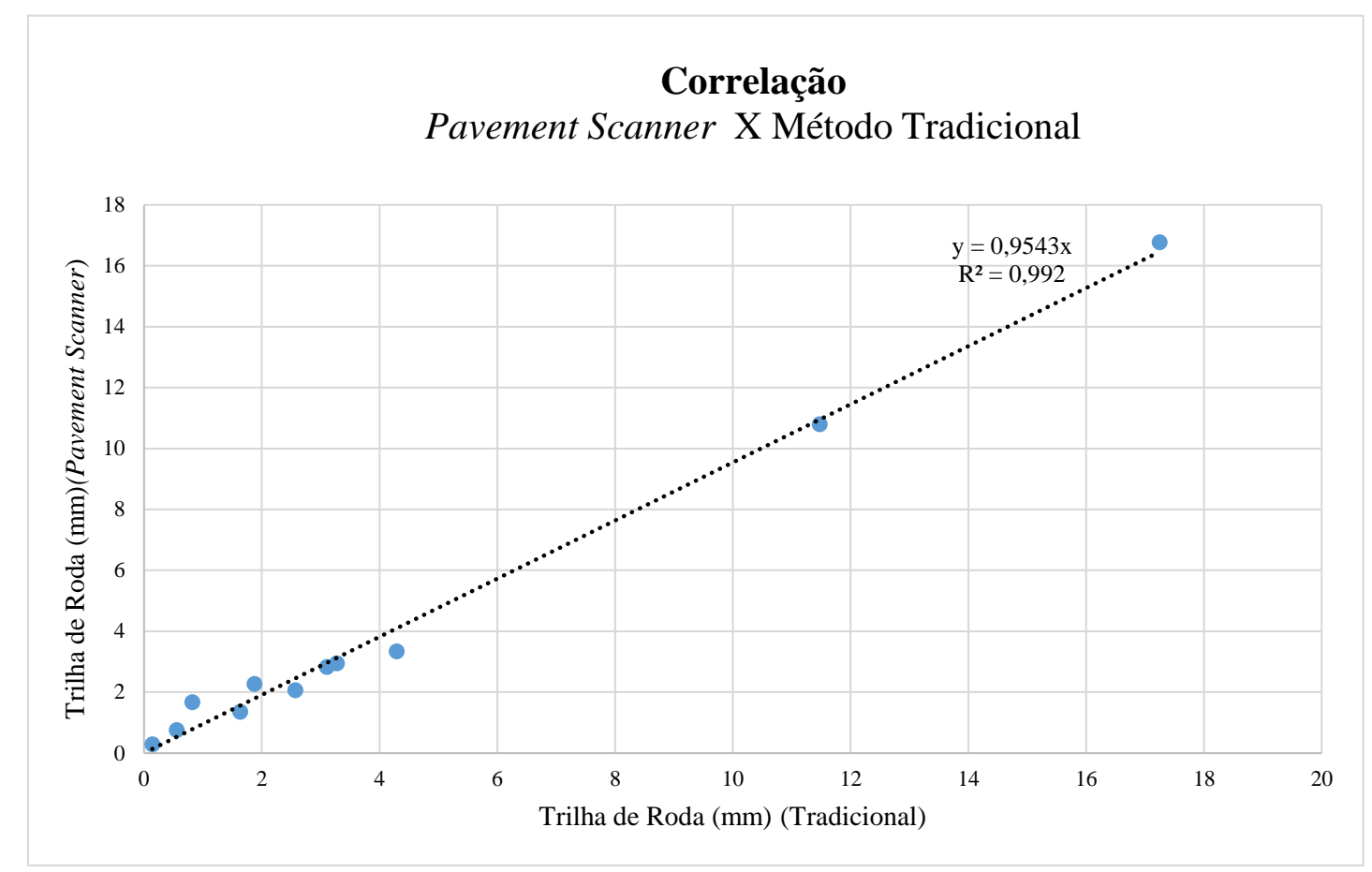

Figura 4.43 - Correlação da média dos valores de Trilha de Roda obtidos com o Pavement Scanner e com o Levantamento Tradicional

O gráfico apresentado demonstra uma boa correlação entre a trilha de roda determinada pelo método tradicional e o dado extraído do Pavement Scanner com $\mathrm{R}^{2}$ de 0,99 . O resultado da correlação conduz a valores de trilha de roda pelo Pavement Scanner inferiores em aproximadamente 4,5 \% em relação ao tradicional.

Os dados apresentados no gráfico referem-se à correlação dos valores médios dos resultados de afundamento na trilha de roda. No entanto, buscando-se apresentar uma melhor relação dos pontos estudados, demonstrando possíveis discrepâncias de valores que a média não evidencia, plotou-se na Figura 4.44 os pontos de resultado trilha de roda obtidos de forma tradicional, com a utilização da treliça metálica e de forma mecanizada. 


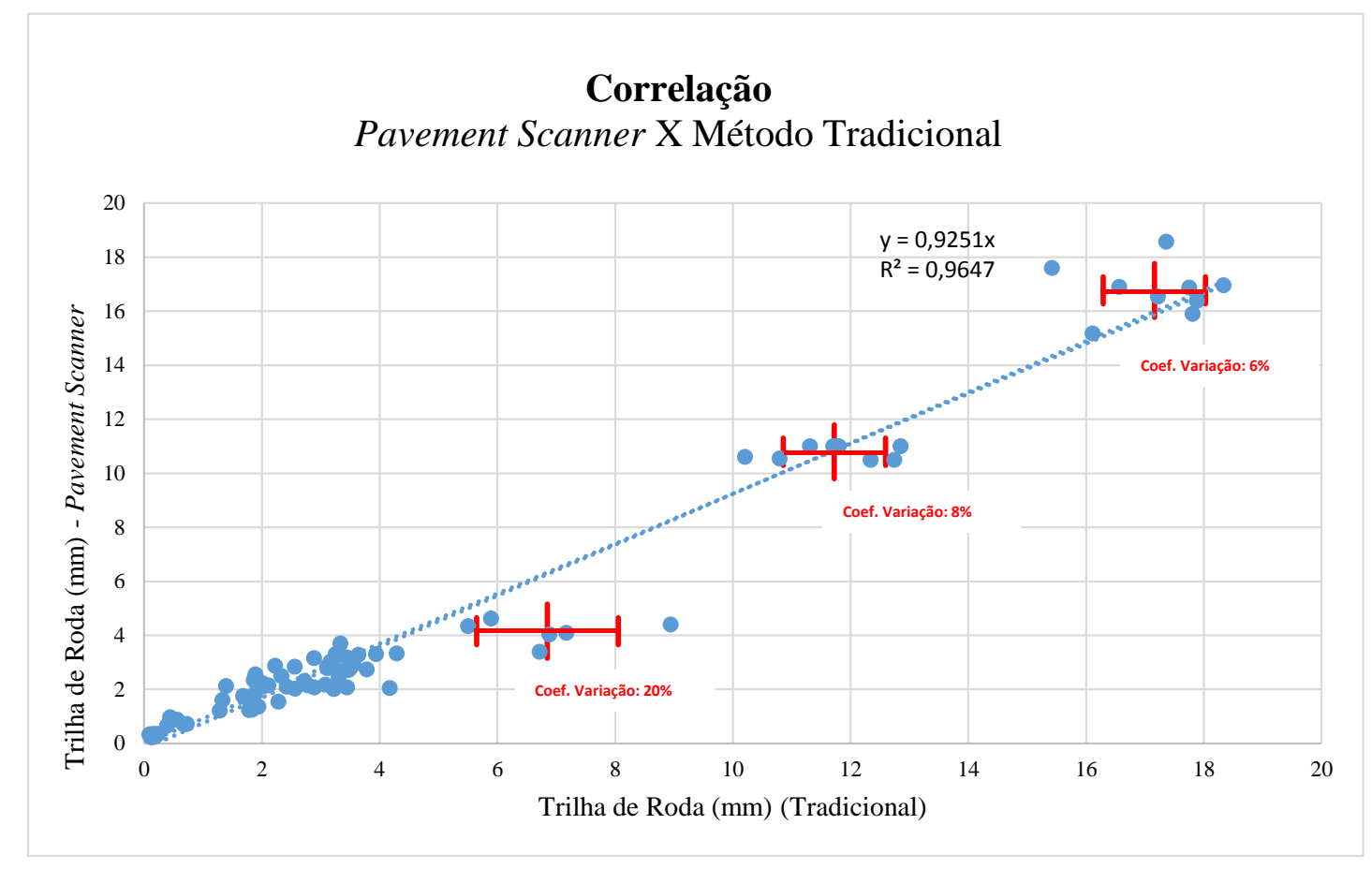

Figura 4.44 - Correlação entre afundamento na Trilha de Roda do Pavement Scanner e o Levantamento Tradicional

Verifica-se que os resultados da trilha de roda com Pavement Scanner apresentam uma tendência "horizontal", em que a variação no eixo das abscissas, que refere-se ao levantamento tradicional é maior para cada seção-teste, se comparada aos valores representados no eixo y, que referem-se aos mecanizados. O gráfico apresentado demonstra que os valores de afundamento em trilha de roda obtidos de forma mecanizada são inferiores em aproximadamente $8 \%$ em relação aos tradicionais. No entanto, a dispersão do levantamento tradicional é superior a $8 \%$ na maioria das seções-teste, chegando até a $26 \%$ na ST-06. De maneira a facilitar a visualização da dispersão do levantamento tradicional, plotou-se os gráficos de média e de desvio padrão de algumas seções-teste (em vermelho), percebe-se que o coeficiente de variação é de 6,8 e $20 \%$, mostrando-se superior à diferença de $8 \%$ na curva de correlação entre os dois tipos de levantamentos. 


\subsection{Resultados da Irregularidade Longitudinal}

A Tabela 4.7 apresenta os resultados do IRI para as faixas 1 e pistas crescentes, enquanto que a Tabela 4.8 para as faixas 2 e pistas decrescentes. Os referidos resultados foram obtidos a partir dos levantamentos com o perfilômetro laser e com o Pavement Scanner, sendo que para o perfilômetro laser foram realizadas 3 repetições e para o Pavement Scanner, 9 amostras. 
Tabela 4.7 - Resultados de IRI para Faixa 1 (pista dupla) e Faixa Crescente (pista simples)

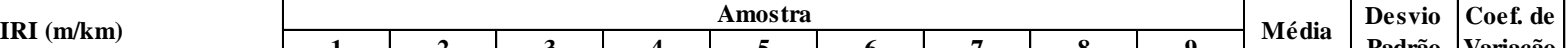

\begin{tabular}{|c|c|c|c|c|c|c|c|c|c|c|c|c|c|c|c|}
\hline \multirow{2}{*}{\multicolumn{2}{|c|}{ IRI (m/km) }} & \multicolumn{9}{|c|}{ Amostra } & \multirow{2}{*}{ Média } & \multirow{2}{*}{$\begin{array}{l}\text { Desvio } \\
\text { Padrão }\end{array}$} & \multirow{2}{*}{\begin{tabular}{|l} 
Coef. de \\
Variação
\end{tabular}} & \multirow{2}{*}{ Variância } & \multirow{2}{*}{$\begin{array}{l}\text { Máx - } \\
\text { Mín }\end{array}$} \\
\hline & & 1 & 2 & 3 & 4 & 5 & 6 & 7 & 8 & 9 & & & & & \\
\hline \multirow{2}{*}{$\begin{array}{c}\text { Seção Teste } \\
01\end{array}$} & Perfilômetro Laser & 1,6 & 1,5 & 1,7 & & & & & & & 1,6 & 0,1 & $8 \%$ & 0,0 & 0,0 \\
\hline & Pavement Scanner & 1,4 & 1,5 & 1,5 & 1,4 & 1,4 & 1,5 & 1,4 & 1,4 & 1,4 & 1,4 & 0,1 & $4 \%$ & 0,0 & 0,1 \\
\hline \multirow{2}{*}{$\begin{array}{c}\text { Seção Teste } \\
02 \\
\end{array}$} & Perfilômetro Laser & 1,7 & 1,7 & 1,8 & & & & & & & 1,7 & 0,0 & $1 \%$ & 0,0 & 0,0 \\
\hline & Pavement Scanner & 1,7 & 1,8 & 1,7 & 1,8 & 1,7 & 1,7 & 1,6 & 1,6 & 1,7 & 1,7 & 0,0 & $3 \%$ & 0,0 & 0,1 \\
\hline \multirow{2}{*}{$\begin{array}{c}\text { Seção Teste } \\
03\end{array}$} & Perfilômetro Laser & 6,9 & 7,4 & 7,0 & & & & & & & 7,1 & 0,3 & $4 \%$ & 0,1 & 0,4 \\
\hline & Pavement Scanner & 5,9 & 6,6 & 6,8 & 5,8 & 6,0 & 6,1 & 5,7 & 6,0 & 6,1 & 6,1 & 0,4 & $6 \%$ & 0,1 & 1,1 \\
\hline \multirow{2}{*}{$\begin{array}{c}\text { Seção Teste } \\
04\end{array}$} & Perfilômetro Laser & 1,7 & 1,9 & & & & & & & & 1,8 & 0,1 & $7 \%$ & 0,0 & 1,9 \\
\hline & Pavement Scanner & 1,6 & 1,6 & 1,6 & 1,6 & 1,6 & 1,6 & 1,5 & 1,6 & 1,6 & 1,6 & 0,0 & $1 \%$ & 0,0 & 0,1 \\
\hline \multirow{2}{*}{$\begin{array}{c}\text { Seção Teste } \\
05\end{array}$} & Perfilômetro Laser & 2,0 & 1,9 & 1,7 & & & & & & & 1,9 & 0,2 & $9 \%$ & 0,0 & 0,3 \\
\hline & Pavement Scanner & 1,6 & 1,7 & 1,7 & 1,7 & 1,7 & 1,6 & 1,6 & 1,6 & 1,7 & 1,6 & 0,0 & $2 \%$ & 0,0 & 0,1 \\
\hline \multirow{2}{*}{$\begin{array}{c}\text { Seção Teste } \\
06\end{array}$} & Perfilômetro Laser & 1,7 & 1,7 & 1,7 & & & & & & & 1,7 & 0,0 & $1 \%$ & 0,0 & 0,0 \\
\hline & Pavement Scanner & 1,5 & 1,7 & 1,6 & 1,6 & 1,5 & 1,6 & 1,5 & 1,6 & 1,6 & 1,6 & 0,1 & $3 \%$ & 0,0 & 0,2 \\
\hline \multirow{2}{*}{$\begin{array}{c}\text { Seção Teste } \\
07\end{array}$} & Perfilômetro Laser & 3,0 & 3,1 & 3,0 & & & & & & & 3,0 & 0,0 & $2 \%$ & 0,0 & 0,0 \\
\hline & Pavement Scanner & 2,7 & 2,7 & 2,7 & 2,7 & 2,7 & 2,6 & 2,7 & 2,7 & 2,7 & 2,7 & 0,0 & $1 \%$ & 0,0 & 0,1 \\
\hline \multirow{2}{*}{$\begin{array}{l}\text { Seção Teste } \\
08\end{array}$} & Perfilômetro Laser & 2,0 & 2,0 & 2,1 & & & & & & & 2,1 & 0,1 & $2 \%$ & 0,0 & 0,0 \\
\hline & \begin{tabular}{|l} 
Pavement Scanner \\
e
\end{tabular} & 1,9 & 2,1 & 2,0 & 1,9 & 1,9 & 1,9 & 1,9 & 2,0 & 1,9 & 1,9 & 0,1 & $4 \%$ & 0,0 & 0,3 \\
\hline
\end{tabular}


Tabela 4.8 - Resultados de IRI para Faixa 2 (pista dupla) e Faixa Decrescente (pista simples)

\begin{tabular}{|c|c|c|c|c|c|c|c|c|c|c|c|c|c|c|c|}
\hline \multirow{2}{*}{\multicolumn{2}{|c|}{ IRI (m/km) }} & \multicolumn{9}{|c|}{ Amostra } & \multirow{2}{*}{ Média } & \multirow{2}{*}{$\begin{array}{l}\text { Desvio } \\
\text { Padrão } \\
\end{array}$} & \multirow{2}{*}{\begin{tabular}{|l|} 
Coef. de \\
Variação
\end{tabular}} & \multirow{2}{*}{ Variância } & \multirow{2}{*}{$\begin{array}{l}\text { Máx - } \\
\text { Mín }\end{array}$} \\
\hline & & 1 & 2 & 3 & 4 & 5 & 6 & 7 & 8 & 9 & & & & & \\
\hline \multirow{2}{*}{$\begin{array}{c}\text { Seção Teste } \\
01\end{array}$} & Perfilômetro Laser & 1,4 & 1,4 & 1,5 & & & & & & & 1,4 & 0,0 & $3 \%$ & 0,0 & 0,0 \\
\hline & Pavement Scanner & 1,3 & 1,4 & 1,4 & 1,3 & 1,3 & 1,3 & 1,3 & 1,3 & 1,3 & 1,3 & 0,1 & $5 \%$ & 0,0 & 0,2 \\
\hline \multirow{2}{*}{$\begin{array}{l}\text { Seção Teste } \\
\quad 02\end{array}$} & Perfilômetro Laser & 1,4 & 3,1 & 3,0 & & & & & & & 2,5 & 0,9 & $37 \%$ & 0,8 & 0,1 \\
\hline & Pavement Scanner & 1,4 & 1,4 & 1,4 & 1,4 & 1,4 & 1,4 & 1,4 & 1,4 & 1,4 & 1,4 & 0,0 & $2 \%$ & 0,0 & 0,1 \\
\hline \multirow{2}{*}{$\begin{array}{c}\text { Seção Teste } \\
03 \\
\end{array}$} & Perfilômetro Laser & 5,5 & 5,5 & 5,4 & & & & & & & 5,5 & 0,1 & $1 \%$ & 0,0 & 0,1 \\
\hline & Pavement Scanner & 5,2 & 5,8 & 5,6 & 5,6 & 5,7 & 5,3 & 5,4 & 5,6 & 5,4 & 5,5 & 0,2 & $4 \%$ & 0,0 & 0,5 \\
\hline \multirow{2}{*}{$\begin{array}{c}\text { Seção Teste } \\
04\end{array}$} & Perfilômetro Laser & 10,9 & 11,1 & & & & & & & & 11,0 & 0,1 & $1 \%$ & 0,0 & 11,1 \\
\hline & Pavement Scanner & 9,4 & 9,4 & 9,4 & 9,3 & 9,3 & 8,9 & 9,2 & 9,4 & 9,4 & 9,3 & 0,2 & $2 \%$ & 0,0 & 0,5 \\
\hline \multirow{2}{*}{$\begin{array}{c}\text { Seção Teste } \\
05\end{array}$} & Perfilômetro Laser & 2,0 & 2,0 & 1,9 & & & & & & & 1,9 & 0,1 & $4 \%$ & 0,0 & 0,1 \\
\hline & Pavement Scanner & 1,8 & 1,8 & 1,7 & 1,7 & 1,8 & 1,7 & 1,7 & 1,8 & 1,8 & 1,8 & 0,0 & $3 \%$ & 0,0 & 0,2 \\
\hline \multirow{2}{*}{$\begin{array}{c}\text { Seção Teste } \\
06\end{array}$} & Perfilômetro Laser & 1,9 & 1,9 & 1,9 & & & & & & & 1,9 & 0,0 & $1 \%$ & 0,0 & 0,0 \\
\hline & Pavement Scanner & 1,8 & 1,9 & 1,9 & 1,8 & 1,8 & 1,8 & 1,8 & 1,8 & 1,8 & 1,8 & 0,0 & $2 \%$ & 0,0 & 0,1 \\
\hline \multirow{2}{*}{$\begin{array}{c}\text { Seção Teste } \\
07\end{array}$} & Perfilômetro Laser & 2,3 & 2,2 & 2,3 & & & & & & & 2,3 & 0,0 & $1 \%$ & 0,0 & 0,0 \\
\hline & Pavement Scanner & 1,9 & 1,9 & 2,0 & 1,9 & 1,9 & 1,9 & 1,9 & 1,9 & 2,0 & 1,9 & 0,0 & $2 \%$ & 0,0 & 0,1 \\
\hline \multirow{2}{*}{$\begin{array}{c}\text { Seção Teste } \\
08\end{array}$} & Perfilômetro Laser & 4,1 & 4,0 & 4,0 & & & & & & & 4,0 & 0,0 & $1 \%$ & 0,0 & 0,0 \\
\hline & Pavement Scanner & 3,7 & 3,8 & 3,8 & 3,7 & 3,6 & 3,6 & 3,7 & 3,6 & 3,8 & 3,7 & 0,1 & $2 \%$ & 0,0 & 0,2 \\
\hline
\end{tabular}


Os coeficientes de variação do Pavement Scanner e do Perfilômetro Laser são baixos, não sendo possível verificar qual dos dois tipos de levantamento mecanizado apresenta maior variabilidade de resultados.

Era esperado que os valores de IRI do Pavement Scanner resultassem em menor variação, dado que o referido equipamento apresenta resultados de irregularidade em uma distância fixa em relação à linha de bordo da sinalização. No entanto, conforme apresentado, não foi verificada discrepância de resultados entre os dois levantamentos, o que pode ter ocorrido em função da extensão e quantidade de amostras que permite a manutenção da faixa de rolamento na avaliação com o perfilômetro laser.

De maneira a ilustrar a variação dos resultados IRI para cada tipo de levantamento, foram plotados gráficos ilustrativos, indicando-se com uma seta vermelha pontos de elevada variação em cada levantamento, conforme apresentado nas Figuras 4.45 a 4.60.

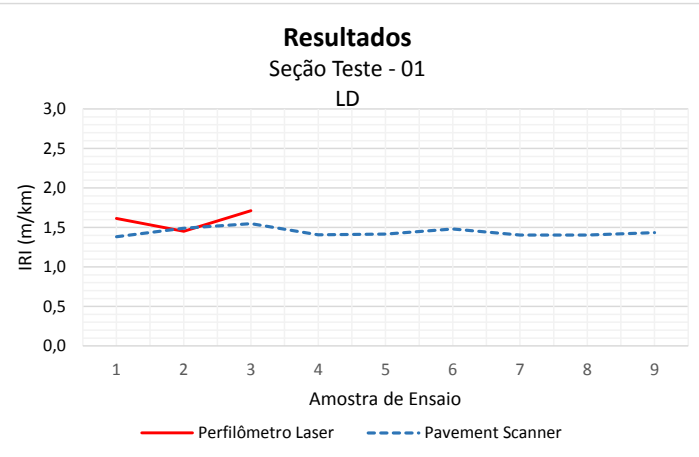

Figura 4.45 - Resultados do IRI- ST-01 Lado Direito

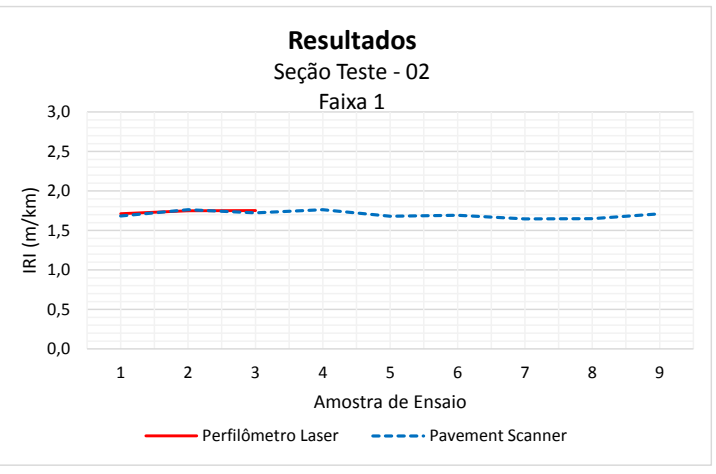

Figura 4.46 - Resultados do IRI- ST-02 Faixa 1 


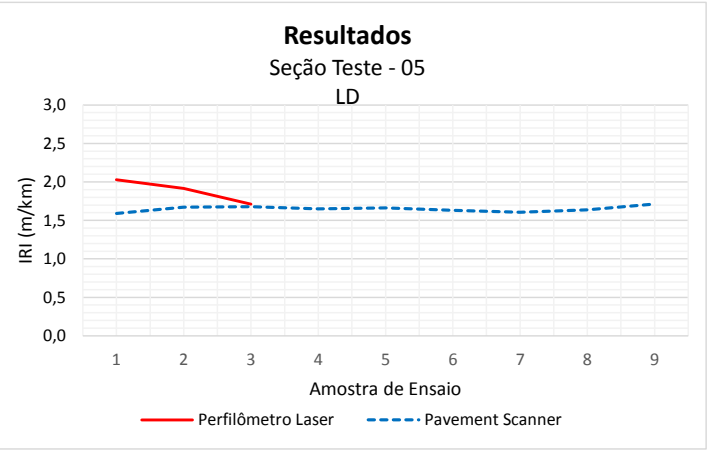

Figura 4.47 - Resultados do IRI- ST-05 Lado Direito

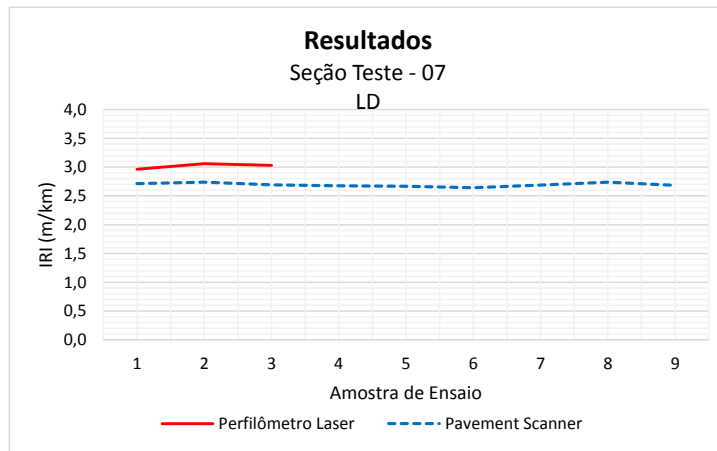

Figura 4.49 - Resultados do IRI- ST-07 Lado Direito

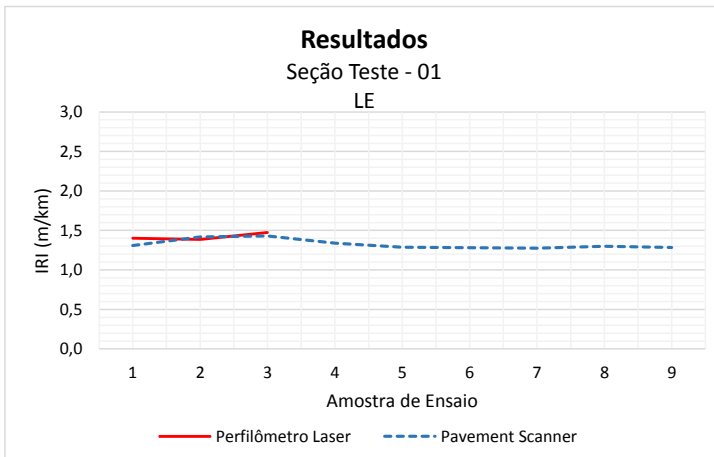

Figura 4.51 - Resultados do IRI- ST-01 Lado Esquerdo

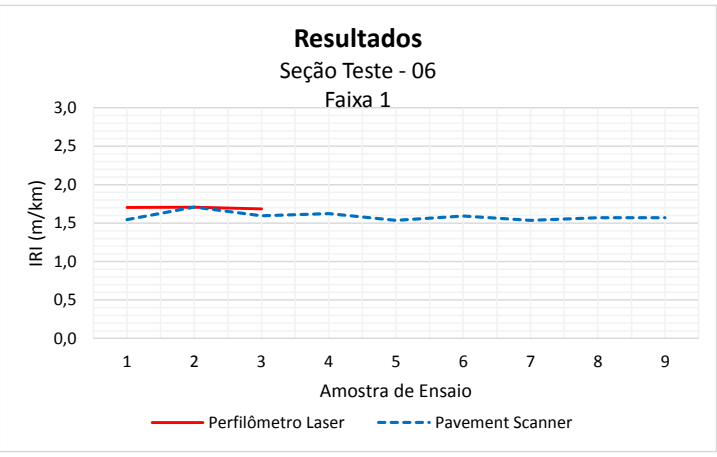

Figura 4.48 - Resultados do IRI- ST-06 Faixa 1

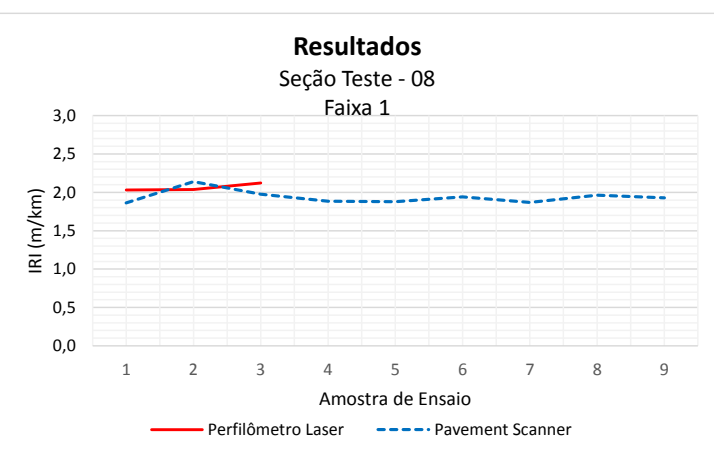

Figura 4.50 - Resultados do IRI- ST-08 Faixa 1

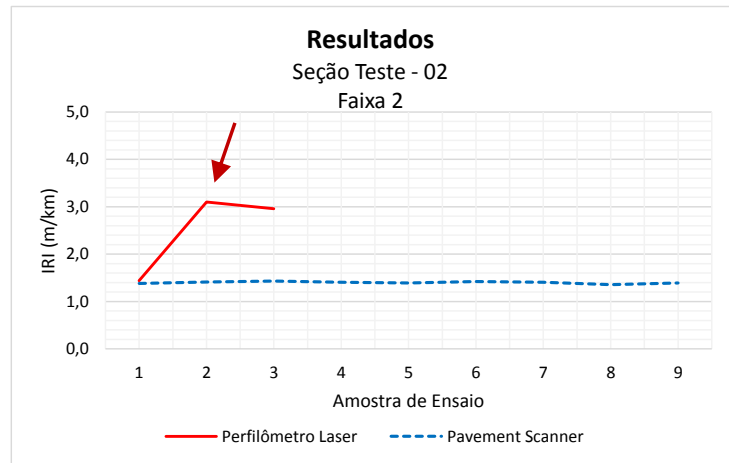

Figura 4.52 - Resultados do IRI- ST-02 Faixa 2 


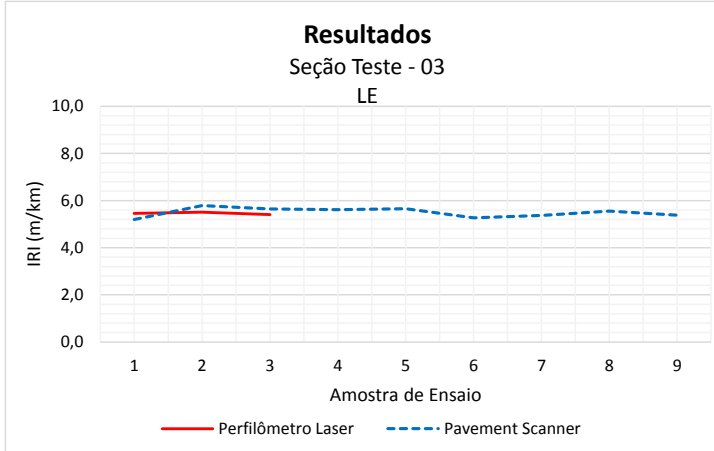

Figura 4.53 - Resultados do IRI- ST-03 Lado Esquerdo

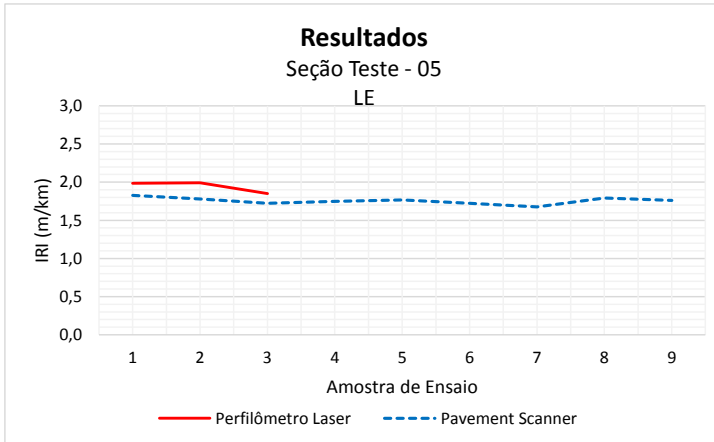

Figura 4.55 - Resultados do IRI- ST-05 Lado Esquerdo

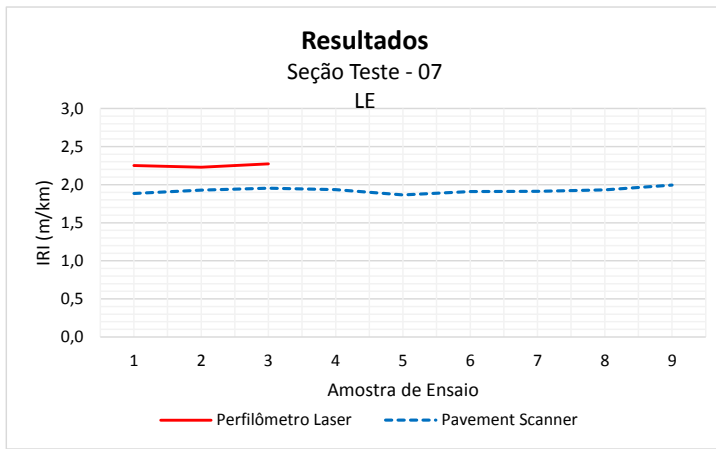

Figura 4.57 - Resultados do IRI- ST-07 Lado Esquerdo

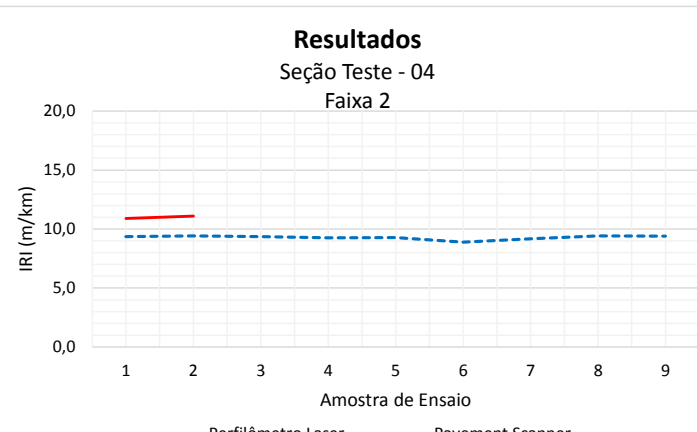

_ Perfilômetro Laser _._._..Pavement Scanner

Figura 4.54 - Resultados do IRI- ST-04 Faixa 2

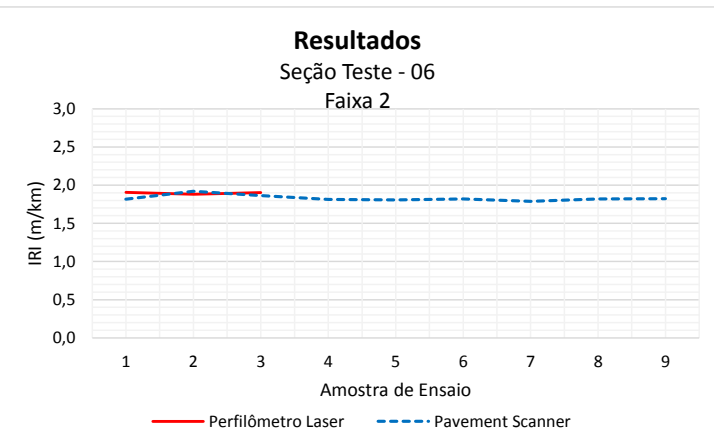

Figura 4.56 - Resultados do IRI- ST-06 Faixa 2

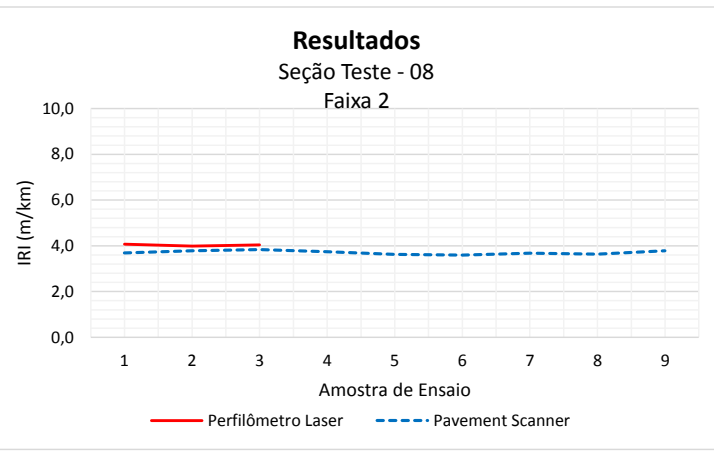

Figura 4.58 - Resultados do IRI- ST-07 Faixa 2

Constata-se pelos gráficos plotados que não há variações significativas de resultados entre os dois levantamentos, com exceção do levantamento com o Perfilômetro Laser na ST-02, Faixa 02, que apresentou duas amostras com maior variação em relação ao Pavement Scanner e à primeira amostra. Esse fato pode ter sido motivado pelo 
operador do perfilômetro laser ter realizado o levantamento em alinhamento longitudinal diferente do recomendado.

A Figura 4.59 apresenta o gráfico de correlação entre os ensaios realizados pelo equipamento Pavement Scanner e os resultados dos ensaios realizados com o Perfilômetro Laser para todas as seções-teste.

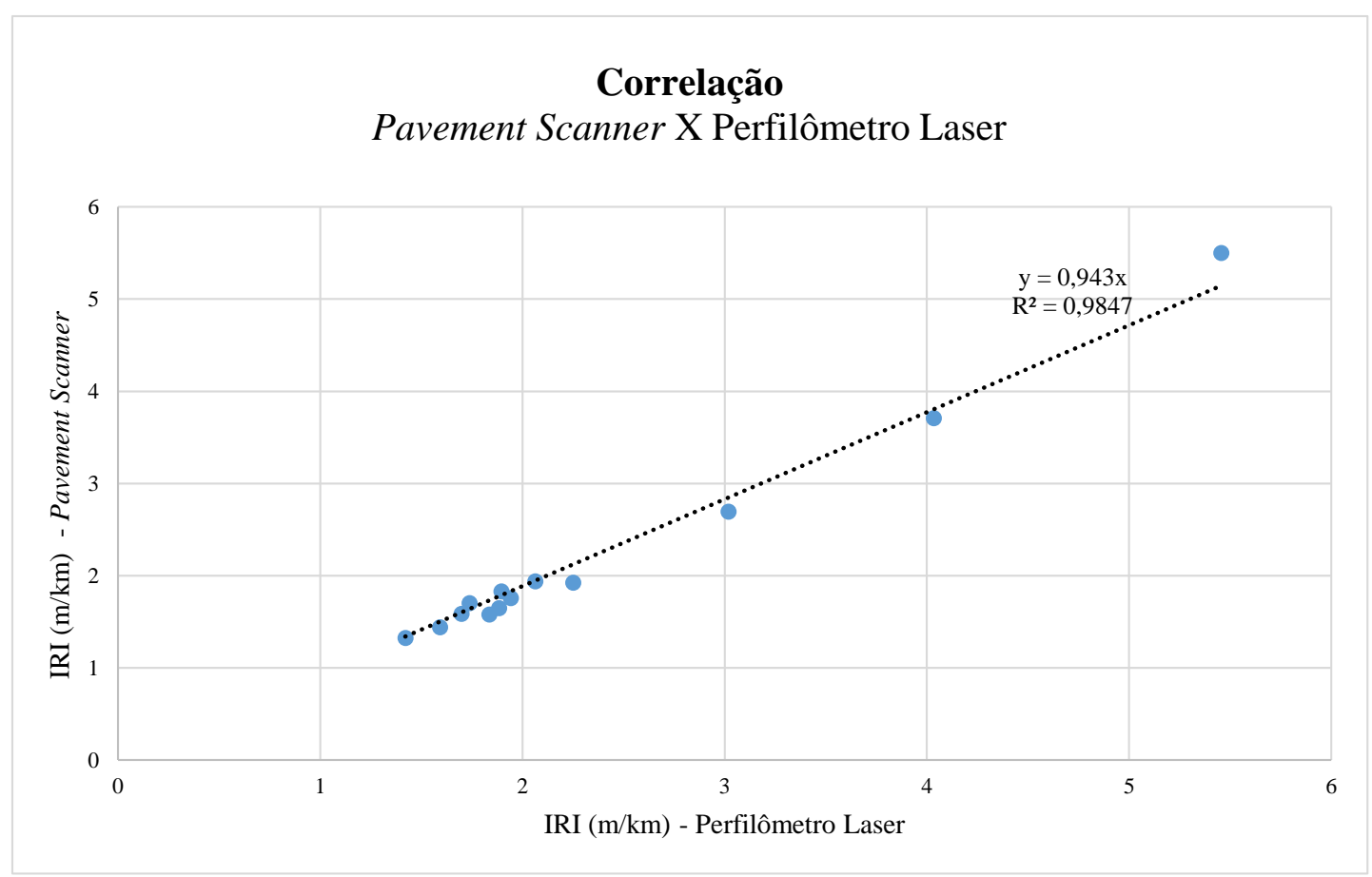

Figura 4.59 - Correlação dos valores médios de IRI do Pavement Scanner x Perfilômetro Laser

O gráfico apresentado demonstra uma boa correlação entre o IRI obtido pelo método perfilômetro laser e o dado extraído do Pavement Scanner com $\mathrm{R}^{2}$ de 0,98 . O resultado da correlação conduz de IRI pelo Pavement Scanner inferiores em aproximadamente $5 \%$ em relação ao com o perfilômetro laser, no entanto faz-se necessário um estudo mais específico analisando a relevância estatística deste resultado.

Os dados apresentados no gráfico referem-se à correlação dos valores médios IRI. No entanto, buscando-se apresentar uma melhor relação dos pontos estudados, demonstrando possíveis discrepâncias de valores que a média não evidencia, plotouse na Figura 4.60 os pontos de resultado de IRI obtidos pelo Pavement Scanner e pelo Perfilômetro Laser. 


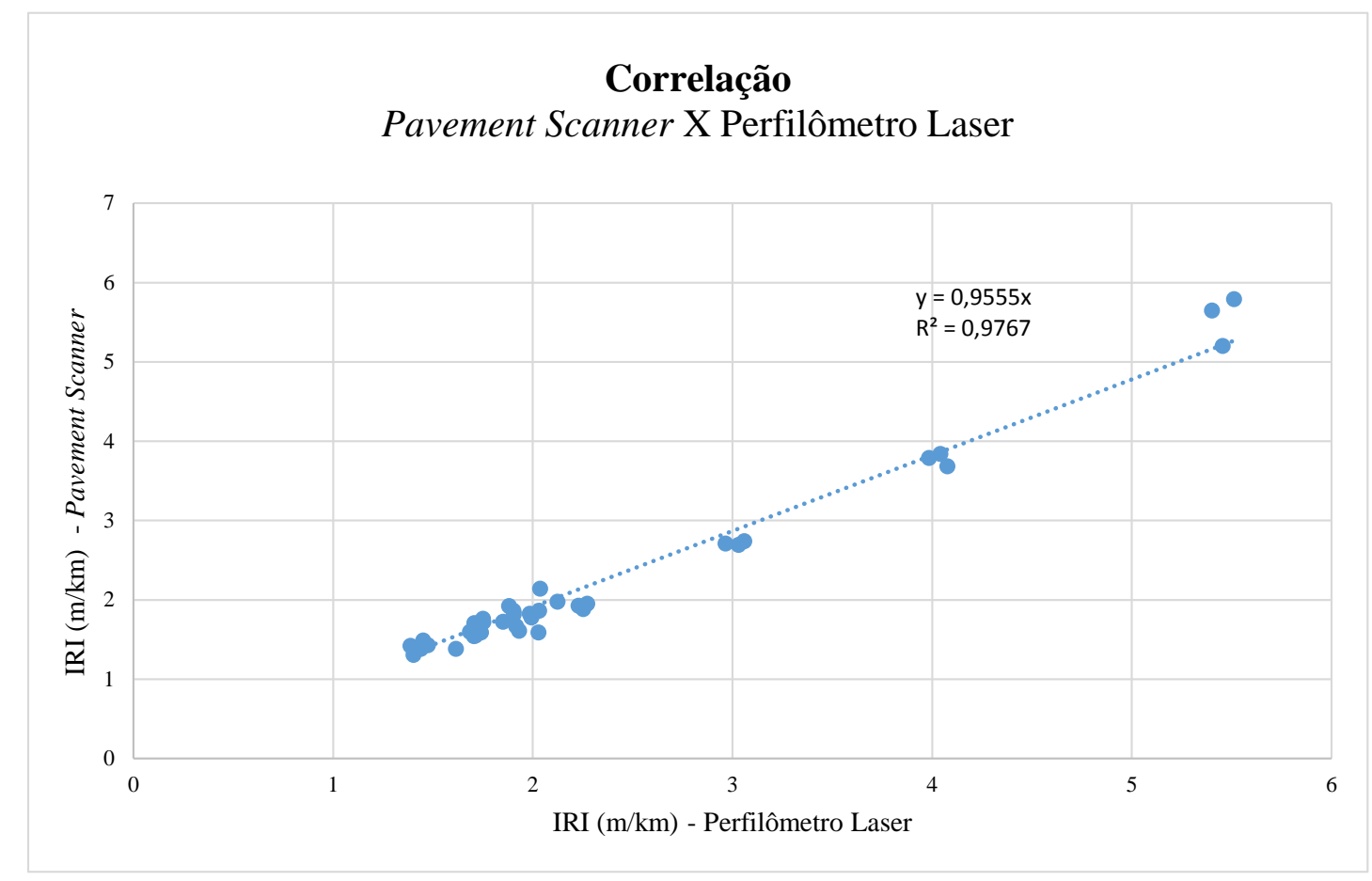

Figura 4.60 - Correlação dos valores de IRI do Pavement Scanner x Perfilômetro Laser

O gráfico apresentado demonstra valores muito próximos aos obtidos com as médias de IRI, denotando a baixa variabilidade entre os resultados médios em cada seção-teste e os pontuais nos dois tipos de avaliação.

\subsection{Análise da Influência da Velocidade do Veículo}

Foram realizados levantamentos com o Pavement Scanner em três velocidades distintas, com o intuito de se verificar a influência da velocidade de operação do veículo na qualidade dos resultados coletados.

A Tabela 4.9 resume para cada velocidade estudada $(60 \mathrm{~km} / \mathrm{h}, 70 \mathrm{~km} / \mathrm{h}$ e $80 \mathrm{~km} / \mathrm{h})$ os resultados de IGG com duas amostras distintas. É apresentada a média do IGG para cada velocidade, bem como, a média dos resultados das três velocidades para cada seção-teste. De posse desses dados, foram calculados os percentuais de cada par de amostra com relação à média da seção-teste estudada. Por fim, resume-se o status comparativo dos referidos percentuais, denominados como: 
- Maior - resultado do par de amostras para velocidade específica é maior que a média dos pares das três velocidades estudadas;

- Intermediário - resultado do par de amostras para velocidade específica apresenta valor intermediário em relação à média dos pares das três velocidades estudadas;

- Menor - resultado do par de amostra para velocidade específica é menor que a média dos pares das três velocidades estudadas.

Tabela 4.9 - Análise da Influência da Velocidade nos Resultados do IGG

\begin{tabular}{|c|c|c|c|c|c|c|c|}
\hline \multicolumn{8}{|c|}{ IGG } \\
\hline \multirow{2}{*}{ Seção-Teste } & \multirow{2}{*}{$\begin{array}{c}\text { Velocidade } \\
(\mathbf{k m} / \mathbf{h})\end{array}$} & \multicolumn{2}{|c|}{ Amostras } & \multirow{2}{*}{$\begin{array}{l}\text { Média por } \\
\text { Levant. }\end{array}$} & \multirow{2}{*}{ Média Total } & \multirow{2}{*}{$\begin{array}{l}\text { Comparação } \\
\text { com a Média }\end{array}$} & \multirow{2}{*}{$\begin{array}{l}\text { Status do } \\
\text { Resultado }\end{array}$} \\
\hline & & 1 & 2 & & & & \\
\hline \multirow{3}{*}{01} & 60 & 0,8 & 0,6 & 0,7 & \multirow{3}{*}{0,8} & $-13 \%$ & menor \\
\hline & 70 & 1,0 & 0,6 & 0,8 & & $5 \%$ & intermediário \\
\hline & 80 & 1,1 & 0,6 & 0,9 & & $8 \%$ & maior \\
\hline \multirow{3}{*}{$\begin{array}{c}02 \\
\text { Faixa } 1\end{array}$} & 60 & 1,4 & 1,2 & 1,3 & \multirow{3}{*}{1,3} & $-1 \%$ & menor \\
\hline & 70 & 1,5 & 1,1 & 1,3 & & $1 \%$ & maior \\
\hline & 80 & 1,4 & 1,1 & 1,3 & & $0 \%$ & intermediário \\
\hline \multirow{3}{*}{$\begin{array}{c}02 \\
\text { Faixa } 2\end{array}$} & 60 & 5,1 & 4,4 & 4,8 & \multirow{3}{*}{5,0} & $-5 \%$ & menor \\
\hline & 70 & 5,3 & 4,5 & 4,9 & & $-2 \%$ & intermediário \\
\hline & 80 & 6,1 & 4,7 & 5,4 & & $7 \%$ & maior \\
\hline \multirow{3}{*}{03} & 60 & 228,2 & 230,5 & 229,3 & \multirow{3}{*}{229,4} & $0 \%$ & intermediário \\
\hline & 70 & 232,7 & 228,8 & 230,8 & & $1 \%$ & maior \\
\hline & 80 & 228,3 & 228,1 & 228,2 & & $-1 \%$ & menor \\
\hline \multirow{3}{*}{$\begin{array}{c}04 \\
\text { Faixa } 1\end{array}$} & 60 & 30,6 & 33,0 & 31,8 & \multirow{3}{*}{30,2} & $5 \%$ & maior \\
\hline & 70 & 26,0 & 33,0 & 29,5 & & $-2 \%$ & intermediário \\
\hline & 80 & 27,4 & 30,9 & 29,1 & & $-3 \%$ & menor \\
\hline \multirow{3}{*}{$\begin{array}{c}04 \\
\text { Faixa } 2\end{array}$} & 60 & 258,1 & 261,8 & 260,0 & \multirow{3}{*}{259,1} & $0 \%$ & intermediário \\
\hline & 70 & 255,9 & 254,5 & 255,2 & & $-2 \%$ & menor \\
\hline & 80 & 259,0 & 265,4 & 262,2 & & $1 \%$ & maior \\
\hline \multirow{3}{*}{05} & 60 & 4,6 & 4,9 & 4,7 & \multirow{3}{*}{4,2} & $14 \%$ & maior \\
\hline & 70 & 3,9 & 4,0 & 4,0 & & $-5 \%$ & intermediário \\
\hline & 80 & 3,8 & 3,8 & 3,8 & & $-9 \%$ & menor \\
\hline \multirow{3}{*}{$\begin{array}{c}06 \\
\text { Faixa } 1\end{array}$} & 60 & 4,9 & 6,5 & 5,7 & \multirow{3}{*}{5,6} & $1 \%$ & maior \\
\hline & 70 & 5,0 & 6,3 & 5,6 & & $-1 \%$ & menor \\
\hline & 80 & 5,3 & 5,9 & 5,6 & & $0 \%$ & intermediário \\
\hline \multirow{3}{*}{$\begin{array}{c}06 \\
\text { Faixa } 2\end{array}$} & 60 & 3,9 & 4,3 & 4,1 & \multirow{3}{*}{4,2} & $-2 \%$ & menor \\
\hline & 70 & 4,4 & 3,9 & 4,2 & & $-1 \%$ & intermediário \\
\hline & 80 & 4,6 & 4,0 & 4,3 & & $3 \%$ & maior \\
\hline & 60 & 39,1 & 35,9 & 37,5 & & $3 \%$ & maior \\
\hline 07 & 70 & 33,8 & 37,3 & 35,5 & 36,3 & $-2 \%$ & intermediário \\
\hline & 80 & 36,8 & 35,2 & 36,0 & & $-1 \%$ & menor \\
\hline & 60 & 19,8 & 19,8 & 19,8 & & $7 \%$ & maior \\
\hline 08 & 70 & 19,9 & 17,0 & 18,5 & 18,6 & $-1 \%$ & intermediário \\
\hline & 80 & 17,1 & 17,8 & 17,4 & & $-6 \%$ & menor \\
\hline & 60 & 101,3 & 94,4 & 97,8 & & $3 \%$ & intermediário \\
\hline 08 & 70 & 96,3 & 84,3 & 90,3 & 95,4 & $-5 \%$ & menor \\
\hline & 80 & 100,5 & 95,4 & 97,9 & & $3 \%$ & maior \\
\hline
\end{tabular}


O gráfico apresentado na Figura 4.61 resume as informações obtidas na Tabela 4.9.

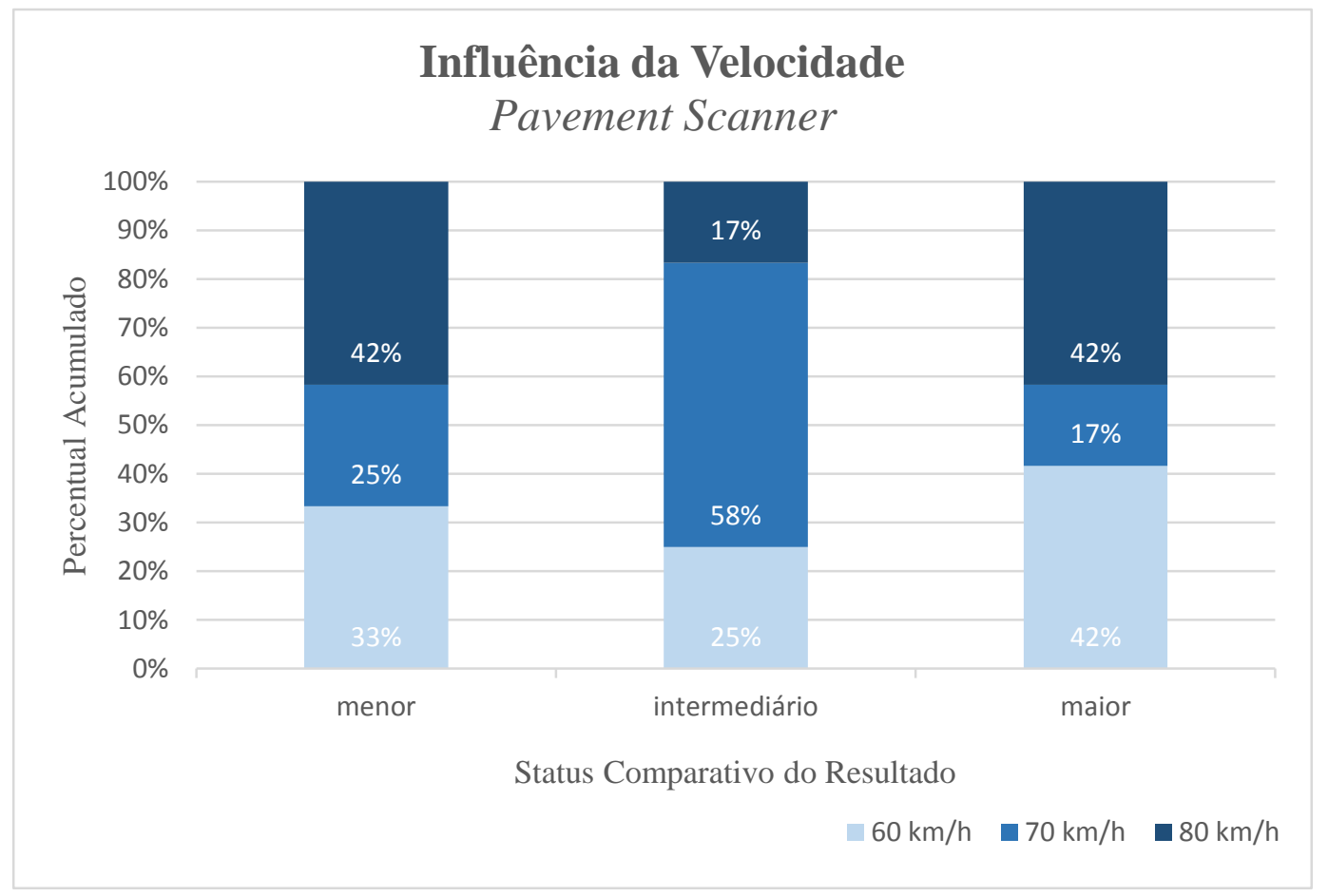

Figura 4.61 - Influência da Velocidade no Cálculo do IGG

Os levantamentos realizados na menor velocidade $(60 \mathrm{~km} / \mathrm{h})$ apresentam $42 \%$ de valores acima da média da seção-teste, $25 \%$ dos valores em status intermediário e $42 \%$ dos valores abaixo da média. O levantamento em $70 \mathrm{~km} / \mathrm{h}$ possui resultados de $17 \%$ de valores acima da média da seção-teste, $58 \%$ dos valores em status intermediário e $25 \%$ dos valores abaixo da média. Finalmente, a amostras cujo levantamento foi realizado em $80 \mathrm{~km} / \mathrm{h}$ possui resultados de $42 \%$ de valores acima da média da seçãoteste, $17 \%$ dos valores em status intermediário e $42 \%$ dos valores abaixo da média.

Verifica-se com base nas informações demonstradas que não há uma tendência de resultados mais rigorosos (com maior IGG), menos rigorosos (com menor IGG) ou resultados intermediários para cada velocidade estudada, demonstrando que os dados não dependem da velocidade de levantamento e que não há perda de qualidade para velocidades mais elevadas. 


\subsection{Análise da Influência da Luminosidade durante o Levantamento}

Foram realizados levantamentos com o Pavement Scanner em duas condições de luminosidade distintas (dia e noite), com o intuito de se verificar a influência da luminosidade na qualidade dos resultados coletados.

A Tabela 4.10 resume para cada período estudado os resultados de IGG com três amostras distintas. É apresentada a média do IGG para cada período, bem como, a média dos resultados dos dois períodos para cada seção-teste. De posse desses dados, foram calculados os percentuais de cada par de amostra com relação à média da seçãoteste estudada. Por fim, resume-se o status comparativo dos referidos percentuais, denominados como:

- Maior - resultado das três amostras para período específico do dia é maior que a média dos resultados dos dois períodos;

- Intermediário - resultado das três amostras para período específico do dia apresenta valor intermediário em relação à média dos resultados dos dois períodos;

- Menor - resultado das três de amostras para período específico do dia é menor que a média dos resultados dos dois períodos. 
Tabela 4.10 - Análise da Influência da Luminosidade nos Resultados do IGG

\begin{tabular}{|c|c|c|c|c|c|c|c|c|}
\hline \multicolumn{9}{|c|}{ IGG } \\
\hline \multirow{2}{*}{ Seção-Teste } & \multirow{2}{*}{ Período } & \multicolumn{3}{|c|}{ Amostras } & \multirow{2}{*}{$\begin{array}{l}\text { Média por } \\
\text { Levant. }\end{array}$} & \multirow{2}{*}{ Média Total } & \multirow{2}{*}{$\begin{array}{l}\text { Comparação } \\
\text { com a Média }\end{array}$} & \multirow{2}{*}{$\begin{array}{l}\text { Status do } \\
\text { Resultado }\end{array}$} \\
\hline & & 1 & 2 & 3 & & & & \\
\hline \multirow{2}{*}{01} & Dia & 0,8 & 1,0 & 1,1 & 1,0 & \multirow{2}{*}{0,8} & $21 \%$ & maior \\
\hline & Noite & 0,6 & 0,6 & 0,6 & 0,6 & & $-21 \%$ & menor \\
\hline \multirow{2}{*}{$\begin{array}{c}02 \\
\text { Faixa } 1\end{array}$} & Dia & 1,4 & 1,5 & 1,4 & 1,4 & \multirow{2}{*}{1,3} & $11 \%$ & maior \\
\hline & Noite & 1,2 & 1,1 & 1,1 & 1,2 & & $-11 \%$ & menor \\
\hline \multirow{2}{*}{$\begin{array}{c}02 \\
\text { Faixa } 2\end{array}$} & Dia & 5,1 & 5,3 & 6,1 & 5,5 & \multirow{2}{*}{5,0} & $9 \%$ & maior \\
\hline & Noite & 4,4 & 4,5 & 4,7 & 4,6 & & $-9 \%$ & menor \\
\hline \multirow{2}{*}{03} & Dia & 228,2 & 232,7 & 228,3 & 229,7 & \multirow{2}{*}{229,4} & $0 \%$ & maior \\
\hline & Noite & 230,5 & 228,8 & 228,1 & 229,1 & & $0 \%$ & menor \\
\hline \multirow{2}{*}{$\begin{array}{c}04 \\
\text { Faixa } 1\end{array}$} & Dia & 30,6 & 26,0 & 27,4 & 28,0 & \multirow{2}{*}{30,2} & $-7 \%$ & menor \\
\hline & Noite & 33,0 & 33,0 & 30,9 & 32,3 & & $7 \%$ & maior \\
\hline \multirow{2}{*}{$\begin{array}{c}04 \\
\text { Faixa } 2\end{array}$} & Dia & 258,1 & 255,9 & 259,0 & 257,7 & \multirow{2}{*}{259,1} & $-1 \%$ & menor \\
\hline & Noite & 261,8 & 254,5 & 265,4 & 260,6 & & $1 \%$ & maior \\
\hline \multirow{2}{*}{05} & Dia & 4,6 & 3,9 & 3,8 & 4,1 & \multirow{2}{*}{4,2} & $-2 \%$ & menor \\
\hline & Noite & 4,9 & 4,0 & 3,8 & 4,2 & & $2 \%$ & maior \\
\hline \multirow{2}{*}{$\begin{array}{c}06 \\
\text { Faixa } 1\end{array}$} & Dia & 4,9 & 5,0 & 5,3 & 5,1 & \multirow{2}{*}{5,6} & $-10 \%$ & menor \\
\hline & Noite & 6,5 & 6,3 & 5,9 & 6,2 & & $10 \%$ & maior \\
\hline \multirow{2}{*}{$\begin{array}{c}06 \\
\text { Faixa } 2\end{array}$} & Dia & 3,9 & 4,4 & 4,6 & 4,3 & \multirow{2}{*}{4,2} & $3 \%$ & maior \\
\hline & Noite & 4,3 & 3,9 & 4,0 & 4,1 & & $-3 \%$ & menor \\
\hline \multirow{2}{*}{07} & Dia & 39,1 & 33,8 & 36,8 & 36,6 & \multirow{2}{*}{36,3} & $1 \%$ & maior \\
\hline & Noite & 35,9 & 37,3 & 35,2 & 36,1 & & $-1 \%$ & menor \\
\hline \multirow{2}{*}{$\begin{array}{c}08 \\
\text { Faixa } 1\end{array}$} & Dia & 19,8 & 19,9 & 17,1 & 18,9 & \multirow{2}{*}{18,6} & $2 \%$ & maior \\
\hline & Noite & 19,8 & 17,0 & 17,8 & 18,2 & & $-2 \%$ & menor \\
\hline \multirow{2}{*}{$\begin{array}{c}08 \\
\text { Faixa } 2\end{array}$} & Dia & 101,3 & 96,3 & 100,5 & 99,4 & & $4 \%$ & maior \\
\hline & Noite & 94,4 & 84,3 & 95,4 & 91,3 & & $-4 \%$ & menor \\
\hline
\end{tabular}

O gráfico apresentado na Figura 4.62 resume as informações obtidas na Tabela 4.10. 


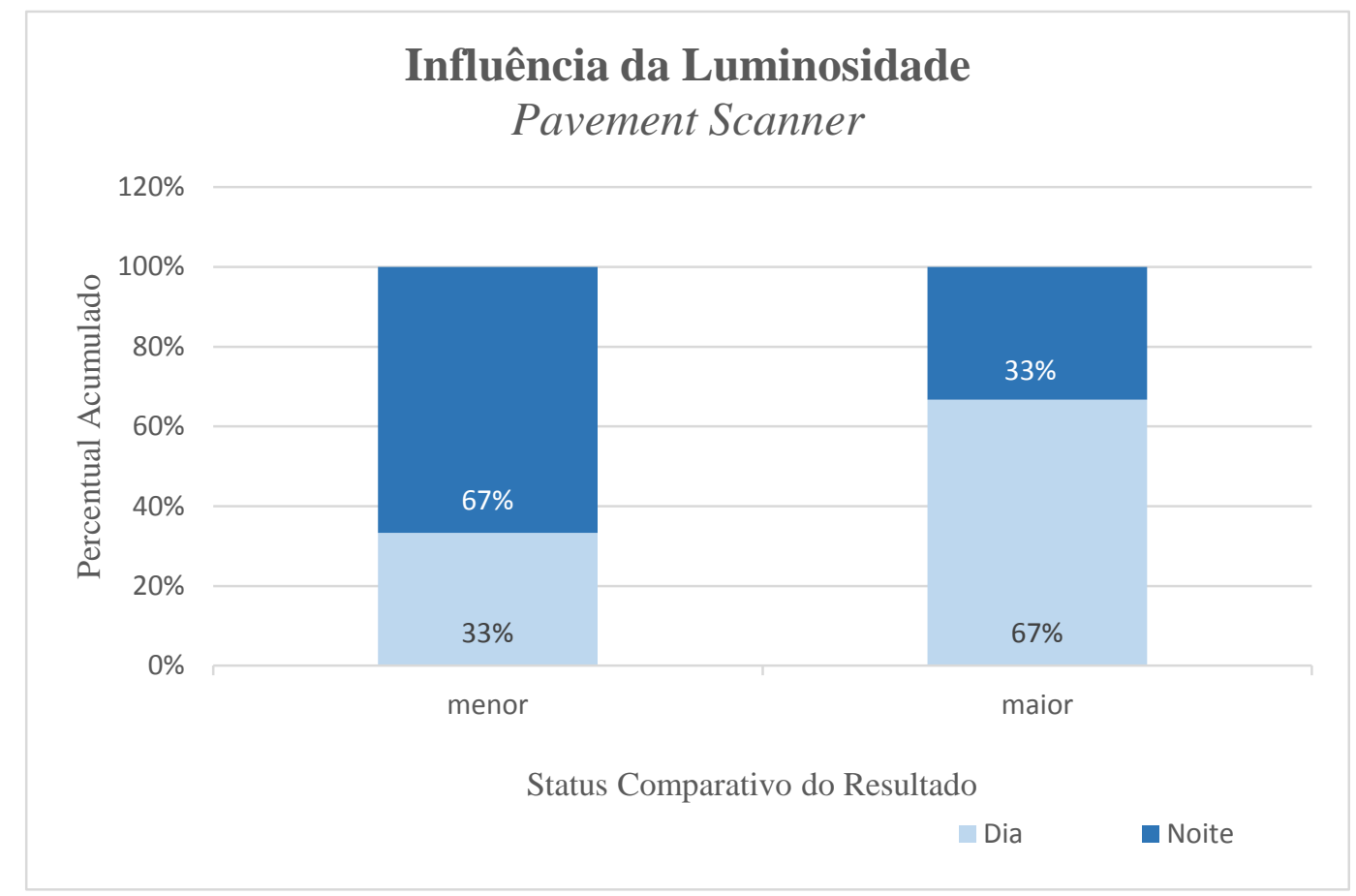

Figura 4.62 -Influência da Luminosidade no Cálculo do IGG

Os levantamentos realizados durante o dia apresentam $67 \%$ dos valores de IGG acima da média da seção-teste, enquanto que os realizados durante à noite, apresentam $33 \%$ de valores na mesma condição.

Os resultados obtidos não são conclusivos, haja vista que os percentuais se apresentam discrepantes entre si e que há um número limitado de amostras.

\subsection{Análise da Influência do Tipo de Revestimento}

Para avaliar a influência do tipo de revestimento nos resultados obtidos com o Pavement Scanner foi realizada uma verificação detalhando em qual tipo de revestimento é constatado maior coeficiente de variação obtidos nas nove amostras para as seções-teste nas mesmas condições. A Tabela 4.11 apresenta os resultados. 
Tabela 4.11 - Análise do Coeficiente de Variação para os Diferentes Tipos de Revestimento

\begin{tabular}{c|c|c|c|c}
\hline \multirow{2}{*}{ Geometria } & \multirow{2}{*}{ Condição } & \multicolumn{2}{|c|}{ Coeficiente de Variação } & \multirow{2}{*}{$\begin{array}{c}\text { Maior Coef. } \\
\text { Variação }\end{array}$} \\
\cline { 3 - 4 } & & CBUQ & Micro & \\
\hline Pista Simples & Boa & $29 \%$ & $9 \%$ & CBUQ \\
\hline Pista Simples & Regular a Ruim & $1 \%$ & $5 \%$ & Micro \\
\hline Pista Dupla Fx 1 & Boa & $11 \%$ & $10 \%$ & CBUQ \\
\hline Pista Dupla Fx 2 & Regular a Ruim & $12 \%$ & $6 \%$ & CBUQ \\
\hline Pista Dupla Fx 1 & Boa & $10 \%$ & $10 \%$ & - \\
\hline Pista Dupla Fx 2 & Regular a Ruim & $2 \%$ & $6 \%$ & Micro \\
\hline
\end{tabular}

Os resultados obtidos não são conclusivos, mesmo com aproximadamente $60 \%$ dos maiores coeficientes de variação do levantamento mecanizado obtidos para revestimentos do tipo CBUQ. Apesar do percentual para CBUQ ser superior ao do microrrevestimento, os dados não são discrepantes, não sendo possível por essa análise concluir quanto à influência do tipo de revestimento.

Ressalta-se porém que para revestimentos do tipo microrrevestimento, o processamento do Pavement Scanner considera um módulo de análise para revestimentos porosos, que desconsideram os sulcos no revestimento que erroneamente poderiam ser detectados como trincas.

\subsection{Resultados da Repetitividade dos Defeitos}

Buscando-se uma análise mais particularizada dos levantamentos realizados nas seções-teste, tornou-se necessário estudar as informações coletadas referentes a cada tipo específico de defeito, visando a obtenção de um diagnóstico da precisão dos mesmos.

Desta forma, estudou-se a ocorrência de cada defeito, em cada estaca, para os três levantamentos realizados (tradicional, tradicional detalhado e mecanizado). Atribuiuse a esses defeitos um percentual de repetitividade, ou seja, toda vez que o defeito foi detectado em cada estaca ou estação, verificou-se o percentual de amostras que o 
mesmo foi identificado. Para o levantamento tradicional fez-se a relação entre o número de vezes da detecção pelo número de amostras (quatorze ensaios), já para o tradicional detalhado, dividiu-se por cinco amostras e para o mecanizado, a relação foi por nove ensaios.

As Figuras 4.63 a 4.70 ilustram a repetitividade de defeitos para cada seção-teste estudada, ressaltando-se que para a ST-01 não foram detectados defeitos nos levantamentos realizados.

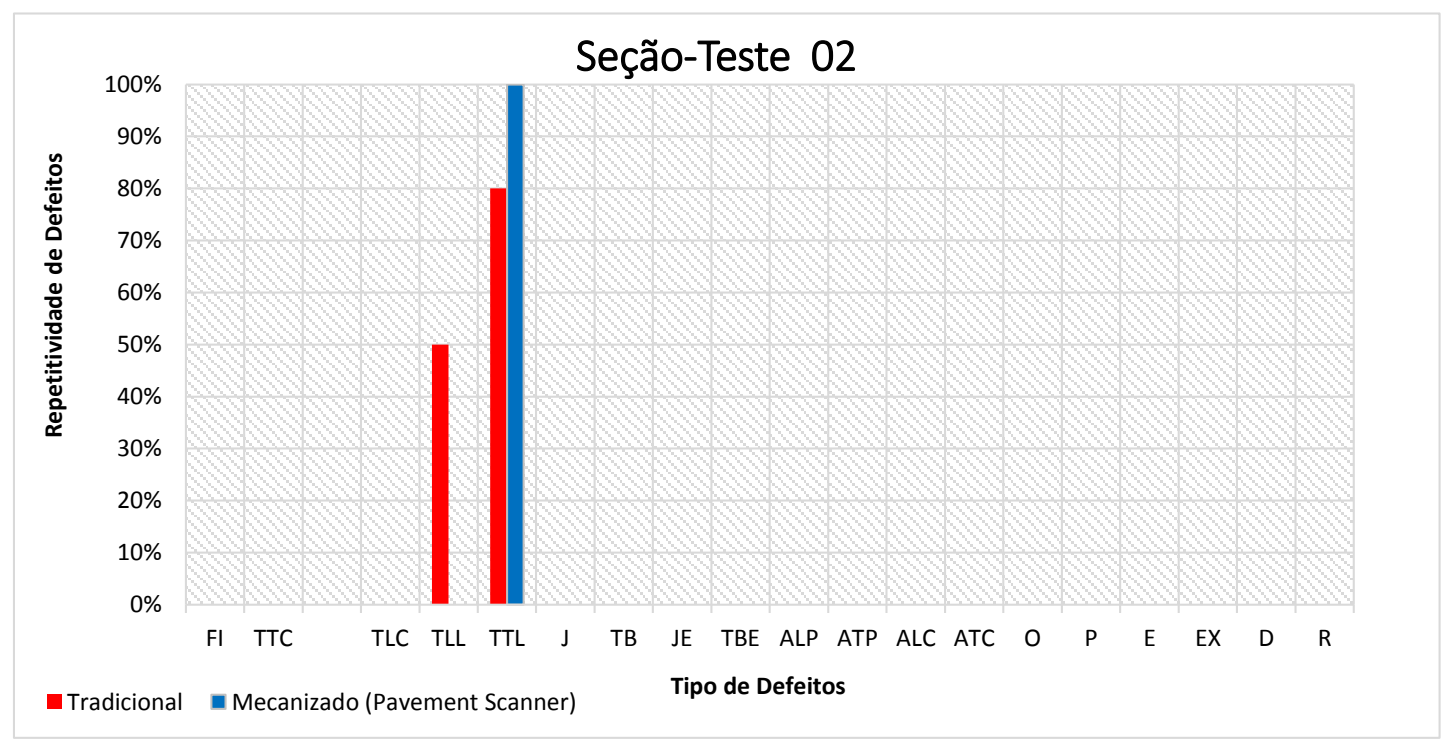

Figura 4.63 - Análise da Repetitividade dos Defeitos - ST-02

O resultado mecanizado da seção-teste 02 apresentou $100 \%$ de repetitividade para a detecção de trincas transversais longas, enquanto que pelo método tradicional, o referido defeito foi indicado com $80 \%$ de precisão. Constata-se para essa seção-teste que não houve detecção do Pavement Scanner para as trincas de bordo, representada neste caso, como TLL. 


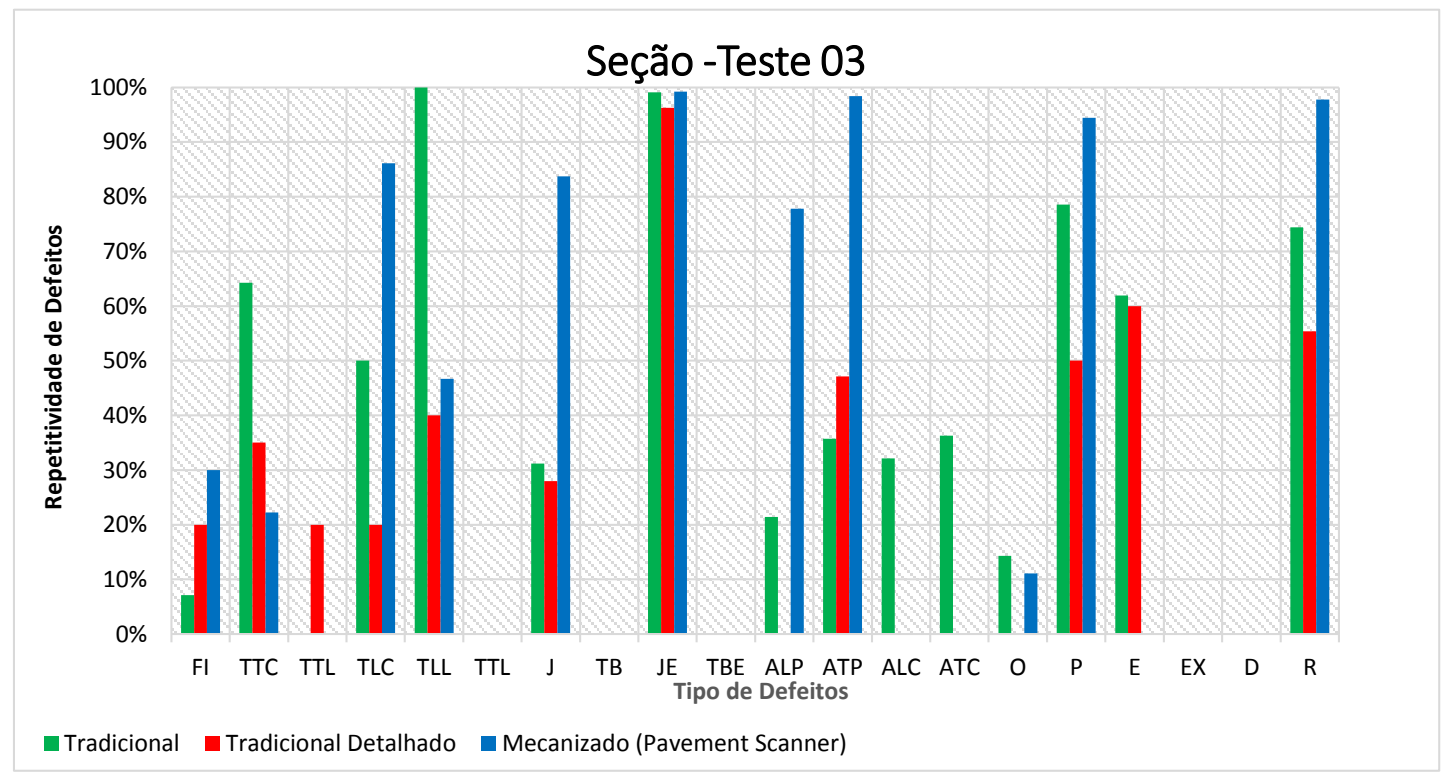

Figura 4.64 - Análise da Repetitividade dos Defeitos - ST-03

Verifica-se que o levantamento mecanizado da seção-teste 03 apresenta elevada repetitividade na detecção de remendos, panelas, afundamentos plásticos, jacaré com e sem erosão, além dos trincamentos longitudinais curtos. Os levantamentos tradicionais apresentam menor nível de precisão para todos os defeitos, com exceção do trincamento longitudinal longo, que no caso em questão, encontra-se no bordo entre a pista e o acostamento e para o trincamento classe 3.

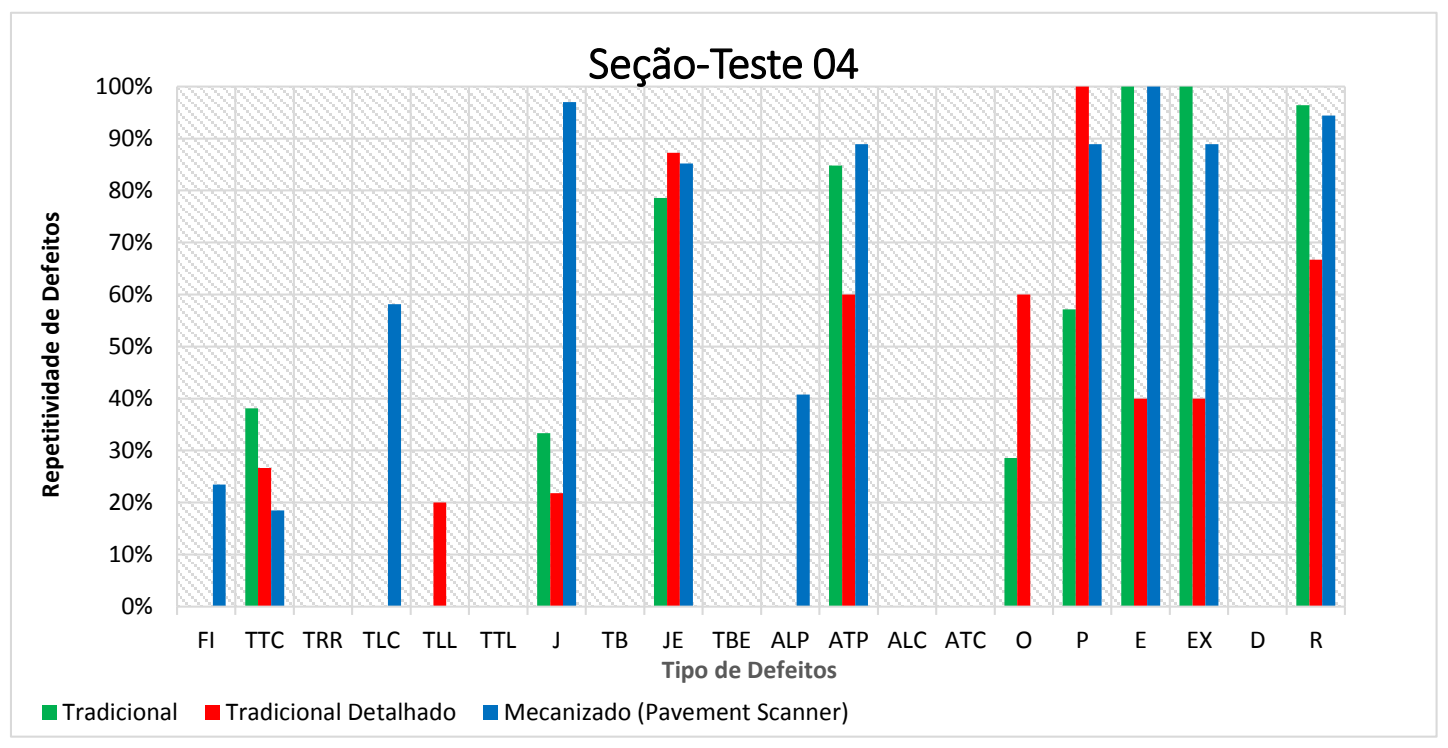

Figura 4.65 - Análise da Repetitividade dos Defeitos - ST-04 
Para a seção-teste 04 verificou-se que o levantamento mecanizado apresentou elevado grau de precisão de resultados para detecção de remendos, panelas, afundamentos plásticos, jacaré com e sem erosão, escorregamento e exsudação. Não foi detectado pelo Pavement Scanner ondulação nem trincas longitudinais longas, que neste caso são trincas de bordo.

O processamento do parâmetro de ondulação no software LCMS ainda encontra-se em fase de ajustes para a detecção correta deste defeito.

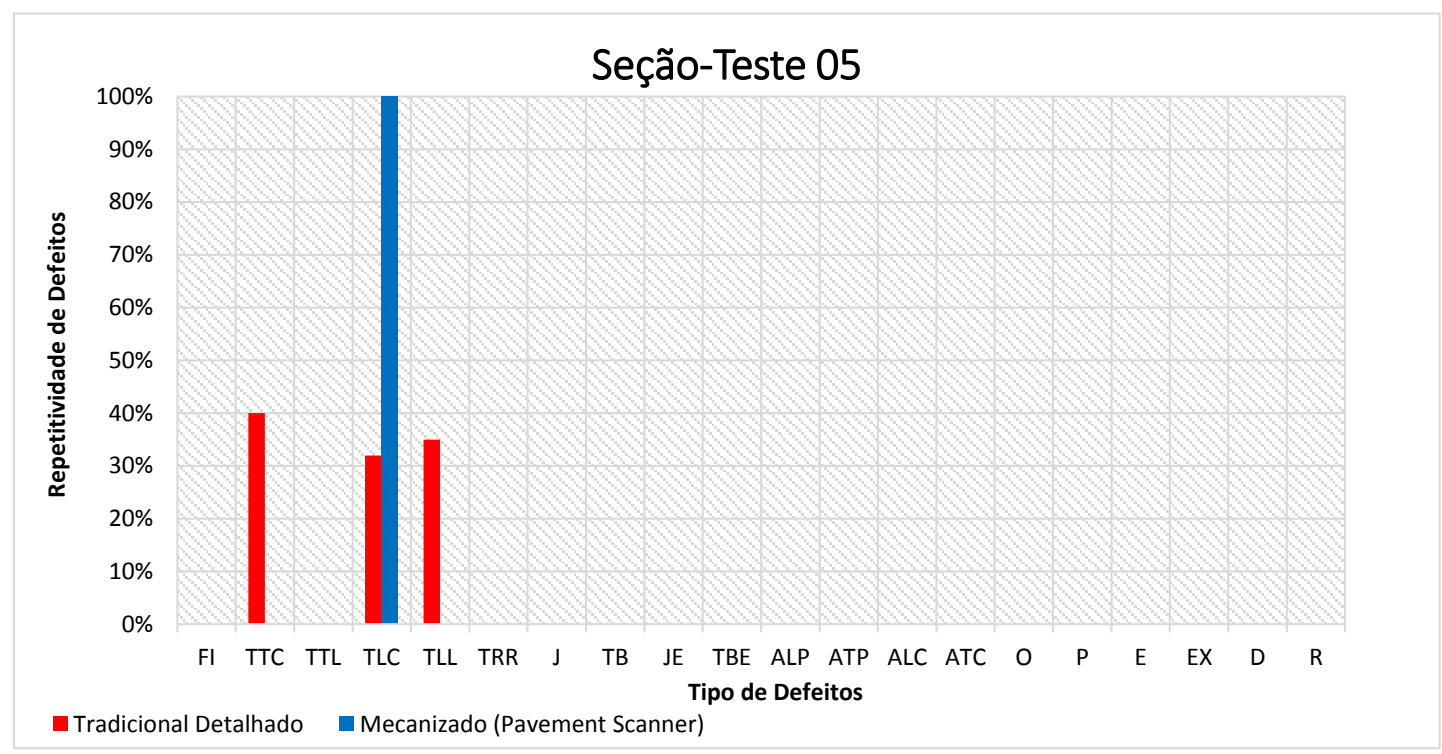

Figura 4.66 - Análise da Repetitividade dos Defeitos - ST-05

Na seção-teste 05 foram detectadas somente trincas isoladas, apresentando $100 \%$ de repetitividade do levantamento mecanizado para o trincamento longitudinal curto. Os trincamentos transversais curtos e longitudinal longo não foram detectados mecanicamente, mas sim, pelos levantamentos tradicionais, porém com baixa repetitividade média de $40 \%$ e $35 \%$, respectivamente. 


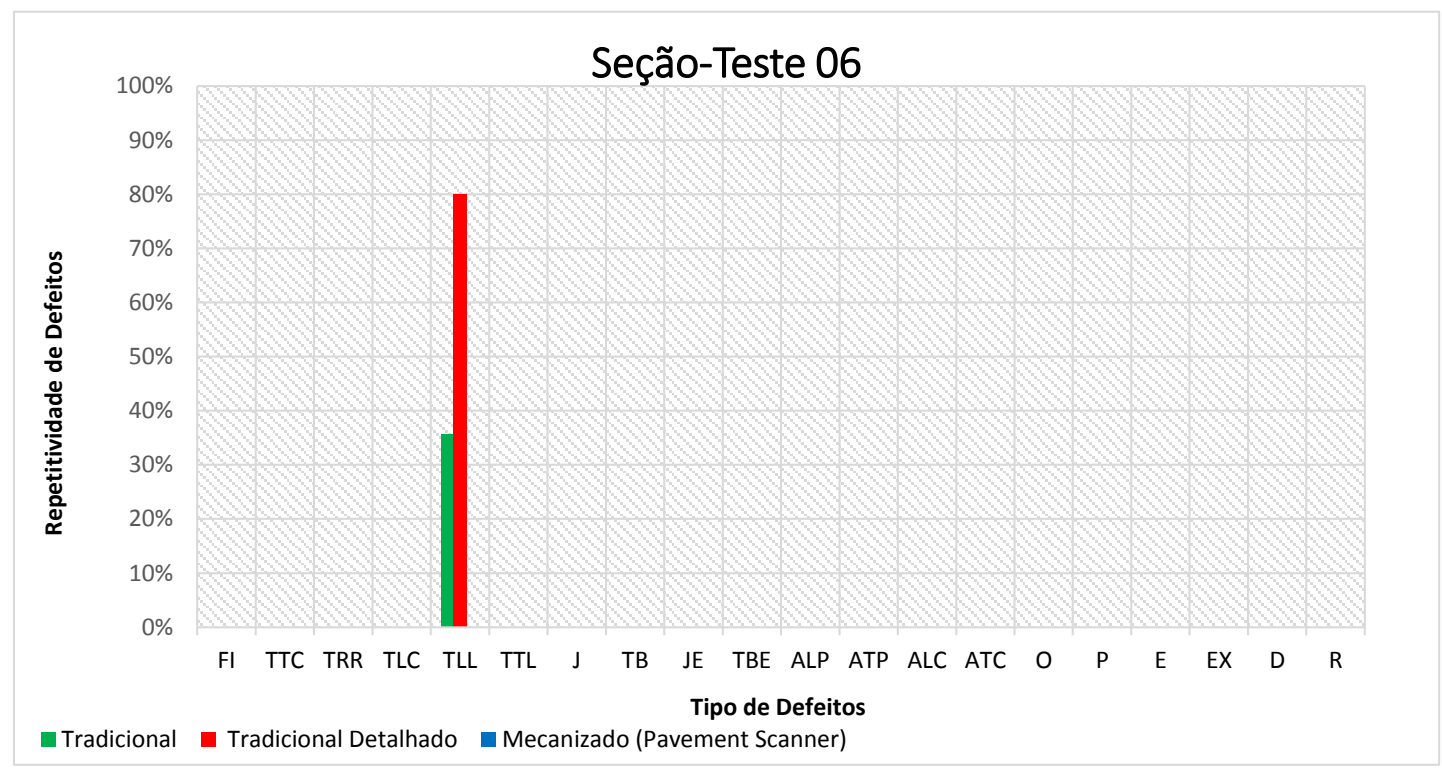

Figura 4.67 - Análise da Repetitividade dos Defeitos - ST-06

Para a seção-teste 06 não houve detecção do trincamento longitudinal longo no bordo da rodovia pelo Pavement Scanner, enquanto que os levantamentos tradicionais detectaram o mesmo.

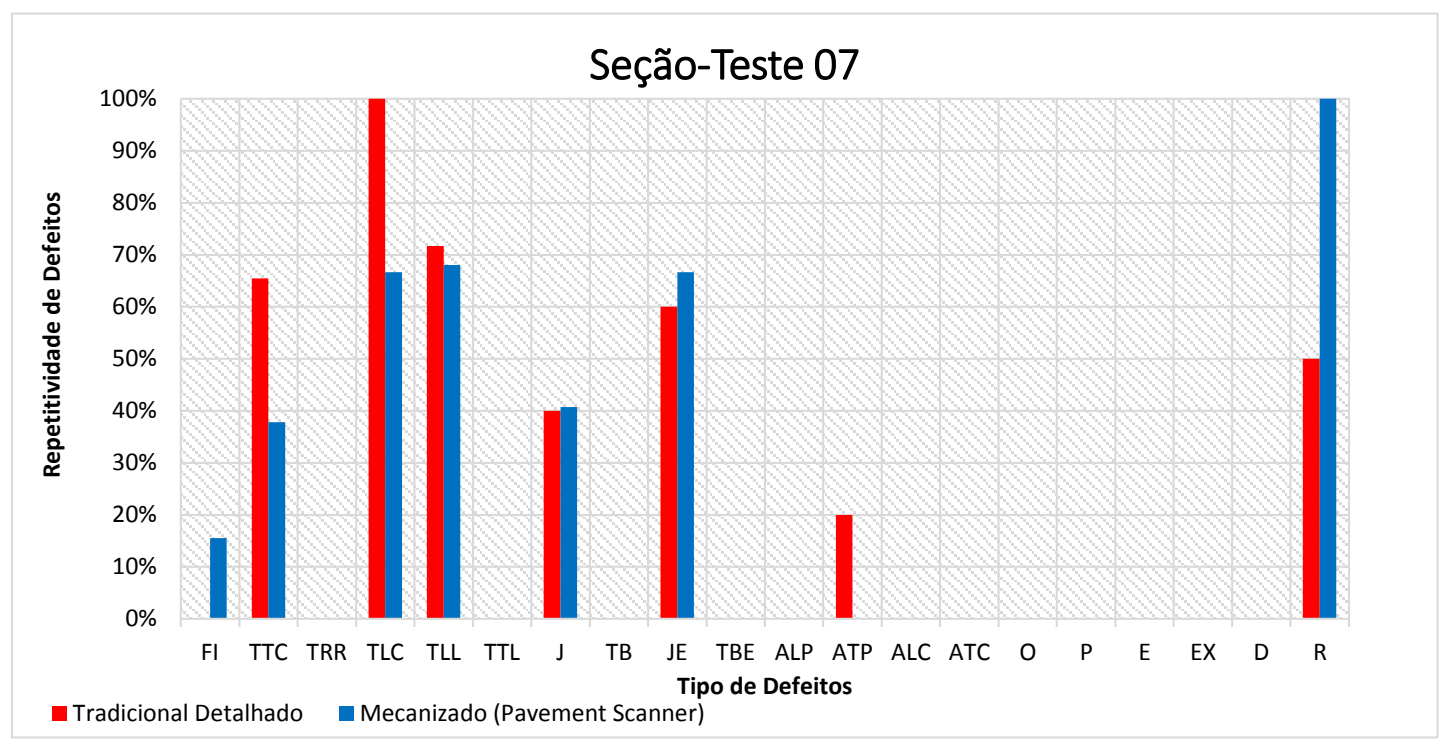

Figura 4.68 - Análise da Repetitividade dos Defeitos - ST-07

O levantamento mecanizado na seção-teste 07 demonstra maiores repetitividades na detecção de remendos e trincamento do tipo jacaré em relação ao levantamento tradicional. O levantamento tradicional, por sua vez, demonstra maior repetitividade na detecção de trincamentos isolados. 


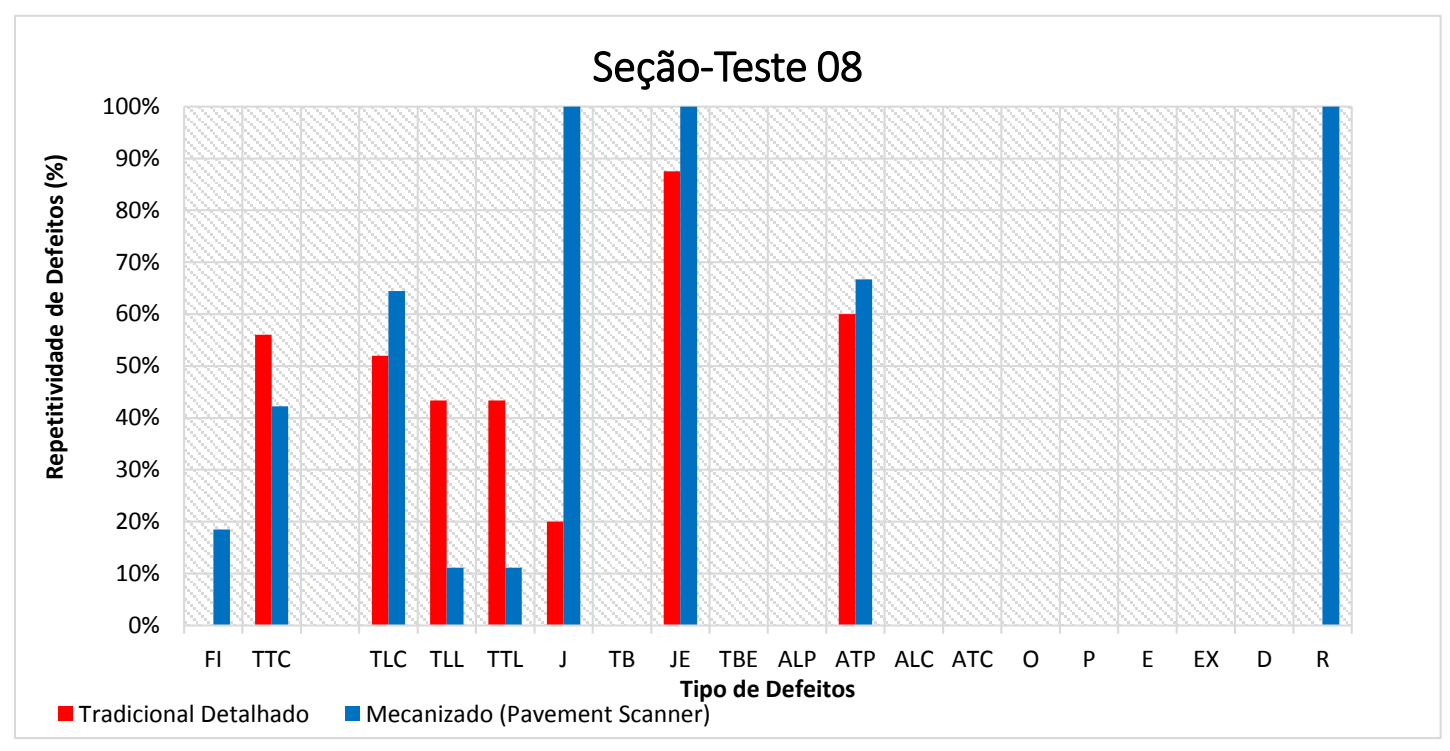

Figura 4.69 - Análise da Repetitividade dos Defeitos - ST-08

O Pavement Scanner, na seção-teste 08, apresentou elevada repetitividade na identificação de remendos e trincamento do tipo jacaré e jacaré com erosão. Houve boa detecção também para os afundamentos e trincas longitudinais curtas. $\mathrm{O}$ levantamento tradicional apresentou baixa repetitividade principalmente na detecção de trincas jacaré do tipo FC-2, haja vista, que visualmente pode ser mais difícil definir a classe do trincamento.

De forma a resumir todas as informações expostas com relação à repetitividade de defeitos, torna-se importante apresentar o gráfico da Figura 4.70 que foi concebido a partir da média da repetitividade de cada defeito, em cada seção-teste estudada. 


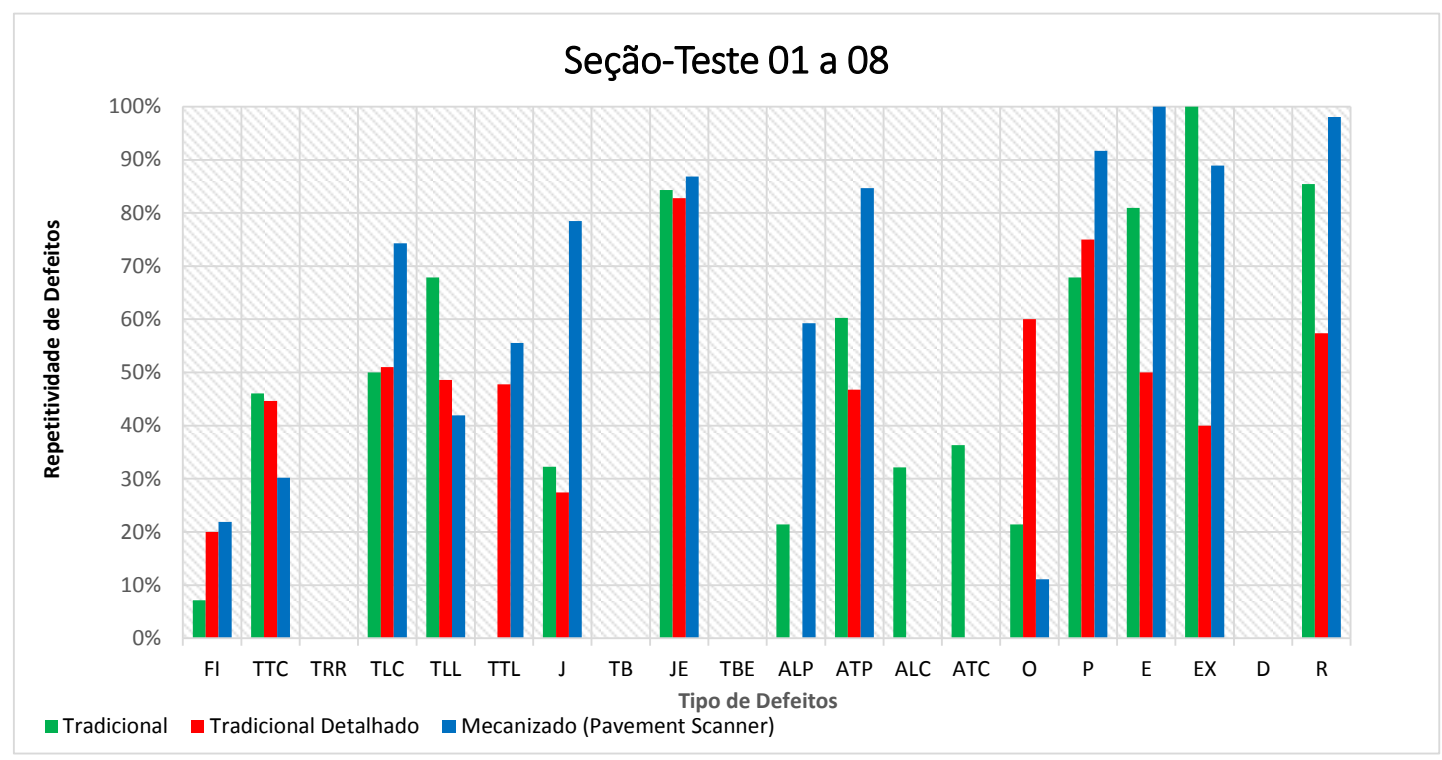

Figura 4.70 - Análise da Repetitividade dos Defeitos

Verifica-se que a detecção de remendos tem maior precisão no levantamento mecanizado. Este defeito tem seu perímetro mapeado no Pavement Scanner, sendo identificado como remendo pelo software LCMS e posteriormente, o responsável pelo tratamento dos dados, realiza varredura visual nas imagens em 3D, de forma a verificar se todos os remendos foram computados.

A exsudação teve boa repetitividade em ambos os levantamentos, com exceção do tradicional detalhado. A exsudação é detectada no Pavement Scanner a partir dos dados de retorno de intensidade de laser.

As panelas apresentaram maior repetitividade no levantamento mecanizado, com aproximadamente $90 \%$ de precisão de resultados. Esse defeito também tem seu perímetro e área interna delineado pelo software LCMS. Também é realizada uma verificação visual final com o objetivo de identificar possíveis falhas de detecção do software.

A ondulação não teve boa repetitividade, já que o algoritmo de processamento deste defeito no Pavement Scanner está em processo de revisão. 
Os afundamentos consolidados não foram detectados nem pelo Pavement Scanner, nem pelo método de levantamento tradicional detalhado, apresentando baixa repetitividade no levantamento tradicional, indicando baixa precisão de resultados.

Os afundamentos plásticos apresentaram maior repetitividade no levantamento mecanizado em relação ao tradicional. Os afundamentos na trilha são identificados no Pavement Scanner a partir dos dados de trilha de roda de seções transversais contínuas em extensão mínima de 6 metros, onde foi estabelecido, com base em inúmeros testes, o limite de afundamento por seção, valor este, que ao ser ultrapassado, é identificado como ATR. Os afundamentos locais também são identificados com base nos dados de trilha de roda, porém para seções de até 1 metro, com afundamentos mínimos para detecção também definidos baseados em inúmeros testes.

Os trincamentos do tipo jacaré, classe FC-2 e FC-3 apresentaram precisão de aproximadamente $85 \%$ na detecção no Pavement Scanner, apresentando melhor repetitividade em comparação aos outros métodos. As trincas FC-2 apresentam menor precisão de resultados nos levantamentos tradicionais, possivelmente devido a maior dificuldade para definir a classe de trincamento visualmente.

Os trincamentos isolados do tipo transversal longo e longitudinal curto apresentaram maior repetitividade no método mecanizado. Já o longitudinal longo que na maioria dos casos é detectado apenas no bordo da sinalização não apresenta boa repetitividade no Pavement Scanner.

\subsection{Análise da Reprodutividade e Repetitividade}

\subsubsection{Procedimento para Obtenção da Reprodutividade e Repetitividade}

A ISO 5725-2 (1994) apresenta procedimentos de estudos e análises estatísticas para avaliação da variabilidade de resultados com vistas na repetitividade e reprodutividade. Segundo a norma, a repetitividade refere-se à variabilidade entre medidas realizadas sob as mesmas circunstâncias, que no estudo em questão, pode ser 
dada como a variabilidade de resultados obtidos em cada seção-teste para o mesmo operador. Já a reprodutividade refere-se à variabilidade de resultados obtidos em diferentes laboratórios, que no estudo em questão pode ser analisada a variação para diferentes operadores.

Para início da análise da reprodutividade e repetitividade devem ser primeiramente realizados testes estatísticos para verificação dos valores das amostras que eventualmente possam ser considerados dispersos ou outliers, através dos testes de Grubbs, Snedecor e Dixon. O teste de Grubbs detecta valores extremos de distribuições normais, em que os dados testados são os valores mínimo e máximo, tendo como resultado uma probabilidade que indica se os dados pertencem ao núcleo de uma população de dados, baseando-se na diferença entre a média da amostra e os dados mais extremos, considerando o desvio padrão. O teste de Snedecor, baseado na distribuição F, compara a variância de uma população de dados, duas a duas, para certa probabilidade, verificando-se a variância de dois conjuntos da população de dados é igual para um desejado nível de confiança (95\%). Por fim, é realizado o teste de Dixon que identifica valores afastados da amostra, de forma a estabelecer um critério para rejeição de valores extremos, sendo um teste bilateral, ou seja, são testados os valores mínimo e máximo.

A norma ISO 5725-2(1994), com vistas à verificação da repetitividade e reprodutividade apresenta as equações 4.1 a 4.4 :

Variância de repetitividade $\left(S^{2}{ }_{r j}\right)$ :

$$
S_{r j}^{2}=\frac{\sum_{i=1}^{p}\left(n_{i j}-1\right) S_{i j}^{2}}{\sum_{i=1}^{p}\left(n_{i j}-1\right)}
$$

Em que:

$n_{i j}=$ número de resultados para o operador $\mathrm{i}$, na seção-teste $\mathrm{j}$;

$S_{i j}=$ desvio padrão para o operador i, na seção-teste $\mathrm{j}$. 
$\checkmark$ Variância entre laboratórios $\left(S_{L j}{ }^{2}\right)$

$$
S_{L j}^{2}=\frac{S_{d j}{ }^{2}-S_{r j}{ }^{2}}{n_{i j}}
$$

Em que:

$$
S_{d j}^{2}=\frac{1}{p-1} \sum_{i=1}^{p} n_{i j}\left(\bar{x}_{i j}-\overline{\bar{x}}_{j}\right)^{2}
$$

Onde:

$\bar{x}_{i j}=$ média dos resultados para o operador $\mathrm{i}$, na seção-teste $\mathrm{j}$

$\overline{\bar{x}}_{j}=$ média geral dos resultados para a seção-teste $\mathrm{j}$

$\mathrm{p}=$ número de operadores

$\checkmark$ Variância da reprodutividade $\left(S_{R j}^{2}\right)$

$$
S_{R j}^{2}=S_{r j}^{2}+S_{L j}^{2}
$$

Segundo a ISO 5725-2 (1994), o limite aceitável de repetitividade é dado por um valor que em $95 \%$ dos casos não ultrapassa a diferença absoluta entre dois resultados obtidos sob a mesma condição de repetitividade.

Este limite é definido como valor de repetitividade, sendo considerado um parâmetro de precisão, correlacionado com o desvio padrão de cada conjunto de amostras, conforme equação 4.5 :

$$
r=2,8 \times S_{r}
$$

Em que:

$\mathrm{r}=$ valor limite de repetitividade;

$\mathrm{S}_{\mathrm{r}}=$ desvio padrão de repetitividade. 
De forma a verificar se os resultados obtidos nos conjuntos de ensaios obedecem às condições de repetitividade preconizados na ISO 5725 (1994), é aplicada a equação 4.6:

$$
r_{e}^{\prime}=\left(1-\frac{E}{C}\right) \cdot 100
$$

Em que:

$\mathrm{r}_{\mathrm{e}}$ = valor de repetitividade do ensaio;

$\mathrm{E}=$ número de diferenças de leituras maiores que $\mathrm{r}$;

$\mathrm{C}=$ número de diferenças totais de leitura, ou seja, combinação de n leituras 2 a 2.

\subsubsection{Resultados da Reprodutividade e Repetitividade do IGG}

Foi procedida a análise da reprodutividade e repetitividade para os resultados de IGG obtidos nos levantamentos tradicionais e mecanizados.

Para o Pavement Scanner foram realizadas nove amostras em cada seção-teste, com dois operadores, sendo que o operador A realizou cinco repetições e o operador B, quatro repetições.

Foram analisados testes estatísticos de Snedecor, Dixon e Grubbs que comprovaram a homogeneidade dos resultados obtidos no levantamento mecanizado. A Tabela 4.12 demonstra os resultados das variâncias de repetitividade e reprodutividade, em conformidade com o preconizado na Norma ISO 5725-2 (1994). 
Tabela 4.12 - Análise do Desvio Padrão de Repetitividade e Reprodutividade do Pavement Scanner

\begin{tabular}{|c|c|c|c|c|c|c|c|c|c|c|}
\hline Seção-Teste & Operador & $\begin{array}{l}\text { Média } \\
(\bar{x})\end{array}$ & $\begin{array}{c}\text { Média Geral } \\
\qquad(\boldsymbol{x} \overline{\bar{j}}\end{array}$ & $\begin{array}{l}\text { Desv Pad } \\
\quad(S \mathbf{r})\end{array}$ & $\mathrm{Sr}^{2}$ & $S_{d}^{2}$ & $\mathbf{S}_{\mathrm{L}}^{2}$ & $\mathbf{S}_{\mathbf{R}}^{2}$ & Sr & $\mathbf{S}_{\mathrm{R}}$ \\
\hline \multirow{2}{*}{ ST-01 } & A & 0,831 & \multirow{2}{*}{0,802} & 0,221 & 0,049 & \multirow{2}{*}{0,011} & 0,000 & 0,049 & 0,221 & 0,221 \\
\hline & B & 0,766 & & 0,270 & 0,073 & & 0,000 & 0,073 & 0,270 & 0,270 \\
\hline \multirow{2}{*}{$\begin{array}{c}\text { ST-02 } \\
\text { Faixa } 1\end{array}$} & A & 1,322 & \multirow{2}{*}{1,309} & 0,168 & 0,028 & \multirow{2}{*}{0,002} & 0,000 & 0,028 & 0,168 & 0,168 \\
\hline & B & 1,293 & & 0,120 & 0,014 & & 0,000 & 0,014 & 0,120 & 0,120 \\
\hline \multirow{2}{*}{$\begin{array}{l}\text { ST-02 } \\
\text { Faixa } 2\end{array}$} & A & 4,804 & \multirow{2}{*}{4,876} & 0,392 & 0,154 & \multirow{2}{*}{0,066} & 0,000 & 0,154 & 0,392 & 0,392 \\
\hline & B & 4,965 & & 0,752 & 0,566 & & 0,000 & 0,566 & 0,752 & 0,752 \\
\hline \multirow{2}{*}{ ST- 03} & A & 229,736 & \multirow{2}{*}{228,363} & 1,896 & 3,593 & \multirow{2}{*}{24,141} & 4,110 & 7,703 & 1,896 & 2,775 \\
\hline & B & 226,648 & & 2,043 & 4,173 & & 3,994 & 8,166 & 2,043 & 2,858 \\
\hline \multirow{2}{*}{$\begin{array}{l}\text { ST-04 } \\
\text { Faixa } 1\end{array}$} & A & 30,338 & \multirow{2}{*}{29,832} & 2,943 & 8,664 & \multirow{2}{*}{3,292} & 0,000 & 8,664 & 2,943 & 2,943 \\
\hline & B & 29,198 & & 3,013 & 9,079 & & 0,000 & 9,079 & 3,013 & 3,013 \\
\hline \multirow{2}{*}{$\begin{array}{l}\text { ST-04 } \\
\text { Faixa } 2\end{array}$} & A & 259,031 & \multirow{2}{*}{261,001} & 4,258 & 18,133 & \multirow{2}{*}{49,690} & 6,312 & 24,444 & 4,258 & 4,944 \\
\hline & $\mathrm{B}$ & 263,462 & & 4,715 & 22,228 & & 5,493 & 27,720 & 4,715 & 5,265 \\
\hline \multirow{2}{*}{ ST-05 } & A & 4,353 & \multirow{2}{*}{4,209} & 0,406 & 0,165 & \multirow{2}{*}{0,268} & 0,021 & 0,185 & 0,406 & 0,430 \\
\hline & B & 4,028 & & 0,263 & 0,069 & & 0,040 & 0,109 & 0,263 & 0,330 \\
\hline \multirow{2}{*}{$\begin{array}{r}\text { ST-06 } \\
\text { Faixa } 1\end{array}$} & A & 5,711 & \multirow{2}{*}{5,796} & 0,738 & 0,545 & \multirow{2}{*}{0,094} & 0,000 & 0,545 & 0,738 & 0,738 \\
\hline & $\mathrm{B}$ & 5,903 & & 0,443 & 0,196 & & 0,000 & 0,196 & 0,443 & 0,443 \\
\hline \multirow{2}{*}{$\begin{array}{r}\text { ST-06 } \\
\text { Faixa } 2\end{array}$} & A & 4,129 & \multirow{2}{*}{4,229} & 0,216 & 0,047 & \multirow{2}{*}{0,127} & 0,016 & 0,063 & 0,216 & 0,251 \\
\hline & B & 4,353 & & 0,256 & 0,065 & & 0,012 & 0,078 & 0,256 & 0,279 \\
\hline \multirow{2}{*}{ ST-07 } & A & 37,050 & \multirow{2}{*}{36,530} & 2,280 & 5,196 & \multirow{2}{*}{3,463} & 0,000 & 5,196 & 2,280 & 2,280 \\
\hline & B & 35,881 & & 0,701 & 0,491 & & 0,594 & 1,086 & 0,701 & 1,042 \\
\hline \multirow{2}{*}{$\begin{array}{l}\text { ST-08 } \\
\text { Faixa } 1\end{array}$} & A & 18,497 & 17715 & 1,858 & 3,451 & 78 & 0,873 & 4,325 & 1,858 & 2,080 \\
\hline & $\mathrm{B}$ & 16,739 & 17,115 & 1,051 & 1,105 & 7,817 & 1,342 & 2,448 & 1,051 & 1,565 \\
\hline ST-08 & A & 96,040 & 0681 & 7,583 & 57,501 & 76 & 0,000 & 57,501 & 7,583 & 7,583 \\
\hline Faixa 2 & B & 97,780 & 0,014 & 4,123 & 16,998 & , & 0,000 & 16,998 & 4,123 & 4,123 \\
\hline
\end{tabular}

Verifica-se que os valores dos desvios padrões de repetitividade obtidos em cada seção-teste, para cada operador, não dependem da média dos resultados de IGG. Esses desvios podem ser representados como a média dos desvios padrões da repetitividade e de reprodutividade, representativos para o ensaio mecanizado.

Desvio Padrão da repetitividade: $S_{\mathrm{r}}=1,70$

Desvio Padrão da reprodutividade: $\mathrm{S}_{\mathrm{R}}=1,87$

A Tabela 4.13 descreve os valores de repetitividade obtidos nos ensaios com o Pavement Scanner. Percebe-se que todos os operadores das seções-teste não excedem o limite de repetitividade em mais de $95 \%$ dos casos, conforme especificado na ISO 
5725. A exceção é o operador A, na seção-teste 08 que excede o limite de repetitividade em $20 \%$ dos casos.

Verifica-se condições aceitáveis de repetitividade para o levantamento mecanizado. As condições de reprodutividade são boas, uma vez que seus valores são muito próximos à da própria repetitividade, ou seja, a variância entre operadores é muito baixa ou nula em parte dos casos, denotando que o ensaio não é dependente do operador. 
Tabela 4.13 - Valor da Repetitividade do Pavement Scanner

\begin{tabular}{|c|c|c|c|c|c|c|}
\hline $\begin{array}{l}\text { Seção- } \\
\text { Teste }\end{array}$ & Operador & $\mathbf{r}$ & $\mathbf{E}$ & $\mathbf{C}$ & $\mathbf{r}_{\mathrm{e}^{\prime}}$ & \begin{tabular}{|c|} 
Valor da \\
Repetitividade
\end{tabular} \\
\hline \multirow{2}{*}{ ST-01 } & A & 0,688 & 0 & 10 & $100 \%$ & \multirow{2}{*}{$>95 \%$} \\
\hline & B & 0,688 & 0 & 6 & $100 \%$ & \\
\hline \multirow{2}{*}{$\begin{array}{c}\text { ST-02 } \\
\text { Faixa } 1\end{array}$} & A & 0,402 & 0 & 10 & $100 \%$ & \multirow{2}{*}{$>95 \%$} \\
\hline & B & 0,402 & 0 & 6 & $100 \%$ & \\
\hline \multirow{2}{*}{$\begin{array}{c}\text { ST-02 } \\
\text { Faixa } 2\end{array}$} & A & 1,602 & 0 & 10 & $100 \%$ & \multirow{2}{*}{$>95 \%$} \\
\hline & B & 1,602 & 0 & 6 & $100 \%$ & \\
\hline \multirow{2}{*}{ ST-03 } & A & 5,514 & 0 & 10 & $100 \%$ & \multirow{2}{*}{$>95 \%$} \\
\hline & B & 5,514 & 0 & 6 & $100 \%$ & \\
\hline \multirow{2}{*}{$\begin{array}{c}\text { ST-04 } \\
\text { Faixa } 1\end{array}$} & A & 8,339 & 0 & 10 & $100 \%$ & \multirow{2}{*}{$>95 \%$} \\
\hline & B & 8,339 & 0 & 6 & $100 \%$ & \\
\hline \multirow{2}{*}{$\begin{array}{c}\text { ST-04 } \\
\text { Faixa } 2\end{array}$} & A & 12,562 & 0 & 10 & $100 \%$ & \multirow{2}{*}{$>95 \%$} \\
\hline & B & 12,562 & 0 & 6 & $100 \%$ & \\
\hline \multirow{2}{*}{ ST-05 } & A & 0,967 & 0 & 10 & $100 \%$ & \multirow{2}{*}{$>95 \%$} \\
\hline & B & 0,967 & 0 & 6 & $100 \%$ & \\
\hline \multirow{2}{*}{$\begin{array}{c}\text { ST-06 } \\
\text { Faixa } 1\end{array}$} & A & 1,654 & 0 & 10 & $100 \%$ & \multirow{2}{*}{$>95 \%$} \\
\hline & B & 1,654 & 0 & 6 & $100 \%$ & \\
\hline \multirow{2}{*}{$\begin{array}{c}\text { ST-06 } \\
\text { Faixa } 2\end{array}$} & A & 0,661 & 0 & 10 & $100 \%$ & \multirow{2}{*}{$>95 \%$} \\
\hline & B & 0,661 & 0 & 6 & $100 \%$ & \\
\hline \multirow{2}{*}{ ST-07 } & A & 6,383 & 0 & 10 & $100 \%$ & \multirow{2}{*}{$>95 \%$} \\
\hline & B & 6,383 & 0 & 6 & $100 \%$ & \\
\hline \multirow{2}{*}{$\begin{array}{c}\text { ST-08 } \\
\text { Faixa } 1\end{array}$} & A & 4,073 & 0 & 10 & $100 \%$ & \multirow{2}{*}{$>95 \%$} \\
\hline & B & 4,073 & 0 & 6 & $100 \%$ & \\
\hline \multirow{2}{*}{$\begin{array}{c}\text { ST-08 } \\
\text { Faixa } 2\end{array}$} & A & 16,388 & 2 & 10 & $80 \%$ & $<95 \%$ \\
\hline & B & 16,388 & 0 & 6 & $100 \%$ & $>95 \%$ \\
\hline
\end{tabular}


Para o cálculo do IGG pelo método tradicional foram estudadas quatorze amostras na ST-01, ST-03, ST-04 e ST-06, com dois operadores, sendo que cada operador realizou sete repetições.

Foram realizados testes estatísticos de Dixon e Grubbs que comprovaram a homogeneidade dos resultados. No entanto, o teste de Snedecor verificou discrepâncias (outliers) nos resultados da faixa 01 da seção-teste 04, dada à elevada variância no levantamento do operador A, que é significativamente maior que a do operador B. O operador B tem maior experiência nestes levantamentos, obtendo em todas as amostras menor variabilidade. A Tabela 4.14 demonstra os resultados das variâncias de repetitividade e reprodutividade, em conformidade com o preconizado na Norma ISO 5725.

Tabela 4.14 - Análise do Desvio Padrão de Repetitividade e Reprodutividade do IGG pelo Método Tradicional

\begin{tabular}{|c|c|c|c|c|c|c|c|c|c|c|}
\hline Seção-Teste & Operador & $\begin{array}{c}\text { Média } \\
(\boldsymbol{x} \bar{\top})\end{array}$ & $\begin{array}{c}\text { Média Geral } \\
(\boldsymbol{x} \overline{\bar{T}}\end{array}$ & $\begin{array}{c}\text { Desv Pad } \\
(S \mathbf{r})\end{array}$ & $\mathrm{Sr}^{2}$ & $S_{d}^{2}$ & $S_{L}^{2}$ & $\mathbf{S}_{\mathrm{R}}{ }^{2}$ & $\mathrm{Sr}$ & $\mathbf{S}_{\mathrm{R}}$ \\
\hline \multirow{2}{*}{ ST-01 } & A & 0,403 & \multirow{2}{*}{0,347} & 0,128 & 0,016 & \multirow{2}{*}{0,045} & 0,004 & 0,021 & 0,128 & 0,143 \\
\hline & $\mathrm{B}$ & 0,290 & & 0,097 & 0,009 & & 0,005 & 0,014 & 0,097 & 0,120 \\
\hline \multirow{2}{*}{ ST-03 } & A & 245,070 & \multirow{2}{*}{238,924} & 12,072 & 145,722 & \multirow{2}{*}{528,777} & 54,722 & 200,445 & 12,072 & 14,158 \\
\hline & B & 232,779 & & 8,836 & 78,075 & & 64,386 & 142,461 & 8,836 & 11,936 \\
\hline \multirow{2}{*}{$\begin{array}{l}\text { ST-04 } \\
\text { Faixa } 1\end{array}$} & A & 46,426 & \multirow{2}{*}{42,268} & 11,345 & 128,704 & \multirow{2}{*}{242,017} & 16,187 & 144,892 & 11,345 & 12,037 \\
\hline & B & 38,110 & & 5,268 & 27,751 & & 30,609 & 58,361 & 5,268 & 7,639 \\
\hline \multirow{2}{*}{$\begin{array}{l}\text { ST-04 } \\
\text { Faixa } 2\end{array}$} & A & 272,171 & \multirow{2}{*}{259,835} & 17,165 & 294,647 & \multirow{2}{*}{2130,625} & 262,283 & 556,929 & 17,165 & 23,599 \\
\hline & $\mathrm{B}$ & 247,499 & & 13,206 & 174,392 & & 279,462 & 453,854 & 13,206 & 21,304 \\
\hline \multirow{2}{*}{$\begin{array}{r}\text { ST-06 } \\
\text { Faixa } 1\end{array}$} & A & 4,963 & \multirow{2}{*}{5,029} & 0,569 & 0,323 & \multirow{2}{*}{0,061} & 0,000 & 0,323 & 0,569 & 0,569 \\
\hline & B & 5,095 & & 0,391 & 0,153 & & 0,000 & 0,153 & 0,391 & 0,391 \\
\hline \multirow{2}{*}{$\begin{array}{r}\text { ST-06 } \\
\text { Faixa } 2\end{array}$} & A & 7,381 & \multirow{2}{*}{7,508} & 1,642 & 2,697 & \multirow{2}{*}{0,225} & 0,000 & 2,697 & 1,642 & 1,642 \\
\hline & B & 7,635 & & 2,251 & 5,066 & & 0,000 & 5,066 & 2,251 & 2,251 \\
\hline
\end{tabular}

Verifica-se que os valores dos desvios padrão de repetitividade e reprodutividade obtidos em cada seção-teste, para cada avaliador, são muito mais elevados que os apresentados para o levantamento mecanizado.

Desvio Padrão da repetitividade: $\mathrm{S}_{\mathrm{r}}=6,08$

Desvio Padrão da reprodutividade: $\mathrm{S}_{\mathrm{R}}=7,98$ 
A Tabela 4.15 descreve os valores de repetitividade obtidos nos ensaios tradicionais para obtenção do IGG. Percebe-se que em apenas 50\% dos grupos de amostras o ensaio tradicional apresentou grau de precisão ou compatível, ou seja, não excederam o limite de repetitividade em mais de $95 \%$ dos casos, conforme especificado na ISO 5725.

Verifica-se que o avaliador A apresentou baixa precisão em $70 \%$ dos casos, dado que é o que possui menor experiência no levantamento.

Tabela 4.15 - Valor da Repetitividade do Levantamento Tradicional

\begin{tabular}{c|c|c|c|c|c|c}
\hline $\begin{array}{c}\text { Seção } \\
\text { Teste }\end{array}$ & Operador & $\mathbf{r}$ & $\mathbf{E}$ & $\mathbf{C}$ & $\mathbf{r}_{\mathbf{e}}{ }^{\prime}$ & $\begin{array}{c}\text { Valor da } \\
\text { Repetitividade }\end{array}$ \\
\hline \multirow{2}{*}{ ST-01 } & $\mathrm{A}$ & 0,315 & 0 & 21 & $100 \%$ & $>95 \%$ \\
\cline { 2 - 7 } & $\mathrm{B}$ & 0,315 & 0 & 21 & $100 \%$ & $>95 \%$ \\
\hline \multirow{2}{*}{ ST-03 } & $\mathrm{A}$ & 29,271 & 2 & 21 & $90 \%$ & $<95 \%$ \\
\cline { 2 - 7 } & $\mathrm{B}$ & 29,271 & 0 & 21 & $100 \%$ & $>95 \%$ \\
\hline \multirow{2}{*}{$\begin{array}{c}\text { ST-04 } \\
\text { Faixa 1 }\end{array}$} & $\mathrm{A}$ & 23,258 & 4 & 21 & $81 \%$ & $<95 \%$ \\
\hline \multirow{2}{*}{$\begin{array}{c}\text { ST-04 } \\
\text { Faixa 2 }\end{array}$} & $\mathrm{B}$ & 23,258 & 0 & 21 & $100 \%$ & $>95 \%$ \\
\cline { 2 - 7 } & $\mathrm{B}$ & 42,519 & 1 & 21 & $90 \%$ & $<95 \%$ \\
\hline $\begin{array}{c}\text { ST-06 } \\
\text { Faixa 1 }\end{array}$ & $\mathrm{A}$ & 1,344 & 2 & 21 & $90 \%$ & $<95 \%$ \\
\cline { 2 - 7 } & $\mathrm{B}$ & 1,344 & 0 & 21 & $100 \%$ & $>95 \%$ \\
\hline $\begin{array}{c}\text { ST-06 } \\
\text { Faixa 2 }\end{array}$ & $\mathrm{A}$ & 5,450 & 0,00 & 1,01 & $100 \%$ & $>95 \%$ \\
\cline { 2 - 7 } & $\mathrm{B}$ & 5,450 & 3,00 & 21 & $86 \%$ & $<95 \%$ \\
\hline
\end{tabular}

Portanto, percebe-se que o levantamento tradicional não atende ao valor de repetitividade em $50 \%$ dos casos estudados e que não apresenta boa reprodutividade, sendo seu resultado dependente do avaliador.

Vale pontuar que os levantamentos tradicionais objetos desta pesquisa foram realizados com cautela, seguindo todas as prerrogativas do DNIT PRO-006/2003. Esses levantamentos, podem apresentar variações muito superiores às estudadas nesta dissertação, dado que no cotidiano, na maioria das vezes, esse levantamento é realizado em uma extensão de rodovia muito grande, em curto período de tempo, portanto, sem o grau de detalhamento requerido em norma. 


\subsection{Correlação entre IGG e PCI}

Com base nos dados obtidos com o Pavement Scanner procedeu-se à determinação do PCI proposto pelo Departamento de Transportes do Estado de New York - NYSDOT, em 2003.

Foram definidos para cada repetição realizada, em todas as seções-teste, os fatores funcionais que afetam o desempenho do pavimento, a serem considerados no cálculo do PCI do NYSDOT (2003):

- Classificação da Superfície;

- Qualidade ao rolamento (IRI);

- Afundamentos;

- Falhas e defeitos dominantes (trincamentos interligados).

O cálculo do PCI foi realizado de forma amostral, similar ao preconizado no DNIT PRO-006/2003, com amostras afastadas de $20 \mathrm{~m}$, alternando as faixas de tráfego, considerando-se a delimitação em comprimento de 3 metros em ré e 3 metros em avante em relação à estação, com aproximadamente $15 \%$ da área total do pavimento analisada.

Para a classificação da superfície, que variam de 1 a 10 , foram utilizadas as recomendações do NYSDOT, com relação à frequência, severidade e aparência dos defeitos no pavimento. Essa classificação apresenta um grau maior de subjetividade comparado aos outros defeitos analisados.

Para a definição dos valores de dedução do IRI e do afundamento de cada estação da seção-teste foram utilizadas as curvas de dedução apresentadas no capítulo 2.4.3.

Para as falhas e defeitos dominantes foram definidos para cada estação se os trincamentos interligados apresentam-se isolados ou de forma generalizada. 
A Tabela 4.16 explicita os valores de PCI encontrados para as nove repetições em cada seção-teste, bem como, os valores de IGG já apresentados anteriormente. 
Tabela 4.16 - Resultados do PCI para cada Seção-Teste

\begin{tabular}{|c|c|c|c|c|c|c|c|c|c|c|c|c|c|c|c|}
\hline \multirow{2}{*}{\multicolumn{2}{|c|}{ Resultados para Correlação }} & \multicolumn{9}{|c|}{ Amostra } & \multirow{2}{*}{ Média } & \multirow{2}{*}{$\begin{array}{l}\text { Desvio } \\
\text { Padrão }\end{array}$} & \multirow{2}{*}{\begin{tabular}{|l|} 
Coef. de \\
Variação \\
\end{tabular}} & \multirow{2}{*}{ Variância } & \multirow{2}{*}{$\begin{array}{l}\text { Máx - } \\
\text { Mín }\end{array}$} \\
\hline & & 1 & 2 & 3 & 4 & 5 & 6 & 7 & 8 & 9 & & & & & \\
\hline \multirow{2}{*}{$\begin{array}{c}\text { Seção Teste } \\
01\end{array}$} & PCI & 95,0 & 94,5 & 94,0 & 94,9 & 95,0 & 94,8 & 95,0 & 95,1 & 95,0 & 94,8 & 0,4 & $0 \%$ & 0,1 & 1,1 \\
\hline & IGG & 1,1 & 0,8 & 0,6 & 1,0 & 0,6 & 1,1 & 0,6 & 0,9 & 0,5 & $\mathbf{0 , 8}$ & 0,2 & $29 \%$ & 0,1 & 0,6 \\
\hline \multirow{2}{*}{$\begin{array}{l}\text { Seção Teste } \\
02 \text { FX1 }\end{array}$} & PCI & 90,5 & 89,3 & 90,2 & 89,3 & 90,4 & 90,3 & 90,9 & 91,0 & 90,1 & 90,2 & 0,6 & $1 \%$ & 0,4 & 1,7 \\
\hline & IGG & 1,5 & 1,4 & 1,2 & 1,5 & 1,1 & 1,4 & 1,1 & 1,3 & 1,3 & 1,3 & 0,1 & $11 \%$ & 0,0 & 0,4 \\
\hline \multirow{2}{*}{$\begin{array}{l}\text { Seção Teste } \\
02 \text { FX2 }\end{array}$} & PCI & 93,9 & 93,6 & 93,4 & 93,6 & 93,8 & 93,6 & 93,6 & 94,2 & 93,8 & 93,7 & 0,2 & $0 \%$ & 0,1 & 0,8 \\
\hline & IGG & 4,5 & 5,1 & 4,4 & 5,0 & 4,5 & 6,1 & 4,7 & 4,5 & 4,2 & 4,8 & 0,6 & $12 \%$ & 0,3 & 1,9 \\
\hline \multirow{2}{*}{$\begin{array}{l}\text { Seção Teste } \\
03\end{array}$} & PCI & 12,6 & 12,1 & 13,4 & 12,2 & 12,4 & 12,6 & 13,0 & 12,8 & 12,3 & 12,6 & 0,4 & $3 \%$ & 0,2 & 1,3 \\
\hline & IGG & 228,5 & 228,2 & 230,5 & 232,7 & 228,8 & 228,3 & 228,1 & 224,7 & 225,5 & 228,4 & 2,4 & $1 \%$ & 5,7 & 8,1 \\
\hline \multirow{2}{*}{$\begin{array}{c}\text { Seção Teste } \\
04 \\
\text { Faixa } 01\end{array}$} & PCI & 81,2 & 81,3 & 80,0 & 80,9 & 80,8 & 80,7 & 81,2 & 81,6 & 80,6 & 80,9 & 0,5 & $1 \%$ & 0,2 & 1,6 \\
\hline & IGG & 29,1 & 30,6 & 33,0 & 26,0 & 33,0 & 27,4 & 30,9 & 26,0 & 32,5 & 29,8 & 2,8 & $10 \%$ & 8,1 & 7,0 \\
\hline \multirow{2}{*}{$\begin{array}{c}\text { Seção Teste } \\
04 \\
\text { Faixa } 02 \\
\end{array}$} & PCI & 4,9 & 5,7 & 5,6 & 4,3 & 5,9 & 5,3 & 6,2 & 4,9 & 6,0 & 5,4 & 0,6 & $11 \%$ & 0,4 & 1,9 \\
\hline & IGG & 264,8 & 261,8 & 258,1 & 255,9 & 254,5 & 259,0 & 265,4 & 269,2 & 260,2 & 261,0 & 4,8 & $2 \%$ & 22,9 & 14,6 \\
\hline \multirow{2}{*}{$\begin{array}{c}\text { Seção Teste } \\
05\end{array}$} & PCI & 90,9 & 90,0 & 90,1 & 90,2 & 90,3 & 90,3 & 91,0 & 90,0 & 90,3 & 90,3 & 0,3 & $0 \%$ & 0,1 & 1,0 \\
\hline & IGG & 4,3 & 4,6 & 4,9 & 3,9 & 4,0 & 3,8 & 3,8 & 4,3 & 4,1 & 4,2 & 0,4 & $9 \%$ & 0,1 & 1,1 \\
\hline \multirow{2}{*}{$\begin{array}{c}\text { Seção Teste } \\
06 \\
\text { Faixa } 01\end{array}$} & PCI & 91,2 & 90,4 & 91,6 & 91,1 & 92,3 & 91,5 & 92,3 & 91,8 & 91,9 & 91,6 & 0,6 & $1 \%$ & 0,4 & 2,0 \\
\hline & IGG & 5,9 & 4,9 & 6,5 & 5,0 & 6,3 & 5,3 & 5,9 & 5,9 & 6,4 & 5,8 & 0,6 & $10 \%$ & 0,4 & 1,5 \\
\hline \multirow{2}{*}{$\begin{array}{c}\text { Seção Teste } \\
06 \\
\text { Faixa } 02 \\
\end{array}$} & PCI & 89,5 & 87,0 & 87,9 & 88,3 & 88,7 & 88,4 & 88,9 & 88,4 & 88,3 & 88,4 & 0,7 & $1 \%$ & 0,5 & 2,5 \\
\hline & IGG & 4,1 & 3,9 & 4,3 & 4,4 & 3,9 & 4,6 & 4,0 & 4,4 & 4,3 & 4,2 & 0,2 & $6 \%$ & 0,1 & 0,7 \\
\hline \multirow{2}{*}{$\begin{array}{c}\text { Seção Teste } \\
07\end{array}$} & PCI & 63,0 & 62,8 & 64,9 & 64,8 & 64,5 & 63,6 & 64,5 & 63,9 & 64,0 & 64,0 & 0,8 & $1 \%$ & 0,6 & 2,1 \\
\hline & IGG & 39,2 & 39,1 & 35,9 & 33,8 & 37,3 & 36,8 & 35,2 & 35,9 & 35,6 & 36,5 & 1,8 & $5 \%$ & 3,2 & 5,4 \\
\hline \multirow{2}{*}{$\begin{array}{c}\text { Seção Teste } \\
08 \\
\text { Faixa } 01 \\
\end{array}$} & PCI & 85,5 & 81,0 & 82,6 & 84,7 & 84,7 & 84,0 & 85,2 & 83,8 & 84,4 & 84,0 & 1,4 & $2 \%$ & 1,9 & 4,4 \\
\hline & IGG & 16,0 & 19,8 & 19,8 & 19,9 & 17,0 & 17,1 & 17,8 & 16,8 & 15,3 & 17,7 & 1,7 & $10 \%$ & 3,0 & 4,6 \\
\hline \multirow{2}{*}{$\begin{array}{c}\text { Seção Teste } \\
08 \\
\text { Faixa } 02 \\
\end{array}$} & PCI & 34,5 & 33,8 & 33,6 & 35,5 & 35,2 & 36,3 & 35,1 & 37,2 & 35,6 & 35,2 & 1,1 & $3 \%$ & 1,3 & 3,7 \\
\hline & IGG & 103,9 & 101,3 & 94,4 & 96,3 & 84,3 & 100,5 & 95,4 & 101,9 & 93,3 & 96,8 & 6,0 & $6 \%$ & 36,0 & 19,6 \\
\hline
\end{tabular}


Verifica-se que o coeficiente de variação do PCI é muito inferior ao do IGG, mesmo ambos sendo obtidos como resultado do Pavement Scanner. Isso ocorre pelo fato do PCI apresentar seu índice de maneira mais global e não tão detalhada em comparação ao IGG, já que muitos defeitos não são mensurados de maneira objetiva no cálculo do PCI. Adicionalmente, no PCI é considerado índice de qualidade ao rolamento, expressado de maneira subjetiva com "classificação da superfície", além de índices definidos de maneira objetiva, como as deduções do IRI e afundamentos.

Observa-se que as seções-teste cujos defeitos não foram detectados pelo IGG, como é o caso da seção-teste 01 , apresentaram o PCI em função principalmente dos valores de irregularidade longitudinal. A ST-01 e a ST-02 faixa 1 apresentam valores de IGG semelhantes e muito baixos, no entanto, comparando-se os valores de PCI, percebe-se uma maior diferença devido à irregularidade longitudinal (fator não mensurado no cálculo do IGG).

A Figura 4.71 apresenta o gráfico de correlação entre os valores de PCI e os valores de IGG para todas as amostras e seções-teste.

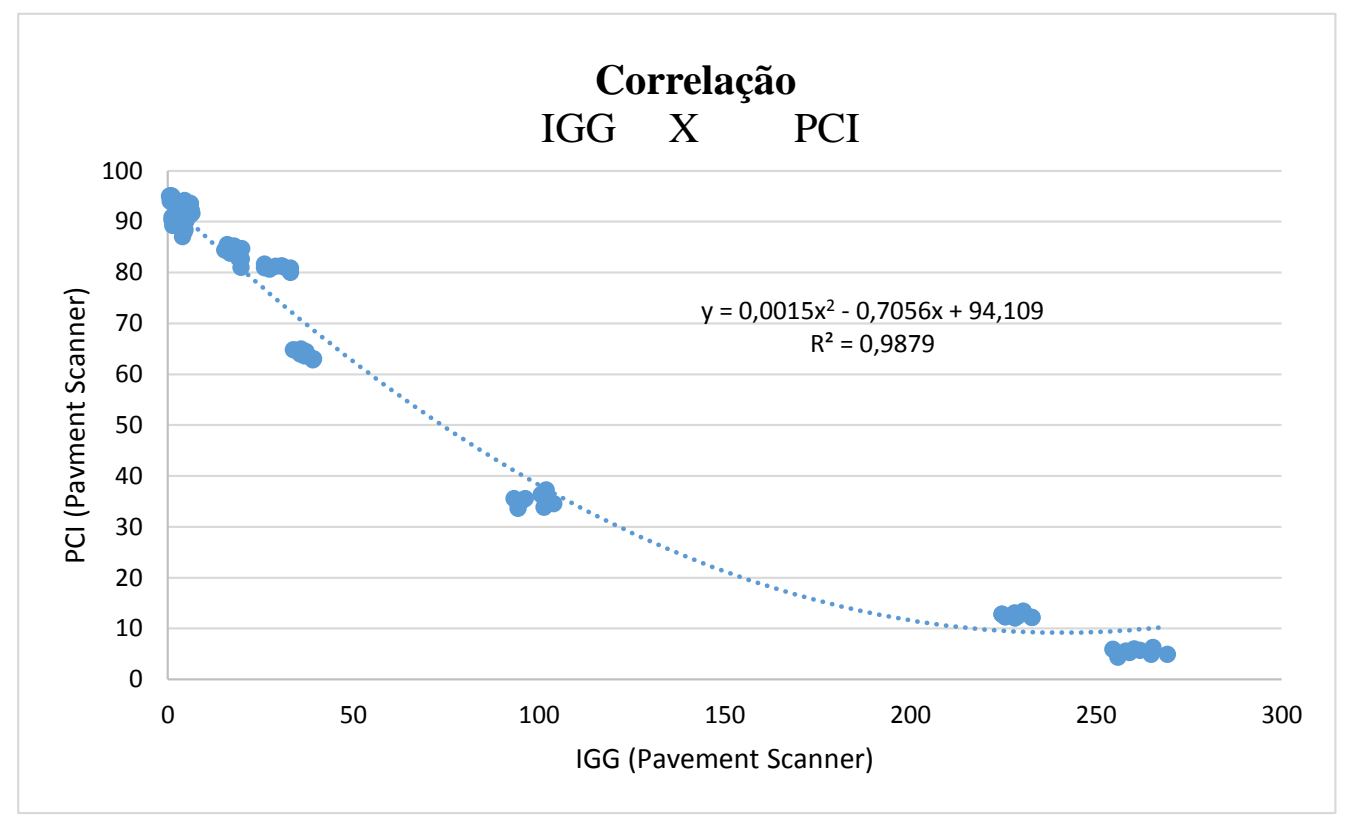

Figura 4.71 - Correlação entre o PCI e o IGG, ambos do Pavement Scanner 
O gráfico apresentado demonstra uma boa correlação entre o PCI e o IGG, ambos obtidos com o Pavement Scanner, com $\mathrm{R}^{2}$ de 0,98.

De forma a verificar os resultados obtidos e o grau de correlação entre as duas metodologias de avaliação do pavimento, apresentam-se nas Figuras 4.72 e 4.73 os gráficos de escala de conceito de todas as amostras estudadas.

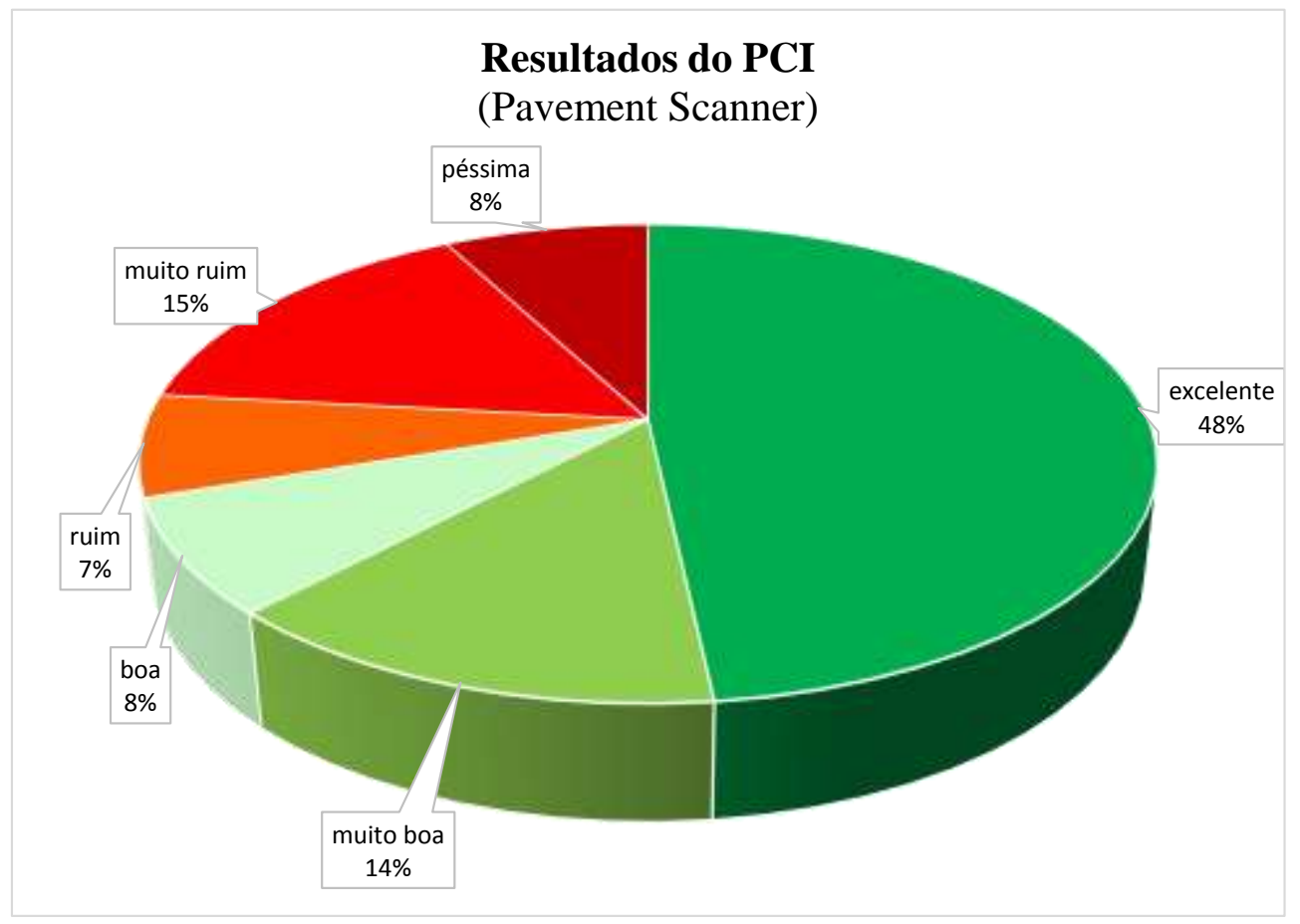

Figura 4.72 - Escala de conceitos do PCI 


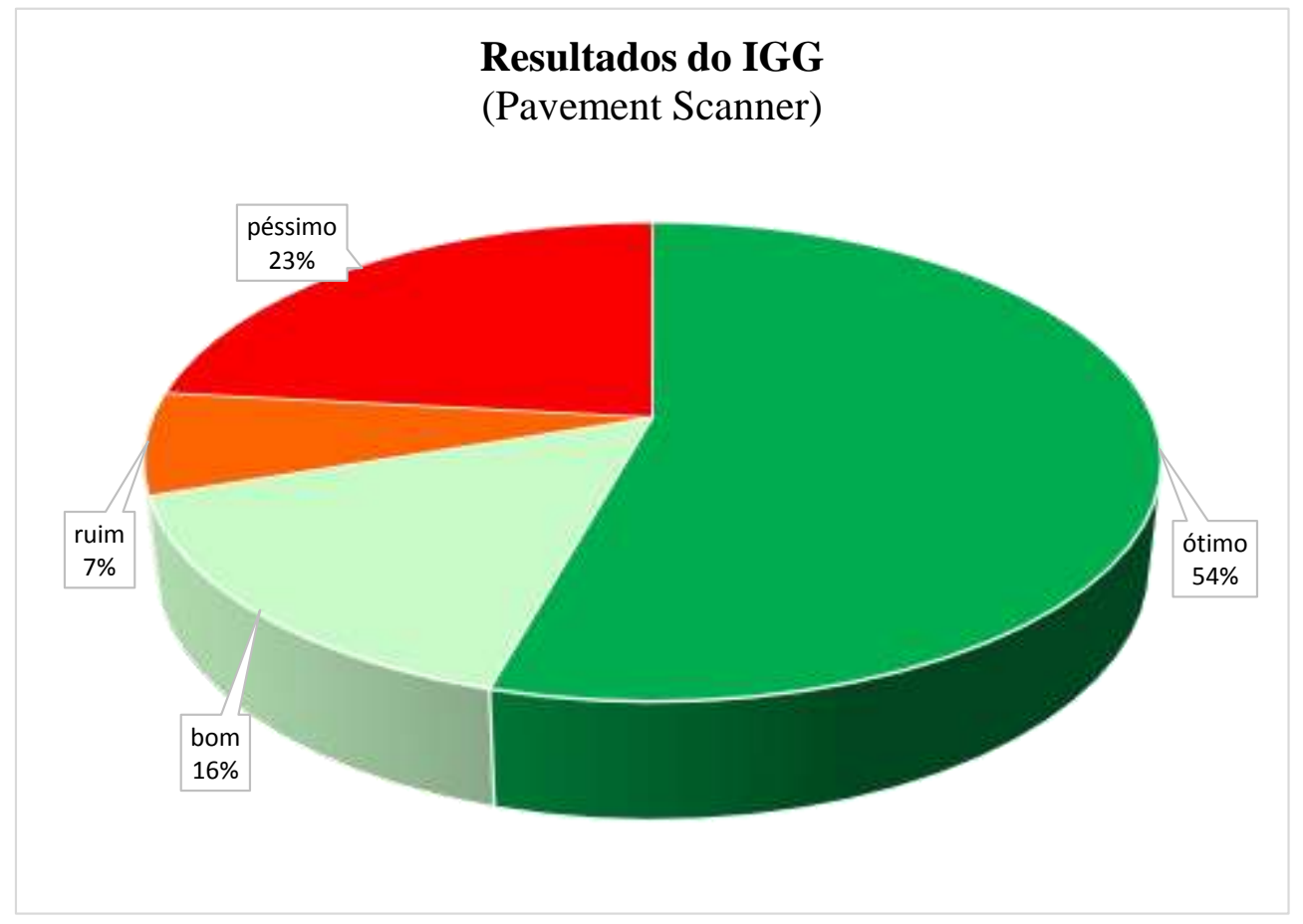

Figura 4.73 - Escala de Conceitos do IGG

Verifica-se muita similaridade entre os resultados obtidos para ambas as metodologias, em que para o PCI, 70\% das amostras estão em condição variando de boa a excelente, enquanto para o IGG, o percentual é o mesmo, no entanto, para os conceitos de bom a ótimo. O PCI e o IGG apresentaram 7\% de amostras em condição regular e 30\% em condição variando de ruim a péssimo.

Esses gráficos denotam grande correlação de resultados entre as duas metodologias, demonstrando a não necessidade de grande detalhamento de defeitos, como é o caso do IGG, para a avaliação da qualidade do pavimento.

\subsection{Análise do IGG com relação ao percentual amostral}

O IGG, conforme o Procedimento DNIT-PRO 006/2003, foi concebido para definir a gravidade funcional do pavimento de forma amostral, onde se é avaliada $15 \%$ da área total da rodovia. 
O Pavement Scanner por ser um levantamento contínuo de varredura total da área do pavimento pode fornecer um índice de gravidade global da área completa do trecho da rodovia, analisando-se todos os defeitos existentes, ponderando-os e apresentando um índice da condição real do pavimento.

A Tabela 4.17 apresenta a comparação com base no levantamento com o Pavement Scanner entre o IGG preconizado pelo DNIT-PRO 006/2003 concebido de forma amostral e o IGG considerando todos os defeitos detectados na via continuamente. Para cada repetição de ensaio mecanizado realizado em campo, o IGG foi analisado conforme preconizado nas normas nacionais e de maneira contínua, de modo a possibilitar a comparação. 
Tabela 4.17 - Resultados do IGG amostral e do IGG contínuo

\begin{tabular}{|c|c|c|c|c|c|c|c|c|c|c|c|c|c|c|c|c|}
\hline \multirow{2}{*}{\multicolumn{2}{|c|}{ IGG Pavement Scanner }} & \multicolumn{9}{|c|}{ Amostra } & \multirow{3}{*}{$\begin{array}{c}\text { Média } \\
0,5 \\
\end{array}$} & \multirow{3}{*}{\begin{tabular}{|c|}
$\begin{array}{c}\text { Dife rença } \\
(\%)\end{array}$ \\
$-35 \%$ \\
\end{tabular}} & \multirow{3}{*}{$\begin{array}{c}\begin{array}{c}\text { Desvio } \\
\text { Padrão }\end{array} \\
0,1 \\
\end{array}$} & \multirow{3}{*}{\begin{tabular}{|c|}
$\begin{array}{c}\text { Coef. de } \\
\text { Variação }\end{array}$ \\
$20 \%$ \\
\end{tabular}} & \multirow{3}{*}{\begin{tabular}{|c|} 
Variância \\
0,0 \\
\end{tabular}} & \multirow{3}{*}{$\begin{array}{c}\begin{array}{c}\text { Máx } \\
\text { Mín }\end{array} \\
0,3 \\
\end{array}$} \\
\hline & & \multirow{2}{*}{1} & \multirow{2}{*}{$\begin{array}{l}2 \\
0\end{array}$} & \multirow{2}{*}{$\begin{array}{l}3 \\
0 \\
\end{array}$} & \multirow{2}{*}{$\begin{array}{l}4 \\
1 \\
\end{array}$} & \multirow{2}{*}{$\begin{array}{l}5 \\
1 \\
\end{array}$} & \multirow{2}{*}{$\begin{array}{l}6 \\
1 \\
\end{array}$} & \multirow{2}{*}{$\begin{array}{l}7 \\
0 \\
\end{array}$} & \multirow{2}{*}{8} & \multirow{2}{*}{$\begin{array}{l}9 \\
0 \\
\end{array}$} & & & & & & \\
\hline Seção Teste & Contínuo (100\% da área) & & & & & & & & & & & & & & & \\
\hline & Amostral (15\% da área) & 1 & 1 & 1 & 1 & 1 & 1 & 1 & 1 & 0 & 0,8 & - & 0,2 & $29 \%$ & 0,1 & 0,6 \\
\hline \multirow{2}{*}{$\begin{array}{c}\text { Seção Teste } \\
02 \text { FX1 }\end{array}$} & Contínuo (100\% da área) & 2 & 3 & 2 & 3 & 2 & 3 & 2 & 2 & 2 & 2,2 & $71 \%$ & 0,3 & $12 \%$ & 0,1 & 0,7 \\
\hline & Amostral (15\% da área) & 1 & 1 & 1 & 2 & 1 & 1 & 1 & 1 & 1 & 1,3 & - & 0,1 & $11 \%$ & 0,0 & 0,4 \\
\hline \multirow{2}{*}{$\begin{array}{c}\text { Seção Teste } \\
02 \text { FX2 }\end{array}$} & Contínuo (100\% da área) & 6 & 6 & 6 & 7 & 7 & 7 & 6 & 6 & 6 & 6,4 & $32 \%$ & 0,4 & $7 \%$ & 0,2 & 1,4 \\
\hline & Amostral (15\% da área) & 5 & 5 & 4 & 5 & 5 & 6 & 5 & 5 & 4 & 4,8 & - & 0,6 & $12 \%$ & 0,3 & 1,8 \\
\hline \multirow{2}{*}{$\begin{array}{c}\text { Seção Teste } \\
03\end{array}$} & Contínuo (100\% da área) & 231 & 228 & 222 & 229 & 227 & 228 & 224 & 233 & 224 & 227,5 & $0 \%$ & 3,7 & $2 \%$ & 13,5 & 11,7 \\
\hline & Amostral (15\% da área) & 228 & 228 & 230 & 233 & 229 & 228 & 228 & 225 & 226 & 228,4 & - & 2,4 & $1 \%$ & 5,7 & 8,1 \\
\hline \multirow{2}{*}{$\begin{array}{c}\text { Seção Teste } \\
04 \text { FX1 }\end{array}$} & Contínuo (100\% da área) & 29 & 26 & 26 & 25 & 26 & 24 & 26 & 22 & 24 & 25,4 & $-15 \%$ & 1,9 & $7 \%$ & 3,6 & 6,9 \\
\hline & Amostral (15\% da área) & 29 & 31 & 33 & 26 & 33 & 27 & 31 & 26 & 33 & 29,8 & - & 2,8 & $10 \%$ & 8,1 & 7,0 \\
\hline \multirow{2}{*}{$\begin{array}{c}\text { Seção Teste } \\
04 \text { FX2 }\end{array}$} & Contínuo (100\% da área) & 248 & 260 & 243 & 248 & 242 & 228 & 231 & 240 & 254 & 243,8 & $-7 \%$ & 10,4 & $4 \%$ & 108,2 & 32,7 \\
\hline & Amostral (15\% da área) & 265 & 258 & 262 & 256 & 255 & 259 & 265 & 269 & 260 & 261,0 & - & 4,8 & $2 \%$ & 22,9 & 14,6 \\
\hline \multirow{2}{*}{$\begin{array}{c}\text { Seção Teste } \\
05\end{array}$} & Contínuo (100\% da área) & 3 & 4 & 4 & 3 & 3 & 3 & 3 & 3 & 3 & 3,3 & $-21 \%$ & 0,2 & $5 \%$ & 0,0 & 0,4 \\
\hline & Amostral (15\% da área) & 4 & 5 & 5 & 4 & 4 & 4 & 4 & 4 & 4 & 4,2 & - & 0,4 & $9 \%$ & 0,1 & 1,1 \\
\hline \multirow{2}{*}{$\begin{array}{c}\text { Seção Teste } \\
06 \text { FX1 }\end{array}$} & Contínuo (100\% da área) & 5 & 4 & 5 & 5 & 5 & 5 & 5 & 5 & 5 & 4,9 & $-16 \%$ & 0,4 & $8 \%$ & 0,2 & 1,3 \\
\hline & Amostral (15\% da área) & 6 & 5 & 6 & 5 & 6 & 5 & 6 & 6 & 6 & 5,8 & - & 0,6 & $10 \%$ & 0,4 & 1,6 \\
\hline \multirow{2}{*}{$\begin{array}{c}\text { Seção Teste } \\
06 \text { FX2 }\end{array}$} & Contínuo (100\% da área) & 5 & 5 & 5 & 5 & 4 & 5 & 4 & 5 & 5 & 4,7 & $11 \%$ & 0,3 & $6 \%$ & 0,1 & 0,9 \\
\hline & Amostral (15\% da área) & 4 & 4 & 4 & 4 & 4 & 5 & 4 & 4 & 4 & 4,2 & - & 0,2 & $6 \%$ & 0,1 & 0,7 \\
\hline \multirow{2}{*}{$\begin{array}{c}\text { Seção Teste } \\
07\end{array}$} & Contínuo (100\% da área) & 43 & 40 & 39 & 39 & 41 & 41 & 41 & 40 & 40 & 40,5 & $11 \%$ & 1,2 & $3 \%$ & 1,4 & 3,7 \\
\hline & Amostral (15\% da área) & 39 & 39 & 36 & 34 & 37 & 37 & 35 & 36 & 36 & 36,5 & - & 1,8 & $5 \%$ & 3,2 & 5,4 \\
\hline \multirow{2}{*}{$\begin{array}{c}\text { Seção Teste } \\
08 \text { FX1 } \\
\end{array}$} & Contínuo (100\% da área) & 17 & 20 & 20 & 20 & 21 & 19 & 22 & 20 & 19 & 19,7 & $11 \%$ & 1,5 & $8 \%$ & 2,3 & 5,4 \\
\hline & Amostral (15\% da área) & 16 & 20 & 20 & 20 & 17 & 17 & 18 & 17 & 15 & 17,7 & - & 1,7 & $10 \%$ & 3,0 & 4,6 \\
\hline \multirow{2}{*}{$\begin{array}{c}\text { Seção Teste } \\
08 \text { FX2 }\end{array}$} & Contínuo (100\% da área) & 84 & 82 & 79 & 87 & 80 & 81 & 81 & 83 & 79 & 81,9 & $-15 \%$ & 2,6 & $3 \%$ & 6,8 & 8,7 \\
\hline & Amostral (15\% da área) & 104 & 101 & 94 & 96 & 84 & 101 & 95 & 102 & 93 & 96,8 & - & 6,0 & $6 \%$ & 36,0 & 19,6 \\
\hline
\end{tabular}


É demonstrado que há uma variação média entre o método amostral e o contínuo nas faixas ruins e regulares de até $15 \%$. Nas faixas em boas condições, o percentual de variação entre os dois levantamentos é maior, pois como o IGG apresenta um valor pequeno, qualquer variação nos resultados denota uma diferença percentual elevada.

A Figura 4.74 apresenta o gráfico de correlação entre os valores do IGG contínuo e o IGG amostral, conforme preconizado pelo DNIT-PRO 006/2003 para todas as amostras e seções-teste.

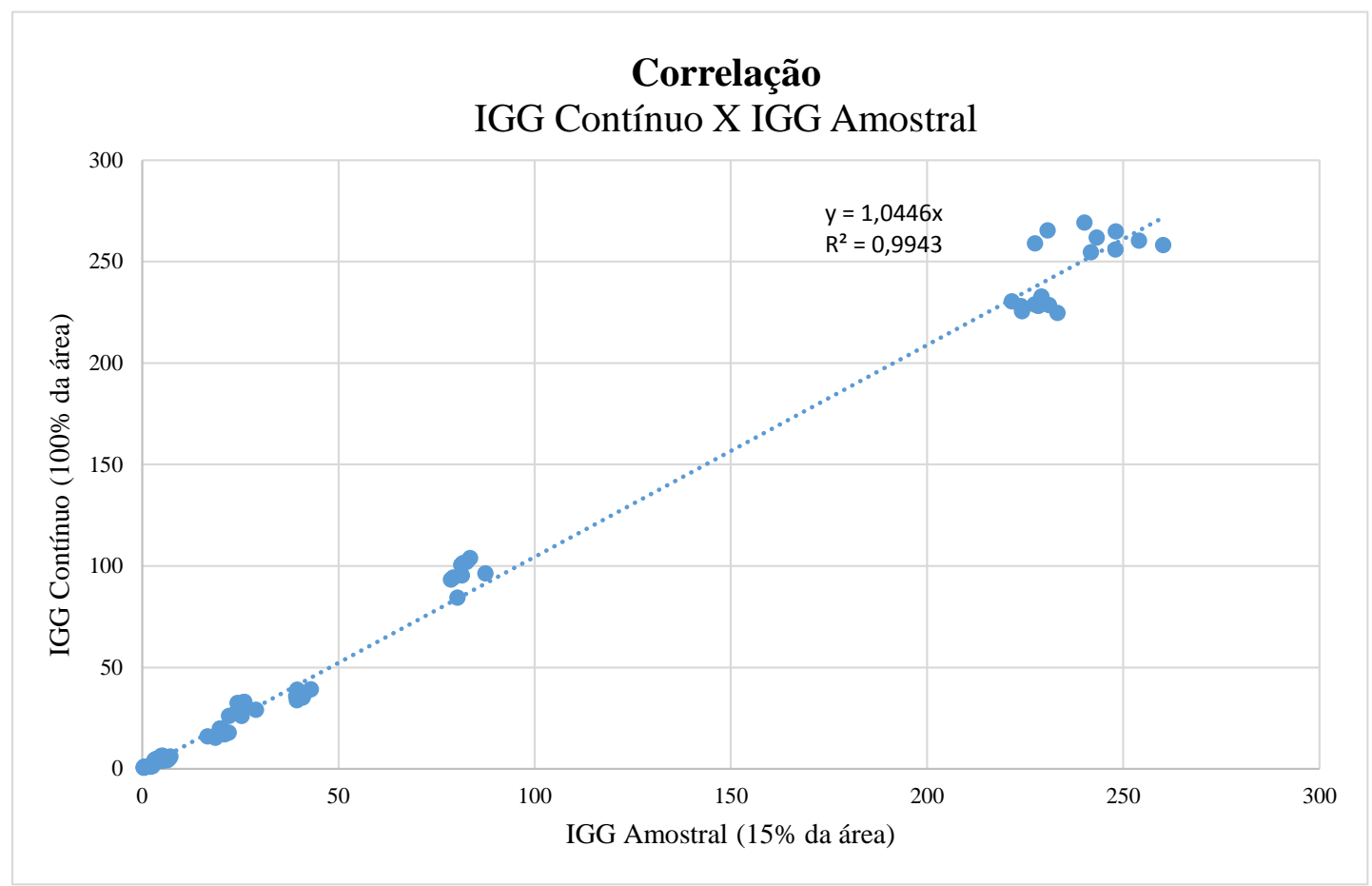

Figura 4.74 - Correlação do IGG contínuo e IGG amostral, ambos do Pavement Scanner

O gráfico apresentado demonstra uma boa correlação entre os dois resultados, ambos obtidos com o Pavement Scanner, com $\mathrm{R}^{2}$ de 0,99 . A curva de correlação apresenta o resultado para o IGG contínuo em média 4\% superior ao IGG amostral. 


\subsection{Análise da Variabilidade do IGG com Relação à Posição Inicial}

Foi realizada a análise para algumas seções-teste variando-se a posição inicial do levantamento, de 0 a 19 metros, de forma a avaliar a variabilidade dos resultados de IGG e sua dependência com relação à posição inicial.

Com base no levantamento tradicional detalhado foi possível analisar a variabilidade da somatória do índice de gravidade individual (IGI) dos defeitos. A parcela referente às medições em trilha de roda não variou, pois as mesmas foram levantadas a cada 20 metros, em relação à estaca 0 do levantamento.

Também foi estudada a variabilidade do IGG com base nos dados extraídos do Pavement Scanner para as seções-teste com características regulares e ruins. Nesta análise, foi possível verificar o IGI dos defeitos e o IGG, já que o equipamento fornece os dados de trilha de roda em qualquer posição solicitada. A Tabelas 4.18 a 4.22 demonstram a variabilidade de resultados obtidos pelo levantamento do método tradicional.

Tabela 4.18 - Análise da Variabilidade de Resultados do Método Tradicional- ST-

02

\begin{tabular}{|c|c|c|c|c|c|}
\hline \multirow{4}{*}{$\begin{array}{l}\text { Localização } \\
\text { Inicial } \\
\text { (m) }\end{array}$} & \multicolumn{5}{|c|}{$\begin{array}{c}\text { Seção Teste } 02 \\
\text { Faixa } 1\end{array}$} \\
\hline & \multicolumn{5}{|c|}{ Amostra } \\
\hline & 1 & 2 & 3 & 4 & 5 \\
\hline & $\begin{array}{c}\text { IGI Sem } \\
\text { Flecha }\end{array}$ & $\begin{array}{c}\text { IGI Sem } \\
\text { Flecha }\end{array}$ & $\begin{array}{c}\text { IGI Sem } \\
\text { Flecha }\end{array}$ & \begin{tabular}{|c|} 
IGI Sem \\
Flecha
\end{tabular} & $\begin{array}{c}\text { IGI Sem } \\
\text { Flecha }\end{array}$ \\
\hline 0 & 0,0 & 0,0 & 0,0 & 0,0 & 0,0 \\
\hline 1 & 0,0 & 0,0 & 0,0 & 0,0 & 0,0 \\
\hline 2 & 0,0 & 0,0 & 0,0 & 0,0 & 0,0 \\
\hline 3 & 0,0 & 0,0 & 0,0 & 0,0 & 0,0 \\
\hline 4 & 0,0 & 0,0 & 0,0 & 0,0 & 0,0 \\
\hline 5 & 0,0 & 0,0 & 0,0 & 0,0 & 0,0 \\
\hline 6 & 0,0 & 0,0 & 0,0 & 0,0 & 0,0 \\
\hline 7 & 0,0 & 0,0 & 0,0 & 0,0 & 0,0 \\
\hline 8 & 0,0 & 0,0 & 0,0 & 0,0 & 0,0 \\
\hline 9 & 0,0 & 0,0 & 0,0 & 0,0 & 0,0 \\
\hline 10 & 0,0 & 0,0 & 0,0 & 0,0 & 0,0 \\
\hline 11 & 0,0 & 0,0 & 0,0 & 0,0 & 0,0 \\
\hline 12 & 0,0 & 0,0 & 0,0 & 0,0 & 0,0 \\
\hline 13 & 0,0 & 0,0 & 0,0 & 0,0 & 0,0 \\
\hline 14 & 2,2 & 0,0 & 0,0 & 2,2 & 2,2 \\
\hline 15 & 2,2 & 2,2 & 2,2 & 2,2 & 2,2 \\
\hline 16 & 2,2 & 2,2 & 2,2 & 2,2 & 2,2 \\
\hline 17 & 2,2 & 2,2 & 2,2 & 2,2 & 2,2 \\
\hline 18 & 2,2 & 2,2 & 2,2 & 2,2 & 2,2 \\
\hline 19 & 2,2 & 2,2 & 2,2 & 2,2 & 2,2 \\
\hline Média & 0,7 & 0,6 & 0,6 & 0,7 & 0,7 \\
\hline Des vio Padrão & 1,0 & 1,0 & 1,0 & 1,0 & 1,0 \\
\hline Coef de Variação & $157 \%$ & $178 \%$ & $178 \%$ & $157 \%$ & $157 \%$ \\
\hline
\end{tabular}

IGG Detalhado - Análise da Variabilidade de Resultados

\begin{tabular}{|c|c|c|c|c|c|}
\hline \multirow{4}{*}{$\begin{array}{c}\text { Localização } \\
\text { Inicial } \\
\text { (m) }\end{array}$} & \multicolumn{5}{|c|}{$\begin{array}{l}\text { Seção Teste } 02 \\
\text { Faixa } 2\end{array}$} \\
\hline & \multicolumn{5}{|c|}{ Amostra } \\
\hline & 1 & 2 & 3 & 4 & 5 \\
\hline & $\begin{array}{c}\text { IGISem } \\
\text { Flecha }\end{array}$ & $\begin{array}{c}\text { IGISem } \\
\text { Flecha }\end{array}$ & $\begin{array}{c}\text { IGISem } \\
\text { Flecha }\end{array}$ & $\begin{array}{c}\text { IGISem } \\
\text { Flecha }\end{array}$ & $\begin{array}{c}\text { IGISem } \\
\text { Flecha }\end{array}$ \\
\hline 0 & 6,7 & 13,7 & 13,8 & 4,0 & 4,6 \\
\hline 1 & 4,4 & 8,9 & 11,1 & 4,0 & 2,2 \\
\hline 2 & 2,2 & 8,9 & 11,1 & 4,0 & 2,2 \\
\hline 3 & 2,2 & 8,9 & 11,1 & 4,0 & 2,2 \\
\hline 4 & 2,2 & 8,9 & 8,9 & 2,2 & 2,2 \\
\hline 5 & 2,2 & 8,9 & 8,9 & 2,2 & 2,2 \\
\hline 6 & 2,2 & 8,9 & 8,9 & 0,0 & 2,2 \\
\hline 7 & 4,4 & 8,9 & 11,1 & 2,2 & 6,7 \\
\hline 8 & 4,4 & 8,9 & 11,1 & 4,4 & 6,7 \\
\hline 9 & 4,4 & 8,9 & 11,1 & 4,4 & 6,7 \\
\hline 10 & 6,7 & 8,9 & 11,1 & 6,7 & 8,9 \\
\hline 11 & 6,7 & 11,1 & 13,3 & 6,7 & 8,9 \\
\hline 12 & 6,7 & 11,1 & 13,3 & 6,7 & 8,9 \\
\hline 13 & 6,7 & 11,1 & 13,3 & 6,7 & 8,9 \\
\hline 14 & 4,4 & 11,1 & 11,1 & 6,7 & 6,7 \\
\hline 15 & 4,4 & 11,1 & 11,1 & 4,4 & 6,7 \\
\hline 16 & 4,4 & 11,1 & 11,1 & 4,4 & 6,7 \\
\hline 17 & 4,4 & 11,1 & 11,1 & 4,4 & 6,7 \\
\hline 18 & 4,4 & 8,9 & 8,9 & 4,4 & 6,7 \\
\hline 19 & 4,4 & 8,9 & 8,9 & 4,4 & 6,7 \\
\hline Média & 4,4 & 9,9 & 11,0 & 4,4 & 5,7 \\
\hline Des vio Padrão & 1,6 & 1,4 & 1,6 & 1,8 & 2,5 \\
\hline Coef de Variação & $36 \%$ & $14 \%$ & $14 \%$ & $41 \%$ & $45 \%$ \\
\hline
\end{tabular}


Tabela 4.19 - Análise da Variabilidade de Resultados do Método Tradicional - ST03

\begin{tabular}{|c|c|c|c|c|c|}
\hline \multirow{4}{*}{$\begin{array}{c}\text { Localização } \\
\text { Inicial } \\
\text { (m) }\end{array}$} & \multicolumn{5}{|c|}{ Seção Teste 03} \\
\hline & \multicolumn{5}{|c|}{ Amostra } \\
\hline & 1 & 2 & 3 & 4 & 5 \\
\hline & $\begin{array}{c}\text { IGISem } \\
\text { Flecha } \\
\end{array}$ & $\begin{array}{c}\text { IGI Sem } \\
\text { Flecha } \\
\end{array}$ & $\begin{array}{c}\text { IGI Sem } \\
\text { Flecha }\end{array}$ & $\begin{array}{c}\text { IGI Sem } \\
\text { Flecha }\end{array}$ & $\begin{array}{c}\text { IGI Sem } \\
\text { Flecha }\end{array}$ \\
\hline $\mathbf{0}$ & 166,5 & 162,9 & 188,8 & 178,2 & 134,1 \\
\hline 1 & 161,9 & 168,1 & 199,4 & 181,9 & 125,6 \\
\hline 2 & 161,9 & 164,4 & 193,1 & 181,9 & 129,4 \\
\hline 3 & 154,4 & 164,4 & 175,6 & 170,6 & 129,4 \\
\hline 4 & 154,4 & 143,8 & 172,5 & 149,4 & 129,4 \\
\hline 5 & 152,5 & 136,3 & 168,8 & 149,4 & 135,6 \\
\hline 6 & 156,3 & 142,5 & 165,0 & 147,5 & 139,4 \\
\hline 7 & 161,9 & 148,8 & 171,3 & 146,3 & 139,4 \\
\hline 8 & 160,7 & 158,1 & 177,5 & 140,0 & 138,8 \\
\hline 9 & 148,1 & 161,9 & 187,5 & 133,1 & 122,5 \\
\hline 10 & 151,9 & 165,6 & 206,9 & 148,8 & 116,9 \\
\hline 11 & 158,1 & 159,4 & 188,1 & 148,8 & 123,1 \\
\hline 12 & 166,3 & 171,9 & 184,4 & 162,5 & 124,4 \\
\hline 13 & 170,0 & 178,1 & 194,4 & 162,5 & 130,6 \\
\hline 14 & 166,3 & 185,0 & 192,5 & 156,3 & 134,4 \\
\hline 15 & 177,5 & 185,0 & 196,3 & 152,5 & 136,9 \\
\hline 16 & 180,0 & 188,8 & 200,0 & 156,3 & 141,9 \\
\hline 17 & 178,1 & 193,8 & 205,6 & 149,4 & 148,1 \\
\hline 18 & 174,4 & 200,0 & 195,6 & 156,9 & 148,1 \\
\hline 19 & 180,6 & 196,3 & 201,9 & 160,6 & 154,4 \\
\hline Média & 164,1 & 168,7 & 188,3 & 156,6 & 134,1 \\
\hline Desvio Padrão & 10,0 & 18,5 & 12,7 & 13,3 & 9,6 \\
\hline Coef de Variação & $6 \%$ & $11 \%$ & $7 \%$ & $8 \%$ & $7 \%$ \\
\hline
\end{tabular}

Tabela 4.20 - Análise da Variabilidade de Resultados do Método Tradicional - ST-

04

\begin{tabular}{|c|c|c|c|c|c|}
\hline \multirow{4}{*}{$\begin{array}{l}\text { Localização Inicial } \\
\text { (m) }\end{array}$} & \multicolumn{5}{|c|}{$\begin{array}{c}\text { Seção Teste } 04 \\
\text { Faixa } 1\end{array}$} \\
\hline & \multicolumn{5}{|c|}{ Amostra } \\
\hline & 1 & 2 & 3 & 4 & 5 \\
\hline & $\begin{array}{c}\text { IGISem } \\
\text { Flecha }\end{array}$ & $\begin{array}{c}\text { IGISem } \\
\text { Flecha }\end{array}$ & $\begin{array}{c}\text { IGISem } \\
\text { Flecha }\end{array}$ & $\begin{array}{c}\text { IGI Sem } \\
\text { Flecha }\end{array}$ & $\begin{array}{c}\text { IGI Sem } \\
\text { Flecha }\end{array}$ \\
\hline \multicolumn{6}{|c|}{ 然 } \\
\hline 1 & 20,0 & 28,8 & 36,3 & 12,5 & 10,0 \\
\hline 2 & 20,0 & 28,8 & 46,3 & 12,5 & 10,0 \\
\hline 3 & 22,5 & 32,5 & 46,3 & 12,5 & 10,0 \\
\hline 4 & 32,5 & 32,5 & 46,3 & 22,5 & 20,0 \\
\hline 5 & 32,5 & 32,5 & 46,3 & 22,5 & 20,0 \\
\hline 6 & 35,0 & 42,5 & 46,3 & 22,5 & 20,0 \\
\hline 7 & 35,0 & 42,5 & 56,3 & 22,5 & 20,0 \\
\hline 8 & 35,0 & 42,5 & 56,3 & 22,5 & 20,0 \\
\hline 9 & 25,0 & 30,0 & 46,3 & 22,5 & 20,0 \\
\hline 10 & 25,0 & 40,0 & 38,8 & 12,5 & 20,0 \\
\hline 11 & 15,0 & 40,0 & 38,8 & 0,0 & 10,0 \\
\hline 12 & 25,0 & 47,5 & 46,3 & 0,0 & 12,5 \\
\hline 13 & 22,5 & 40,0 & 42,5 & 0,0 & 12,5 \\
\hline 14 & 32,5 & 50,0 & 42,5 & 17,5 & 30,0 \\
\hline 15 & 50,0 & 50,0 & 52,5 & 17,5 & 30,0 \\
\hline 16 & 50,0 & 50,0 & 52,5 & 17,5 & 30,0 \\
\hline 17 & 40,0 & 50,0 & 45,0 & 27,5 & 30,0 \\
\hline 18 & 40,0 & 50,0 & 50,0 & 27,5 & 30,0 \\
\hline 19 & 40,0 & 50,0 & 50,0 & 27,5 & 27,5 \\
\hline Média & 31,4 & 41,1 & 46,6 & 16,8 & 20,1 \\
\hline Des vio Padrão & 9,9 & 8,1 & 5,5 & 9,0 & 7,7 \\
\hline Coef de Variação & $32 \%$ & $20 \%$ & $12 \%$ & $53 \%$ & $38 \%$ \\
\hline
\end{tabular}

\begin{tabular}{|c|c|c|c|c|c|}
\hline \multirow{4}{*}{$\begin{array}{l}\text { Localização Inicial } \\
\text { (m) }\end{array}$} & \multicolumn{5}{|c|}{$\begin{array}{c}\text { Seção Teste } 04 \\
\text { Faixa } 2\end{array}$} \\
\hline & \multicolumn{5}{|c|}{ Amostra } \\
\hline & 1 & 2 & 3 & 4 & 5 \\
\hline & $\begin{array}{c}\text { IGIS Sem } \\
\text { Flecha }\end{array}$ & $\begin{array}{c}\text { IGI Sem } \\
\text { Flecha }\end{array}$ & $\begin{array}{l}\text { IGI Sem } \\
\text { Flecha }\end{array}$ & $\begin{array}{c}\text { IGISem } \\
\text { Flecha }\end{array}$ & $\begin{array}{c}\text { IGISem } \\
\text { Flecha }\end{array}$ \\
\hline \multicolumn{6}{|c|}{ 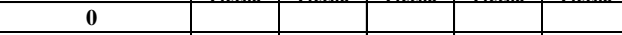 } \\
\hline 1 & 205,0 & 195,0 & 197,5 & 197,5 & 102,5 \\
\hline 2 & 192,5 & 195,0 & 205,0 & 205,0 & 110,0 \\
\hline 3 & 192,5 & 195,0 & 192,5 & 205,0 & 110,0 \\
\hline 4 & 205,0 & 182,5 & 205,0 & 212,5 & 110,0 \\
\hline 5 & 205,0 & 195,0 & 205,0 & 212,5 & 122,5 \\
\hline 6 & 212,5 & 202,5 & 205,0 & 220,0 & 122,5 \\
\hline 7 & 212,5 & 202,5 & 217,5 & 232,5 & 137,5 \\
\hline 8 & 212,5 & 202,5 & 225,0 & 232,5 & 137,5 \\
\hline 9 & 213,8 & 191,3 & 213,8 & 251,3 & 137,5 \\
\hline 10 & 213,8 & 191,3 & 213,8 & 251,3 & 137,5 \\
\hline 11 & 201,3 & 191,3 & 201,3 & \begin{tabular}{|l|l}
243,8 \\
\end{tabular} & 125,0 \\
\hline 12 & 197,5 & 178,8 & 201,3 & 231,3 & 137,5 \\
\hline 13 & 197,5 & 191,3 & 225,0 & 231,3 & 130,0 \\
\hline 14 & 197,5 & 191,3 & 218,8 & 226,3 & 120,0 \\
\hline 15 & 212,5 & 218,8 & 233,8 & 233,8 & 120,0 \\
\hline 16 & 208,8 & 218,8 & 233,8 & 220,0 & 112,5 \\
\hline 17 & 208,8 & 218,8 & 233,8 & 212,5 & 120,0 \\
\hline 18 & 208,8 & 218,8 & 233,8 & 225,0 & 120,0 \\
\hline 19 & 208,8 & 223,8 & 226,3 & 217,5 & 100,0 \\
\hline Média & 205,6 & 200,2 & 215,1 & 224,3 & 121,7 \\
\hline Desvio Padrão & 7,2 & 13,4 & 13,6 & 15,1 & 12,2 \\
\hline Coef de Variação & $3 \%$ & $7 \%$ & $6 \%$ & $7 \%$ & $10 \%$ \\
\hline
\end{tabular}


Tabela 4.21 - Análise da Variabilidade de Resultados do Método Tradicional - ST07

\begin{tabular}{|c|c|c|c|c|c|}
\hline \multirow{4}{*}{$\begin{array}{l}\text { Localização } \\
\text { Inicial } \\
\text { (m) }\end{array}$} & \multicolumn{5}{|c|}{ Seção Teste 07} \\
\hline & \multicolumn{5}{|c|}{ Amostra } \\
\hline & 1 & 2 & 3 & 4 & 5 \\
\hline & $\begin{array}{c}\text { IGISem } \\
\text { Flecha }\end{array}$ & $\begin{array}{c}\text { IGI Sem } \\
\text { Flecha }\end{array}$ & $\begin{array}{c}\text { IGI Sem } \\
\text { Flecha }\end{array}$ & $\begin{array}{c}\text { IGI Sem } \\
\text { Flecha }\end{array}$ & $\begin{array}{c}\text { IGI Sem } \\
\text { Flecha }\end{array}$ \\
\hline 0 & 42,4 & 34,2 & 23,8 & 40,0 & 35,3 \\
\hline 1 & 36,3 & 27,5 & 27,5 & 37,5 & 32,5 \\
\hline 2 & 41,3 & 27,5 & 31,3 & 41,3 & 32,5 \\
\hline 3 & 45,0 & 35,0 & 31,3 & 45,0 & 36,3 \\
\hline 4 & 46,3 & 35,0 & 32,5 & 46,3 & 37,5 \\
\hline 5 & 40,0 & 35,0 & 31,9 & 38,8 & 37,5 \\
\hline 6 & 41,3 & 30,6 & 28,1 & 36,9 & 36,3 \\
\hline 7 & 43,8 & 31,9 & 30,6 & 38,8 & 31,3 \\
\hline 8 & 43,8 & 29,4 & 31,9 & 38,8 & 32,5 \\
\hline 9 & 43,8 & 29,4 & 30,6 & 40,0 & 37,5 \\
\hline 10 & 42,5 & 29,4 & 34,4 & 34,4 & 36,3 \\
\hline 11 & 46,3 & 33,1 & 34,4 & 38,1 & 40,0 \\
\hline 12 & 46,3 & 33,1 & 33,1 & 34,4 & 40,0 \\
\hline 13 & 50,0 & 31,9 & 33,1 & 33,1 & 41,3 \\
\hline 14 & 50,0 & 31,9 & 33,1 & 40,6 & 45,0 \\
\hline 15 & 50,0 & 31,9 & 31,3 & 41,9 & 45,0 \\
\hline 16 & 43,8 & 30,0 & 31,3 & 43,8 & 45,0 \\
\hline 17 & 47,5 & 35,6 & 28,8 & 43,8 & 41,3 \\
\hline 18 & 43,8 & 31,9 & 30,6 & 40,0 & 37,5 \\
\hline 19 & 50,0 & 30,6 & 30,6 & 48,8 & 36,3 \\
\hline Média & 44,7 & 31,7 & 31,0 & 40,1 & $\mathbf{3 7 , 8}$ \\
\hline Des vio Padrão & 3,7 & 2,5 & 2,5 & 4,0 & 4,2 \\
\hline Coef de Variação & $8 \%$ & $8 \%$ & $8 \%$ & $10 \%$ & $11 \%$ \\
\hline
\end{tabular}

Tabela 4.22 - Análise da Variabilidade de Resultados do Método Tradicional - ST08

\begin{tabular}{|c|c|c|c|c|c|}
\hline \multirow{4}{*}{$\begin{array}{c}\text { Localização } \\
\text { Inicial } \\
\text { (m) }\end{array}$} & \multicolumn{5}{|c|}{$\begin{array}{c}\text { Seção Teste } 08 \\
\text { Faixa } 1\end{array}$} \\
\hline & \multicolumn{5}{|c|}{ Amostra } \\
\hline & 1 & 2 & 3 & 4 & 5 \\
\hline & $\begin{array}{c}\text { IGISem } \\
\text { Flecha }\end{array}$ & $\begin{array}{c}\text { IGI Sem } \\
\text { Flecha }\end{array}$ & $\begin{array}{c}\text { IGI Sem } \\
\text { Flecha }\end{array}$ & $\begin{array}{c}\text { IGI Sem } \\
\text { Flecha }\end{array}$ & $\begin{array}{c}\text { IGI Sem } \\
\text { Flecha }\end{array}$ \\
\hline 0 & 11,1 & 15,5 & 15,5 & 6,9 & 13,8 \\
\hline 1 & 20,0 & 12,5 & 20,0 & 10,0 & 20,0 \\
\hline 2 & 12,5 & 15,0 & 12,5 & 10,0 & 12,5 \\
\hline 3 & 12,5 & 12,5 & 12,5 & 10,0 & 12,5 \\
\hline 4 & 12,5 & 12,5 & 12,5 & 10,0 & 12,5 \\
\hline 5 & 12,5 & 12,5 & 12,5 & 10,0 & 12,5 \\
\hline 6 & 12,5 & 10,0 & 10,0 & 10,0 & 12,5 \\
\hline 7 & 10,0 & 10,0 & 10,0 & 10,0 & 12,5 \\
\hline 8 & 10,0 & 10,0 & 10,0 & 7,5 & 10,0 \\
\hline 9 & 7,5 & 5,0 & 7,5 & 7,5 & 7,5 \\
\hline 10 & 5,0 & 5,0 & 5,0 & 7,5 & 5,0 \\
\hline 11 & 5,0 & 5,0 & 5,0 & 5,0 & 5,0 \\
\hline 12 & 7,5 & 7,5 & 5,0 & 7,5 & 7,5 \\
\hline 13 & 7,5 & 7,5 & 7,5 & 10,0 & 7,5 \\
\hline 14 & 10,0 & 7,5 & 7,5 & 7,5 & 10,0 \\
\hline 15 & 10,0 & 7,5 & 7,5 & 7,5 & 10,0 \\
\hline 16 & 10,0 & 10,0 & 10,0 & 7,5 & 10,0 \\
\hline 17 & 12,5 & 10,0 & 10,0 & 12,5 & 12,5 \\
\hline 18 & 12,5 & 10,0 & 10,0 & 12,5 & 12,5 \\
\hline 19 & 15,0 & 10,0 & 10,0 & 12,5 & 15,0 \\
\hline Média & 10,8 & 9,8 & 10,0 & 9,1 & 11,1 \\
\hline Des vio Padrão & 3,4 & 3,1 & 3,7 & 2,1 & 3,5 \\
\hline Coef de Variação & $32 \%$ & $31 \%$ & $37 \%$ & $23 \%$ & $32 \%$ \\
\hline
\end{tabular}

\begin{tabular}{|c|c|c|c|c|c|}
\hline \multicolumn{6}{|c|}{ IGG Detalhado - Análise da Variabilidade de Resultados } \\
\hline \multirow{4}{*}{$\begin{array}{l}\text { Localização } \\
\text { Inicial } \\
\text { (m) }\end{array}$} & \multicolumn{5}{|c|}{$\begin{array}{c}\text { Seção Teste } 08 \\
\text { Faixa } 2\end{array}$} \\
\hline & \multicolumn{5}{|c|}{ Amostra } \\
\hline & 1 & 2 & 3 & 4 & 5 \\
\hline & $\begin{array}{c}\text { IGI Sem } \\
\text { Flecha } \\
\end{array}$ & $\begin{array}{c}\text { IGI Sem } \\
\text { Flecha }\end{array}$ & \begin{tabular}{|c} 
IGI Sem \\
Flecha
\end{tabular} & $\begin{array}{c}\text { IGISem } \\
\text { Flecha }\end{array}$ & $\begin{array}{c}\text { IGISem } \\
\text { Flecha }\end{array}$ \\
\hline $\mathbf{0}$ & 88,3 & 104,3 & 104,6 & 92,1 & 62,4 \\
\hline 1 & 83,8 & 102,5 & 95,0 & 68,8 & 72,5 \\
\hline 2 & 95,0 & 110,0 & 110,0 & 86,3 & 72,5 \\
\hline 3 & 95,0 & 110,0 & 110,0 & 86,3 & 87,5 \\
\hline 4 & 95,0 & 110,0 & 110,0 & 86,3 & 87,5 \\
\hline 5 & 98,8 & 110,0 & 98,8 & 86,3 & 87,5 \\
\hline 6 & 98,8 & 98,8 & 98,8 & 86,3 & 80,0 \\
\hline 7 & 98,8 & 110,0 & 110,0 & 86,3 & 91,3 \\
\hline 8 & 98,8 & 110,0 & 110,0 & 71,3 & 91,3 \\
\hline 9 & 87,5 & 106,3 & 95,0 & 75,0 & 83,8 \\
\hline 10 & 91,3 & 95,0 & 95,0 & 82,5 & 83,8 \\
\hline 11 & 91,3 & 96,3 & 100,0 & 82,5 & 83,8 \\
\hline 12 & 91,3 & 96,3 & 100,0 & 82,5 & 91,3 \\
\hline 13 & 88,8 & 96,3 & 90,0 & 82,5 & 88,8 \\
\hline 14 & 90,0 & 86,3 & 90,0 & 101,3 & 88,8 \\
\hline 15 & 100,0 & 111,3 & 107,5 & 101,3 & 77,5 \\
\hline 16 & 115,0 & 111,3 & 126,3 & 116,3 & 92,5 \\
\hline 17 & 111,3 & 133,8 & 137,5 & 116,3 & 92,5 \\
\hline 18 & 111,3 & 137,5 & 137,5 & 116,3 & 92,5 \\
\hline 19 & 115,0 & 137,5 & 145,0 & 116,3 & 103,8 \\
\hline Média & 97,2 & 108,7 & 108,5 & 91,1 & 85,6 \\
\hline Des vio Padrão & 9,3 & 13,8 & 16,1 & 15,1 & 9,1 \\
\hline Coef de Variação & $10 \%$ & $13 \%$ & $15 \%$ & $17 \%$ & $11 \%$ \\
\hline
\end{tabular}


Os resultados demonstram variabilidade de resultados de IGI de até 53\% nas seçõesteste em boas condições, com exceção da ST-02, faixa 01, que por possuir médias de IGG muito baixas, apresenta coeficiente de variação alto. Para as seções-teste em condições regulares, ruins e péssimas, verifica-se uma variação de até $17 \%$ nos valores de IGI.

As Tabelas 4.23 a 4.29 demonstram a variabilidade de resultados obtidos pelo levantamento mecanizado com o Pavement Scanner. Para este tipo de levantamento foi possível verificar a variabilidade real do IGG, já que foram obtidos os dados de defeitos e de afundamentos nas trilhas de roda a cada metro. De maneira a facilitar a visualização dos resultados a cada metro, para cada amostra, estão apresentados em escala de cor, baseados na escala de conceitos do IGG. 
Tabela 4.23 - Análise da Variabilidade de Resultados do Pavement Scanner- ST-02
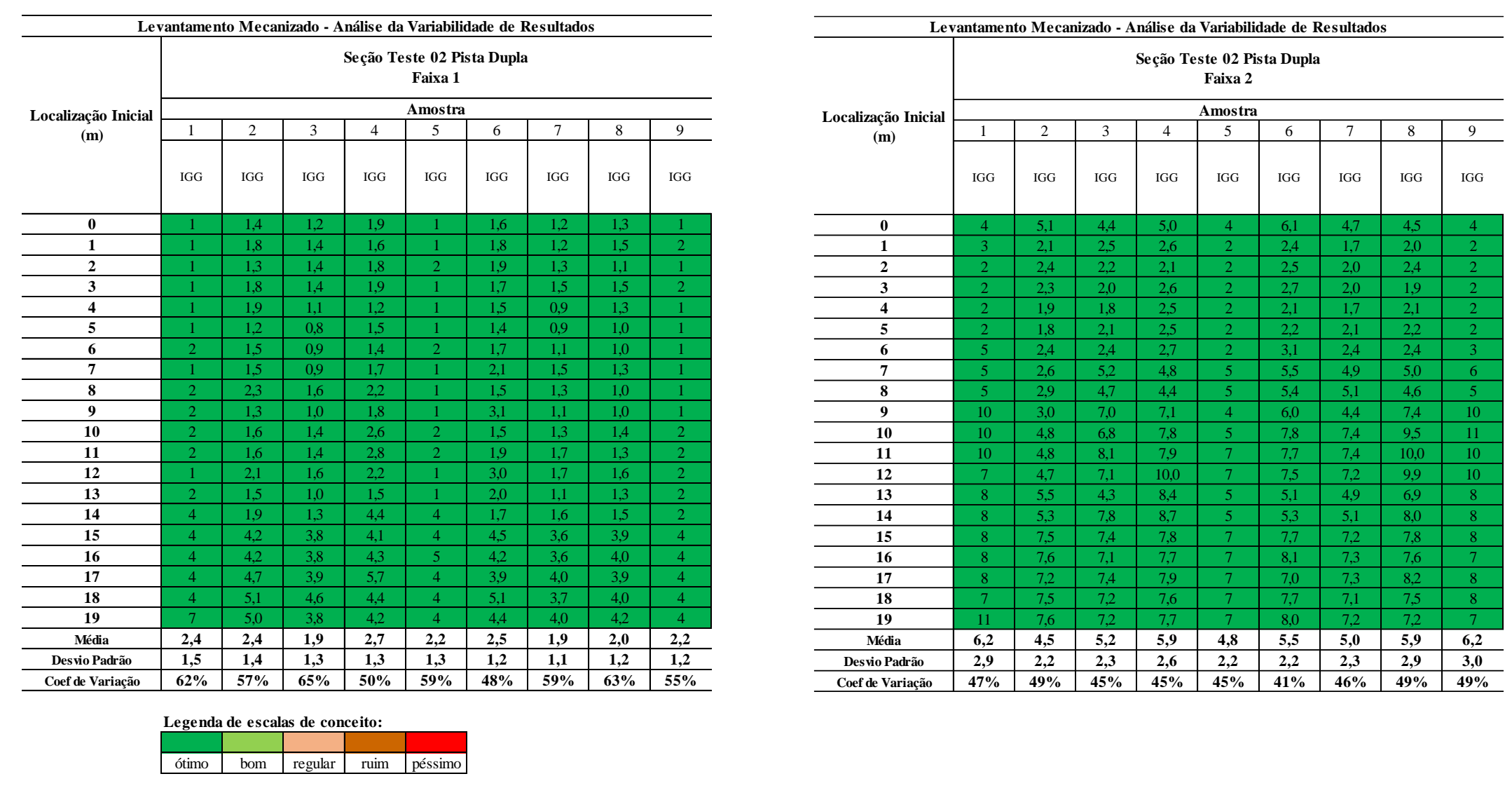

\begin{tabular}{|l|l|l|l|l|}
\hline ótimo & bom & regular & ruim & péssimo \\
\hline
\end{tabular} 
Tabela 4.24 - Análise da Variabilidade de Resultados do Pavement Scanner- ST-03

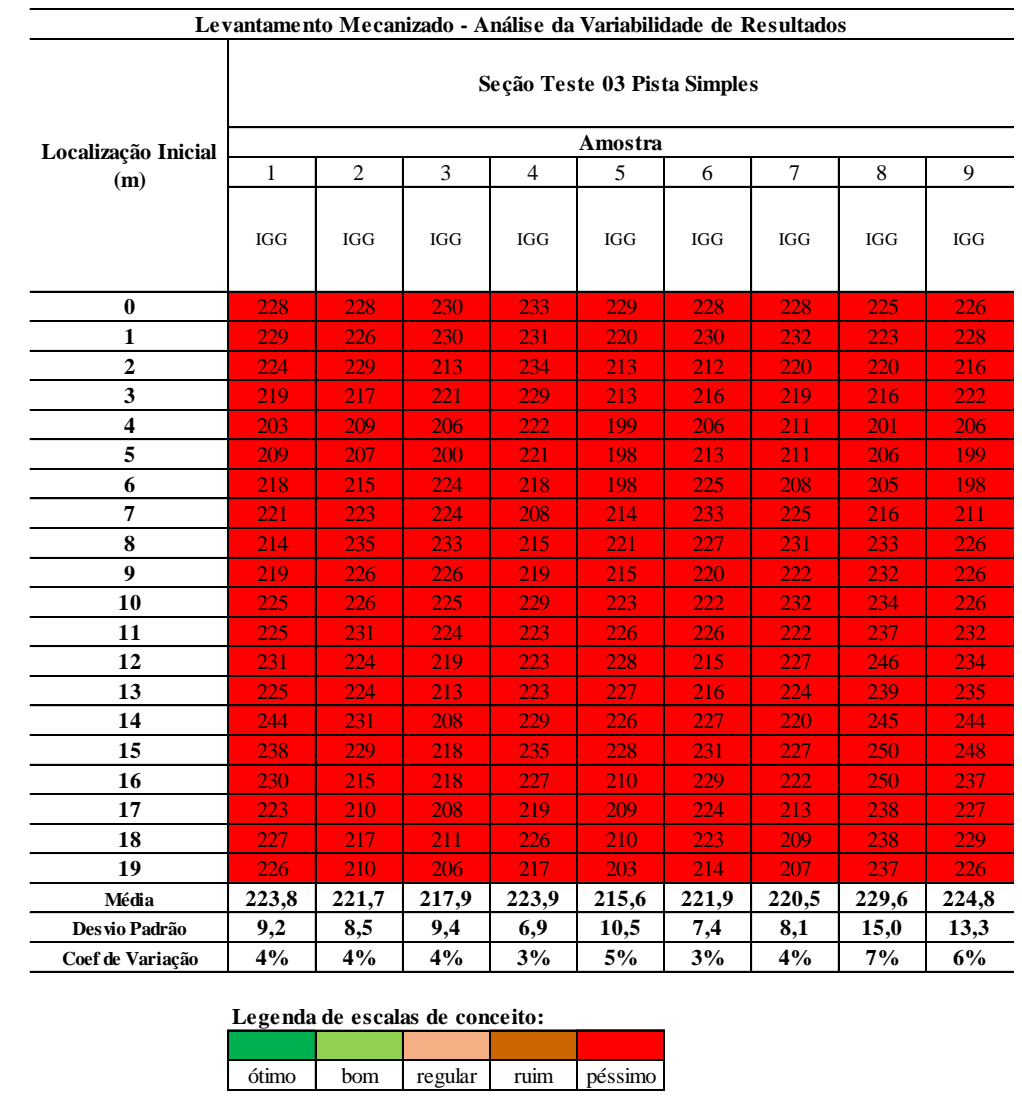


Tabela 4.25 - Análise da Variabilidade de Resultados do Pavement Scanner- ST-04
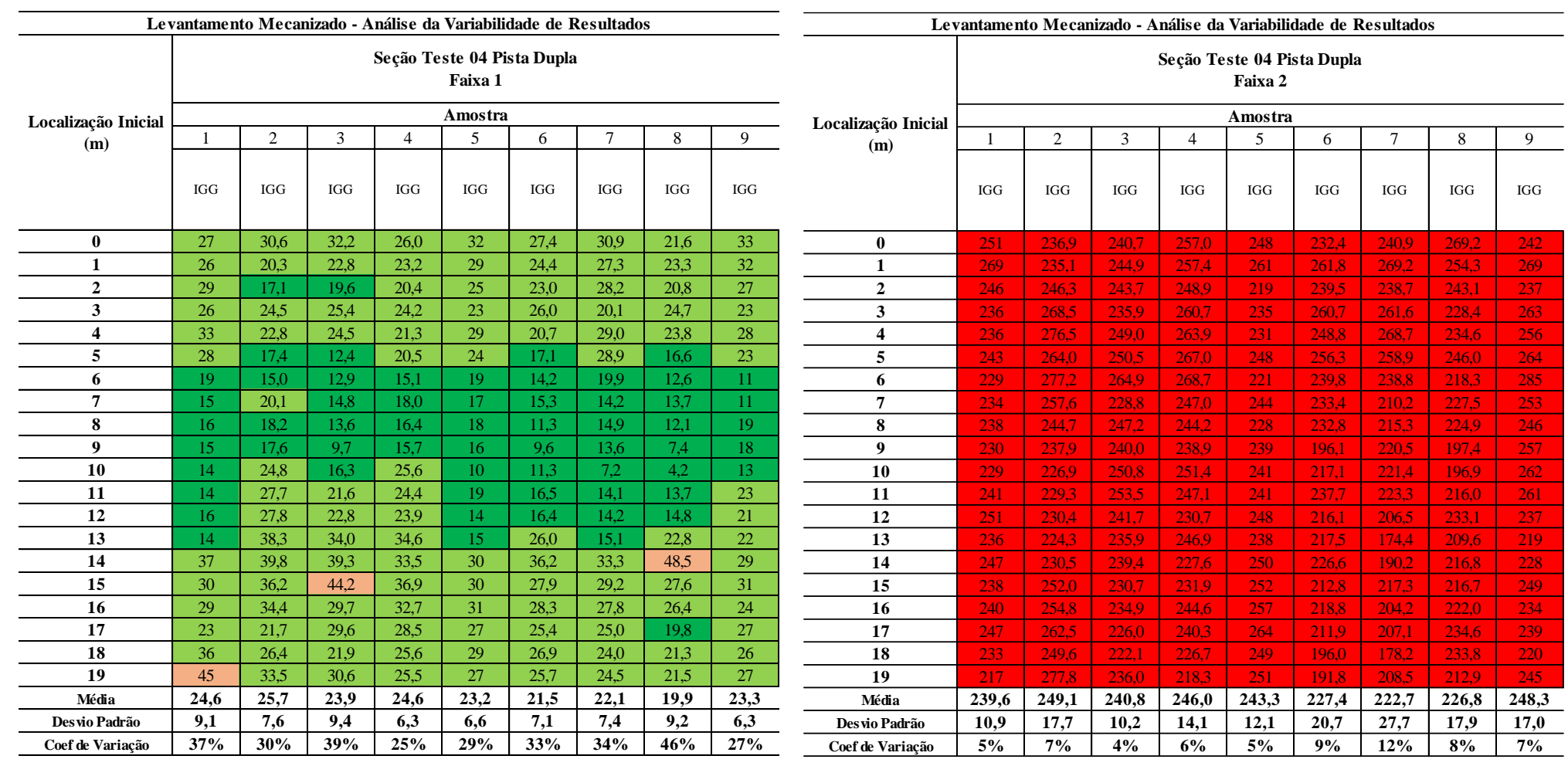

Legenda de escalas de conceito:

\begin{tabular}{|l|l|l|l|l|}
\hline & & & & \\
\hline ótimo & bom & regular & ruim & péssimo \\
\hline
\end{tabular} 
Tabela 4.26 - Análise da Variabilidade de Resultados do Pavement Scanner- ST-05

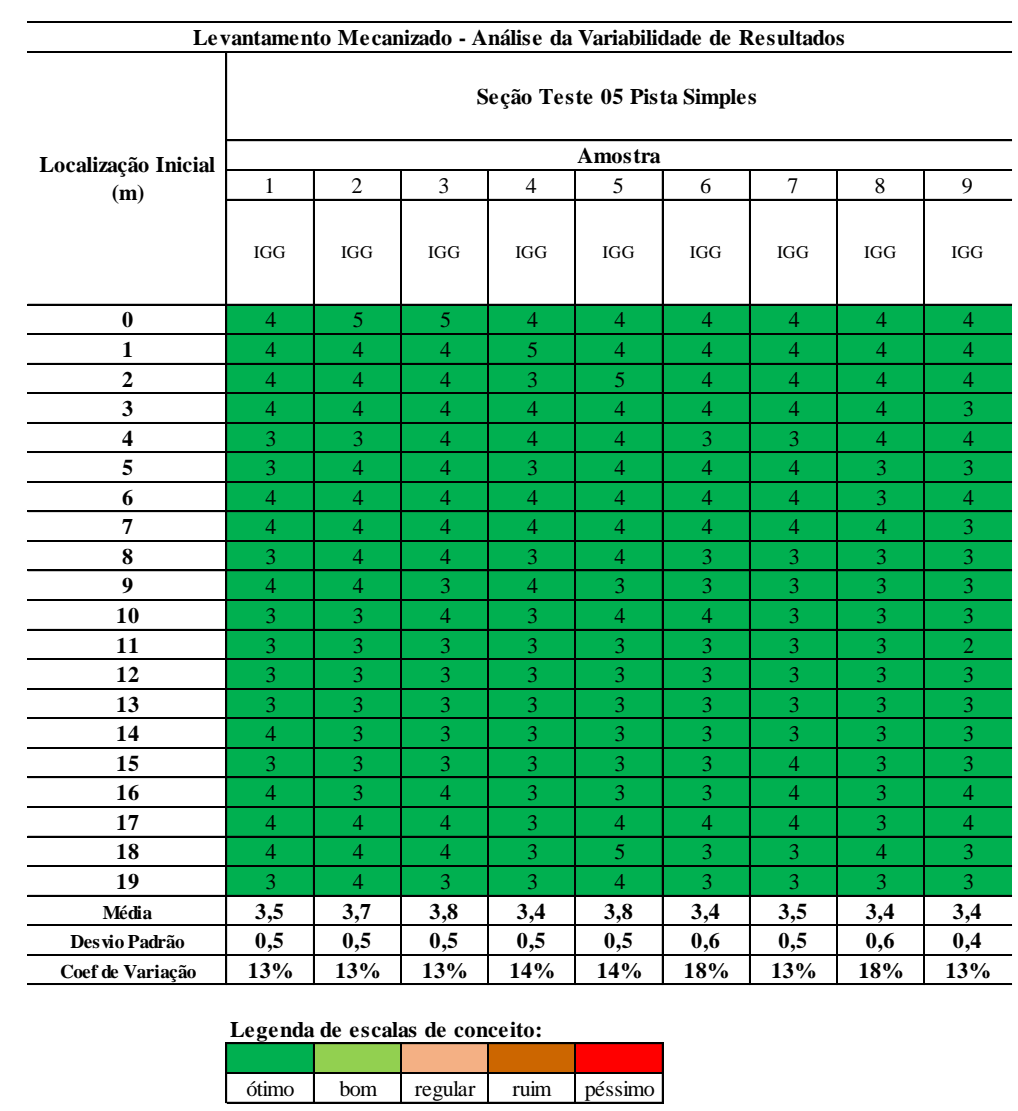


Tabela 4.27 - Análise da Variabilidade de Resultados do Pavement Scanner- ST-06

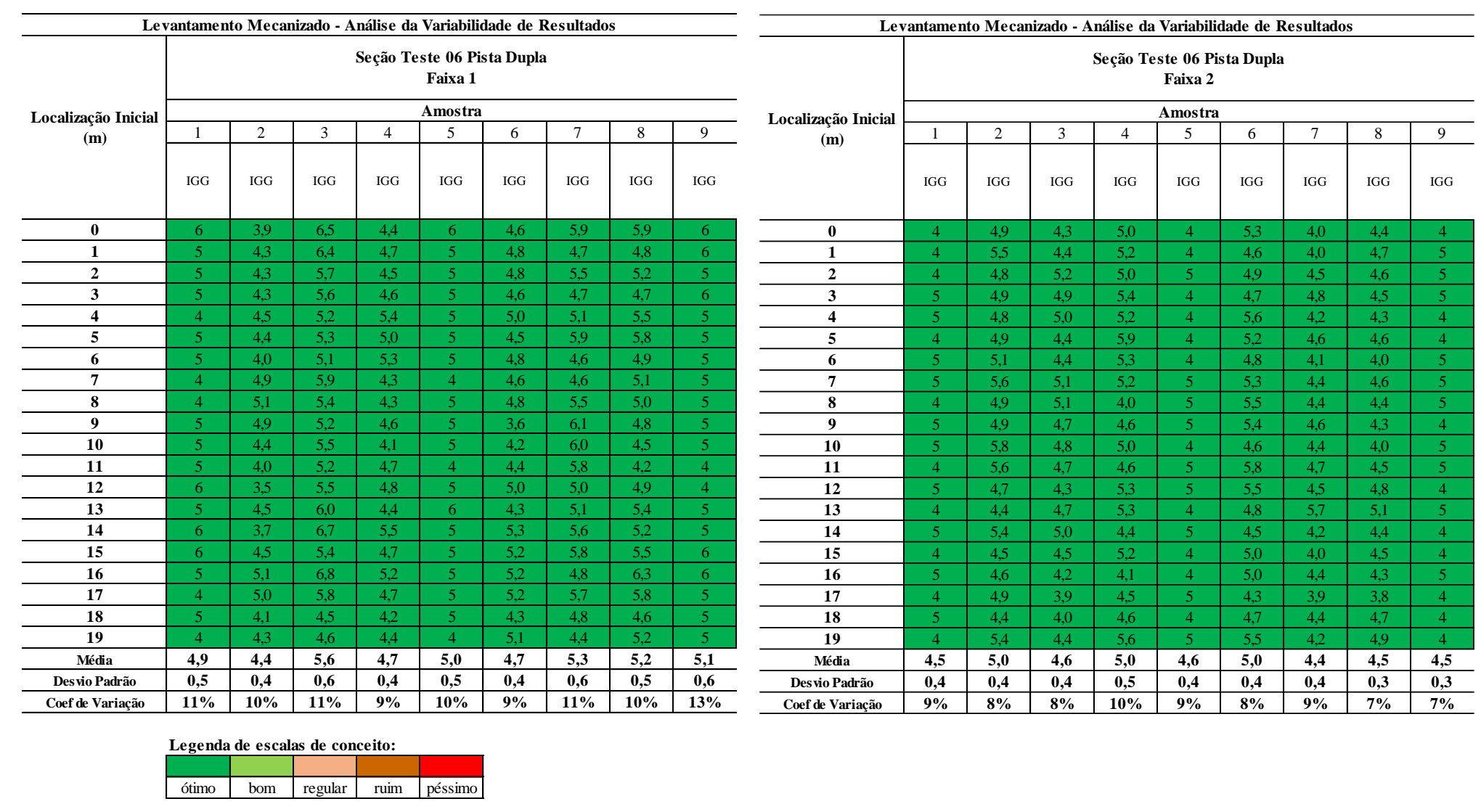


Tabela 4.28 - Análise da Variabilidade de Resultados do Pavement Scanner- ST-07

\begin{tabular}{|c|c|c|c|c|c|c|c|c|c|}
\hline \multicolumn{10}{|c|}{ Levantamento Mecanizado - Análise da Variabilidade de Resultados } \\
\hline \multirow{4}{*}{$\begin{array}{l}\text { Localização Inicial } \\
\text { (m) }\end{array}$} & \multicolumn{9}{|c|}{ Seção Teste 07 Pista Simples } \\
\hline & \multicolumn{9}{|c|}{ Amostra } \\
\hline & 1 & 2 & 3 & 4 & 5 & 6 & 7 & 8 & 9 \\
\hline & IGG & IGG & IGG & IGG & IGG & IGG & IGG & IGG & $\mathrm{IGG}$ \\
\hline $\mathbf{0}$ & 39 & 39 & 36 & 34 & 37 & 37 & 35 & 36 & 36 \\
\hline 1 & 41 & 40 & 39 & 37 & 37 & 38 & 36 & 39 & 37 \\
\hline 2 & 42 & 42 & 34 & 36 & 35 & 38 & 33 & 38 & 33 \\
\hline 3 & 42 & 37 & 36 & 38 & 34 & 40 & 38 & 36 & 37 \\
\hline 4 & 47 & 40 & 38 & 42 & 39 & 41 & 38 & 42 & 37 \\
\hline 5 & 46 & 39 & 36 & 41 & 40 & 40 & 34 & 36 & 37 \\
\hline 6 & 43 & 35 & 41 & 38 & 40 & 41 & 35 & 35 & 37 \\
\hline 7 & 41 & 36 & 39 & 37 & 39 & 38 & 36 & 35 & 37 \\
\hline 8 & 44 & 37 & 35 & 37 & 40 & 34 & 35 & 34 & 34 \\
\hline 9 & 47 & 35 & 34 & 37 & 36 & 35 & 32 & 37 & 33 \\
\hline 10 & 45 & 36 & 32 & 35 & 41 & 39 & 31 & 35 & 31 \\
\hline 11 & 48 & 35 & 33 & 34 & 40 & 41 & 32 & 35 & 33 \\
\hline 12 & 46 & 35 & 35 & 35 & 38 & 41 & 36 & 36 & 35 \\
\hline 13 & 43 & 35 & 34 & 34 & 38 & 37 & 38 & 34 & 37 \\
\hline 14 & 43 & 37 & 39 & 34 & 38 & 41 & 35 & 41 & 34 \\
\hline 15 & 41 & 38 & 39 & 37 & 37 & 40 & 36 & 43 & 34 \\
\hline 16 & 35 & 37 & 37 & 35 & 40 & 37 & 37 & 43 & 33 \\
\hline 17 & 32 & 33 & 39 & 33 & 43 & 39 & 41 & 41 & 38 \\
\hline 18 & 37 & 40 & 38 & 41 & 42 & 39 & 40 & 39 & 38 \\
\hline 19 & 37 & 38 & 34 & 37 & 42 & 39 & 38 & 38 & 42 \\
\hline Média & 41,9 & 37,2 & 36,4 & 36,4 & 38,7 & 38,8 & 35,9 & 37,7 & 35, \\
\hline Desvio Padrão & 4,3 & 2,2 & 2,5 & 2,5 & 2,4 & 2,0 & 2,8 & 3,0 & 2,5 \\
\hline Coef de Variação & $10 \%$ & $6 \%$ & $7 \%$ & $7 \%$ & $6 \%$ & $5 \%$ & $8 \%$ & $8 \%$ & $7 \%$ \\
\hline
\end{tabular}

Legenda de escalas de conceito:

\begin{tabular}{|l|l|l|l|l|}
\hline ótimo & bom & regular & ruim & péssimo \\
\hline
\end{tabular} 
Tabela 4.29 - Análise da Variabilidade de Resultados do Pavement Scanner- ST-08
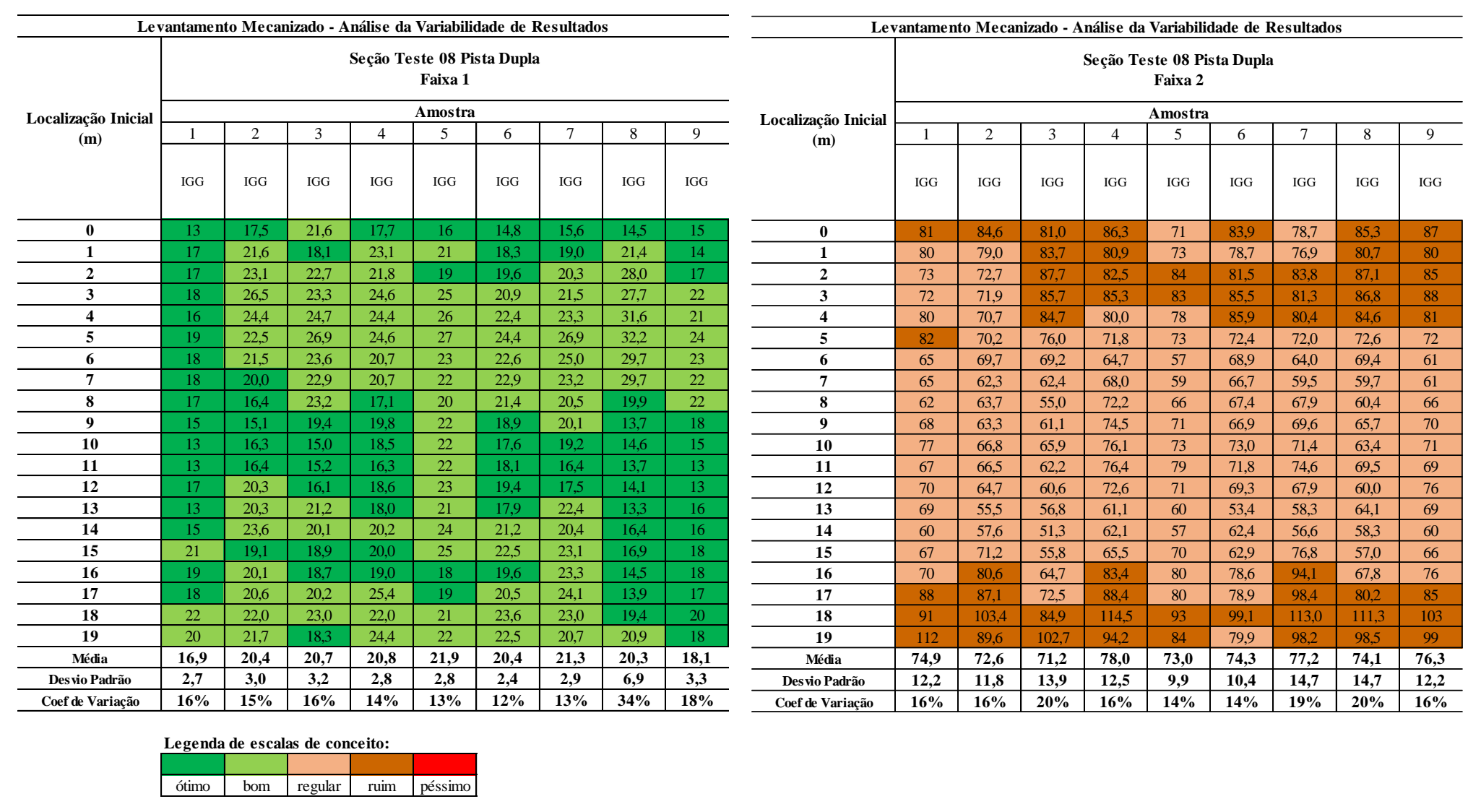

\begin{tabular}{|l|l|l|l|l|}
\hline & & & & \\
\hline ótimo & bom & regular & ruim & péssimo \\
\hline
\end{tabular} 
Verifica-se um coeficiente de variação de até $12 \%$ nas seções-teste em péssima condição e de até $20 \%$ nas seções-teste em condição ruim. Em parte das amostras há mudanças nos limites do conceito para a mesma seção-teste, denotando que a alteração da localização inicial ou de partida do levantamento pode acarretar em dispersões até do ponto de vista de tomada de decisões gerenciais, já que em muitos casos, as mesmas são adotadas com base nos conceitos do IGG, como é o caso da faixa 1 da ST-04 cuja condição varia de ótimo a regular. 


\section{CONCLUSÕES E SUGESTÕES PARA NOVAS PESQUISAS}

Este capítulo apresenta as principais conclusões sobre os estudos desenvolvidos na presente dissertação, ressaltando que as mesmas são restritas ao equipamento utilizado. São apresentadas ainda recomendações para trabalhos futuros na mesma linha de pesquisa, no intuito de aprimorar e complementar os conceitos estudados.

\subsection{Conclusões}

Os ensaios mecanizados com o Pavement Scanner mostraram-se de fácil realização, já que a varredura de dados é feita em velocidades compatíveis com as rodovias estudadas. Os ensaios visuais ou tradicionais foram mais dificultosos, dado o risco de acidentes, principalmente para a obtenção do afundamento na trilha de roda com a treliça metálica.

Verificou-se que os coeficientes de variação do IGG obtidos com os levantamentos mecanizados são menores em comparação aos dos levantamentos tradicionais, apresentando o valor máximo de 6\%, enquanto o tradicional, apresenta o máximo de 24\%. Além disso, os dados de IGG dos levantamentos tradicionais detalhados são mais discrepantes, apresentando uma diferença máxima no valor do IGG de 114. A curva de correlação entre os dois levantamentos demonstra valores de IGG mecanizados aproximadamente 3,5\% inferiores aos tradicionais. No entanto, é importante ressaltar que a variabilidade dos resultados tradicionais é superior ao referido percentual.

Os coeficientes de variação dos dados de trincamento obtidos nos levantamentos mecanizados são inferiores aos dos levantamentos tradicionais. Os percentuais de trincamento obtidos pelo método mecanizado são inferiores aos dos tradicionais, sendo essa diferença explicada pela resolução dos levantamentos, em que o mecanizado apresenta maior resolução ( $1 \mathrm{~m}$ x $0,2 \mathrm{~m})$ ou seja, maior detalhamento de resultados e o tradicional, menor resolução ( $1 \mathrm{~m}$ x 1,2m), denotando menor precisão de resultados e tendência a superestimar resultados de trincamento. 
Com relação ao afundamento médio na trilha de roda, o Pavement Scanner apresentou menor coeficiente de variação em comparação ao outro método, principalmente devido à imprecisão do levantamento com a treliça metálica e pela dificuldade de levantamento da trilha de roda em rodovias com VDM elevado. A curva de correlação entre os dois métodos demonstra que os valores de afundamento em trilha de roda mecanizados são inferiores em aproximadamente $8 \%$ em relação aos tradicionais. No entanto, a dispersão do levantamento tradicional é superior a $8 \%$ na maioria das seções-teste, chegando até a $26 \%$.

Era esperado que os valores de IRI do Pavement Scanner resultassem em menor variação, dado que o referido equipamento apresenta resultados de irregularidade em uma distância fixa em relação à linha de bordo da sinalização. No entanto, não foi verificado discrepância de resultados entre os dois levantamentos, que pode ter ocorrido em função da extensão e quantidade de amostras que permite a manutenção da faixa de rolamento na avaliação com o perfilômetro laser. O resultado da correlação conduz de IRI pelo Pavement Scanner inferiores em aproximadamente $5 \%$ em relação ao com o perfilômetro laser, no entanto faz-se necessário um estudo mais específico analisando a relevância estatística deste resultado.

Também foi demonstrado que os parâmetros avaliados não dependem da velocidade de levantamento e que não há perda de qualidade para velocidades mais elevadas. Com relação às diferentes condições de luminosidade, os resultados obtidos não são conclusivos, haja vista o número limitado de amostras.

Foram analisadas a repetitividade de cada defeito e pôde-se concluir que o Pavement Scanner possui maior repetitividade na detecção da maioria dos defeitos.

Com base na ISO 5725 (1994) foi demonstrado que o Pavement Scanner apresenta ótimas condições de repetitividade, com aproximadamente $96 \%$ dos cenários positivos. As condições de reprodutividade são boas, uma vez que seus valores são muito próximos à da própria repetitividade, denotando a não dependência do operador nos resultados finais do ensaio. O levantamento tradicional não apresenta precisão 
suficiente, atendendo ao valor de repetitividade em apenas $50 \%$ dos casos estudados, além de apresentar elevado desvio padrão de reprodutividade, sendo resultados dependentes do avaliador.

O PCI apresenta menor coeficiente de variação que o IGG, ambos obtidos pelo método mecanizado, possivelmente pelo fato do PCI ser definido de maneira mais global e não tão detalhada em comparação ao IGG. Foi obtida uma boa correlação entre as duas metodologias, com $\mathrm{R}^{2}$ de 0,98 . Adicionalmente os gráficos de escala de conceitos de cada metodologia mostrou muita similaridade entre os resultados obtidos, demonstrando a não necessidade de grande detalhamento de defeitos, como é o caso do IGG, para a avaliação da qualidade funcional do pavimento. Os resultados extraídos do Pavement Scanner por meio de um único índice (PCI) permitem a tomada de decisão tanto em nível de projeto, como em nível de rede, já que os mesmos utilizam dados de defeitos, bem como, dados referentes à qualidade ao rolamento (IRI).

Foi demonstrado que há uma variação média entre o método amostral e o contínuo nas faixas ruins e regulares de até $15 \%$ para mais ou para menos, denotando uma variabilidade significativa nos resultados.

Para análise da variabilidade do IGG com relação à posição inicial, os resultados demonstram variabilidade de resultados de IGI de até 53\% nas seções-teste em boas condições, e nas seções-teste em condições regulares, ruins e péssimas, uma variação de até $20 \%$ nos valores de IGG. Em parte das amostras há mudanças nos limites do conceito para a mesma seção-teste, denotando que a alteração da localização inicial do levantamento pode acarretar em dispersões até do ponto de vista de tomada de decisões gerenciais.

A coleta de dados usual para a tomada de decisão em nível de rede é geralmente diferente daquela utilizada em nível de projeto, portanto, os requisitos de qualidade para a condição do pavimento também são diferentes. A coleta em nível de rede tradicionalmente envolve o levantamento de grandes quantidades de dados do estado do pavimento, que são convertidos em índices de condição, sendo usualmente 
realizada por métodos mecanizados. No nível de projeto, dados mais específicos são normalmente coletados em termos de identificação de defeitos e suas severidades, sendo o nível de informação adequado para utilização em decisões técnicas. Tendo em vista os resultados obtidos com o Pavement Scanner percebe-se que os dados são de rápida restituição, sendo possível coleta de grandes extensões de rodovia, em curto intervalo de tempo, porém com o nível de detalhamento necessário para decisões em nível de projeto e em nível de rede.

\subsection{Sugestões para Novas Pesquisas}

- Avaliar a aplicabilidade do Pavement Scanner para pavimentos rígidos;

- Estudar um número maior de amostra de seções-teste na faixa de IGG de regular a ruim;

- Aperfeiçoar os módulos de detecção do software LCMS na detecção de ondulações e trincamento longitudinal longo na trilha de roda;

- Elaborar especificação de serviço atentando para os levantamentos de campo utilizando o Pavement Scanner. 
AMERICAN ASSOCIATION OF STATE HIGHWAY AND TRANSPORTATION OFFICIALS - AASHTO. Guide for Design Management Systems. Washington D.C., 1990.

AMERICAN ASSOCIATION OF STATE HIGHWAY AND TRANSPORTATION OFFICIALS - AASHTO. Guide for Design of Pavement Structures. Washington D.C., 1986.

APS, M.; BALBO, J. T.;SEVERI, A. A. Avaliação Superficial de Pavimentos Asfálticos em Vias Urbanas Utilizando o Método do PCI. In: $31^{\mathrm{a}}$ Reunião Anual de Pavimentação, São Paulo, 1998.

ASTM D6433-03. Standard Practice for Roads and Parking Lots Pavement Condition Index Surveys. American Society of Testing and Materials, West Conshohocken, PA, 2003.

ASTM E1703-10. Standard Test Method for Measuring Rut-Depth of Pavement Surfaces Using a Straightedge. American Society of Testing and Materials, West Conshohocken, PA, 2010.

ASTM E965-96(2006). Standard Test Method for Measuring Pavement Macrotexture Depth Using a Volumetric Technique. American Society of Testing and Materials, West Conshohocken, PA, 2006.

BALBO, J.T. Pavimentos asfálticos: patologia e manutenção. São Paulo: Plêiade, 1997.

BENNETT, C. R. Evaluation of a High Speed Transverse Profile Logger. Highway and Traffic Consultants Ltd., 1998.

BENNETT, C.; PATERSON, W.D.O. A Guide to Calibration and Adaptation of HDM-4, in: The Highway Development and Management Series, The World Bank, Washington, D.C., 2000.

BENNETT, C.R; MCPHERSON, K. Success Factors for Road Management Systems. The World Bank, Washington, D.C., 2005. 
BERNUCCI, L.B.; MOTTA, L.M.G.; CERATTI, J.A.P.; SOARES, J.B. Pavimentação Asfáltica - Formação Básica para Engenheiros. $1^{\text {a }}$ Ed. - Rio de Janeiro: Petrobrás ABEDA, 2008.

CHEETHAM, A.; FALLS, L. C.; LANDERS, S. Development of a Pavement Surface Performance Measure for the British Columbia Pavement Management System. $5^{\text {a }}$ International Conference on Managing Pavement. Washington, D.C., 2001.

CNT. Confederação Nacional dos Transportes. 17 ${ }^{\mathrm{a}}$ Edição. Brasília, 2013. Disponível em: < http://pesquisarodovias.cnt.org.br/Paginas/index.aspx > Acesso em: 21 de Agosto de 2013.

DEPARTAMENTO DE ESTRADAS DE RODAGEM (São Paulo) - Estatística do Volume Médio Diário das Rodovias, São Paulo, 2014. Disponível em: < http://www.der.sp.gov.br/website/Malha/vdm.aspx >. Acesso em: 15 nov. 2014.

DEPARTAMENTO DE ESTRADAS DE RODAGEM (São Paulo) - IP-DEP00/003: Avaliação Funcional e Estrutural de Pavimento. São Paulo, 2006.

DEPARTAMENTO NACIONAL DE ESTRADAS DE RODAGEM - DNERPRO 164/94: Calibração e Controle de Sistemas Medidores de Irregularidade de Superfície de Pavimento (Sistemas Integradores IPR/USP e Maysmeter). Norma Rodoviária, Brasil, 1994.

DEPARTAMENTO NACIONAL DE ESTRADAS DE RODAGEM - DNERPRO 182/94: Medição de Irregularidade de Superfície de Pavimento com Sistemas Integradores IPR/USP e Maysmeter. Norma Rodoviária, Brasil, 1994.

DEPARTAMENTO NACIONAL DE ESTRADAS DE RODAGEM - DNERPRO 229/94: Manutenção de Sistemas Medidores de Irregularidade de Superfície de Pavimento-Integrador IPR/USP e Maysmeter. Norma Rodoviária, Brasil, 1994.

DEPARTAMENTO NACIONAL DE ESTRADAS DE RODAGEM - Manual de Reabilitação de Pavimentos Asfálticos. Rio de Janeiro, 1998.

DEPARTAMENTO NACIONAL DE INFRAESTRUTURA DE TRANSPORTES - DNIT 005/2003 - TER: Defeitos nos pavimentos flexíveis e semi-rígidos Terminologia. Rio de Janeiro, 2003.

DEPARTAMENTO NACIONAL DE INFRAESTRUTURA DE TRANSPORTES - DNIT 006/2003 - PRO: Avaliação objetiva da superfície de pavimentos flexíveis e semi-rígidos - Procedimento. Norma Rodoviária, Brasil, 2003. 
DEPARTAMENTO NACIONAL DE INFRAESTRUTURA DE TRANSPORTES

- DNIT 008/2003 - PRO: Levantamento visual contínuo para avaliação da superfície de pavimentos flexíveis e semi-rígidos. Norma Rodoviária, Brasil, 2003.

DEPARTAMENTO NACIONAL DE INFRAESTRUTURA DE TRANSPORTES. Manual de Gerência de Pavimentos. Rio de Janeiro, 2011.

DEPARTAMENTO NACIONAL DE INFRAESTRUTURA DE TRANSPORTES. Manual de Restauração de Pavimentos Asfálticos. Rio de Janeiro, 2006.

DEPARTAMENTO NACIONAL DE INFRAESTRUTURA DE TRANSPORTES. Sistema de Gerência de Pavimentos. Relatório dos Levantamentos Funcionais das Rodovias Federais. Brasília, 2011.

DOMINGUES, F.A.A. MID - Manual para Identificação de Defeitos de Revestimentos Asfálticos. São Paulo, 1993.

FARIAS, M. M.; SOUZA, R. O. Irregularidade Longitudinal e sua Influência na Avaliação Funcional de Pavimentos. In: VII Encontro Nacional de Conservação Rodoviária, Vitória, ES, 2002.

FEDERAL HIGHWAY ADMINISTRATION. Study of LTPP Distress Data. Washington, D.C., 1998.

FLINTSCH, G.W.; BRYANT, J.W. Asset Management Data Collection for Supporting Decision Processes. Federal Highway Administration, Washington, D.C., 2008.

GEIPOT. Research on the interrelationships between costs of highway construction, maintenance and utilization. Final report on the Brazil-UNDP Highway Research Project. (12 Volumes). Brasilia, DF, 1982.

HAAS, R.; HUDSON, W.R.; ZANIEWSKIJ, J. Modern Pavement Management. Malabar/Flórida: Krieger Publishing Company, 1994.

HEADQUARTERS DEPARTAMENT OF THE ARMY - Pavement Maintenance Management. Technical Manual 5-623. Washington, DC, 1982. 
HUDSON, W.R.; HAAS, R., Pavement Management Systems. New York: McGraw-Hill Book Company, 1978.

ISO 5725-2 (1994). Accuracy (trueness and precision) of measurement methods and results - Part 2: Basic method for the determination of repeatability and reproducibility of a standard measurement method. International Organization for Standardization, 2003.

KSAIBATI, K.; McNAMARA, R.; ARMAGHANI, J. A Comparison of Roughness Measurements from Laser and Ultrasonic Road Profilers. In: Research Report FL/DOT/SMO/98-425, Florida, 1998.

KUlKaRnI, R.B; MILlER, R.W., Pavement Management System: Past, Present, and Future. In: Transportation Research Record No 1853 (2003), p. 6571. Washington D.C., 2003.

LAURENT, J.; HÉBERT, J. F. High Performance 3D Sensors for the Characterization of Road Surface Defects. Proceedings of the IAPR Workshop on Machine Vision Applications, Nara, Japan, 2002.

LAURENT, J.; SAVARD. Y.; LEFEBVRE, D. Use of 3D Laser Profiling Sensors for the Automated Measurement of Road Surface Conditions (ruts, cracks, texture). 6th Symposium on Pavement Surface Characteristics. Potoroz, 2008.

MARCON, A.F., Contribuição ao Desempenho de um Sistema de Gerência de Pavimentos para a Malha Rodoviária Estadual de Santa Catarina, 1996. Tese ITA, São José dos Campos, São Paulo, 1996.

NEW YORK STATE DEPARTMENT OF TRANSPORTATION. Pavement Condition Assessment - NYSDOT Network Level. New York, 2010.

NGUYEN, T. S.; BEGOT, S.; DUCULTY, F.; BARDET, J. C.; AVILA, M. Pavement Cracking Detection Using an Anisotropy Measurement. International Conference on Computer Graphics and Imaging (CGIM). Austria, 2010 .

OLIVEIRA, M.E. Estudo Comparativo entre Medições de Irregularidades de Pavimentos Realizadas no Brasil e nos Estados Unidos. 2002. Dissertação (Mestrado em Engenharia de Transportes) - Escola Politécnica da Universidade de São Paulo, 2002. 
PATERSON, W.D.O; SCULLION, T. Information Systems for Road Management: Draft Guidelines on System Design and Data Issues. The World Bank, Washington, D.C., 1990.

Pavemetrics e INO. LCMS Data Processing Library: User Manual. Canadá, 2013.

PEREIRA, A. M; Um Método de Avaliação de Pavimentos Flexíveis e SemiRígidos. 11ª Reunião das Organizações Rodoviárias. Brasília, 1972.

PETERSON, D.E., Pavement Management Practices. National Cooperative Research Program. Synthesis of Highway Practice 135. Transportation Research Board. Washington D.C., 1987.

PINTO, S.; PREUSSLER, E.S. Pavimentação Rodoviária - Conceitos Fundamentais Sobre Pavimentos Flexíveis. 2a Ed. - Rio de Janeiro: IBP, 2010.

QUEIROZ, C.A.V. Modelos de Previsão do Desempenho para a Gerência de Pavimentos no Brasil. GEIPOT/DNER, 1984.

QUEIROZ, C.A.V., HUDSON, W.R. e HAAS, R., 1992. Standardization of Pavement Management Systems in Brazil and Other Developing Countries. In: Transportation Researh Record No 1344 - Transportation Research Board - p. 3137, Washington D.C. , 1992.

SAVARD. Y.; LAURENT, J.; HÉBERT, J. F. 3D laser road profiling for the automated measurement of road surface conditions and geometry. Baltic Roads Conference, 2013.

SAYERS, M. W; KARAMIHAS, S. M. The Little Book of Profiling. University of Michigan. Ann Arbor, 1998.

SHAHIN, M.Y. Pavement Management for Airports, Roads, and Parking Lots. $2^{\text {a }}$ Ed. New York: Chapman \& Hall, 2005.

SHAHIN, M.Y.; KOHN, S.D. Development of a Pavement Condition Rating Procedure for Roads, Streets and Parking Lots. Construction Engineering Research Laboratory, U.S. Army Corps of Engineers, Technical Report M-268, 1979. 
STRATEGIC HIGHWAY RESEARCH PROGRAM - SHRP. Distress Identification Manual for the Long Term Pavement Performance Project. Washington, D C., 1993.

TIMM, D. H.; MCQUEEN, J. M. A Study of Manual vs. Automated Pavement Condition Surveys. Alabama Department of Transportation.AL, 2004.

YODER, E. J. \& WITCZAK, M W. Principles of Pavement Design. $2^{\mathrm{a}}$ ed. EUA: Wiley-Interscience Publication, 1975.

YSHIBA, J. K., Modelos de Desempenho de Pavimentos: Estudo de Rodovias do Estado do Paraná. 2003. Dissertação (Doutorado em Engenharia) - Escola de Engenharia de São Carlos, Universidade de São Paulo, São Paulo, 2003. 